\title{
Giving maltreated children a voice : a study of self- reported quality of life, and the effectiveness and cost- effectiveness of the child-interview intervention during the investigation of reports of child maltreatment
}

Citation for published version (APA):

Snoeren, F. M. M. (2014). Giving maltreated children a voice : a study of self-reported quality of life, and the effectiveness and cost-effectiveness of the child-interview intervention during the investigation of reports of child maltreatment. [Doctoral Thesis, Maastricht University]. Maastricht University. https://doi.org/10.26481/dis.20141203fs

Document status and date:

Published: 01/01/2014

DOI:

$10.26481 /$ dis.20141203fs

Document Version:

Publisher's PDF, also known as Version of record

Please check the document version of this publication:

- A submitted manuscript is the version of the article upon submission and before peer-review. There can be important differences between the submitted version and the official published version of record. People interested in the research are advised to contact the author for the final version of the publication, or visit the DOI to the publisher's website.

- The final author version and the galley proof are versions of the publication after peer review.

- The final published version features the final layout of the paper including the volume, issue and page numbers.

Link to publication

\footnotetext{
General rights rights.

- You may freely distribute the URL identifying the publication in the public portal. please follow below link for the End User Agreement:

www.umlib.nl/taverne-license

Take down policy

If you believe that this document breaches copyright please contact us at:

repository@maastrichtuniversity.nl

providing details and we will investigate your claim.
}

Copyright and moral rights for the publications made accessible in the public portal are retained by the authors and/or other copyright owners and it is a condition of accessing publications that users recognise and abide by the legal requirements associated with these

- Users may download and print one copy of any publication from the public portal for the purpose of private study or research.

- You may not further distribute the material or use it for any profit-making activity or commercial gain

If the publication is distributed under the terms of Article 25fa of the Dutch Copyright Act, indicated by the "Taverne" license above,

Download date: 26 Apr. 2023 


\section{Giving maltreated children a voice}

A study of self-reported quality of life, and the effectiveness and cost-effectiveness of the child-interview intervention during the investigation of reports of child maltreatment

\section{PROEFSCHRIFT}

ter verkrijging van de graad van doctor aan de Universiteit Maastricht op gezag van Rector Magnificus, Prof dr. L. Soete volgens het besluit van het College van Decanen in het openbaar te verdedigen

op woensdag 3 december 2014 om 16.00 uur

door

Froukje Martje Marieke Snoeren 


\section{Promotoren}

Prof. Dr. S. M. A. A. Evers

Prof. Dr. F. Lamers-Winkelman (Vrije Universiteit Amsterdam)

\section{Copromotor}

Dr. C. Hoefnagels (Trimbos-instituut)

\section{Beoordelingscommissie}

Prof. Dr. N. de Vries (voorzitter)

Prof. Dr. L. Alink (Universiteit Leiden)

Prof. Dr. F. J. M. Feron

Prof. Dr. C. Finkenauer (Vrije Universiteit Amsterdam)

Dr. C. Meesters

This study is a joint project of the Trimbos institute, the Netherlands Institute for Mental Health and Addiction (Utrecht) and the CAHPRI School for Public Health and Primary Care, Maastricht University. The research is funded by ZonMw (project 15700.2012). 
Lieve papa

Jij maakte het begin mee, maar niet het eind.

Elke dag mis ik je, vandaag zou ik willen dat je bij me was. 



\section{Contents}

Chapter 1 Introduction

PART I

Chapter 2 Measuring perceived social support and perceived stress among primary school children in the Netherlands

PART II

Chapter 3 Design of a prospective study on mental health and quality of life of maltreated children (aged $5-16$ years) after a report to an advice and reporting center on child abuse and neglect

Chapter 4 The quality of life of maltreated children who have been reported to advice and reporting centers on child abuse and neglect

Chapter 5 Self-reported quality of life of maltreated children and factors associated: A prospective study

PART III

Chapter 6 Design of a quasi-experiment on the effectiveness and cost-effectiveness of using the child-interview intervention during the investigation following a report of child abuse and/or neglect

Chapter 7 Effect and economic evaluation of the child-interview intervention: The child as a participant in the investigation after a report of child maltreatment

Chapter 8 General Discussion

Chapter 9 Summary

Valorization

Samenvatting (Summary in Dutch)

Dankwoord (Acknowledgements)

Curriculum Vitae

Publications 


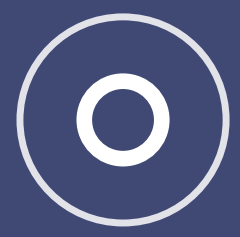

(0)

0

(O)

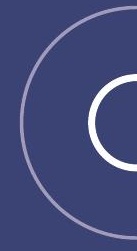

o

(2)

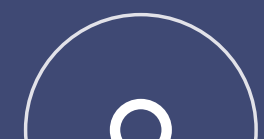




\section{CHAPTER 1}

Introduction

○

(2) 


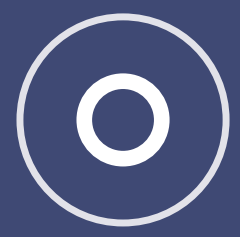

(0)

0

(O)

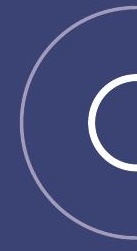

o

(2)

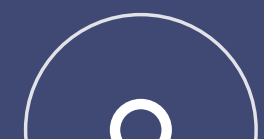




\section{Introduction}

This thesis consists of three parts, each of which discusses giving children a voice, from a different point of view. Part I reports on the development of self-report questionnaires for children. Rather than only using information from proxies, children were given a voice by asking them to self-report on topics regarding their well-being, viz. perceived social support and perceived stress. The reliability and dimensionality of these questionnaires were tested among primary school children in the general population. These self-report questionnaires were then used in the child maltreatment studies presented in Parts II and III.

Part II discusses studies in which maltreated children were given a voice by asking them to self-report on their quality of life over time, over a period of up to 1.5 years after a report had been filed with a Dutch advice and reporting agency on child abuse and neglect (Advies- en Meldpunt Kindermishandeling; AMK). It also examines the potential association between quality of life and various factors, such as perceived social support and perceived stress.

Part III reports on the effectiveness and cost-effectiveness of the 'child-interview' intervention. This intervention gives children a voice by interviewing them as part of the AMK investigation that follows after a maltreatment report is filed. The intervention is compared with an intervention in which only adults are interviewed during the AMK investigation.

\section{Child maltreatment}

Child maltreatment is 'The abuse and neglect that occurs to children under 18 years of age. It includes all types of physical and/or emotional ill-treatment, sexual abuse, neglect, negligence and commercial or other exploitation, which results in actual or potential harm to the child's health, survival, development or dignity in the context of a relationship of responsibility, trust or power' (World Health Organization, 1999). Child maltreatment violates the rights of the child and has serious physical and psychosocial consequences which adversely affect their health (World Health Organization, 1999).

The research for this thesis included the following types of child maltreatment: physical abuse, emotional abuse, physical neglect, emotional neglect, and sexual abuse. Witnessing domestic violence was not part of the inclusion criteria for the studies reported on in this thesis. At the time the research protocol was drafted, (being a witness) domestic violence was not part of the Dutch definition of child maltreatment (yet). In many cases, however, a child falls victim to more than one type of maltreatment, referred to in this thesis 
as 'multiple maltreatment'. Cases in which domestic violence was part of such multiple maltreatment were included.

\section{Prevalence of child maltreatment}

The prevalence of child maltreatment was systematically examined for the first time in the Netherlands in 2005. This Netherlands' Prevalence Study of Maltreatment of Children and Youths (NPM-2005; Van IJzendoorn, Prinzie, Euser, Groeneveld, Brilleslijper-Kater, et al., 2007) was based on the large periodical National Incidence Studies (NIS) on the prevalence of child maltreatment in the US (Euser, Van IJzendoorn, Prinzie, \& Bakermans-Kranenburg, 2010; Sedlak, Mettenburg, Basena, Petta, McPherson, et al., 2010). Sentinel reports were used in combination with records from the AMKs. This study estimated that 107,000 (30 per 1000) children a year are exposed to some form of child maltreatment in the Netherlands. In the same year, a self-report study was conducted among secondary school pupils, resulting in an estimate of 160,000 (45 per 1000) maltreated children every year (Lamers-Winkelman, Slot, Bijl, \& Vijlbrief, 2007). These self-reported data are valuable, because it is the child maltreatment victims themselves who know most about their own maltreatment experiences. Still, retrospective reports are also vulnerable to recall bias, and the frequency of abuse may be particularly difficult to recall. Moreover, the definition of maltreatment may be interpreted differently by different participants. In contrast, sentinel reports completed by professionals who work with maltreatment victims use the same definitions, but they may not be aware of all cases of maltreatment (Euser, Alink, Pannebakker, Vogels, Bakermans-Kranenburg, et al., 2013).

In 2010, both study designs were combined to monitor the prevalence of child maltreatment in the Netherlands. By combining self-reports and sentinel reports and by using standardized definitions of child maltreatment, Alink and colleagues (2011) estimated that 118,000 (34 per 1000) Dutch children a year are exposed to child abuse and/or neglect (Alink, Van IJzendoorn, Bakermans-Kranenburg, Pannebakker, Vogels, et al., 2011; Euser et al., 2013). This number is similar to that reported by the American NIS-4, which found that 39.5 per 1000 children experienced some form of child maltreatment in 2005/2006 (Sedlak et al., 2010).

\section{Advice and reporting agencies on child abuse and neglect (AMKs)} In the Netherlands, 17 AMKs cover all regions. AMKs can be approached by both professionals and non-professionals, such as neighbors and family members. Professional advice is provided and suspicions of child maltreat- 
ment can be reported. The reports are subsequently discussed in a multidisciplinary meeting, usually involving at least one or two social workers, a doctor, a psychologist, and a team leader. During this meeting the plan is drafted for the AMK investigation to collect information to verify or falsify the report. Currently, two methods are used for this investigation: the adultonly intervention ( $\mathrm{Al}$ intervention) and the child-interview intervention $(\mathrm{Cl}$ intervention). Both interventions are initial interviews aiming to (1) discover the existence of family problems, (2) explore if the family needs help and is willing to accept help. The only difference between the interventions is that in the $\mathrm{Cl}$ intervention children are also interviewed during the AMK investigation. The expected benefit of the $\mathrm{Cl}$ intervention is to give the child a sense of being in control. Also, it is assumed that talking to children can refine the referral to the care system, because these children may provide information that cannot be retrieved from other informants.

In the Al intervention, information to substantiate the alleged child maltreatment is obtained by interviewing adults only. Usually, it is both parents, the teacher(s) and the family doctor who are interviewed, but other adults such as (adult) family members, social worker(s), therapist(s), or healthcare specialist(s) can also be approached, depending on the social environment of the reported child/family. Information is collected by an AMK employee by phone- or emailcontact or during a home visit. In the $\mathrm{Cl}$ intervention, the multidisciplinary team discusses which adults to approach, and in addition to these adult interviews, children aged six years and older are also interviewed. The child interview takes place at home or at school, in a separate room. The duration of the interview depends on the child's age, developmental stage, willingness to talk, and needs. According to the AMK manual, the $\mathrm{Cl}$ intervention is the preferred method. However, the effectiveness of this intervention has never been studied, which was therefore one of the aims of this PhD project.

After the AMK investigation has been completed, all information is evaluated by the same multi-disciplinary team. This team assesses whether the alleged maltreatment has been verified or falsified, and recommends suitable child and/or family care. If voluntary care is rejected, the AMK can report the family to child protection services, which can arrange more compulsory action (Baeten, 2009).

Since NPM-2005, attention for child maltreatment has increased both among politicians and in the media. The number of reports to the AMKs has increased substantially, from 13,815 in 2006 to over 19,000 in 2012 (Euser et al., 2013; Jeugdzorg Nederland, 2013; MOGroep Jeugdzorg, 2007). 
This substantial increase implies improved awareness, recognition, and reporting of child maltreatment. Unfortunately, most cases of child maltreatment still do not come to the attention of the AMKs. Even when taking into consideration that $11.7 \%$ of the 19,000 reports in 2012 could not be verified and $7.5 \%$ were falsified (Jeugdzorg Nederland, 2013), many reports included more than one child per family, which shows that the 19,000 reports a year are only the tip of the iceberg, as the estimated child maltreatment prevalence was 118,000 (Alink et al., 2011).

\section{Consequences of child maltreatment}

Child maltreatment has a huge impact on the lives of children and adults, as it has been associated with adverse effects in both the short and the long term (Dubowitz \& Bennett, 2007; Gilbert, Widom, Browne, Fergusson, Webb, et al, 2009; Kendall Tacket, Meyer Williams, \& Finkelhor, 1993; Nelson, Heath, Madden, Cooper, Dinwiddie, et al., 2002; Springer, Sheridan, Kuo, \& Carnes, 2007). Firstly, several studies have shown that adverse consequences include impaired neurobiological development, physical health, and mental health, including behavioral problems and socio-emotional problems. Initial consequences, such as attachment problems, may develop over time into a variety of adulthood psychiatric disorders such as personality and mood disorders. Thus, child maltreatment victims are at risk for adverse life outcomes, such as substance abuse, unemployment or revictimization (Gilbert et al., 2009; Leeb, Lewis, \& Zolotor, 2011). Studies have also shown that adults who have been maltreated during childhood are at risk for abusing their own children (Stith, Liu, Davies, Boykin, Alder, et al., 2009).

Secondly, interest in the extent to which life events influence individuals' perception of life has been steadily increasing. Such information on children's perception of life could allow us to create a better picture of their overall functioning. Quality of life, defined by the WHO as 'the individuals' perception of their position in life in the context of culture and value systems in which they live, in relation to their goals, expectations, standards and concerns' (WHO Quality of Life Group, 1995, p. 1405), adds this subjective component to objective, clinical measures and is therefore increasingly used in healthrelated research (Gielen, McDonnell, Wu, O'Campo, \& Faden, 2001; Peeters \& Stiggelbout, 2010; Klassen, Anthony, Khan, Sung, \& Klaassen, 2011) and clinical practice (Bastiaansen, Koot, Bongers, Varni, \& Verhulst, 2005). There have been few studies on perceived quality of life of child maltreatment victims (Leeb et al., 2011). The available literature has focused mainly on long-term outcomes. There is evidence of adverse quality of life outcomes in 
adults after childhood maltreatment (Afifi, Murray, Cox, De Graaf, Ten Have, et al., 2007; Al-Fayez, Oheari, \& Gado, 2012; Corso, Edwards, Fang, \& Mercy, 2008). Studies regarding the quality of life of maltreated children shortly after or even during the maltreatment have been scarce, which is unfortunate as perceptions regarding quality of life shortly after or during maltreatment may differ from retrospective perceptions reported years later in adulthood.

Studying the quality of life outcomes of maltreated children shortly after they are reported to an AMK was therefore one of the aims of this PhD project.

Thirdly, research has demonstrated that child maltreatment not only impacts on the child and its surroundings, but also has an impact on society. Adverse consequences to health and quality of life imply that maltreated children and their families are likely to utilize multiple public services, such as healthcare and social services. This service use leads to substantial costs to society (Fang, Brown, Florence, \& Mercy, 2012). A Dutch study reported a conservative estimate of societal costs of 965 million euros in 2003, approximately 138 euros per household a year (Meerding, 2005). Given this considerable burden to society and the current scarcity of funds, there is greater emphasis on economic evaluations. These types of studies are valuable to assist policy makers in their decisions regarding prevention and regarding the most effective treatments. However, to our knowledge, there have been few economic evaluations on child maltreatment (Corso \& Lutker, 2006; Corso $\&$ Fertig, 2010). One of the aims of this PhD project was therefore to conduct an economic evaluation of an intervention targeting maltreated children after they were reported to an AMK.

\section{A more child-oriented approach in research and practice}

In recent decades, there has been a shift to a more child-oriented approach in both research and practice. As a result, the value of child self-report questionnaires and child interviews has increasingly been recognized. There are several reasons for this increased interest in giving children a voice. In the first place, discrepancies between child and proxy reports were found when collecting data on subjective constructs (Eiser \& Morse, 2001; Rajmil, Fernandez, Gispert, Rue, Glutting, et al., 1999; Theunissen, Vogels, Koopman, Verrips, Zwinderman, et

al., 1998; Wallander, Schmitt, Burstrom, Cavrini, Devlin, et al., 2001). Proxy informants, usually a parent or teacher, were often used as the source of information for children younger than 12 years. However, proxies can be influenced by their own experiences and perceptions, which may differ from those of the child (Cremeens, Eiser, \& Blades, 2006; Ingerski, Shaw, Gray, \& Janicke, 2010). Particularly in cases of child maltreatment, an abusive parent may 
not be the most reliable informant (Corso \& Lutzker, 2006; Prosser \& Corso, 2007).

Secondly, it used to be doubted whether children are able to recall details of the abusive situation, and whether their imagination or suggestibility would impair their reports (Ceci \& Bruck, 1993). In the meantime, however, abundant proof has been found that children are able to provide accurate and reliable information (e.g. Lamb, Orbach, Herschkowitz, Esplin, \& Horowitz, 2009; Patterson \& Pipe, 2009), as long as they are approached with appropriate interviewing tools that help them understand the concept that they need to report on or talk about (Bell, 2007; Eiser \& Morse, 2001; Mabugu, Revill, \& Van den Berg, 2013). For example, the use of pictures (e.g. smileys) has been recommended when young children are asked about their perceived quality of life. Another recommendation is to use different questionnaire versions for different age groups, with age-specific terminology and age-specific answering options, e.g. fewer answering categories for younger children (Mabugu et al, 2013; Ravens-Sieberer, Erhart, Wille, Wetzel, Nickel, \& Bullinger, 2006).

Finally, the belief has grown that talking about maltreatment may be the start of the recovery process (Graham-Bermann, Kulkarni, \& Kanukollu, 2011; Zech \& Rime, 2005). It may contribute to enhanced feelings of control over the situation and to increased self-esteem (Black \& Ponirakis, 2000; GrahamBermann et al., 2011; Palmer, Brown, Rae-Grant, \& Loughlin, 1999). Keeping maltreatment a secret is associated with additional trauma (Hebert, Tourigny, Cyr, McDuff, \& Joly, 2009). In addition, AMK social workers also report that in their experience talking with these children yields valuable information, which helps them in referral to tailored care. They emphasize that this information cannot be obtained from other sources.

To facilitate a child-oriented approach that benefits from the valuable and reliable information that children can provide, it is crucial to develop selfreport questionnaires for children to report on issues regarding their wellbeing. The topic of questionnaire development is addressed in Part I of this thesis. The self-report questionnaires discussed in Part I were used to give maltreated children a voice in research (Part II) and AMK practice (Part III).

There is growing interest in efforts to understand and optimize child development by giving children a voice (Lippman, Moore, \& McIntosh, 2011). Quality of life has become an important topic of research, because of the subjective component included in this construct. Information on children's quality of life outcomes after maltreatment is limited and was therefore examined in the research reported on in this thesis (Part II). In addition, we studied factors that may be associated with quality of life outcomes of maltreated children. Identifying factors related to quality of life after child maltreatment 
helps to understand what factors may make children more vulnerable to adverse outcomes. This information is important to enable referral to suitable care.

The AMKs have also shifted towards more child-oriented practice. Instead of using only adults as informants during the AMK investigation following a report of suspected child maltreatment (Al intervention), they give children a voice by using the $\mathrm{Cl}$ intervention. According to the AMK manual, interviewing the child as part of the AMK investigation is nowadays the preferred approach (Baeten, 2009). However, in a substantial number of cases - $40 \%$ in our study sample children are not yet interviewed during the investigation. A variety of reasons for this have been reported in AMK records. Among the most commonly reported reasons is resistance from the parent(s). It would help AMK social workers in their communication with parents if there was scientific evidence on the effectiveness of the $\mathrm{Cl}$ intervention. This effectiveness, as well as an economic evaluation of this intervention, are addressed in Part III of this thesis.

\section{Outline of this thesis}

A thesis overview and study flow chart is presented in figure 1.

Part I:

Chapter 2 describes the development of two self-report questionnaires to measure perceived social support and perceived stress for children aged 8-11, and evaluates the internal consistency, test-retest reliability and factor analysis to assess the dimensionality of these questionnaires.

Part II:

Chapter $\mathbf{3}$ presents the design of a prospective study on mental health and quality of life of maltreated children aged 5-16 years. These children and one of their parents were recruited shortly after a report to an AMK and were asked to complete a questionnaire on four occasions at 6-month intervals over a 1.5-year period. Chapter 4 reports on the quality of life of maltreated children at the time of the first assessment, i.e. shortly after the report to the AMK. Findings are put in perspective by comparing the quality of life of the maltreated children with norm populations from the general population. In addition, the chapter examines demographic, socio-economic and maltreatment characteristics that may be associated with the quality of life of maltreated children. Chapter 5 reports on the quality of life of maltreated children over a 1.5-year period, as well as child, family/environmental, and parental factors that were associated with quality of life over time. 
Part III:

Chapter 6 presents the design of a quasi-experiment on the effectiveness and cost-effectiveness of using the $\mathrm{Cl}$ intervention during the AMK investigation. Chapter 7 examines the effectiveness of the $\mathrm{Cl}$ intervention in comparison with the $\mathrm{Al}$ intervention, as well as presenting an economic evaluation comparing these two AMK investigation methods.

Chapter $\mathbf{8}$ provides a general discussion, in which the main findings of all three parts of the thesis are summarized and in which study limitations and strengths are discussed, as well as suggestions for future research and implications for practice. The thesis concludes with a short summary (in English and Dutch) in Chapter 9.

PART I

\begin{tabular}{|c|c|c|}
\hline $\begin{array}{l}\text { Developing self-report } \\
\text { questionnaires }\end{array}$ & $\begin{array}{l}\text { Test } 1 \\
(N=223)\end{array}$ & $\begin{array}{l}\text { Re-test }(N=173) \\
2-5 \text { weeks after test } 1\end{array}$ \\
\hline
\end{tabular}

PART II

PART III

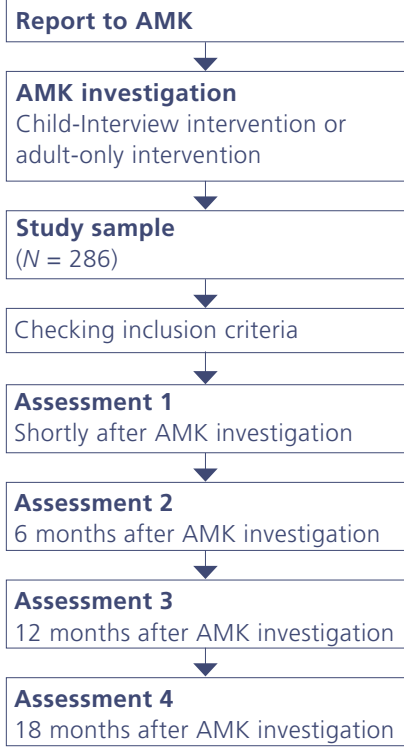

Figure 1. Thesis overview and study flow chart 


\section{References}

Afifi, T. O., Murray, W. E., Cox, B. J., de Graaf, R., ten Have, M., \& Sareen, J. (2007). Child abuse and health-related quality of life in adulthood. The Journal of Nervous and Mental Disease, 195(10), 797-804.

Al-Fayez, G. A., Oheari, J. U., \& Gado, O. M. (2012). Prevalence of physical, psychological, and sexual abuse among a nationwide sample of Arab high school students: association with family characteristics, anxiety, depression, self-esteem, and quality of life. Social Psychiatry and Psychiatric Epidemiology, 47, 53-66.

Alink, L. R. A., Van IJzendoorn, M. H., Bakermans-Kranenburg, M. J., Pannebakker, F. D., Vogels, T., \& Euser, S. (2011). Kindermishandeling in Nederland anno 2010: De Tweede Nationale Prevalentiestudie Mishandeling van Kinderen en Jeugdigen (NPM-2010) (Child maltreatment in the Netherlands in 2010: the second prevalence study of the maltreatment of children and youth in the Netherlands). Leiden: Casimir Publishers.

Baeten, P. (2009). Protocol van handelen- Bij vermoedens van kindermishandeling in relatie van afhankelijkheid en onvrijheid (Manual- How to act in case of suspected child maltreatment relating to dependence and restriction of freedom). Utrecht: MO Groep.

Bastiaansen, D., Koot, H. M., Bongers, I. L., Varni, J. W., \& Verhulst, F. C. (2005). Measuring quality of life in children referred for psychiatric problems: Psychometric properties of the PedsQL 4.0 generic core scales. Quality of Life Research, 13, 489-495.

Bell, A. (2007). Designing and testing questionnaires for children. Journal of Research in Nursing, 12, 461-471.

Black, M. M., \& Ponirakis, R. (2000). Computer-administered interviews with children about maltreatment: Methodological, developmental, and ethical issues. Journal of Interpersonal Violence, 15(7), 682-695.

Ceci, S. J., \& Bruck, M. (1993). Suggestibility of the child witness: A historical review and synthesis. Psychological Bulletin, 113(3), 403-439.

Corso, P. S., Edwards, V. J., Fang, X., \& Mercy, J. A. (2008). Health-related quality of life among adults who experienced maltreatment during childhood. American Journal of Public Health, 98(6), 1094-1100.

Corso, P. S., \& Lutzker, J. R. (2006). The need for economic analysis in research on child maltreatment. Child Abuse \& Neglect, 30, 727-738.

Corso, P. S., \& Fertig, A. R. (2010). The economic impact of child maltreatment in the United States: are estimates credible? Child Abuse \& Neglect, 34, 296-304.

Cremeens, J., Eiser, C., \& Blades, M. (2006). Characteristics of health-related self-report measures for children aged three to eight years: A review of the literature. Quality of Life Research 15, 739-754.

Dubowitz, H., \& Bennett, S. (2007). Physical abuse and neglect of children. The Lancet, 369, 1891- 1899.

Eiser, C., \& Morse, R. (2001). Can parents rate their child's health-related quality of life? Results of a systematic review. Quality of Life Research, 10, 347-357.

Euser, S., Van IJzendoorn, M. H., Prinzie, P., \& Bakermans-Kranenburg, M. J. (2010). Prevalence of child maltreatment in The Netherlands. Child Maltreatment, 15, 5-17.

Euser, S., Alink, L. R. A., Pannebakker, F., Vogels, T., Bakermans-Kranenburg, M. J., \& Van IJzendoorn, M. H. (2013). The prevalence of child maltreatment in the Netherlands across a 5-year period. Child Abuse \& Neglect, 37(10), 841-851.

Fang, X., Brown, D.S., Florence, C. S., \& Mercy, J. A. (2012). The economic burden of child maltreatment in the United States and implications for prevention. Child Abuse \& Neglect, 36, 156-165.

Graham-Bermann, S. A., Kulkarni, M. R., \& Kanukollu, S. (2011). Is disclosure therapeutic for children following exposure to traumatic violence? Journal of Interpersonal Violence, 26(5), 1056-1076. 
Gielen, A. C., McDonnell, K. A., Wu, A. W., O'Campo, P., \& Faden, R. (2001). Quality of life among women living with HIV: The importance of violence, social support, and self-care behaviors. Social Science \& Medicine, 52(2), 315-322.

Gilbert, R., Widom, C. S., Browne, K., Fergusson, D., Webb, E., \& Janson, S. (2009). Burden of consequences of child maltreatment in high income countries. The Lancet, 373(9657), 68-81.

Hebert, M., Tourigny, M., Cyr, M., McDuff, P., \& Joly, J. (2009). Prevalence of childhood sexual abuse and timing of disclosure in a representative sample of adults from Quebec. The Canadian Journal of Psychiatry, 54(9), 631-636.

Ingerski, L. M., Shaw, K., Gray, W. N., \& Janicke, D. M. (2010). A pilot study comparing traumatic stress symptoms by child and parent report across pediatric chronic illness groups. Journal of Developmental and Behavioral Pediatrics, 31(8), 1-7. Jeugdzorg Nederland. (2013). AMK cijfers in 2012 (AMK annual report 2012). Zalsman: Zwolle.

Kendall Tacket, K. A., Meyer Williams, L., \& Finkelhor, D.(1993). The impact of sexual abuse on children: A review and synthesis of recent empirical studies. Psychological Bulletin, 113, 164-180.

Klassen, A. F., Anthony, S. J., Khan, A., Sung, L., \& Klaassen, R. (2011). Identifying determinants of quality of life of children with cancer and childhood cancer survivors: A systematic review. Supportive Care in Cancer, 19(9), 1275-1287.

Lamb, M. E., Orbach, Y., Herschkowitz, I. Esplin, P.W., \& Horowitz, D. (2007). A structured forensic interview protocol improves the quality and informativeness of investigative interviews with children: A review of research using the NICHD Investigative Interview Protocol. Child Abuse \& Neglect, 31, 1201-1231.

Lamers-Winkelman, F., Slot, N. W., Bijl, B., Vijlbrief, A. C. (2007). Scholieren over mishandeling: resultaten van een landelijk onderzoek naar de omvang van kindermishandeling onder leerlingen van het voortgezet onderwijs (Pupils about abuse: results of a national study on the prevalence conducted in secondary education). PI Research, Vrije Universiteit Amsterdam, Faculteit de Psychologie en Pedagogiek, WODC.

Leeb, R. T., Lewis, T., \& Zolotor, A. J. (2011). A review of physical and mental health consequences of child abuse and neglect and implications for practice. American Journal of Lifestyle Medicine, 5(5), 454-468.

Lippman, L. H., Moore, K. A., \& McIntosh, H. (2011). Positive indicators of child well-being. A conceptual framework, measures, and methodological issues. Applied Research Quality of Life, 6, 425-449.

Mabugu, T., Revill, P., \& Van den Berg, B. (2013). The methodological challenges for the estimation of quality of life in children for use in economic evaluation in low-income countries. Value in Health Regional Issues, 2, 231-239.

Meerding, W. (2005). De maatschappelijke kosten van kindermishandeling (Costs to society of childhood maltreatment): In Kindermishandeling: de politiek een zorg. Edited by Willems, J., Baartman, H., \& Bullens, R. Amsterdam: SWP. MOGroep Jeugdzorg. (2007). Adviezen en meldingen over kindermishandeling in 2006 (AMK annual report 2006). Utrecht: Nederlands Jeugdinstituut.

Nelson, E. C., Heath, A. C., Madden, P. A. F., Cooper, L., Dinwiddie, S. H., Bucholz, K. K., Glowinski, A., McLaughlin, T., Dunne, M. P., Statham, D. J., \& Martin, N. G.(2002). Association between self-reported childhood sexual abuse and adverse psychosocial outcomes: Results from a twin study. Archives of General Psychiatry, 59(2),139-145.

Palmer, S. E., Brown, R. A., Rae-Grant, N. I., \& Loughlin, M. J. (1999). Responding to children's disclosure of familial abuse: What survivors tell us. Child Welfare League of America, LXXVIII(2), 259-282.

Patterson, T., \& Pipe, M. (2009). Exploratory assessment of child abuse. Children's responses to interviewer's questions across multiple interviews. Child Abuse \& Neglect, 33, 490-504. 
Peeters, Y., \& Stiggelbout, A. M. (2010). Health state valuations of patients and the general public analytically compared: A meta-analytical comparison of patient and population health state utilities. Value Health, 13(2), 306-309.

Prosser, L. A., \& Corso, P. S. (2007). Measuring health-related quality of life for child maltreatment: A systematic literature review. Health and Quality of Life Outcomes, 5, 42-52.

Rajmil, L., Fernandez, E., Gispert, R., Rue, M., Glutting, J. P., Plasencia, A., \& Segura, A. (1999). Influence of proxy respondents in children's health interview surveys. Epidemiology Community Health, 53, 38-42.

Ravens-Sieberer, U., Erhart, M., Wille, N., Wetzel, R., Nickel, J., \& Bullinger, M. (2006). Generic health-related quality-of-life assessment in children and adolescents. Methodological considerations. Pharmacoeconomics, 24(12), 1199-1220.

Sedlak, A. J., Mettenburg, J., Basena, M., Petta, I., McPherson, K., Greene, A., \& Li, S. (2010). Fourth National Incidence Study of child abuse and neglect (NIS-4): Report to congress. Washington, DC: Department of Health and Human Services, Administration of Children and Families.

Springer, K. W., Sheridan, J., Kuo, D., Carnes, M. (2007). Long-term physical and mental health consequences of childhood physical abuse: Results from a large population-based sample of men and women. Child Abuse \& Neglect, 31(5), 517-530.

Stith, S. M., Liu, T., Davies, L. C., Boykin, E. L., Alder, M. C., Harris, J. M., Som, A., et al. (2009). Risk factors in child maltreatment: A meta-analytic review of the literature. Aggression and Violent Behavior, 14, 13-29.

Theunissen, N. C. M., Vogels, T. G. C., Koopman, H. M., Verrips, G. H. W., Zwinderman, K. A. H., Verloove-Vanhorick, S. P., \& Wit, J. M. (1998). The proxy problem: Child report versus parent report in health-related quality of life research. Quality of Life Research, 7, 387-397.

Van IJzendoorn, M .H., Prinzie, P., Euser, E. M., Groeneveld, M. G., Brilleslijper-Kater, S. N., Van Noort-Van der Linden, A. M. T., Bakermans-Kranenburg, M. J., Juffer, F., Mesman, J., Klein Velderman, M., San Martin Beuk, M., Ohlsen-Koole, P. C. (2007). Kindermishandeling in Nederland anno 2005: de nationale prevalentiestudie van kinderen en jeugdigen (NPM-2005) (Netherlands' Prevalence Study of Maltreatment of children and youth). Leiden: WODC/ Universiteit Leiden.

Wallander, J. L., Schmitt, M., \& Koot, H. M. (2001). Quality of life in children and adolescents: Issues, instruments, and applications. Journal of Clinical Psychology, 57(4), 571-585.

World Health Organization Quality of Life Group (1995). The World Health Organization Quality of Life of Life Assessment (WHOQOL): Position paper from the World Health Organization. Social Science \& Medicine, 41(10), 1403-1409.

World Health Organization. (1999). Report of the consultation on child abuse prevention (document WHO/HSC/PVI/99.1). Geneva, World Health Organization conference, 29-31 March 1999.

Zech, E., \& Rime, B. (2005). Is talking about an emotional experience helpful? Effects on emotional recovery and perceived benefits. Clinical Psychology and Psychotherapy, 12, 270-287. 


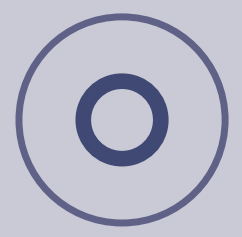

(0)

0

(O)

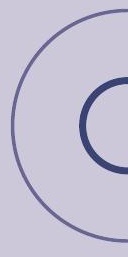

O

o

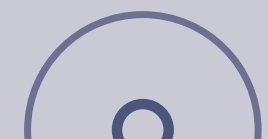


Part I

O

(a)

( 

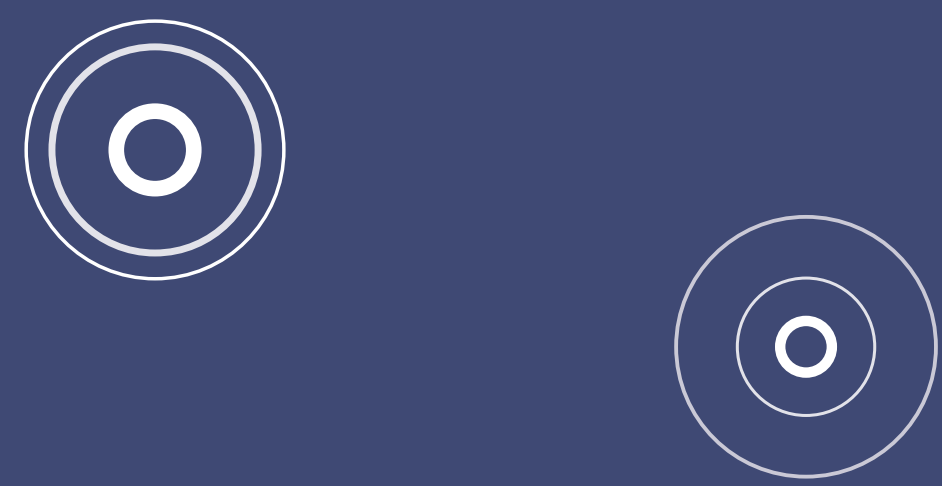

(0)

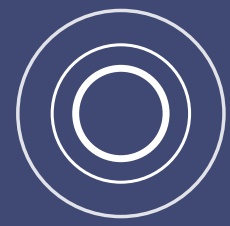

○)

(2) 


\section{CHAPTER 2}

Measuring perceived social support and perceived stress among primary school children in the Netherlands

\section{F. Snoeren \& C. Hoefnagels}

Published in Child Indicators Research (2014), 7(3), 473-486. 

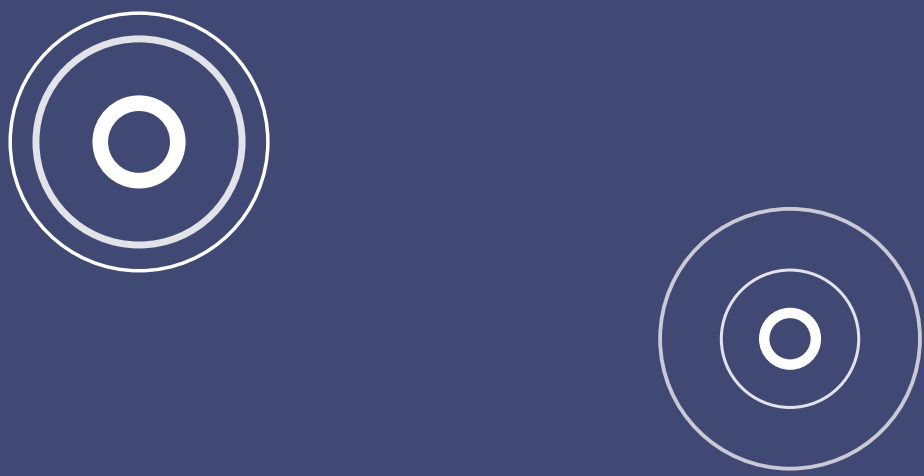

Abstract

Stress and social support play major roles in children's lives and are both associated with psychological and physical well-being. Although these constructs have been shown to explain and predict well-being and health in adults and adolescents, the evidence for children is limited. From a developmental perspective, it would be premature to assume similar models for social support, stress and well-being for children as were established for adolescents and adults. Recently, the interest in child self-reports in the assessment of constructs related to well-being has increased, and research has shown that children can provide reliable and accurate information. Since no self-report questionnaires to measure stress and social support among children aged 8-11 years are available in the Netherlands, two questionnaires were adjusted for use in this younger age group and examined for internal consistency and test-retest reliability among 223 primary school children. In addition, an exploratory factor analysis (PAF) was conducted to demonstrate the dimensionality of the questionnaires. Overall, moderate to good internal consistency and test-retest reliability were found for both questionnaires. The findings suggest that both show potential as feasible and psychometrically adequate self-report measures for primary school children.

Keywords: Social support, Stress, Primary school children, Questionnaire development, Reliability, Exploratory factor analysis 


\section{Introduction}

Stress and social support play major roles in children's lives and are both associated with psychological and physical well-being (Bokhorst, Westenberg, Oosterlaan, \& Heyne, 2009; Cohen \& Wills, 1985; Malecki \& Demaray 2002; Skok, Harvey, \& Reddihough, 2006; Wong, Ratner, Gladstone, Davtyan, \& Koopman, 2010). According to Lazarus (1966), feelings of stress arise due to everyday problems or life events, when a situation is judged as threatening or otherwise demanding (Cohen \& Wills, 1985; Compas, 1987). Social support can be obtained from sources such as relatives, friends, and neighbors (Reevy \& Maslach, 2001). In this study we use Barrera's definition of perceived social support: Perceived social support represents cognitive appraisal of being reliably connected to others (Barrera 1986).

Research findings agree that social support and stress are interrelated (e.g. Ellis, Nixon, \& Williamson, 2009; Guralnick, Hammond, Neville, \& Connor, 2008; Skok et al., 2006; Vranceanu, Hobfoll, \& Johnson, 2007). Cohen and Wills (1985) suggested two theoretical explanations for this relationship. In the buffering model, social support is seen as a buffer against stressful life events, and well-being is greater if social support is provided in situations perceived as stressful. The main effects model assumes that social support has a beneficial effect on well-being, regardless of the occurrence of stressful events. In this model, well-being is based on the primary positive effects of social support (e.g. sense of belonging, reassurance). Empirical support has been found for both models. Which model best describes the relationship between social support and stress depends on the situation (Ellis et al., 2009; Skok et al., 2006).

Although the constructs of stress and social support have proven to be important in explaining and predicting well-being and health in adults (e.g. Guralnick et al., 2008; Skok et al., 2006; Vranceanu et al., 2007) and in adolescents (e.g. Garnefski \& Diekstra, 1996; Helsen, Vollebergh, \& Meeus, 2000; Wong et al., 2010), the evidence for children is limited, especially concerning perceived stress (e.g. Boekaerts \& Röder 1999; Perrin, Smith, \& Yule, 2000). From a developmental perspective, it would be premature to assume that the relationship between social support, stress and well-being would be comparable for children, adolescents and adults. Differences in social development (Bokhorst et al., 2008; Booth, Granger, \& Shirtcliff, 2008; Steinberg \& Monahan, 2007) and stress regulation (Kudielka, Buske-Kirschbaum, Hellhammer, \& Kirschbaum, 2004; Neupert, Almeida, \& Charles, 2007; Washington, 2009) across all age groups are to be expected in view of the 
different developmental stages from childhood to adulthood. Children are more dependent on adult care than adolescents, and childhood is a critical period in which coping and adaption mechanisms are developed. Cognitive processes, types of stressful events and the role of the parents are all factors that develop with age and affect children's vulnerability (Compas, 1987). This emphasizes the importance of research into the relationship between stress, social support and well-being among children. Such research requires assessment tools. The U.N. Convention (2009) has encouraged the development of measures to monitor child well-being at both national and international level (Lippman, Moore, \& McIntosh, 2011). The assessment of constructs such as social support and stress at particular developmental stages, especially among primary school children, is lagging behind, so it is necessary to develop reliable instruments for children worldwide, including the Netherlands.

As Lippman and colleagues (2011) observed, there has been an increasing focus on understanding and optimizing child development in the last 15 years. Involving children as self-reporters has increasingly become the preferred method in assessing child well-being. Until recently, parents and other adults, such as teachers, were used as proxy informants when collecting data on health and quality of life among children younger than 12 years. However, the use of proxies is not always preferable when measuring subjective constructs, as research findings show discrepancies between child and parent reports (Rajmil, Fernandez, Gispert, Rue, Glitting, et al.,1999; Theunissen, Vogels, Koopman, Verrips, Zwinderman, et al., 1998; Whiteman \& Green, 1997). These discrepancies might be caused by the 'proxy effect': parents underreport due to lack of knowledge about their children's health. Another explanation may be the 'saliency principle': proxy respondents report events that they interpret as more relevant with greater accuracy than other events (Rajmil et al., 1999). In addition, parental perspectives might be influenced by their own experiences or perceptions (Cremeens, Eiser, \& Blades, 2006; Ingerski, Shaw, Gray, \& Janicke, 2010). As a consequence, the value of obtaining children's self-reports about their health, functioning, abilities and emotions is increasingly recognized, and research has shown that children can provide reliable and accurate information when used as informants (Bell, 2007; Fuchs, 2005). Piaget's theory of cognitive development in children states that children start to develop language and reading skills at the age of seven or eight (Borgers, Hox, \& Sikkel, 2004). Bell (2007) also suggests that survey questions can be used for children from approximately age seven.

In the Netherlands, however, no self-report questionnaires have so far been available to measure perceived social support and perceived stress 
among children aged 8 to 11 years. The aim of this study was therefore to develop reliable self-report questionnaires to measure these constructs among this age group. As a starting point for the development of these questionnaires, we used existing questionnaires for adolescents, with good reliability and construct validity, and used their subscales as a theoretical basis to measure social support and stress perceived by children. We hypothesized that an exploratory factor analysis would demonstrate whether the underlying dimensions in the adolescent scales would be the same for the child questionnaires.

The study consisted of two stages. In stage one, two self-report questionnaires were developed with the assistance of primary school teachers, which we called the Perceived Social Support Questionnaire 8-11 (PSSQ8-11) and the Perceived Stress Questionnaire 8-11 (PSQ8-11). In stage two, some psychometric properties of these questionnaires were examined. Research questions were: (a) Are the PSSQ 8-11 and the PSQ8-11 internally consistent?, (b) Are the PSSQ8-11 and the PSQ8-11 test-retest reliable, and (c) Does the factor structure of the PSSQ8-11 and the PSQ8-11 correspond with the factor structure of the original questionnaires?

\section{Methods}

\section{Questionnaire development}

To develop the self-report questionnaires for children aged 8 to 11 years, we used existing questionnaires measuring perceived stress and perceived social support among adolescents (12 years and up), viz. the 'Maastricht University Stress Instrument for Children' (MUSIC; Kraag, Meesters, Van Bekkum, Fekkes, et al., submitted) and the 'Sociale Steun Lijst-Interacties voor jongeren' (SSL-I adolescent version; Hoefnagels, Meesters, \& Simenon, 2007). These measures had been developed for Dutch studies among adolescents and were the only Dutch self-report instruments measuring perceived stress and social support in adolescents at the time of our study.

A form was developed and presented to six experienced primary school teachers, who were asked to record if the questionnaire items were understandable to children aged 8 to 11 years. The teachers were asked to provide alternative phrasing if they considered items to be insufficiently clear for this age group. Based on a literature study on cognitive development and questionnaire development for young children, and based on the teachers' comments on the questionnaire items, a first draft of the questionnaires for 
children was prepared. The main adjustments were language adjustments, for example, substitution of difficult words. The adjusted version was then tested in a pilot study among Dutch primary school children aged 8 to 11 . The pilot observations led to further adjustments of words that children found difficult. As part of this adjustment, two items of each questionnaire were merged because their wording became similar. This resulted in two age-appropriate questionnaires ready to be examined for their psychometric properties: the Perceived Social Support Questionnaire 8-11 and the Perceived Stress Questionnaire 8-11. The study to examine psychometric characteristics of these questionnaires was approved by the Dutch Medical Ethics Committee for Mental Health Care (METiGG) in April 2009.

\section{Measures}

Perceived Social Support Questionnaire 8-11 (PSSQ8-11). This questionnaire was based on the SSL-I adolescent version (Hoefnagels et al., 2007), which has good internal consistency $(a>$.78). The SSL-I adolescent version is an adapted version of the Social Support Inventory-Interactions for adults (Van Sonderen, 1993). The Social Support Inventory is widely used in both national and international research. To confirm its reliability (internal consistency and test-retest reliability), content validity and construct validity, Van Sonderen (1993) reported data from five different studies. All these studies showed similar results, indicating acceptable reliability and validity. The SSL-I adolescent version has 19 items and consists of three subscales: daily emotional support (5 items), emotional support in problem situations ( 7 items) and negative interactions (7 items).

The PSSQ8-11 has 18 items and consists of the same subscales as the SSL-I adolescent version, but with only 4 items on the daily emotional support subscale. As in the SSL-I adolescent version, children were asked to rate how often they had perceived various types of social support over the last week on a 4-point Likert scale ( 1 = almost never, 2 = sometimes, $3=$ often, $4=$ very often). A higher sum score on the daily emotional support and emotional support in problem situations subscales corresponds with greater perceived positive social interactions. A higher sum score on the negative interactions subscale corresponds with greater perceived negative social interactions.

Perceived Stress Questionnaire 8-11 (PSQ8-11). This questionnaire was based on the MUSIC (Kraag et al., submitted). MUSIC has 20 items and consists of two subscales: psychological stress and physiological stress, with 10 items each. Its construct validity and reliability are good ( $a=0.78$ for the psychological subscale and $a=0.82$ for the physiological subscale) (Kraag et 
al. submitted). Reliability and construct validity of the MUSIC have been examined as part of the development of the questionnaire and again as part of a larger follow-up study. Construct validity was examined by comparing the MUSIC stress scores with scores on the Depression Anxiety Stress Scale (child version). In the larger study, MUSIC stress scores were also compared with anxiety and depression scores (Kraag et al., submitted).

The PSQ8-11 has 19 items and consists of two subscales: psychological stress (9 items) and physiological stress (10 items). As in the MUSIC, children were asked to rate how often they had experienced various stressors or reactions to stress over the last week, on a 4-point Likert scale $(1=$ never, 2 = sometimes, 3 = often, 4 = very often). A higher score on the questionnaire corresponds with greater perceived stress.

\section{Participants and Procedure}

Letters explaining the study were sent to all primary schools in the city and region of Tilburg, a city in the south of the Netherlands. A week later, schools were contacted by a researcher, the first author of this paper, to provide additional information about the study. The power calculation was based on the range proposed by Stevens (1992), so 10 children per questionnaire item were invited to participate in the study. If schools agreed to participate in the study, all children in the 8 to 11 age range were expected to participate, unless parents refused consent. After the required number of respondents had been attained, no further schools were approached for participation. A total of 223 children (123 boys and 100 girls) aged 8 to 11 years $(M=9.5$, $S D=0.9$ ) were thus recruited from 3 primary schools (1 urban, 2 rural). School procedures for informed consent were followed: parents were informed about the study through a letter sent by the schools, in which they were asked to notify the school if they refused consent for participation of their child in the study. None of the parents refused their child's participation. All children present at the moment that had been scheduled for questionnaire completion were invited to participate in the study during a group class session. The children were asked to read and answer the questions individually. A teacher was present to provide group instruction and answer questions. The children who had participated in the first session and who were present on the day scheduled for the retest completed the questionnaire again, using the same method. Retests were completed 2 to 5 weeks after the initial questionnaires had been completed. Differences in the time that elapsed between test and retest were partly due to a two-week spring break. One hundred and seventy-three children $(M=9.5, S D=0.9)$, including 94 boys 
(54\%) and 79 girls (46\%), participated in the retest. On both occasions, questionnaires were sent to the schools by mail. Teachers were asked to have their class complete them and return the completed questionnaires by mail within a week.

\section{Data Analysis}

Data were analyzed using SPSS version 19. Internal consistency was examined for both the questionnaires as a whole and the subscales, using Cronbach's alphas. A Cronbach's alpha of at least .70 is considered sufficient (Evers, Van Vliet-Mulder, \& Groot, 2000).

Test-retest reliability was examined for the sum scores of the questionnaires as a whole as well as those of the subscales. Sum score correlations between the test and retest were calculated using Pearson correlations. A correlation of .60 or higher is considered sufficient (Evers et al., 2000).

To examine whether the underlying dimensions of the adolescent subscales would also be found in the present child sample, an exploratory factor analysis was performed, using principle axis factoring (PAF) with Oblimin rotation. The PAF was performed twice for each questionnaire. First, all factors with an eigenvalue higher than 1.0 were extracted. Subsequently, the number of factors was limited to the number of subscales of the adolescent scales (3 factors for the PSSQ8-11 and 2 factors for the PSQ8-11). An eigenvalue higher than 1.0 was used as a cut-off value. Items were assigned to the factor of their highest loading (preferably above .40) (Stevens, 1992).

\section{Results}

\section{Perceived Social Support Questionnaire 8-11 (PSSQ8-11)}

Overall, results showed good internal consistency for the PSSQ8-11 (Table 1). Internal consistency of the subscales was moderate to good, with the exception of the daily emotional support subscale (Evers et al., 2000). No substantial improvements were obtained by deleting items.

Test-retest reliability of the questionnaire and its subscales was good, with the exception of the emotional support in problem situations subscale (Table 2) (Evers et al., 2000). 
Table 1.

Internal consistency of the PSSQ8-11 and PSQ8-11 and their subscales

\begin{tabular}{lll}
\hline & $N$ & Cronbach's $a$ \\
\hline PSSQ8-11 & 222 & .73 \\
Daily emotional support (4 items) & 223 & .59 \\
Emotional support in problem situations (7 items) & 223 & .69 \\
Negative social interactions (7 items) & 223 & .75 \\
\hline PSQ8-11 & 216 & .85 \\
Psychological stress (9 items) & 218 & .76 \\
Physical stress (10 items) & 221 & .80 \\
\hline
\end{tabular}

Table 2.

Descriptives and test-retest reliability of the PSSQ8-11 and PSQ8-11 and their subscales on test and retest

\begin{tabular}{lllllll}
\hline & $N$ & $M(1)^{\mathrm{a}}$ & $S D(1)^{\mathrm{a}}$ & $M(2)^{\mathrm{a}}$ & $S D(2)^{\mathrm{a}}$ & Pearson $r$ \\
\hline PSSQ8-11 & 170 & 50.3 & 6.6 & 49.6 & 6.3 & $.72^{\mathrm{b}}$ \\
$\quad \begin{array}{l}\text { Daily emotional support } \\
\text { Emotional support in problem }\end{array}$ & 171 & 11.0 & 2.2 & 10.6 & 2.2 & $.72^{\mathrm{b}}$ \\
$\quad \begin{array}{l}\text { situations } \\
\text { Negative social interactions }\end{array}$ & 173 & 17.5 & 3.6 & 16.5 & 2.2 & $.59^{\mathrm{b}}$ \\
\hline PSQ8-11 & 167 & 21.8 & 3.8 & 22.4 & 4.0 & $.72^{\mathrm{b}}$ \\
$\quad \begin{array}{l}\text { Psychological stress } \\
\text { Physical stress }\end{array}$ & 170 & 19.4 & 4.2 & 18.6 & 4.5 & $.79^{\mathrm{b}}$ \\
\hline
\end{tabular}

a (1): test; (2) retest

${ }^{b}$ Correlation is significant at the 0.01 level (2-tailed)

The exploratory factor analysis (PAF) with extraction of all factors with an eigenvalue higher than 1 resulted in 4 factors explaining $34.8 \%$ of the variance (Table 3). When the number of factors was limited to three, $31.1 \%$ of the variance was explained (Table 4). When the items were assigned to their factors based on the factor loadings, this 3-factor solution proved to be an exact fit with the three dimensions of the adolescent scale. 
Table 3.

PSSQ8-11 items and PAF factor loadings on all factors with eigenvalue $>1.0$

\begin{tabular}{lrrrr}
\hline In the last week, did someone ever: & Factor 1 & Factor 2 & Factor 3 & Factor 4 \\
\hline 1. cuddle you? & -.149 & .067 & -.406 & .031 \\
\hline 2. help you out? & .169 & .442 & -.043 & .112 \\
\hline 3. cheer you up? & .096 & .517 & -.128 & .022 \\
\hline 4. say nice things to you? & -.009 & .182 & -.477 & -.063 \\
\hline 5. listen to you? & .235 & .130 & -.358 & -.023 \\
\hline $6 . \quad$ give you a good idea? & -.052 & .444 & -.001 & -.189 \\
\hline 7. encourage you to keep going? & -.228 & .362 & -.147 & -.084 \\
\hline 8. show you he/she likes you? & -.014 & -.039 & -.769 & -.052 \\
\hline 9. comfort you? & .037 & .473 & -.207 & .107 \\
\hline 10. help you by explaining a question to you? & .046 & .498 & .050 & .028 \\
\hline 11. tell you everything will be alright? & -.097 & .585 & .030 & -.067 \\
\hline 12. behave unfriendly towards you? & .397 & .085 & -.009 & -.424 \\
\hline 13. break an agreement he/she made with you? & .467 & -.019 & -.036 & -.068 \\
\hline 14. say unfriendly things to you? & .136 & -.015 & -.073 & -.843 \\
\hline 15. blame you for something you didn't do? & .663 & -.046 & -.088 & .049 \\
\hline 16. treat you unfairly? & .563 & .158 & .087 & -.184 \\
\hline 17. ask you something that was too complicated & .241 & -.187 & -.246 & -.130 \\
$\quad$ for you? & & & & \\
\hline 18. meddle with you too much? & .563 & .059 & .156 & -.074 \\
\hline
\end{tabular}

\section{Perceived Stress Questionnaire 8-11 (PSQ8-11)}

Results showed good internal consistency and good test-retest reliability for the PSQ8-11 and both of its subscales (Tables 1 and 2).

The exploratory factor analysis (PAF) with extraction of all factors with an eigenvalue higher than 1 resulted in 5 factors explaining $41.4 \%$ of the variance. Table 5 shows the factors and the item loadings. The PAF limited to two factors explained $30.6 \%$ of the variance (Table 6). When the items were assigned to their factors, this two-factor solution proved to be comparable with the dimensions of the adolescent scale, with the exception of items 2, 3, 6 and 9 (psychological stress subscale). 
Table 4.

PSSQ8-11 items and PAF factor loadings in three-factor solution

\begin{tabular}{lccr}
\hline In the last week, did someone ever: & Factor $1^{\text {a }}$ & Factor $2^{\text {b }}$ & Factor $3^{\text {c }}$ \\
\hline 1. cuddle you? & .088 & .152 & -.402 \\
\hline 2. help you out? & .438 & -.081 & -.007 \\
\hline 3. cheer you up? & .525 & -.077 & -.101 \\
\hline 4. say nice things to you? & .208 & -.045 & -.469 \\
\hline 5. listen to you? & .145 & -.214 & -.321 \\
\hline 6. give you a good idea? & .445 & -.078 & -.014 \\
\hline 7. encourage you to keep going? & .376 & .156 & -.155 \\
\hline 8. show you he/she likes you? & -.004 & -.040 & -.762 \\
\hline 9. comfort you? & .484 & .036 & -.171 \\
\hline 10. help you by explaining a question to you? & .503 & -.018 & .073 \\
\hline 11. tell you everything will be alright? & .591 & .049 & .033 \\
\hline 12. behave unfriendly towards you? & .085 & -.662 & -.025 \\
\hline 13. break an agreement he/she made with you? & -.024 & -.489 & -.013 \\
\hline 14. say unfriendly things to you? & .022 & -.603 & -.121 \\
\hline 15. blame you for something you didn't do? & -.047 & -.572 & -.035 \\
\hline 16. treat you unfairly? & .153 & -.661 & .113 \\
\hline 17. ask you something that was too complicated & -.180 & -.324 & -.245 \\
for you? & & & \\
\hline 18. meddle with you too much? & .044 & $\mathbf{. 5 7 5}$ & .181 \\
\hline
\end{tabular}

a the items with the highest factor loading on factor 1 correspond with the 'emotional support in problem situations' subscale of the SSL-I youngster version

b the items with the highest factor loading on factor 2 correspond with the 'negative interactions' subscale of the SSL-I youngster version

c the items with the highest factor loading on factor 3 correspond with the 'daily emotional support' subscale of the SSL-I youngster version

\section{Discussion}

The aim of this study was to develop reliable self-report questionnaires to measure perceived social support and perceived stress among children aged 8 to 11 years. Several studies (Bell, 2007; Borgers et al., 2004; Rebok, Riley, Forrest, Starfield, Green, et al., 2001; Stevens, 2009) have reported that children of this age have the ability to reliably answer self-report questionnaires if certain conditions are met, such as simple language, short questions, avoiding negatively worded items and providing clear response scales. Both questionnaires developed in this study take these considerations into account. The PSSQ8-11 and the PSQ8-11 showed moderate to good internal consistency, 
Table 5.

PSQ8-11 items and PAF factor loadings on all factors with eigenvalue $>1.0$

\begin{tabular}{|c|c|c|c|c|c|}
\hline In the last week, how often did you: & Factor 1 & Factor 2 & Factor 3 & Factor 4 & Factor 5 \\
\hline 1. find it hard to calm down? & -.068 & .618 & -.080 & .023 & -.208 \\
\hline $\begin{array}{l}\text { 2. feel like there was a lot to do and too } \\
\text { little time? }\end{array}$ & .350 & .061 & -.169 & -.076 & -.183 \\
\hline 3. think of problematic things? & .458 & .047 & .079 & .088 & -.324 \\
\hline $\begin{array}{l}\text { 4. easily become annoyed with other } \\
\text { children in your class? }\end{array}$ & .142 & .500 & .052 & -.055 & -.054 \\
\hline $\begin{array}{l}\text { 5. become impatient if something didn't } \\
\text { work out right away? }\end{array}$ & .042 & .569 & .058 & -.005 & -.176 \\
\hline 6. think about things that have happened? & .030 & .105 & -.107 & .130 & -.634 \\
\hline 7. become impatient while waiting? & -.173 & .659 & -.096 & .089 & .111 \\
\hline 8. easily become upset? & .109 & .649 & -.010 & -.015 & .137 \\
\hline 9. easily become sad? & .388 & .197 & .017 & .110 & .060 \\
\hline 10. have a stomach ache? & .107 & -.056 & .038 & .600 & .120 \\
\hline 11. grow tired without knowing why? & .386 & -.010 & -.169 & .181 & -.081 \\
\hline 12. have a headache? & .318 & .009 & -.149 & .333 & .065 \\
\hline 13. have trouble falling asleep? & -.066 & -.003 & -.953 & -.052 & -.004 \\
\hline $\begin{array}{l}\text { 14. have the feeling that your heart was } \\
\text { beating fast? }\end{array}$ & .218 & .094 & -.016 & .309 & -.111 \\
\hline $\begin{array}{l}\text { 15. have warm and sweaty hands all of a } \\
\text { sudden? }\end{array}$ & .301 & .070 & -.186 & .021 & .117 \\
\hline $\begin{array}{l}\text { 16. sleep badly or wake up in the middle } \\
\text { of the night? }\end{array}$ & .170 & .054 & -.578 & .126 & -.076 \\
\hline $\begin{array}{l}\text { 17. have no appetite for food, although } \\
\text { you had hardly eaten anything? }\end{array}$ & -.035 & .040 & -.085 & .417 & -.130 \\
\hline $\begin{array}{l}\text { 18. feel nauseous or feel like you had to } \\
\text { throw up? }\end{array}$ & -.120 & .054 & .008 & .768 & -.078 \\
\hline 19. feel dizzy? & .380 & .001 &,- 167 & .248 & -.078 \\
\hline
\end{tabular}

with exception of one subscale of the PSSQ8-11, viz. that of daily emotional support $(a=.59)$. The test-retest reliability also proved moderate to good for both questionnaires, with the exception of another subscale of the PSSQ8-11, viz. emotional support in problem situations $(r=.59)$. A possible explanation for the lower reliability of these subscales can be found in the relatively small subscale sizes (the daily emotional support subscale consists of 4 items, and the emotional support in problem situations subscale of 7 items).

To examine possible differences in developmental stage between adolescents and children, an exploratory factor analysis (PAF) was used to discover whether the underlying dimensions in the adolescent scales would be 
Table 6.

PSQ8-11 items and PAF factor loadings on a two-factor solution

\begin{tabular}{|c|c|c|}
\hline In the last week, how often did you: & Factor 1 & Factor 2 \\
\hline 1. find it hard to calm down? & .061 & .678 \\
\hline 2. feel like there was a lot to do and too little time? & .354 & .138 \\
\hline 3. think of problematic things? & .436 & .130 \\
\hline 4. easily become annoyed with other children in your class? & .018 & .531 \\
\hline $\begin{array}{l}\text { 5. become impatient if something didn't work out right } \\
\text { away? }\end{array}$ & .016 & .621 \\
\hline 6. think about things that have happened? & .362 & .242 \\
\hline 7. become impatient while waiting? & -.012 & .575 \\
\hline 8. easily become upset? & .031 & .596 \\
\hline 9. easily become sad? & .356 & .162 \\
\hline 10. have a stomach ache? & .535 & -.174 \\
\hline 11. grow tired without knowing why? & .600 & -.015 \\
\hline 12. have a headache? & .630 & -.083 \\
\hline 13. have trouble falling asleep? & .491 & .057 \\
\hline 14. have the feeling that your heart was beating fast? & .484 & .070 \\
\hline 15. have warm and sweaty hands all of a sudden? & .346 & .037 \\
\hline 16. sleep badly or wake up in the middle of the night? & .649 & .073 \\
\hline $\begin{array}{l}\text { 17. have no appetite for food, although you had hardly } \\
\text { eaten anything? }\end{array}$ & .441 & .001 \\
\hline 18. feel nauseous or feel like you had to throw up? & .561 & -.033 \\
\hline 19. feel dizzy? & .658 & -.019 \\
\hline
\end{tabular}

the same for the present child sample. The PAF was performed both with and without factor limit to assess whether factor solutions would be comparable for adolescents and children, or whether a different structure would prove to offer a better fit. Results of the PAF on the PSSQ8-11 showed that a factor solution with a limit to three factors offered an exact fit with the factors of the adolescent scale. The PAF on the PSQ8-11 extracting all factors with an eigenvalue higher than 1 resulted in an uninterpretable five-factor solution. When the factor count was limited to 2 factors, results were comparable to the factor structure of the adolescent scale. The 4 items that according to their highest factor loading could not be assigned to the expected factor were all part of the psychological stress subscale.

There are several possible explanations for the PAF findings for PSQ8-11. First, two different theoretical approaches point in the same direction. Looking at children from a developmental perspective shows that young 
children tend to use more concrete, physical concepts than older children. With age, children become better able to use abstract psychological terms and referrals (Schaffer, 1996). This may mean that it is easier for younger children to attribute feelings of stress to physiological experiences instead of psychological phenomena. Piaget's theory of developmental stages supports this view: after the age of seven, children reach the stage of concrete operations, in which they develop reading and writing skills, but abstract thought remains difficult (Allen, 1988; Borgers et al., 2004). Between the ages of 11 and 15 years, children finalize skills such as logical and abstract thinking (Borgers et al., 2004).

A second explanation for the finding that not all items loaded on the assumed factor of psychological stress might be found by approaching child development from the psychogenic perspective (Notaro, Gelman, \& Zimmerman, 2001; Toyama, 2010). Notaro and colleagues (2001) and Toyama (2010) studied children's abilities to recognize the psychological cause of stress. Results showed that children typically denied the possibility that bodily reactions can be caused by psychological distress. Apparently, they think that bodily reactions can only occur due to physical causes. As they grow older, children accept that bodily responses can also originate in mental states. Recognition of the psychogenic body starts between ages 8 and 11 (Toyama, 2010).

A third explanation might be an inadequate sense of time in this age group. We asked the children to rate how often they had experienced stressors or reactions to stress over the last week. Although children have been shown to be able to recall information about their health, they may find it difficult to recall exactly when something has occurred (Allen, 1988; Stevens, 2009).

The current study was subject to some limitations. First, this study was the first to provide data on the reliability and dimensionality of the PSSQ8-11 and PSQ8-11, so additional studies are needed to replicate the present findings. Second, we used existing questionnaires for adolescents as a starting point to develop the child self-report questionnaires. We claimed that the necessity of developing self-report questionnaires for children lies in the developmental differences between children and adolescents. Our preliminary tests using exploratory factor analysis provided support for the assumption that underlying dimensions on these constructs might be comparable for children and adolescents. Hence, construct validity should be examined to rule out the possibility that not all items used to measure adolescents' perception of stress and social support are fully applicable to children or that more child-specific items should be added (e.g. related to children's play or 
bullying) in order to get a more complete view of children's perceived social support and perceived stress. Third, the sample consisted of primary school children only, and the appropriateness of the questionnaires for children with special needs, for example those with reading difficulties, remains to be tested. Poor reading skills might negatively affect the data quality (Fuchs, 2005; Stevens, 2009). Fourth, variations in the time that elapsed between test and retest might have influenced the findings, although additional testing (not presented) did not show that the time variation affected the test-retest findings in this study.

In any case, the results of the study do suggest that the PSSQ8-11 and the PSQ8-11 show potential for use in primary school settings, enabling perceived social support and perceived stress to be measured by child selfreport. This is in line with earlier studies suggesting that children are the preferred informants for issues concerning their well-being (Lippman et al., 2011) and studies showing why the use of self-report measures is preferred to prevent proxy errors (Cremeens et al., 2006; Rajmil et al., 1999). The findings imply that in measuring perceived social support and stress among children, one should consider the use of self-report measures instead of or in addition to parent or teacher reports.

\section{Acknowledgments}

The authors wish to thank C. C. A. van Bekkum and G. Kraag, authors of the MUSIC, and E. van Sonderen, author of the Sociale Steun Lijst. This research was funded by ZonMw (project 15700.2012). 


\section{References}

Allen, J. (1988). Children's cognition of stressful events. Day Care \& Early Education, 16(2), 21-25.

Barrera, M., Jr. (1986). Distinction between social support concepts, measures, and models. American Journal of Community Psychology, 14(4), 413-445.

Bell, A. (2007). Designing and testing questionnaires for children. Journal of Research in Nursing, 12(5), 461-469.

Boekaerts, M., \& Röder, I. (1999). Stress, coping, and adjustment in children with a chronic disease: A review of the literature. Disability and Rehabilitation, 21(7), 311-337.

Bokhorst, C. L., Westenberg, P. M., Oosterlaan, J., \& Heyne, D. A. (2008). Changes in social fears across childhood and adolescence: Age-related differences in the factor structure of the fear survey schedule for children-revised. Journal of Anxiety Disorders, 22, 135-142.

Bokhorst, C. L., Sumter, S. R., \& Westenberg, P. M. (2009). Social support from parents, friends, classmates, and teachers in children and adolescents aged 9 to 18 years: Who is perceived as most supportive? Social Development, 19(2), 417-426.

Booth, A., Granger, D. A., \& Shirtcliff, E. A. (2008). Gender- and age-related differences in the association between social relationship quality and trait levels of salivary cortisol. Journal of Research on Adolescence, 18(2), 239-260.

Borgers, N., Hox, J., \& Sikkel, D. (2004). Response effects in surveys on children and adolescents: The effect of number of response options, negative wording, and neutral mid-point. Quality and Quantity, 38, 17-33.

Cohen, S., \& Wills, T. A. (1985). Stress, social support and the buffering hypothesis. Psychological Bulletin, 98(2), 310-357.

Compas, B. E. (1987). Stress and life events during childhood and adolescence. Clinical Psychology Review, 7, 275-302.

Cremeens, J., Eiser, C., \& Blades, M. (2006). Characteristics of health-related self-report measures for children aged three to eight years: A review of the literature. Quality of Life Research, 15, 739-754.

Ellis, A. A., Nixon, R. D. V., \& Williamson, P. (2009). The effects of social support and negative appraisals on acute stress symptoms and depression in children and adolescents. British Journal of Clinical Psychology, 48, 347-361.

Evers, A., Van Vliet-Mulder, J. C., \& Groot, C. J. (2000). Documentatie van tests en testresearch in Nederland (Documentation of tests and test research in The Netherlands). Assen: Van Gorcum.

Fuchs, M. (2005). Children and adolescents as respondents. Experiments on question order, response order, scale effects and the effect of numeric values associated with the response options. Journal of Official Statistics, 21(4), 701-725.

Garnefski, N., \& Diekstra, R. F. W. (1996). Perceived social support, from family, school, and peers: Relationship with emotional and behavioral problems among adolescents. American Academy of Child and Adolescent Psychiatry, 35(12), 1657-1664.

Guralnick, M. J., Hammond, M. A., Neville, B., \& Connor, R. T. (2008). The relationship between sources and functions of social support and dimensions of child- and parent-related stress. Journal of Intellectual Disability Research, 52(12), 1138-1154.

Helsen, M., Vollebergh, W., \& Meeus, W. (2000). Social support from parents and friends and emotional problems in adolescence. Journal of Youth and Adolescence, 29(3), 319-335.

Hoefnagels, C., Meesters, C., \& Simenon, J. (2007). Social support as predictor of psychopathology in the adolescent offspring of psychiatric patients. Journal of Child and Family Studies, 16, 91-101.

Ingerski, L. M., Shaw, K., Gray, W. N., \& Janicke, D. M. (2010). A pilot study comparing traumatic stress symptoms by child and parent report across pediatric chronic illness groups. Journal of Developmental and Behavioral Pediatrics, 31(8), 1-7.

Kraag, G., Meesters, C., Van Bekkum, C., Fekkes, M., Kok, G., \& Huijer Abu-Saad, H. (submitted). The Development of the MUSIC, a short questionnaire for the assessment of stress symptoms in preadolescents. 
Kudielka, B. M., Buske-Kirschbaum, A., Hellhammer, D. H., \& Kirschbaum, C. (2004). Differential heart rate reactivity and recovery after psychosocial stress (TSST) in healthy children, younger adults, and elderly adults: The impact of age and gender. International Journal of Behavioral Medicine, 11(2), 116-121.

Lazarus, R. S. (1966). Psychological stress and the coping process. New York: McGraw-Hill.

Lippman, L. H., Moore, K. A., \& McIntosh, H. (2011). Positive indicators of child well-being. A conceptual framework, measures, and methodological issues. Applied Research Quality of Life. doi:10.1007/s11482-011-9138-6.

Malecki, C. K., \& Demaray, M. K. (2002). Measuring perceived social support: Development of the child and adolescent social support scale (casss). Psychology in the Schools, 39(1), 1-18.

Neupert, S. D., Almeida, D. M., \& Charles, S. T. (2007). Age differences in reactivity to daily stressors: The role of personal control. Journal of Gerontology: Psychological Sciences, 62B(4), 216-225.

Notaro, P. C., Gelman, S. A., \& Zimmerman, M. A. (2001). Children's understanding of psychogenic bodily reactions. Child Development, 72(2), 444-459.

Perrin, S., Smith, P., \& Yule, W. (2000). Practitioner review: The assessment and treatment of post- traumatic stress disorder in children and adolescents. Journal of Child Psychology and Psychiatry, 41(3), 277-289.

Rajmil, L., Fernandez, E., Gispert, R., Rue, M., Glutting, J. P., Plasencia, A., et al. (1999). Influence of proxy respondents in children's health interview surveys. Epidemiology \& Community Health, 53, 38-42.

Rebok, G., Riley, A., Forrest, C., Starfield, B., Green, B., Robertson, J., et al. (2001). Elementary school-aged children's reports of their health: A cognitive interviewing study. Quality of Life Research, 10, 59-70.

Reevy, G. M., \& Maslach, C. (2001). Use of social support: Gender and personality differences. Sex Roles, 44, 437-459.

Schaffer, H. R. (1996). Social development. Oxford: Blackwell Publishers Ltd.

Skok, A., Harvey, D., \& Reddihough, D. (2006). Perceived stress, perceived social support, and well-being among mothers of school-aged children with cerebral palsy. Journal of Intellectual \& Developmental Disability, 31(1), 53-57.

Steinberg, L., \& Monahan, K. C. (2007). Age differences in resistance to peer influence. Developmental Psychology, 43(6), 1531-1543.

Stevens, J. (1992). Applied multivariate statistics for the social sciences. Hillsdale: Lawrence Erlbaum.

Stevens, K. (2009). Developing a descriptive system for a new preference-based measure of health-related quality of life for children. Quality of Life Research, 18, 1105-1113.

Theunissen, N. C. M., Vogels, T. G. C., Koopman, H. M., Verrips, G. H. W., Zwinderman, K. A. H., Verloove-Vanhorick, S. P., et al. (1998). The proxy problem: Child report versus parent report in health-related quality of life research. Quality of Life Research, 7, 387-397.

Toyama, N. (2010). Japanese children's and adults' awareness of psychogenic bodily reactions. International Journal of Behavioral Development, 34(1), 1-9.

United Nations. (2009). United Nations treaty collection: Status of treaties: Convention on the rights of The child. Retrieved from http://treaties. un.org/Pages?viewDetails.aspx?src=TREATY\&$m t d s g \_n o=I V 11 \&$ chapter+4\&lang=en\#top

Van Sonderen, E. (1993). Het meten van sociale steun met de Sociale Steun Lijst-Interacties en Sociale Steun Lijst-Discrepanties. (Measurement of social support with the social support inventory-interactions and the social support inventory-discrepancies). Groningen: Noordelijk Centrum voor Gezondheidsvraagstukken.

Vranceanu, A., Hobfoll, S. E., \& Johnson, R. J. (2007). Child-multi-type maltreatment and associated depression and PTSD symptoms: The role of social support and stress. Child Abuse \& Neglect, 31, 71-84.

Washington, T. D. (2009). Psychological stress and anxiety in middle to late childhood and early adolescence: Manifestations and management. Journal of Pediatric Nursing, 24(4), 302-313.

Whiteman, D., \& Green, A. (1997). Wherein lies the truth? Assessment of agreement between parent proxy and child respondent. International Journal of Epidemiology, 26(3), 855-859.

Wong, M., Ratner, J., Gladstone, K. A., Davtyan, A., \& Koopman, C. (2010). Children's perceived social support after a parent is diagnosed with cancer. Journal of Clinical Psychology in Medical Settings, 17, 77-86. 

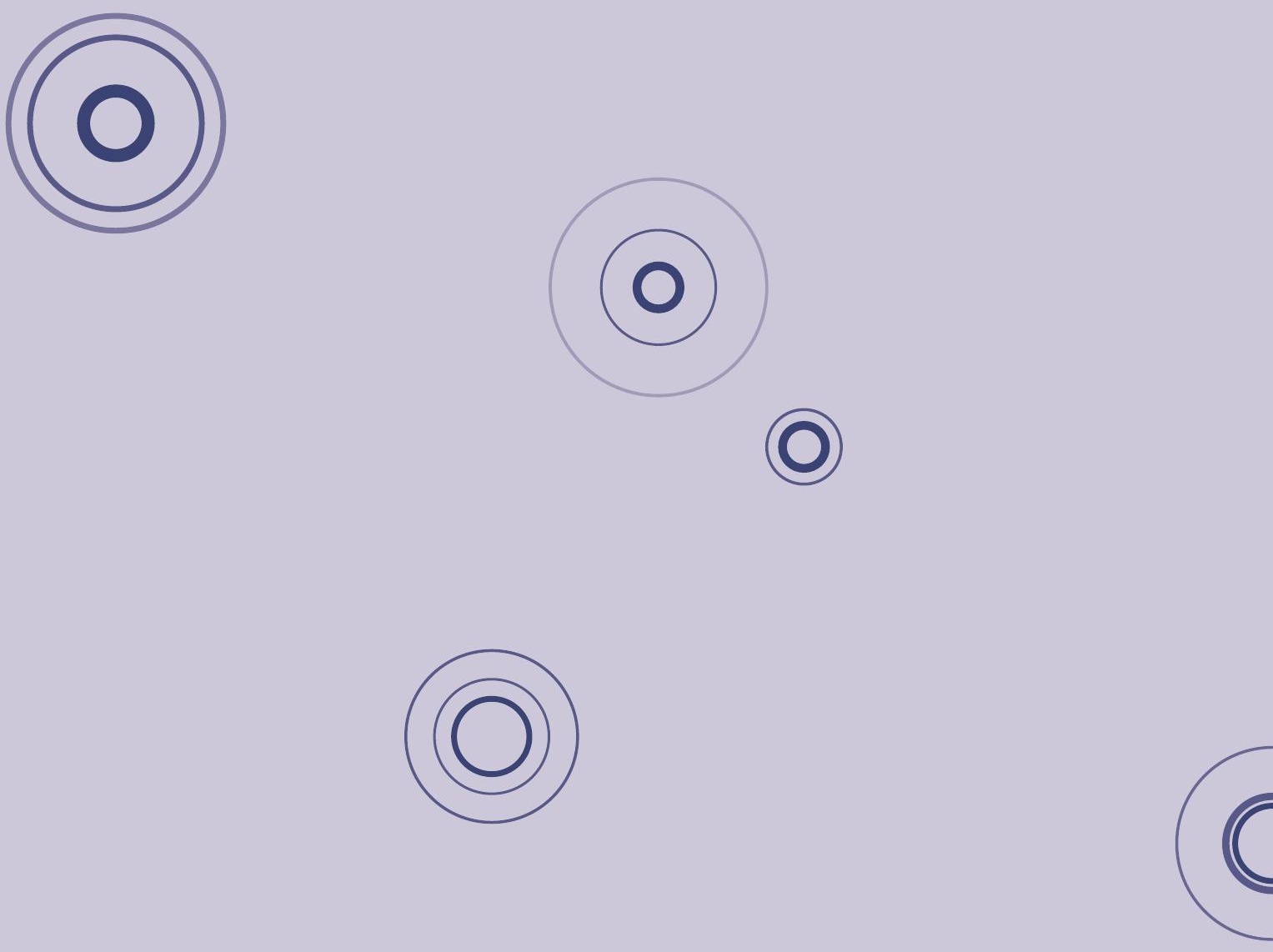

(2)

() 
0

Part II

()

(a)

(O) 


\section{CHAPTER 3}

Design of a prospective study on mental health and quality of life of maltreated children (aged 5-16 years) after a report to an advice and reporting center on child abuse and neglect

F. Snoeren, C. Hoefnagels, S. M. A. A. Evers \&

F. Lamers-Winkelman

(2)

Published in BMC Public Health (2013), 13, 942-952.

(2)

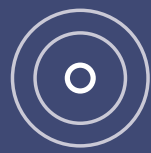



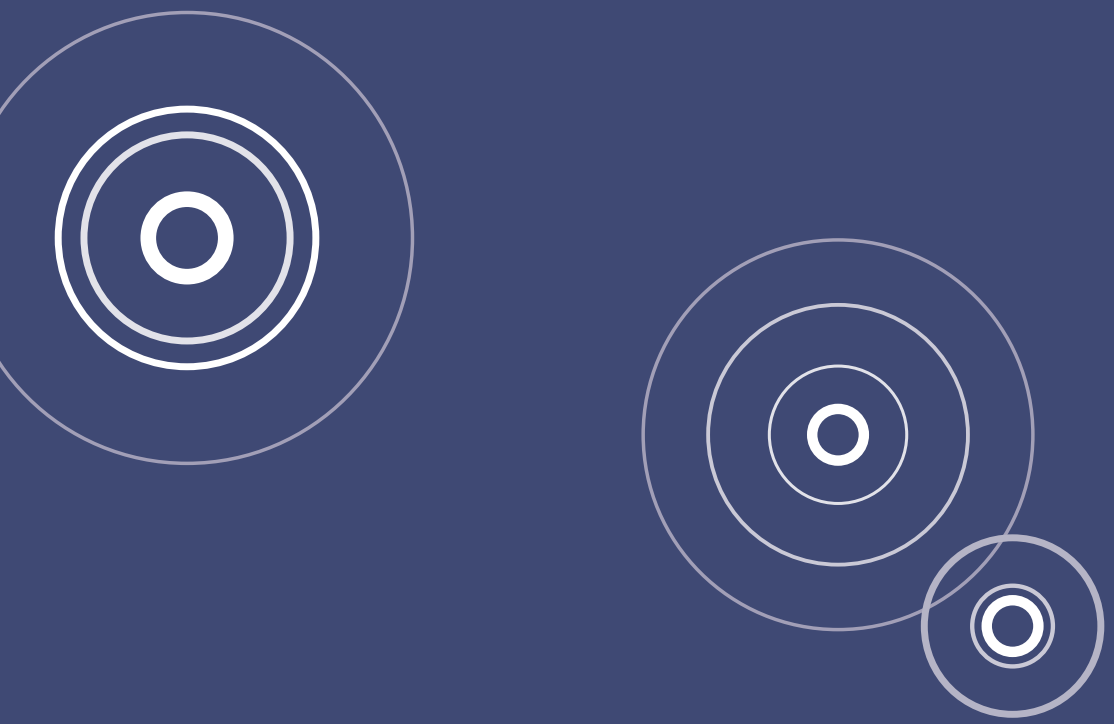

Abstract

Background: Child maltreatment is recognized as a widespread problem with huge implications for mental health and quality of life. Studies have repeatedly shown that victims of child maltreatment report significantly more adverse life outcomes than non-victims. The main objective of the study is (1) to examine the mental health and quality of life of maltreated children over a 1.5 year period beginning shortly after a report has been filed with an Advies- en Meldpunt Kindermishandeling (AMK) (advice and reporting center on child abuse and neglect). Secondary objectives are: (2) to examine how relevant determinants influence the mental health and quality of life of maltreated children, and (3) to examine differences in mental health and quality of life outcomes when comparing families of Dutch origin with families originating from Morocco and Suriname.

Methods/Design: A prospective study will be performed, in which parent-child dyads will be followed over a 1.5 year period. Participants will be recruited shortly after the report to the AMK and they will be asked to complete a questionnaire four times, at baseline and every six months thereafter. Data will be analyzed using a longitudinal multi-level analysis.

Discussion: The study is expected to yield evidence about the mental health and quality of life of maltreated children and about determinants that influence their mental health and quality of life outcomes. Strengths of this study are (1) the design which makes it possible to start examining outcomes shortly after or even during the actual maltreatment and to follow parent-child dyads for 1.5 years, and (2) asking children as informants about their own situation by making use of self-report questionnaires as much as possible. Limitations include the risks of selection bias and loss to follow-up during 1.5 years of data collection.

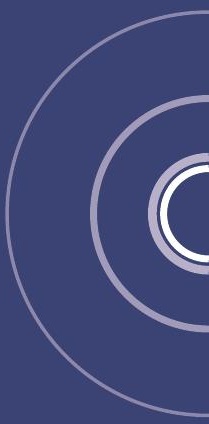




\section{Background}

There is increasing evidence to support the association between child maltreatment and adverse life outcomes during childhood as well as adulthood (Mills, Scott, Alati, O'Callaghan, Najman, et al., 2013; Leeb, Lewis, \& Zolotor, 2011). It is generally known that victims of maltreatment report significantly more short- and long-term mental health problems than non-victims (Dubowitz \& Bennett, 2007; Gilbert, Widom, Browne, Fergusson, Webb, et al., 2009; Kendall Tackett, Meyer Williams, \& Finkelhor, 1993; Nelson, Heath, Madden, Cooper, Dinwiddie, et al., 2002; Springer, Sheridan, Kuo, \& Carnes, 2007). In the last few decades, quality of life has become an important topic of research in the field of childhood maltreatment. Studies have shown that adults who have been maltreated as children report lower quality of life than adults without an abusive past (Afifi, Murray, Cox, De Graaf, Ten Have, et al., 2007; Al-Fayez, Oheari, \& Gado, 2012; Corso, Edwards, Fang, \& Mercy, 2008). The concept of quality of life adds a subjective, self-reported component to objective, clinical measures and has been successfully used in mental health related research (Gielen, McDonnell, Wu, O'Campo, \& Faden, 2001; Klassen, Anthony, Khan, Sung, \& Klaassen, 2011; Peeters \& Stiggelbout, 2010) and in clinical practice (Bastiaansen, Koot, Bongers, Varni, \& Verhulst, 2005).

However, there has not been much quality of life research focusing on children (Coghill, Danckaerts, Sanuga-Barke, Sergeant, \& ADHD Euroqol Guidelines Group, 2009; Matza, Swenson, Flood, Secnik, \& Leidy, 2004), especially maltreated children (Prosser \& Corso, 2007). It is therefore important to study the quality of life of maltreated children and the determinants that influence their quality of life (Coghill et al., 2009; Matza et al., 2004).

A recent Dutch study monitoring the prevalence of all types of child maltreatment in the Netherlands estimated that the number of children and adolescents aged between 0 and 18 years who are exposed to child abuse and neglect was 118,000 (34/1,000 children) in 2010 (Alink, Van IJzendoorn, Bakermans-Kranenburg, Pannebaker, Vogels, et al., 2011). Like most Western countries, the Netherlands has agencies where suspected child maltreatment can be reported by professionals, such as teachers and general practitioners, as well as non-professionals such as relatives and neighbors. In recent decades, the annual number of reports of suspected child maltreatment to these AMKs has increased, now numbering over 19,000 , which is $16 \%$ of the estimated annual exposure to child maltreatment (Alink et al., 2011). The AMKs investigate each report of suspected child maltreatment and if the report is substantiated, the AMK refers the child and the family to voluntary 
child welfare and/or mental health organizations. If voluntary care is rejected, the AMK can report the family to child protection services that can take court action or arrange the child to be placed in care (Baeten, 2009). In view of the finding that longer duration of child maltreatment is associated with poorer outcomes, it is expected that if reporting leads to maltreatment being ended, or sufficient care being provided for child and family, this will benefit children's mental health and quality of life, or at least contribute to minimizing adverse outcomes (Browne \& Finkelhor, 1986; Gilbert et al., 2009; Jonson-Reid, Kohl, \& Drake, 2012; Jud, Landolt, Tatalias, Lach, \& Lips, 2013; Naar-King, Silvern, Ryan, \& Sebring, 2002). Although the AMKs play an important role in the Netherlands, the potential benefits and harms of AMK involvement on children's mental health and quality of life has not yet been studied.

The Dutch society includes large numbers of people with non-Dutch ethnic backgrounds and a substantial part (35\% in 2012) of the maltreatment reports concern families of non-Dutch origin. Miller and Cross (2006) found differences in the perception of child maltreatment by different ethnic groups, which underlines the importance of examining differences in mental health and quality of life outcomes between children from families of Dutch origin and children from families of non-Dutch origins.

The main objective of the proposed study is to examine the mental health and quality of life of maltreated children over a 1.5-year period beginning shortly after the maltreatment has been reported to an AMK. Many studies on child maltreatment have examined (health) outcomes several years after the maltreatment occurred. This may lead to underreporting of childhood adversities due to memory problems, for example dissociation (Corso et al., 2008; Felitti, Anda, Nordenberg, Williamson, Spitz, et al., 1998). There is a lack of studies examining outcomes shortly after or during the actual abuse, even though short-term outcomes may be expected to differ from outcomes years later.

Secondly, this study will explore how several relevant determinants influence children's mental health and quality of life outcomes. These determinants include children's perceived stress and social support, coping and self-esteem. Research findings have shown discrepancies between child and proxy (i.e. parent) reports when measuring subjective determinants (Eiser \& Morse, 2001; Rajmil, Fernandez, Gispert, Rue, Glutting, et al., 1999; Theunissen, Vogels, Koopman, Verrips, Zwinderman, et al., 1998; Whiteman \& Green, 1997). Parents might underreport problems due to lack of knowledge about children's health, and parental perspectives might be influenced by their own experiences or perceptions (Cremeens, Eiser, \& Blades, 2006; Ingerski, 
Shaw, Gray, \& Janicke, 2010; Rajmil et al., 1999). As a consequence, the value of obtaining children's self-reports is increasingly recognized, and this study will therefore use child self-reports as a major outcome measurement. In addition, determinants for parents, such as perceived social support and stress, gender-related stress, coping, life events, subjective and objective neighborhood characteristics and alcohol consumption will be examined (Klevens \& Whitaker, 2007; Stith, Liu, Davies, Boykin, Alder, et al., 2009).

Thirdly, this study will examine differences in mental health and quality of life outcomes between children from families of Dutch origin and children from families originating from Morocco and Suriname. This study aims to categorize families of non-Dutch origin by ethnicity. The two most prevalent groups of non-Dutch people reported to AMKs are families with a Moroccan background and families with origins in Suriname, which featured in $4.9 \%$ and $4.1 \%$, respectively, of all AMK reports in 2012 (Personal communication, A. Verburg, Jeugdzorg Nederland, July 4, 2013).

\section{Methods/Design}

\section{Objective}

The main objective of the study is (1) to examine the mental health and quality of life of maltreated children over a 1.5 year period beginning shortly after the maltreatment has been reported to an AMK. Secondary objectives are: (2) to examine how theoretically and practically relevant determinants influence the mental health and quality of life of maltreated children, and (3) to examine differences in mental health and quality of life outcomes between families of Dutch origin and families originating from Morocco and Suriname.

\section{Study design}

To answer the research questions, a prospective study will be performed in which parent-child dyads will be asked to complete a questionnaire on four occasions over a 1.5 year period. Baseline assessment will take place shortly after the child maltreatment report is filed with an AMK. Parent-child dyads will be approached for follow-up assessments every six months. Figure 1 presents the flow chart of the study. 


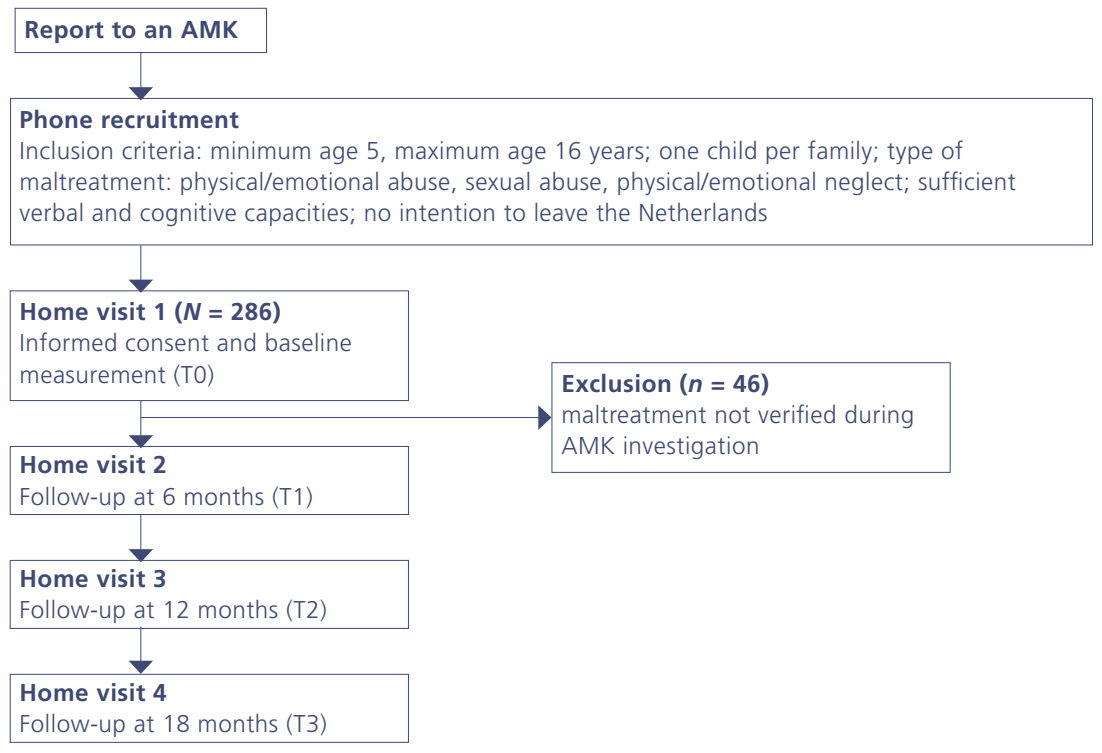

Figure 1. Flow chart of study design

\section{Assessment}

Parent-child dyads will be asked to complete a questionnaire four times. Baseline assessment will take place within three months after the report to the AMK. The follow-up assessments will take place every six months. A member of the research team will be present to provide assistance. If necessary, a Moroccan translator can be present as well. Since the official language in Suriname is Dutch, no translator is needed for these participants. The method used to complete the questionnaire will be discussed with the parent and child, and will depend on the participants' reading and writing skills. If reading and writing skills are poor, the research team member will read the questions out loud and write down the participant's answer on the questionnaire form. If reading and writing skills are sufficient, participants may choose to complete the questionnaire by themselves. To prevent the parents from influencing the children's answers, parents and children will be requested to complete their questionnaires in separate rooms. Respondents will be rewarded for their participation by a 10 euro gift voucher to the parents, while the children will receive either a 5 euro gift voucher (children > 10) or an age-appropriate present (5-10 years). 


\section{Target population}

Children aged between 5 and 16 years and their primary caretaker will be recruited to participate in this study shortly after the report is filed with the AMK. Children younger than 5 years old are excluded from the study, as this study will rely on self-report as much as possible. Studies have shown that children from the age of 5 are able to reliably self-report on their own health status (Engelen, Haentjens, Detmar, Koopman, \& Grootenhuis, 2009). Only one child per family will be asked to participate. When a report to the AMK relates to more than one child of the same family, the oldest child within the age range will be included. Additional criteria for inclusion in the study are: (1) a report to an AMK about physical and/or emotional abuse, physical and/ or emotional neglect and/or sexual abuse, (2) sufficient verbal and cognitive capacities of both parent and child, as the study will use mainly self-report methods for data collection, and (3) no intention to leave the Netherlands within the next 1.5 years, in view of the follow-up period. All families meeting these criteria will be approached by phone within three months after the report to the AMK. During this phone conversation, an AMK employee will screen the potential participants for verbal and cognitive capacities.

This study will focus only on children for whom maltreatment is verified during the AMK investigation. The maltreatment verification status will be established in a multi-disciplinary meeting at the end of the AMK investigation. At the time when eligible participants are first approached by phone, most reports will still be under AMK investigation, so the families' maltreatment status will not be known at the time of study inclusion. Parent-child dyads for whom maltreatment is not confirmed, or dyads that are given a 'no maltreatment' status, will be excluded from the study sample before the first follow-up assessment six months later.

\section{Setting; Dutch advice and reporting centers on child abuse and neglect}

Data will be collected from families who have been reported to an AMK.

There are seventeen AMKs in the Netherlands, which can be contacted either for professional advice or to report suspected child maltreatment. This study will focus only on reports to the AMKs. The Netherlands has a voluntary reporting system. Reports are discussed in a multidisciplinary team which draws up a plan for investigation to discover if the report is substantiated. In this investigation, the AMK collects in- formation from adults (e.g. parents, teachers, general practitioners) and children (aged 6 years and older) to discover the existence of family problems, the need for child and family care and the willingness to accept care. Based on this information, the multidisciplinary 
team evaluates the family situation and develops an intervention plan to end maltreatment and to refer to voluntary care. If voluntary care is rejected, the AMK can report the family to child protection services that can take court action or arrange for the child to be placed in care. The AMK has a maximum of 13 weeks to investigate a report of suspected child maltreatment (Baeten, 2009).

\section{Recruitment and sample size}

Parent-child dyads will be recruited from seven AMKs in the Netherlands. All AMKs in the four largest cities (Amsterdam, Rotterdam, The Hague, and Utrecht) will be approached to participate in the recruitment for the study, in view of their high percentage of residents of Moroccan and Suriname origin. An additional three large AMKs will be asked to take part in the recruitment phase of the study, taking the level of urbanization into account, to ensure that the sample is representative of Dutch society. The study will focus on children aged between 5 and 16 years, as approximately $70 \%$ of all reports to AMKs concern children in this age range (Jeugdzorg Nederland, 2011). In addition, the study will focus on reports to AMKs of physical and/or emotional abuse, physical and/or emotional neglect and/or sexual abuse, which account for about $70 \%$ of all reports to AMKs (Jeugdzorg Nederland, 2011). Families that meet the inclusion criteria will be approached by phone by an AMK employee within three months after the report was filed with the AMK. In this phone call, they will provide general information about the study, and will invite one parent and one child per family to participate.

Based on expert opinion, we expect a participation rate of $5 \%$. This low expected rate is due to the delicate subject of the study: participants will be recruited shortly after a suspected child maltreatment report, so people might refuse to participate due to the perceived accusation and/or perceived stigmatization and/or stress because of the report to the AMK. In addition, we are expecting obstacles in the recruitment process, for instance because there is often no phone number in the AMK records, people may not be available when the phone call is made or people may not be able to speak Dutch. If a parent-child dyad is willing to participate, an appointment with a member of the research team will be made at a time and place of the families' choosing (which in most cases will probably be a home visit). During this visit, prior to starting to complete the questionnaire, parents and children will be asked to give written informed consent for their participation. Parents will also be required to give informed consent for the participation of their child. 
After the baseline assessment, an estimated $40 \%$ of the participants are expected to be lost to follow-up. To minimize loss to follow-up, parents and children will be asked to write down various types of contact information on the informed consent form, e.g. both home and mobile phone numbers and email addresses. If phone numbers are no longer valid at follow-up, an email or letter will be sent to the last known home address with the request to contact the research team. In case of no response, a member of the research team will visit the family at their last known address to check if they have moved.

This study aims to examine differences in outcomes when comparing children from families of Dutch origin with children from families originating from Morocco and Suriname. To prevent numbers that are too small to allow a useful analysis, we will oversample families originating from Morocco and Suriname. To this end, extra time will be invested in reaching these families, even beyond the times of the day when AMK employees would normally make recruitment calls. A separate list with phone numbers of eligible Moroccan and Suriname families will be printed, and a Moroccan AMK employee will call the Moroccan families to minimize the risk of refusal to participate due to a possible language barrier. Overall, we expect about 150 parent-child dyads to be available for the last assessment 1.5 years after the report to the AMK.

\section{Primary outcomes measures}

Mental health. The children's mental health (in terms of internalizing and externalizing psychological problems) will be measured with the Dutch version of the Child Behavior Checklist ( $C B C L$; Verhulst, Ende, \& Van der Koot, 1998). This questionnaire will be completed by the parent. Parents will be asked to what extent they observe various behavioral and emotional problems in their child. The CBCL uses a 3-point scale and consists of 113 items. Internal consistency is good (Table 1).

Quality of life. Quality of life will be measured with one of three ageappropriate versions (5-7, 8-11, 12-18 years) of the Dutch translation of the Pediatric Quality of Life Inventory (PedsQL; Engelen et al., 2009). Children will be asked to express their concerns on the dimensions of physical health and psychosocial health, the latter consisting of the sub dimensions of emotional functioning, social functioning and school functioning. The overall quality of life score will be obtained by adding up the scores on all dimensions. The PedsQL uses a 5-point scale (or a 3-point scale for the 5-7 version) and consists of 23 items. Internal consistency is good (Table 1). 


\section{Secondary outcome measures for children}

Perceived social support. Children's perceived social support will be measured with adapted versions of the Social Support Inventory for adults, called Sociale Steun Lijst (SSL) in Dutch (Van Sonderen, 1993). Children aged 12-16 years will complete the SSL youngster version (Hoefnagels, Meesters, \& Simenon, 2007). Children aged 8-11 years will complete the Perceived Social Support Questionnaire 8-11 (PSSQ8-11; Snoeren \& Hoefnagels, 2013). Both questionnaires will ask the children to express their perceived social support on three subscales: daily emotional support, support in problem situations and negative interactions. The questionnaires use a 4-point scale and consist of 19 items. Internal consistency is sufficient (Table 1). Children aged 5-7 years will complete the negative interactions subscale, using a 2-point scale (yes/no). This subscale consists of 7 items. This is the only reliable subscale for this age group (unpublished internal report by Snoeren \& Hoefnagels), and no other age-appropriate questionnaire with sufficient psychometric properties is available for this age group.

Perceived stress. Children's perceived stress will be measured with adapted versions of the Maastricht University Stress Instrument for Children (MUSIC; Kraag, Meesters, Van Bekkum, Fekkes, Kok, et al., submitted), which will be completed by children aged 12-16 years. Children aged 8-11 years will complete the Perceived Stress Questionnaire 8-11 (PSQ8-11; Snoeren \& Hoefnagels, 2013). Both questionnaires ask children to express their perceived stress on two subscales: psychological stress and physiological stress. The questionnaires use a 4-point scale and consist of 20 items. Internal consistency is sufficient (Table 1). Children aged 5-7 years will complete an adapted version of the PSQ8-11, in which answering options are reduced to 'yes/no' instead of the 4-point scale.

Coping. Children's coping skills will be measured with two different questionnaires for children aged 8-11 and 12-16 years. No age-appropriate questionnaire with sufficient psychometric properties was available for the 5-7 age group. Children aged 12-16 years will complete the Coping Inventory for Stressful Situations (CISS; Endler \& Parker, 2004). Children will be asked to rate the extent to which they use various coping skills in stressful situations, on three subscales: problem-focused coping, emotion-focused coping and avoidance. The CISS uses a 5-point scale and consists of 48 items. Internal consistency is good (Table 1). Children aged 8-11 years will complete the Dutch translation of the Children's Coping Strategies Checklist (Ayers \& Sandler, 1999), called Coping Strategieën Lijst voor Kinderen (CSLK) in Dutch (De Boo, 2005). Children will be asked to rate the extent to which they use various coping skills in stressful situations, on four subscales: active 
Table 1.

Internal consistency of the Dutch translations of the questionnaires used to measure child determinants

\begin{tabular}{lllll}
\hline $\begin{array}{l}\text { Outcome } \\
\text { measure }\end{array}$ & Age group & Questionnaire & Cronbach's a & Reference \\
\hline Mental health & Parent proxy & CBCL & .97 & Verhulst et al., 1998 \\
Quality of life & $12-16$ & PedsQL & .85 & Engelen et al., 2009 \\
& $8-11$ & PedsQL & .82 & Engelen et al., 2009 \\
& $5-7$ & PedsQL & .85 & Engelen et al., 2009 \\
Perceived social & $12-16$ & SSL youngster & .78 & Hoefnagels et al., 2007 \\
support & & version & & \\
& $8-11$ & PSSQ8-11 & .73 & Snoeren \& Hoefnagels, 2013 \\
& $5-7$ & Negative & .57 & Internal report (unpublished) \\
& & interactions & & \\
Perceived stress & $12-16$ & MUSIC & .85 & Hoefnagels et al., 2007 \\
& $8-11$ & PSQ8-11 & .85 & Snoeren \& Hoefnagels, 2013 \\
& $5-7$ & PSQ5-7 & .60 & Internal report (unpublished) \\
Coping & $12-16$ & CISS & $.82-.87$ & Evers et al., 2005 \\
& $8-11$ & CSLK & $.72-.88$ & Boo \& Wicherts, 2008 \\
Self-esteem & $12-16$ & CBSA & $.66-.88$ & Treffers et al., 2002 \\
& $8-11$ & CBSK & .74 & Veerman et al., 2004 \\
\hline
\end{tabular}

coping, distraction, avoidance and support seeking. The CSLK uses a 4-point scale and consists of 54 items. Internal consistency is good (Table 1).

Self-esteem. Children's self-esteem will be measured with two adapted versions (a child version and an adolescent version) of the Self-Perception Profile for Adolescents (Harter, 1985), referred to in Dutch as the Competentie Beleveningsschaal voor Adolescenten (CBSA) for children aged 12-16 years and the Competentie Belevingsschaal voor kinderen (CBSK) for children aged 8-11 years (Treffers, Goedhardt, Veerman, Van den Bergh, Ackeart, et al., 2002; Veerman, Straathof, Treffers, Van den Bergh, \& Ten Brink, 2004).

No age-appropriate questionnaire with sufficient psychometric properties was available for the 5-7 age group. Both questionnaires ask children to express their perceptions of six competencies: academic competence, social acceptance, athletic competence, physical appearance, behavioral conduct and global self-worth. The questionnaires use a 4-point scale and consist of 35 items. Internal consistency is good (Table 1).

In addition to the outcome measures described above, children will be asked about their disclosure of child maltreatment (did they disclose 
maltreatment to anyone, and if so to whom?) in a short interview after the questionnaire is completed.

\section{Secondary outcome measures for parents}

Quality of life. Quality of life of the parents will be measured with the Dutch translation of the RAND 36-item Health Survey (RAND-36; Van der Zee \& Sanderman, 1993), a short version of the RAND Health Insurance Study Questionnaire (Brook, Ware, Davies-Avery, Stewart, Donald, et al., 1979). Parents will be asked to express their concerns on nine dimensions: physical functioning, social functioning, constraint due to physical problems, constraint due to emotional problems, mental health, energy, pain and perception of health. The questionnaire uses different multiple choice answering options for each item and consists of 11 items. Internal consistency is good (Table 2).

Parental stress. Parental stress will be measured with an adapted version and translation of the Parenting Stress Index (Abidin, 1983), referred to in Dutch as Nijmeegse Ouderlijke Stress Index, short version (NOSI-K; De Brock, Verhulst, Gerris, Veerman, Abidin, et al., 2006). Parents will be asked to express their agreement with several hypotheses concerning the upbringing of their child. The NOSI-K uses a 6-point scale and consists of 25 items. Internal consistency is good (Table 2).

Gender-specific stress. Gender-specific stress will be measured with the Dutch translation of the Feminine Gender Role Stress (FGRS) for women and the Masculine Gender Role Stress (MGRS) for men (Van Well, Kolk, \& Arrindell, 2005). Parents will be asked to express the extent to which they perceive several situations as stressful. The FGRS consists of subscales for non-emotional relationships, bodily unattractiveness, victimization, assertive behavior and non-caring behavior. The MGRS consists of subscales for bodily inadequateness, emotional expressionlessness; being subordinate to women, intellectual inferiority and not being able to perform. Both questionnaires use a 6-point scale and consist of 40 items. Internal consistency is good (Table 2).

Perceived social support. Perceived social support will be measured with the Social Support Inventory for adults, called Sociale Steun Lijst (SSL) in Dutch (Van Sonderen, 1993). Parents will be asked to express their perceived social support on three dimensions: SSL-Interactions (SSL-I), SSL-Discrepancies (SSL-D) and SSL-Negative interactions (SSL-N) The dimensions SSL-I and SSL-D both consist of seven subscales (daily emotional support, emotional support in problem situations, appreciation, instrumental interactions, social companionship, informative support) and has 34 items. The SSL-N has 7 items. All dimensions use a 4-point scale. Internal consistency is good (Table 2). 
Table 2.

Internal consistency of the Dutch translations of the questionnaires used to measure adult determinants

\begin{tabular}{llll}
\hline $\begin{array}{l}\text { Outcome } \\
\text { measure }\end{array}$ & Questionnaire & Cronbach's a & Reference \\
\hline Quality of life & Rand-36 & $.71-.92$ & Van der Zee \& Sanderman, 1993 \\
Perceived social & SSL-Interactions & $.90-.93$ & Van Sonderen, 1993 \\
support & SSL-Discrepancies & $.83-.95$ & \\
& SSL-Negative interactions & $.69-.81$ & \\
Parental stress & NOSI-K & .97 & De Brock et al., 2006 \\
Gender specific & FGRS & .93 & Van Well et al., 2005 \\
stress & MGRS & .90 & \\
Coping & CISS & $.82-.87$ & Evers et al., 2005 \\
Neighborhood & Neighborhood & NA & NA \\
perception & Characteristics & & \\
& Scale & & Veerman et al., 2003 \\
Life events & VMG & .80 & \\
\hline
\end{tabular}

Coping. Coping will be measured with the Coping Inventory for Stressful Situations (CISS; Endler \& parker, 2004). Parents will be asked to rate the extent to which they use several coping skills in stressful situations on three subscales: problem-focused coping, emotion-focused coping and avoidance. The CISS uses a 5-point scale and consists of 48 items. Internal consistency is good (Table 2).

Life events. Life events will be recorded with the Dutch Vragenlijst Meegemaakte Gebeurtenissen (VMG; Veerman, Janssen, Ten brink, Van der Horst, \& Koedoot, 2003). Parents will be asked to report if, how many times and when for the last time, various positive or negative life events have occurred in the child's life. In addition, if a life event has occurred, the parent will be asked to rate the child's perception of it as positive or negative. The VMG consist of 24 items. Internal consistency is good (Table 2).

Neighborhood perception. Neighborhood perception will be measured with the Dutch translation of the Neighborhood Characteristics Scale (Ross \& Mirowsky, 1999). Parents will be asked to express their agreement with several hypotheses concerning their neighborhood on two subscales: physical neighborhood disorder and social neighborhood disorder. The Neighborhood Characteristics Scale uses a 5-point scale and consists of 18 items. The original scale has good psychometric properties $(a=.92)$. Information on the psychometric properties of the Dutch translation is not available. 
In addition to the above outcome measures, parents will be asked to complete a recording form to collect information on gender, age, ethnic background, parental education level, current living situation and employment status, net income, financial problems, alcohol use and health care information.

\section{Analyses}

First a non-response analysis, using univariate analysis, will be carried out to compare characteristics of the included participants with the characteristics of the entire population of children aged 5-16 years reported to the seven participating AMKs within the recruitment period of this study. The following characteristics will be studied: age of the child, gender of the child, ethnicity, living situation, type of maltreatment as verified by the AMK, outcome of the AMK procedure.

Missing data at follow-up will be imputed using regression imputation. Prior to the analyses the possible influence of (1) the different AMKs (as families will be derived from 7 AMKs), and (2) the time between the report to the AMK and the completion of the questionnaires will be examined.

The first research question, regarding the mental health and quality of life of maltreated children over a 1.5 year period, will be addressed using a longitudinal multi-level analyses (measurements nested within respondents, i.e. children and parents/caregivers, respectively) to assess changes in mental health and quality of life over time (Kreft \& De Leeuw, 1998). The second research question, regarding the influence of relevant determinants on the mental health and quality of life of maltreated children, will be addressed by exploring the potential effects of these determinants on the outcome variables by testing the interaction between potential effect modifiers at T0 and the outcome variables at Tf-upx (where ' $f$-upx' indicates the successive moments of measurement during follow-up).

To answer the third research question, regarding differences in mental health and quality of life outcomes between children from families of Dutch origin with children from families originating from Morocco and Suriname, 'ethnicity' will be entered as a covariate in the analysis.

\section{Collaboration}

This study is a joint project of the Trimbos institute, the Netherlands Institute for Mental Health and Addiction (Utrecht) and the CAHPRI School for Public Health and Primary Care, Maastricht University and VU University Amsterdam. 
The research is funded by ZonMw (project 15700.2012) and is registered in the Netherlands Trial Register, part of the Dutch Cochrane Centre (NTR3674). The Dutch Medical Ethics Committee for Mental Health Care (METiGG) has approved the study (NL31267.097.10).

\section{Discussion}

Although AMKs play and important role in the Netherlands in the attempt to end child maltreatment and to provide the necessary care for maltreated children and their families, the children's mental health and quality of life after AMK involvement has not yet been studied. This gap in the available knowledge, as well as prior research showing the negative impact of child maltreatment on the mental health and quality of life of children, means there is a need for the present study. The results of this study will primarily provide information on changes in the mental health and quality of life of maltreated children over a period of 1.5 years after an AMK becomes involved. Secondly, the study will explore determinants that positively or negatively influence the mental health and/or quality of life of the maltreated children. These results will help to identify the children that are most vulnerable to developing mental health problems and will define determinants that can be influenced to improve these children's mental health and quality of life or to prevent additional harm. Thirdly, the results will provide information on the differences in mental health and quality of life outcomes between families of Dutch origin and families originating from Morocco and Suriname.

This study has several strengths. First, this study will be performed among maltreated children and their parents shortly after they have been reported to an AMK, which may reduce recall bias. Since there is a lack of studies examining outcomes shortly after or during the actual maltreatment and outcomes may be expected to be different during or shortly after abuse in comparison with years later, this study can contribute to the knowledge about the short-term effects of maltreatment.

Another strength is the use of child self-reports. Many studies have used

proxy informants when collecting data on children's mental health and quality of life. However, the use of proxies is not always the best option when measuring subjective constructs, and research findings have shown discrepancies between child and parent reports (Eiser \& Morse, 2001; Rajmil et al., 1999; Theunissen et al., 1998; Whiteman \& Green, 1997). For example, quality of life studies have reported better agreement between child and 
proxy reports on the physical, more observable, dimensions and poor agreement on the social and emotional, non-observable, quality of life dimensions (Eiser \& Morse, 2001). As a consequence, the value of obtaining children's self-reports is increasingly recognized and several studies have examined the accuracy and reliability of child reports. These studies have shown that children can provide reliable and accurate information as informants (Bell, 2007; Eiser \& Morse, 2001; Fuchs, 2005). The present study will examine the outcomes of maltreated children aged 5-16 years, using child self-reports as much as possible.

Quality of life has become an important topic of research on the adverse effects of childhood maltreatment, as the concept of quality of life adds a subjective component to objective, clinical measures (Bastiaansen et al., 2005; Gielen et al., 2001; Klassen et al., 2011; Peeters \& Stiggelbout, 2010). Self-reported quality of life will be examined as one of the main objectives of this study. This should be useful, as quality of life research focusing on children, especially maltreated children, has so far been scarce (Coghill et al., 2009; Matza et al., 2004; Prosser \& Corso, 2007).

This study also has several limitations. First, selection bias cannot be ruled out. Participation is voluntary and families will be recruited shortly after a report of suspected child maltreatment has been filed with an AMK. This can be expected to be a stressful time for most families. In addition, families might be inclined to refuse participation in view of the perceived accusation and/or stigmatization by the child maltreatment report (Sykes, 2011). This may make it harder to find participants for this study, which may lead to a risk of selection bias. To increase the likelihood of success, the researchers will remain in close contact with the participating AMKs during the recruitment process, so they can adjust the process if necessary. In addition, a nonresponse analysis will be performed to examine the presence of this possible selection bias. Secondly, there is a risk of considerable loss to follow-up. One reason may be that families of maltreated children tend to move more frequently than non-maltreated children and their families (Eckenrode, Rowe, \& Laird, 1995). Families may forget to forward their new address and phone number. To minimize loss to follow-up due to changes in contact information, participants will be asked to provide various kinds of contact information. Another possible reason is that many families reported to AMKs are 'multiproblem' families (Jaffee, Caspi, Moffitt, Polo-Tomas, \& Taylor, 2007), so there might be new and/or additional problems at follow-up which might cause families to drop out of the study. 
To conclude, this study will be the first to provide information on mental health and quality of life outcomes of maltreated children over a 1.5 year period after being reported to an AMK. In addition, it will explore determinants that influence mental health and quality of life outcomes, and will provide information on the influence of ethnicity on maltreatment outcomes. Results will contribute to the knowledge that is required to provide high-quality care to maltreated children.

\section{Competing interests}

All authors declare that they have no competing interests.

\section{Authors' contributions}

All authors participated in describing the design of this study. $\mathrm{CH}$, SMAAE and FLW obtained funding for this study. All authors have read and corrected draft versions of the manuscript and approved the final manuscript.

\section{Acknowledgements}

The authors would like to thank P. Baeten, G. Van Harten en I. Bleijenberg, all interviewers that have contributed to the data collection and the AMKs that have participated in this study: AMK Amsterdam, AMK Midden-Brabant, AMK West-Brabant, AMK Gelderland, AMK Haaglanden, AMK Rotterdam, AMK Utrecht, AMK Zuid-Holland. 


\section{References}

Abidin, R. R. (1983). Parenting Stress Index: Manual, Administration Booklet, and Research Update. Charlottesville, VA: Pediatric Psychology Press.

Afifi, T.O., Murray, W.E., Cox, B.J., de Graaf, R., ten Have, M., \& Sareen, J. (2007). Child abuse and health-related quality of life in adulthood. The Journal of Nervous and Mental Disease, 195(10), 797-804.

Al-Fayez, G.A., Oheari, J.U., \& Gado, O.M. (2012). Prevalence of physical, psychological, and sexual abuse among a nationwide sample of Arab high school students: Association with family characteristics, anxiety, depression, self-esteem, and quality of life. Social Psychiatry and Psychiatric Epidemiology, 47, 53-66.

Alink, L.R.A., van IJzendoorn, M.H., Bakermans-Kranenbrug, M.J., Pannebakker, F.D., Vogels, T., \& Euser, S. (2011). Kindermishandeling in Nederland anno 2010: De tweede Nationale Prevalentiestudie Mishandeling van Kinderen en Jeugdigen (NPM-2010) [Child maltreatment in the Netherlands in 2010: the second prevalence study of the maltreatment of children and adolescents in the Netherlands]. Leiden: Casimir Publishers.

Ayers, T. S., \& Sandler, I. N.(1999). Manual for the Children's Coping Strategies Checklist \& the How I Coped Under Pressure Scale. Tempe: Arizona State University.

Baeten, P. (2009). Protocol van handelen bij vermoedens van kindermishandeling in relatie van afhankelijkheid en onvrijheid (Manual- How to act in case of suspected child maltreatment in relationships of dependence and restricted freedom). Utrecht: MO Groep.

Bastiaansen, D., Koot, H.M., Bongers, I.L., Varni, J.W., \& Verhulst, F.C. (2005). Measuring quality of life in children referred for psychiatric problems: Psychometric properties of the PedsQL 4.0 generic core scales. Quality of Life Research, 13, 489-495.

Bell, A. (2007). Designing and testing questionnaires for children. Journal of Research in Nursing, 12(5), 461-469.

Brock, A. J. L. L. de, Verhulst, A. A., Gerris, J. R. M., Veerman, J. W., \& Abidin, R. R. (2006). NOSI-R. Nijmeegse Ouderlijke Stress Index. Handleiding (Dutch Parenting Stress Index. Manual). Lisse: Harcourt.

Brook, R. J., Ware, J. E., Davies-Avery, A., Stewart, A. L., Donald, C. A., Rogers, W. H., Williams, K. N., \& Johnston, S. A. (1979). Overview of adult health status measures fielded in RAND's Health Insurance Study. Medical Care, 15, 724-735.

Browne, A., \& Finkelhor, D. (1986). Impact of child sexual abuse: A review of the research. Psychological Bulletin, 99, 66-77.

Coghill, D., Danckaerts, M., Sanuga-Barke, E., \& Sergeant, J. (2009). Practitioner review: Quality of life in child mental health. Conceptual challenges and practical choices. Journal of Child Psychology and Psychiatry, 50(5), 544-561.

Corso, P.S., Edwards, V.J., Fang, X., \& Mercy, J.A. (2008). Health-related quality of life among adults who experienced maltreatment during childhood. American Journal of Public Health, 98(6), 1094-1100.

Cremeens, J., Eiser, C., \& Blades, M. (2006). Characteristics of health-related self-report measures for children aged three to eight years: A review of the literature. Quality of Life Research, 15, 739-754.

De Boo, G. M. (2005). Coping Strategieën Lijst voor Kinderen (Children's Coping Strategies Checklist). Amsterdam: Universiteit van Amsterdam.

De Boo, G. M., \& Wicherts, J. M. (2008). Copingstrategieen bij kinderen. Instrument, sekseverschillen en samenhang met sociaal gedrag (Coping strategies of children. Instrument, gender differences and correlation with social behavior). Kind en Adolescent, 24, 94-104.

Dubowitz, H., \& Bennett, S. (2007). Physical abuse and neglect of children. The Lancet, 369, 1891-1899.

Eckenrode, J., Rowe, E., \& Laird, M. (1995). Mobility as a mediator of the effects of child maltreatment on academic performance. Child Development, 66(4),1130-1142.

Eiser, C., \& Morse, R. (2001). Can parents rate their child's health-related quality of life? Results of a systematic review. Quality of Life Research, 10, 347-357. 
Endler, N. S., \& Parker, J. D. A. (2004). Coping inventory for stressful situations. Amsterdam: Pearson Assessment \& Information.

Engelen, V., Haentjens, M.M., Detmar, S.B., Koopman, H.M., \& Grootenhuis, A. (2009). Healthrelated quality of life of Dutch children: Psychometric properties of the PedsQL in the Netherlands. BMC Pediatrics, 9, 68-75.

Evers, A., Van Vliet-Mulder, J. C., \& Groot, C. J. (2005). Documentatie van test en testresearch in Nederland, aanvulling 2005/01 (COTAN) (Documentation of test and test research in the Netherlands, supplement 2005/01). Amsterdam: Boom test uitgevers.

Felitti, V.J., Anda, R.F., Nordenberg, D., Williamson, D.F., Spitz, A.M., Edwards, V., ...Marks, J.S. (1998). Relationship of childhood abuse and household dysfunction to many of the leading causes of death in adults: The adverse childhood experiences (ACE) study. American Journal of Preventive Medicine, 14(4), 245-258.

Fuchs, M. (2005). Children and adolescents as respondents. Experiments on question order, response order, scale effects and the effect of numeric values associated with the response options. Journal of Official Statistics, 21(4), 701-725.

Gielen, A.C., McDonnell, K.A., Wu, A.W., O'Campo, P., \& Faden, R. (2001). Quality of life among women living with HIV: The importance of violence, social support, and self-care behaviors. Social Science and Medicine, 52(2), 315-322.

Gilbert, R., Widom, C.S., Browne, K., Fergusson, D., Webb, E., \& Janson, S. (2009). Burden of consequences of child maltreatment in high income countries. The Lancet, 373, 68-81.

Harter, S. (1985). The self-perception profile for children. Revision of the perceived competence scale for children. Denver, CO: University of Denver.

Hoefnagels, C., Meesters, C., \& Simenon, J. (2007). Social support as predictor of psychopathology in the adolescent offspring of psychiatric patients. Journal of Child and Family Studies, 16, 91-101.

Ingerski, L.M., Shaw, K., Gray, W.N., \& Janicke, D.M. (2010). A pilot study comparing traumatic stress symptoms by child and parent report across pediatric chronic illness groups. Journal of Developmental and Behavioral Pediatrics, 31(8), 1-7.

Jaffee, S. R., Caspi, A., Moffitt, T. E., Polo-Tomas, M., \& Taylor, A. (2007). Individual, family, and neighborhood factors distinguish resilient from non-resilient maltreated children: A cumulative stressors model. Child Abuse \& Neglect, 31, 231-253.

Jeugdzorg Nederland. (2011). AMK cijfers in 2010 (AMK annual report 2010). Zalsman: Zwolle.

Jonzon, E., \& Lindblad, F. (2005). Adult female victims of child sexual abuse. Multi-type maltreatment and disclosure characteristics related to subjective health. Journal of Interpersonal Violence, 20, 651-668.

Jud, A., Landolt, M. A., Tatalias, A., Lach, L. M., \& Lips, U. (2013). Health-related quality of life in the aftermath of child maltreatment: Follow-up study of a hospital sample. Quality of Life Research, 22(6), 1361-1370.

Kendall-Tacket, K.A., Meyer-Williams, L., \& Finkelhor, D. (1993). The impact of sexual abuse on children: A review and synthesis of recent empirical studies. Psychological Bulletin, 113, 164-180.

Klassen, A.F., Anthony, S.J., Khan, A., Sung, L., \& Klaassen, R. (2011). Identifying determinants of quality of life of children with cancer and childhood cancer survivors: A systematic review. Supportive Care in Cancer, 19(9), 1275-1287.

Klevens, J., \& Whitaker, J. (2007). Primary prevention of child physical abuse and neglect: Gaps and promising directions. Child Maltreatment, 12(4), 364-377.

Kraag, G., Meesters, C., Van Bekkum, C., Fekkes, M., Kok, G., \& Huijer Abu-Saad, H. (submitted). The development of the MUSIC, a short questionnaire for the assessment of stress symptoms in preadolescents.

Kreft, I. \& De Leeuw, J. (1998). Introducing multilevel modeling. Thousand Oaks, CA, US: Sage Publications, Inc.

Leeb, R. T., Lewis, T., \& Zolotor, A. J. (2011). A review of physical and mental health consequences of child abuse and neglect and implications for practice. American Journal of Lifestyle Medicine, 5(5), 454-468. 
Matza, L.S., Swensen, A.R., Flood, E.M., Secnik, K., \& Leidy, N.K. (2004). Assessment of healthrelated quality of life in children: A review of conceptual, methodological, and regulatory issues. Value in Health, 7(1), 79-92.

Miller, A. B., \& Cross, T. (2006). Ethnicity in child maltreatment research: A replication of Behl et al.'s content analysis. Child Maltreatment, 11, 16-26.

Mills, R., Scott, J., Alati, R., O'Callaghan, M., Najman, J. M., \& Strathearn, L. (2013). Child maltreatment and adolescent mental health problems in a large birth cohort. Child Abuse \& Neglect, 37(5), 292-302.

Naar-King, S., Silvern, V., Ryan, V., \& Sebring, D. (2002). Type and severity of abuse as predictors of psychiatric symptoms in adolescence. Journal of Family Violence, 17(2), 133-149.

Nelson, E.C., Heath, A.C., Madden, P.A.F., Cooper, L., Dinwiddie, S.H., Bucholz, K.K., ...Martin, N.G. (2002). Association between self-reported childhood sexual abuse and adverse psychosocial outcomes: Results from a twin study. Archives of General Psychiatry, 59(2), 139-145.

Peeters, Y., \& Stiggelbout, A.M. (2010). Health state valuations of patients and the general public analytically compared: A meta-analytical comparison of patient and population health state utilities. Value in Health, 13(2), 306-309.

Prosser, L.A., \& Corso, P.S. (2007). Measuring health-related quality of life for child maltreatment: A systematic literature review. Health and Quality of Life Outcomes, 5, 42-52.

Rajmil, L., Fernandez, E., Gispert, R., Rue, M., Glutting, J.P., Plasencia, A., Segura, A. (1999). Influence of proxy respondents in children's health interview surveys. Epidemiology Community Health, 53, 38-42.

Ross, C. E., \& Mirowsky, J. (1999). Disorder and decay: The concept of measurement of perceived neighborhood disorder. Urban Affairs Review, 3(34), 412-432.

Snoeren, F., \& Hoefnagels, C. (2013). Measuring perceived social support and perceived stress in primary school children in the Netherlands. Child Indicators Research, 1-14.

Springer, K.W., Sheridan, J., Kuo, D., \& Carnes, M. (2007). Long-term physical and mental health consequences of childhood physical abuse: Results from a large population-based sample of men and woman. Child Abuse \& Neglect, 31(5), 517-530.

Stith, S. M., Liu, T., Davies, L. C., Boykin, E. L., Alder, M. C., Harris, J. M., Som, A., et al. (2009). Risk factors in child maltreatment: A meta-analytic review of the literature. Aggression and Violent Behavior, 14, 13-29.

Sykes, J. (2011). Negotiating stigma: Understanding mothers' responses to accusations of child neglect. Child Youth Services Review, 33, 448-456.

Theunissen, N.C.M., Vogels, T.G.C., Koopman, H.M., Verrips, G.H.W., Zwinderman, K.A.H., Verloove-Vanhorick, S.P., \& Wit, J.M. (1998). The proxy problem: Child report versus parent report in health-related quality of life research. Quality of Life Research, 7, 387-397.

Treffers, Ph.,D.,A., Goedhardt, A.W., Veerman, J.W., Bergh, B.R.H. van den, Ackaert, L. \& Rycke, L. de (2002). Handleiding Competentie Belevingsschaal voor Adolescenten (Manual for the Perceived Competence Scale for Adolescents). Lisse: Swets Test Publishers.

Van der Zee, K. I., \& Sanderman, R. (1993). Het meten van de algemene gezondheidstoestand met de Rand-36: een handleiding (Measuring general health with the RAND-36: a manual). Groningen: Noordelijk Centrum voor Gezondheidsvraagstukken.

Van Sonderen, E. (1993). Het meten van de social steun met de Sociale Steun Lijst-Interacties en Sociale Steun Lijst-Discrepanties (Measuring social support with the Sociale Support ScaleInteractions and the Social Support Scale - Discrepancies). Groningen: Noordelijk Centrum voor Gezondheidsvraagstukken.

Van Well, S., Kolk, A. M., \& Arrindell, W. A. (2005). Cross-cultural validity of the masculine and feminine gender role stress scales. Journal of Personality Assessment, 84(3), 271-278.

Veerman, J. W., Janssen, J., Ten Brink, L. T., Van der Horst, H., \& Koedoot, P. (2003). Vragenlijst Meegemaakte Gebeurtenissen (VMG). Voorlopige handleiding 3e herziening herziening (Dutch Life Events Scale. Preliminary manual, 3th revision). ACSW/Praktikon. 
Veerman, J.W., Straathof, M.A.E., Treffers, Ph.D.A., Bergh, B.R.H. van den \& Brink, L.T. ten (2004). Competentiebelevingsschaal voor kinderen (Manual for the Perceived Competence Scale for Children). Amsterdam: Harcourt Test Publishers.

Verhulst, F.C., Ende, J. van der \& Koot, H.M. (1998). Handleiding voor de CBCL/4-18 18 (Manual Child Behavior Checklist/4-18). Rotterdam: Sophia Kinderziekenhuis, Erasmus MC.

Whiteman, D., \& Green, A. (1997). Wherein lies the truth? Assessment of agreement between parent proxy and child respondent. International Journal of Epidemiology, 26(3), 855-859. 

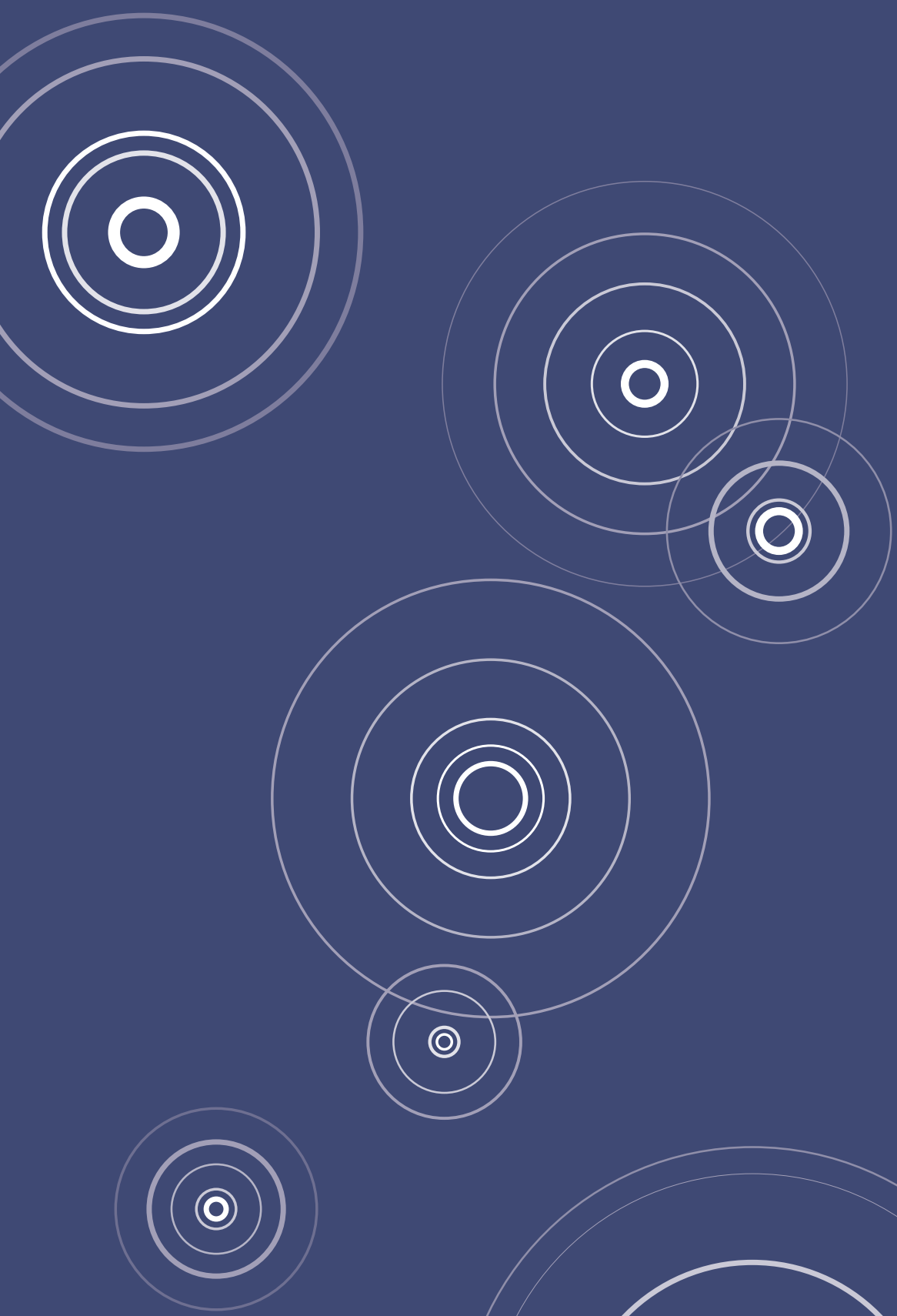


\section{(2)}

\section{CHAPTER 4}

The quality of life of maltreated children who

have been reported to advice and reporting

centers on child abuse and neglect

F. Snoeren, C. Hoefnagels, S. M. A. A. Evers, F. Lamers-Winkelman

Submitted at Journal of Interpersonal Violence (under revision)

(0)

(2)

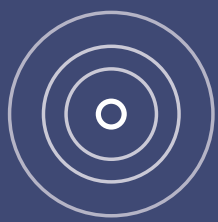



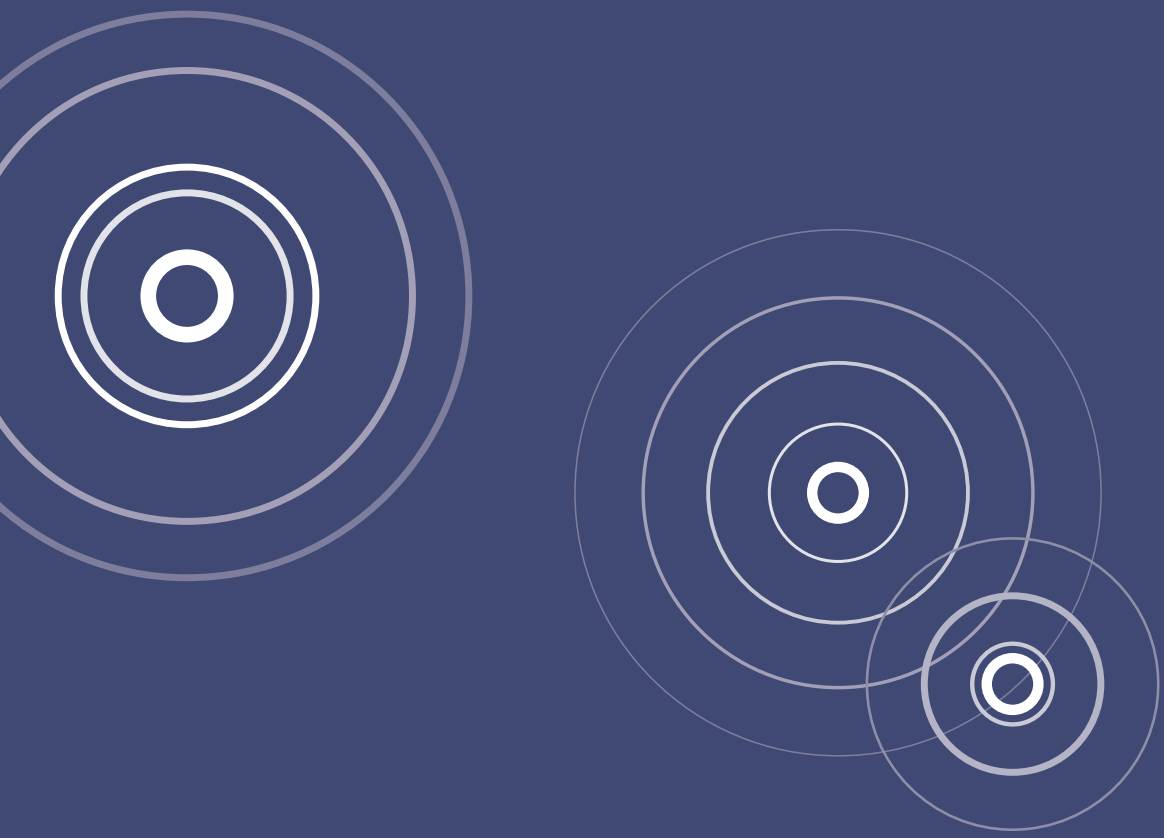

\section{Abstract}

Studies have shown that adults who have been maltreated as children report lower quality of life than people without an abusive past. Quality of life research focusing on maltreated children has been limited, as have studies examining quality of life outcomes shortly after child maltreatment. The primary aim of this study was to examine the quality of life of maltreated children shortly after a report to an advice and reporting center on child abuse and neglect. As a secondary aim, the extent to which socio-demographic and maltreatment characteristics were associated with quality of life was examined. Participants were 228 maltreated children aged 5-16 years $(M=9.99$; $S D=3.20$ ) and their primary caretaker. Children completed the Pediatric Quality of Life Inventory. One-sample t-tests were used to compare the self-reported quality of life of the maltreated children with scores from available norm populations consisting of healthy children. Stepwise multiple regression analyses were used to explore whether socio-demographic and maltreatment characteristics were associated with quality of life of maltreated children. Significant differences were found between the study sample and three different norm populations regarding the overall quality of life and the psychosocial health dimension of quality of life. Quality of life of children aged 8 and 9 years seemed to be more negatively affected by maltreatment than that of children in other age groups. The socio-demographic characteristic of financial problems in the family was associated with lower quality of life. Future research should address the long-term effects of child maltreatment on quality of life.

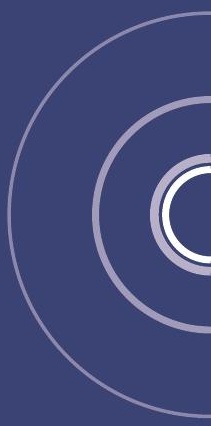




\section{Introduction}

Quality of life has been defined by the World Health Organization as 'the individuals' perception of their position in life in the context of the culture and value systems in which they live, in relation to their goals, expectations, standards and concerns' (World Health Organization Quality of Life Group [WHOQOL Group], 1995, p. 1405). This definition highlights the view that quality of life is multi-dimensional, including perceptions of physical health, psychological health, interpersonal relationships and social roles (WHOQOL Group, 1995). The concept of quality of life has become more important as it adds a client perspective to objective measures and can therefore be successfully used in health-related research (Gielen, McDonnell, Wu, O'Campo, \& Faden, 2001; Peeters \& Stiggelbout, 2010; Klassen, Anthony, Khan, Sung, \& Klaassen, 2011), as well as in clinical practice (e.g. Bastiaansen, Koot, Bongers, Varni, \& Verhulst, 2005). Recently, quality of life has also become an important part of research into childhood maltreatment. Adults who have been maltreated as children report lower quality of life than people without an abusive past (Afifi, Murray, Cox, de Graaf, ten Have, et al., 2007; Al-Fayez, Oheari, \& Gado, 2012; Corso, Edwards, Fang, \& Mercy, 2008). The present study focused on two gaps in the current quality of life literature. In the first place, studies into outcomes of maltreated children have been limited, even though maltreated children are a vulnerable group because they are at risk for developing mental and other health problems (Gilbert, Widom, Browne, Fergusson, Webb, et al., 2009). Second, research has focused on long-term outcomes, so information on the association between child maltreatment and current quality of life outcomes is lacking.

There are several possible explanations for the limited number of studies in which children are used as informants. First, quality of life in children is subject to developmental differences, which complicates research because age-related differences have to be addressed, for example by developing different questionnaire versions for different age groups. As a result, proxies such as parents have usually been asked to report on children's quality of life. However, research findings have shown discrepancies between child and proxy reports (Eiser \& Morse, 2001; Rajmil, Fernandez, Gispert, Rue, Glutting, et al., 1999; Theunissen, Vogels, Koopman, Verrips, Zwinderman, et al., 1998; Whiteman \& Green, 1997). Quality of life research has found greater agreement between child and proxy reports regarding the physical, i.e. more observable, dimensions, and less agreement regarding the social and emotional, i.e. less observable, quality of life dimensions (Eiser \& Morse, 2001). Also, parents may not make reliable proxies in case of child maltreatment, because they 
may be the abusers (Corso \& Lutzker, 2006). Since several studies have shown that children can be used as reliable informants as long as they are offered a valid age-appropriate instrument, the value of including children in research by using child self-reports is increasingly being recognized (Bell, 2007; Eiser \& Morse, 2001; Fuchs, 2005).

The second gap addressed by our study is that many studies into child maltreatment have examined long-term quality of life outcomes. This may lead to bias, in particular to underreporting of childhood adversities due to memory problems, such as dissociation (Corso et al., 2008; Felitti, Anda, Nordenberg, Williamson, Spitz, et al., 1998). Also, quality of life outcomes assessed shortly after or during the maltreatment can be expected to differ from outcomes reported years later.

The primary aim of the present study was therefore to examine the quality of life of maltreated children aged 5 to 16 years, using child self-reports, shortly after a child maltreatment report to a Dutch advice and reporting center on child abuse and neglect (Advies- en Meldpunt Kindermishandeling; AMK). To place the outcomes in perspective, quality of life outcomes of maltreated children were compared with norm populations, while also considering possible age-related differences.

The secondary aim of this study was to examine whether socio-demographic characteristics (child characteristics and socio-economic characteristics of the family) and maltreatment characteristics are associated with quality of life outcomes of maltreated children. Several studies have emphasized the importance of identifying factors that are associated with quality of life. This may help to distinguish children who are at risk for adverse outcomes and to identify factors that can be modified to improve quality of life (Barnett \& Hunter, 2012; Jirojanukul, Skevington, \& Hudson, 2003; Ravens-Sieberer, Erhart, Gosch, $\&$ Wille, 2008). There is extensive literature on the association between quality of life and child characteristics, such as age and gender, as well as socio-economic characteristics such as parental education level, employment status and/or financial situation (Gaspar, Ribeiro, Gaspar de Matos, Leal, \& Ferreira, 2012; Ravens-Sieberer et al., 2008). Lower quality of life was found for older children and for girls (Michel, Bisegger, Fuhr, \& Abel, 2009; Ravens-Sieberer et al., 2008). In addition, adverse socio-economic characteristics seem to have a negative impact on children's quality of life (Gaspar et al., 2012; Jirojanakul et al., 2003; Ravens-Sieberer et al., 2008; Varni, Limbers, \& Burwinkle, 2007). However, whether these characteristics can be generalized to adverse quality of life in a sample consisting of maltreated children is not clear.

Moreover, little information is available on the association between different types of maltreatment, including accumulation of several types of maltreatment 
('multiple maltreatment'), and quality of life outcomes (Jonzon \& Lindblad, 2005; Simon, Herlands, Marks, Mancini, Letamendi, et al., 2009). Our study focused on the following types of maltreatment: physical abuse, emotional abuse, emotional neglect, physical neglect and sexual abuse.

\section{Methods}

\section{Setting: Dutch advice and reporting centers on child abuse and neglect (AMKs)}

Data were collected from families who had been reported to an AMK. In the Netherlands, professionals and non-professionals who suspect child maltreatment are expected to contact an AMK. AMKs either provide professional advice on how to deal with the suspected maltreatment or they take up reports of suspected child maltreatment, in which case an investigation follows. This study focused only on reports to the AMKs. There are 17 AMKs, covering all regions in the Netherlands. An investigation starts with a multidisciplinary team meeting in which a plan for investigating the suspicion is drafted. During the investigation, which has a maximum duration of 13 weeks, the AMK collects information from adults (e.g. parents, teachers, general practitioners) and children to uncover any family problems, the need for child and family care and the willingness to accept professional help. When the suspicion is substantiated, the multidisciplinary team develops an intervention plan, which includes a plan to end maltreatment and a referral to voluntary care. If a family is unwilling to accept voluntary care, the AMK can refer the case to a Child Protection Agency, which (through the Family Court) can force the family to accept help (Baeten, 2009).

\section{Procedure}

Baseline data were derived from a Dutch prospective study into the course of the quality of life of maltreated children after they have been reported to an AMK (Snoeren, Hoefnagels, Evers, \& Lamers-Winkelman, 2013). Inclusion criteria were: age of the child between 5 and 16 years, a report about physical and/or emotional abuse, physical and/or emotional neglect and/or sexual abuse, and sufficient verbal and cognitive capacities on the part of both child and parent to complete a questionnaire. Only one child and one parent (the primary caretaker) per family were asked to participate. When the report related to more than one child of the same family, the oldest child within the age range was included. When the child was placed in care, the adult who was the primary caretaker at the time of the study was asked to participate. All families that met the inclusion 
criteria and had been reported to one of the seven participating AMKs were approached by phone by an AMK employee within three months after the report had been filed with the AMK. Participation in this study was voluntary. If during the phone conversation the parent and child agreed to participate, an appointment was made to complete the questionnaire. A research assistant then visited the participant at a time and place of their choice. Written informed consent was obtained prior to questionnaire completion.

The participation rate was $3.5 \%$, meaning that 286 parents and children completed the questionnaire. This low participation rate had been expected (Snoeren et al., 2013). Some obstacles were encountered during the phone recruitment, for instance phone numbers being missing from the AMK records, people not being available when the phone calls were made or people being unable to speak Dutch. Another possible explanation for the low response might be the delicate subject of the study. Many parents refused to participate due to a perception of accusation and/or stigmatization and/or stress because of the AMK report. Moreover, this study focused only on children for whom maltreatment was verified during the AMK investigation. In most of the cases, the reports were still under AMK investigation when the eligible participants were approached by phone, so the families' maltreatment status was not known at the time of study inclusion. Fifty-eight parent-child dyads were excluded because maltreatment was eventually not verified, resulting in data from 228 parent-child dyads for this study.

To prevent the parents from influencing the children's answers, they were requested to complete their questionnaires in separate rooms. Not all parents or children agreed with this setup, in which case exceptions were made and parents were allowed to be present, but not involved, when their children completed the questionnaire. The percentage of cases in which the child was not interviewed in a separate room was explored in a subsample $(n=128)$. Data revealed that the parent was present in $51.6 \%$ of cases. After having completed the questionnaire, the parents received a 10 euro gift certificate, while the children received either a 5 euro gift certificate (children $>10$ ) or an age-appropriate present (5-10 years) to thank them for their participation. No referral procedures were needed because these are implemented within the AMKs. However, in case a research assistant felt concerned about the child or the living situation, a GP could be contacted for consultation. The study was approved by the Dutch Medical Ethics Committee for Mental Health Care (METiGG) in September 2010.

\section{Measures}

The children's quality of life was assessed by asking them to complete the Pediatric Quality of Life Inventory (PedsQL), while parents completed a 
questionnaire on socio-demographic characteristics, and information on maltreatment characteristics was derived from AMK records.

PedsQL. Quality of life was measured with one of the three ageappropriate versions (5-7, 8-12, 13-18 years) of the Dutch translation of the PedsQL (Engelen et al., 2009; Varni, Seid, \& Rode, 1999). This scale measures children's perceptions and reflects their concerns on the dimensions of physical health (8 items) and psychosocial health, the latter consisting of the subdimensions of emotional functioning ( 5 items), social functioning (5 items) and school functioning (5 items). The overall quality of life score is obtained by adding up the scores for all dimensions. Children were asked to indicate on a 5-point Likert scale to what extent they had experienced difficulties regarding these dimensions over the last month $(0=$ never, $1=$ almost never, $2=$ sometimes, 3 = often, $4=$ almost always). The 5-7 year version consists of a 3-point Likert scale. The answers were reverse-scored and rescaled to a $0-100$ scale $(0=100,1=75,2=50,3=25,4=0)$. A score of 100 represents the best possible quality of life, a score of 0 the worst. The PedsQL has good psychometric properties (Engelen et al., 2009; Varni, Seid, \& Kurtin, 2001) and is widely used to measure quality of life in children. Some examples of the questionnaire items include: 'It is hard for me to run' (physical health dimension), 'I feel afraid or scared' (emotional functioning dimension), 'I have trouble getting along with other kids' (social functioning dimension), 'It is hard for me to pay attention in class' (school functioning dimension). Varni and colleagues (2007) have demonstrated that children as young as 5 years can reliably and validly self-report on their quality of life using the PedsQL.

Socio-demographic questionnaire. The socio-demographic questionnaire consisted of questions on demographic information, age and gender of the child, and information on the socio-economic status of the family, the education level of the parent, the employment status of the parent (currently employed / currently unemployed) and the presence of financial problems.

\section{Statistical analysis}

A non-response analysis was carried out in which the study sample was compared with the AMK population regarding several demographic and maltreatment characteristics that were derived from AMK records using a query. The AMK population consisted of all children aged 5-16 years reported to the participating AMKs during the recruitment period of our study. The following characteristics were assessed: age of the child, gender of the child, ethnicity (Dutch vs. non-Dutch), living situation (comprising traditional family, single-parent family, shared parenthood, newly-formed family, other), type 
of maltreatment as verified by the AMK, outcome of AMK procedure (no maltreatment, maltreatment not verified, maltreatment ended during AMK involvement, referral to voluntary care, report to child protection services, left with unknown destination, or died due to maltreatment). An independent samples t-test was used to compare the two groups in terms of the child's age. The other characteristics were studied using Chi-square tests. Due to the high percentage of multiple maltreatment reports, the characteristic type of maltreatment as verified by AMK was analyzed using dummy variables.

Internal consistency of the PedsQL within the study sample was examined prior to the analyses. Only dimensions or subdimensions with a Cronbach's alpha of at least .70 were used in this study to ensure reliability of the results (Cronbach, 1952).

Next, one-sample t-tests were performed to examine differences in overall quality of life and the psychosocial health dimension between maltreated children and three different available norm populations which were comprised of healthy children. Cohen's $d$ effect sizes were calculated for significant outcomes (Cohen, 1988).

Stepwise multiple regression analyses were used to examine if sociodemographic characteristics and maltreatment characteristics were associated with quality of life outcomes of the maltreated children. According to Van Voorhis and Morgan (2007) a minimum of 10 participants per factor is appropriate for regression equations using six or more factors. In case of stepwise regression, a larger sample size is advised. The sample size of 228 participants is sufficient when 11 characteristics will be included in the regression model. Analyses were performed for the reliable quality-of-life scales. Prior to the analyses, we examined the possible influence of (1) the different AMKs (families being derived from seven AMKs), (2) the presence of parents in the room where the child completed the questionnaire and (3) the time that had elapsed between the report to the AMK and the moment of questionnaire completion. Collinearity was also examined.

\section{Norm populations}

Three types of data from norm populations were available: (1) Norm scores from an American population derived from a study by Varni and colleagues in 2001. This study provided norm data on the total sample of children aged 5-16 years (Varni et al., 2001). (2) Norm scores from a Dutch population derived from the validation study of the Dutch version of the PedsQL in 2009. This study provided norm data on two subgroups: children aged 8-11 and those aged 12-16 years. Unfortunately, the 5-7 year age group was not part of 
this Dutch study sample (Engelen et al., 2009). (3) Norm scores from an American population derived from another study by Varni and colleagues in 2007. This study provided norm data on individual age groups (Varni et al., 2007).

\section{Results}

\section{Sample characteristics}

Participants were 228 children and their parents. Children were between 5 and 16 years old $(M=9.99 ; S D=3.20), 118$ boys and 110 girls. The average age of the parents was $38.12(S D=8.41)$. Parents were mostly mothers or stepmothers (81.6\%). Of the study sample, $36.5 \%$ reported financial problems (8.4\% did not want to tell), with an average duration of 3.16 years $(S D=2.77)$. The other sample characteristics are listed in table 1.

Table 1.

Sample characteristics

\begin{tabular}{lrrrr}
\hline Variables & $N$ & $\%$ & $M$ & $S D$ \\
\hline Age of the child (years) & 228 & & 9.99 & 3.20 \\
Gender of the child & & & & \\
$\quad$ Male & 118 & 51.8 & & \\
$\quad$ Female & 110 & 48.2 & & \\
Age of the parent (years) & 228 & & 38.12 & 8.41 \\
Gender of the parent & & & & \\
$\quad$ Male & 42 & 18.4 & & \\
$\quad$ Female & 186 & 81.6 & & \\
Education level of the parent & & & & \\
$\quad$ No education/primary school only & 25 & 11.1 & & \\
High school degree & 58 & 25.7 & & \\
Lower professional education & 43 & 19.0 & & \\
Secondary professional education & 59 & 26.1 & & \\
Tertiary education (bachelor/master) & 41 & 18.1 & & \\
Employment status of parent & & & & \\
$\quad$ Employed & 110 & 48.2 & & \\
Unemployed & 118 & 51.8 & & \\
Financial problems & & & & \\
Yes & 83 & 36.5 & \\
No & 125 & 55.1 & \\
Did not want to tell & 19 & 8.4 & \\
Average duration of financial problems (years) & 83 & & 3.16 & \\
\hline
\end{tabular}




\section{Maltreatment characteristics}

Of the maltreatment types that were studied, physical abuse was found in $13.6 \%$ of all cases, emotional abuse in $57.5 \%$, physical neglect in $12.3 \%$, and emotional neglect in $32.9 \%$, while sexual abuse was verified in $17.5 \%$. In addition, 'multiple maltreatment' was found in $61.7 \%$ of all cases.

\section{Non-response analysis}

Non-response analysis was performed in which the study sample $(N=286)$ was compared with the AMK population $(N=7932)$. No significant differences were found for the demographic characteristics of age and gender of the child, nor for living situation. Significant differences were found for ethnicity (Chi-square $=10.85(1) ; p=.001)$. The AMK population included $51.9 \%$ Dutch families, vs. $61.9 \%$ in the study sample. The AMK population and study sample also differed significantly regarding two of the types of maltreatment, viz. emotional abuse (Chi-square $=7.19(1) ; p=.007): 56.2 \%$ in the AMK population vs. $48.0 \%$ in the study sample; and emotional neglect (Chi-square $=15.63(1) ; p=.000): 17.2 \%$ in the AMK population vs. $26.3 \%$ in de study sample. There were no significant differences regarding other types of maltreatment verified by the AMK. A comparison of the study sample with the AMK population regarding the outcome of the AMK procedure revealed significant differences (Chi-square $=26.77(7) ; p=.000$ ). Post-hoc analysis showed significant differences in percentages of families who were reported to child protection services (Chi-square $=5.53(1) ; p=.019): 13.0 \%$ of the AMK population, vs. $8.2 \%$ of the study sample.

\section{Internal consistency of PedsQL}

The overall quality of life $(a=.78)$ and the psychosocial health dimension ( $a$ $=.74$ ) had good internal consistency and could therefore be reliably used for analyses. Cronbach's alpha values for the other dimensions were lower than .70 ( $a=.52$ for physical health; $a=.60$ for emotional functioning; $a=.63$ for social functioning and $a=.45$ for school functioning) so these subdimensions were not analyzed separately.

\section{Comparison of the study sample with norm populations}

(1) Comparison of the total sample. One-sample t-test was used to examine the quality of life of the maltreated children in comparison with an American norm population, using norm score data from Varni and colleagues (2001). Significant differences were found with regard to overall quality of life $(t=$ $-2.84 ; d f=228 ; p=.005)$ and the psychosocial health dimension $(t=-5.60$; 
$d f=228 ; p=.000)$, indicating lower quality of life and psychosocial health for maltreated children in this study (Table 2). Effect sizes were small, with Cohen's $d$ values of .12 and .26, respectively.

(2) Comparison of subgroups. One-sample t-tests were performed for the 8-11 year and 12-16 year subgroups to examine differences in quality of life outcomes between the maltreated children and a Dutch norm population (Engelen et al., 2009). For the 8-11 age group, significant differences were found regarding overall quality of life $(t=-2.77 ; d f=84 ; p=.007)$ and the psychosocial health dimension ( $t=-3.67 ; d f=84 ; p=.000$ ), indicating less favorable outcomes for maltreated children aged 8-11 than for non-maltreated children of the same age group. Effect sizes were small, with Cohen's $d$ values of .33 and .44 , respectively. No significant differences were found for the 12-16 age group (Table 2).

Table 2.

Results of one-sample t-tests comparing maltreated children with full sample norm scores (Varni et al., 2001) and norm scores for subgroups aged 8-11 and 12-16 years (Engelen et al., 2009)

\begin{tabular}{|c|c|c|c|c|c|c|}
\hline & \multicolumn{2}{|c|}{ Maltreated children } & \multicolumn{2}{|c|}{ Norm population } & \multirow[b]{2}{*}{$t$} & \multirow[b]{2}{*}{$p$} \\
\hline & $N$ & $M(S D)$ & $N$ & $M(S D)$ & & \\
\hline \multicolumn{7}{|l|}{ Full sample } \\
\hline Quality of life & 228 & $81.20(9.60)$ & 401 & $83.00(14.79)$ & -2.84 & $.005^{*}$ \\
\hline Psychosocial health & 228 & $78.22(11.20)$ & 399 & $82.38(15.51)$ & -5.60 & $.000^{* *}$ \\
\hline \multicolumn{7}{|l|}{ 8-11 years } \\
\hline Quality of life & 85 & $79.20(9.70)$ & 219 & $82.11(8.87)$ & -2.77 & $.007^{\star}$ \\
\hline Psychosocial health & 85 & $76.09(11.40)$ & 219 & $80.63(10.31)$ & -3.67 & $.000^{* *}$ \\
\hline \multicolumn{7}{|l|}{$12-16$ years } \\
\hline Quality of life & 77 & $82.14(10.70)$ & 185 & $82.24(9.15)$ & -.085 & .932 \\
\hline Psychosocial health & 77 & $79.41(12.11)$ & 185 & $80.23(10.18)$ & -.597 & .552 \\
\hline
\end{tabular}

" $p<.05, " * p<.001$

(3) Comparison of different age groups. One-sample t-tests were performed for the individual age groups, using an American norm population (Varni et al., 2007). Significant differences were found for children aged 8, 9 and 14 years. In addition, significant differences on the psychosocial health dimension were found for 11-year-old children. Results indicate a lower quality of life for maltreated children in these age groups in comparison with non-maltreated children of the same age groups. Effect sizes were small to moderate (see table 3). 
Table 3.

Results of one-sample t-tests on quality of life and psychosocial health outcomes comparing maltreated children with American norm scores per age group (Varni et al., 2007)

\begin{tabular}{|c|c|c|c|c|c|c|c|}
\hline \multirow{2}{*}{$\begin{array}{l}\text { Quality of life } \\
\text { Age }\end{array}$} & \multicolumn{2}{|c|}{ Maltreated children } & \multicolumn{5}{|c|}{ Norm population } \\
\hline & $n$ & $M(S D)$ & $n$ & $M(S D)$ & $t$ & Cohen's $d$ & $p$ \\
\hline 5 & 13 & $85.28(7.75)$ & 693 & $83.22(12.18)$ & 0.96 & & .356 \\
\hline 6 & 25 & $83.08(8.00)$ & 913 & $82.12(12.73)$ & 0.60 & & .555 \\
\hline 7 & 26 & $81.07(7.34)$ & 869 & $80.98(12.98)$ & 0.07 & & .949 \\
\hline 8 & 22 & $76.85(7.11)$ & 864 & 83.54 (12.95) & -4.41 & 0.52 & $.000^{* *}$ \\
\hline 9 & 26 & $77.34(8.52)$ & 827 & $83.71(13.76)$ & -3.81 & 0.46 & $.001^{* *}$ \\
\hline 10 & 17 & $82.93(11.14)$ & 825 & $84.16(12.72)$ & -0.46 & & .655 \\
\hline 11 & 20 & $80.96(11.47)$ & 675 & $85.61(12.47)$ & -1.81 & & .086 \\
\hline 12 & 24 & $80.89(10.03)$ & 669 & $84.01(12.97)$ & -1.53 & & .141 \\
\hline 13 & 15 & $86.62(11.87)$ & 609 & $84.23(13.15)$ & 0.78 & & .449 \\
\hline 14 & 16 & $80.23(10.11)$ & 560 & $85.71(11.97)$ & -2.17 & 0.46 & $.047^{*}$ \\
\hline 15 & 11 & $82.16(9.34)$ & 554 & $84.70(12.73)$ & -0.90 & & .388 \\
\hline 16 & 13 & $81.59(11.68)$ & 327 & $85.76(11.41)$ & -1.29 & & .222 \\
\hline \multicolumn{8}{|c|}{ Psychosocial health } \\
\hline Age & $n$ & $M(S D)$ & $n$ & $M(S D)$ & $t$ & Cohen's $d$ & $p$ \\
\hline 5 & 13 & $82.05(10.23)$ & 696 & $81.56(13.76)$ & 0.17 & & .865 \\
\hline 6 & 25 & $80.71(9.31)$ & 914 & $79.91(14.40)$ & 0.43 & & .670 \\
\hline 7 & 26 & 77.52 (9.38) & 870 & 78.55 (14.73) & -0.56 & & .580 \\
\hline 8 & 22 & $72.03(10.05)$ & 867 & $81.53(14.25)$ & -4.44 & 0.67 & $.000^{* *}$ \\
\hline 9 & 26 & $73.40(10.26)$ & 829 & $81.20(14.99)$ & -3.88 & 0.52 & $.001^{* *}$ \\
\hline 10 & 17 & $82.65(11.43)$ & 829 & $82.09(14.06)$ & 0.20 & & .843 \\
\hline 11 & 20 & $78.48(11.86)$ & 675 & $84.32(13.45)$ & -2.20 & 0.43 & $.040^{*}$ \\
\hline 12 & 24 & $77.99(11.18)$ & 672 & $82.20(14.45)$ & -1.85 & & .078 \\
\hline 13 & 15 & $85.60(13.08)$ & 610 & $82.34(14.69)$ & 0.96 & & .352 \\
\hline 14 & 16 & $77.60(10.65)$ & 562 & $83.98(13.28)$ & -2.40 & 0.48 & $.030^{*}$ \\
\hline 15 & 11 & $79.43(9.79)$ & 556 & $82.72(14.21)$ & -1.12 & & .290 \\
\hline 16 & 13 & $76.67(14.40)$ & 328 & $83.98(13.03)$ & -1.83 & & .092 \\
\hline
\end{tabular}

${ }^{*} p<.05,{ }^{* *} p<.01$

\section{Stepwise multiple regression analysis}

Stepwise multiple regression analyses were used to examine whether socio-demographic characteristics and maltreatment characteristics were associated with quality of life outcomes for maltreated children. Prior to the analyses, the possible influence of the variables (1) AMK, (2) presence of 
parent during child's questionnaire completion, and (3) time between AMK report and questionnaire completion were examined. None of these variables was significantly associated with overall quality of life or of the psychosocial health dimension, so they were not included in the analyses. There was no collinearity between the characteristics.

A stepwise multiple regression analysis for overall quality of life showed that one variable was significantly associated with quality of life, viz. selfreported financial problems in the family. This variable explained $6.4 \%$ of the variance and had a beta of $-.268(p=.003)$. None of the other sociodemographic and maltreatment characteristics contributed significantly to overall quality of life (Table 4).

The next analysis examined the psychosocial health dimension. Selfreported financial problems were again associated with poor outcomes, explaining $4.3 \%$ of the variance and with a beta of $-.226(p=.012)$. None of the other socio-demographic and maltreatment characteristics contributed significantly to the psychosocial health dimension (Table 4).

Table 4.

Results of socio-demographic and maltreatment characteristics in stepwise multiple regression analysis

\begin{tabular}{lcccr}
\hline & \multicolumn{2}{c}{ Overall quality of life } & \multicolumn{2}{c}{ Psychosocial health } \\
\cline { 2 - 5 } Characteristics & beta & $p$ & beta & $p$ \\
\hline Age of child & .026 & .690 & .032 & .631 \\
Gender of child & .064 & .336 & .020 & .767 \\
Education level of parents & .005 & .946 & .004 & .952 \\
Employment status & .034 & .607 & .050 & .450 \\
Financial problems & -.268 & $.003^{*}$ & -.226 & $.012^{*}$ \\
Physical abuse & -.051 & .435 & -.098 & .138 \\
Emotional abuse & -.008 & .906 & -.023 & .733 \\
Physical neglect & -.043 & .519 & -.066 & .327 \\
Emotional neglect & -.060 & .358 & -.097 & .142 \\
Sexual abuse & .030 & .653 & .016 & .810 \\
Multiple maltreatment & .027 & .687 & .025 & .713 \\
\hline
\end{tabular}




\section{Discussion}

The primary aim of this study was to examine the self-reported quality of life of maltreated children (aged 5 to 16 years) shortly after a child maltreatment report to an AMK. To place the outcomes in perspective, quality of life outcomes of maltreated children were compared with those in norm populations comprised of healthy children. Significantly lower quality of life for the maltreated children was found. The results of this study were as expected based on previous studies using adult reports (Dubowitz \& Bennett, 2007; Gilbert et al., 2009; Kendall-Tacket, Meyer-Williams, Finkelhor, 1993; Lamers-Winkelman, Willemen, \& Visser, 2012; Nelson, Heath, Madden, Cooper, Dinwiddie, et al., 2002; Springer, Sheridan, Kuo, \& Carnes, 2007), which also suggested that child maltreatment is related to children's quality of life. This is, however, the first study to examine quality of life by self-report in a sample of maltreated children. As a result, the current findings on quality of life cannot be compared with other samples of maltreated children.

The present study compared quality of life outcomes of maltreated children with those of the three available norm populations. Both overall quality of life and the psychosocial health dimension were studied. The results for the full sample showed a significantly lower quality of life for maltreated children than for non-maltreated children, though the effect sizes were small. These small effect sizes may have been caused by developmental differences. Since examining the full sample of children between 5 and 16 years old does not take account of developmental differences, we performed additional comparisons using more age-specific data, resulting in significant findings for the different age groups. A subgroup comparison revealed significantly lower quality of life for maltreated children in the 8-11 year age group, but not for those in the 12-16 year age group, compared with their non-maltreated peers. A possible explanation may be the greater dependence of the younger children on parental care. Young adolescents become less dependent on adult care and have more opportunity to turn to extrafamilial resources (such as peers) for support (Helsen, Vollebergh, \& Meeus, 2000).

To further specify findings, we also compared all age groups separately. Significant differences were found for children aged 8, 9 and 14 years. As regards the psychosocial health dimension, significant differences were also found for the 11-year-old children. Effect sizes were moderate. However, considering the number of tests carried out on the sample, Bonferroni corrections might have to be considered. This would result in only the findings for children aged 8 and 9 years remaining significant. This would be in line 
with the findings of the other subgroup analyses, and would suggest that child maltreatment affects children in some age groups more than those in other age groups. Despite the significant results, the findings need to be interpreted with caution, due to the small sample sizes that remain when the full sample is split up into twelve separate age groups. Also, future research is needed to confirm these age-specific findings on the quality of life of maltreated children.

This study also explored which socio-demographic and/or maltreatment characteristics were associated with the quality of life of maltreated children. Financial problems, as reported by parents, were found to be associated with lower quality of life for the maltreated children. Several other studies have also found a negative association between financial difficulties and quality of life outcomes, both in adults (Havasi, 2011; Shen \& Sambamoorthi, 2012) and in children (Chen, Matthews, \& Boyce, 2002; Felder Puig, Baumgartner, Topf, Gadner, \& Formann, 2008). Prior studies have also confirmed the negative association between financial problems and child maltreatment (e.g. Trickett, Aber, Carlson, \& Cicchetti, 1991). Financial problems may put strain and stress upon family life, which is likely to affect children's as well as adults' quality of life. Some authors suggest that this strain and stress affects maltreated children more than non-maltreated children, due to an accumulation of stressors (Margolin \& Gordis, 2003). Future research should focus on exploring the characteristics more thoroughly, for example by exploring possible inter-relatedness between socio-demographic and/or maltreatment characteristics.

A major strength of this study was the use of children's self-reports. There is a lack of studies examining the quality of life of maltreated children using the children as informants, whereas research findings have shown discrepancies between child and proxy reports when collecting data on quality of life (Eiser \& Morse, 2001; Rajmil et al., 1999; Theunissen et al., 1998; Whiteman \& Green, 1997). In addition, this study was performed among maltreated children who had recently been reported to an AMK (within 3 months). Few studies have examined outcomes shortly after or during the actual maltreatment (Prosser \& Corso, 2007), and outcomes may be expected to differ from those obtained years later. This study was not designed to predict the development of quality of life over time. It is possible that the quality of life of maltreated children does not remain low over time into adulthood. Quality of life may improve if the AMK succeeds in ending maltreatment and providing well-tailored child care. This may prevent lower quality of life outcomes, or may reduce the severity of negative outcomes. There is thus a need for studies examining 
how the quality of life of maltreated children develops over time (Corso \& Fertig, 2010; Prosser \& Corse, 2007).

There are several limitations to the current study. First, selection bias cannot be ruled out. This might be caused by self-selection, since participation was voluntary. Another reason may be the recruitment method, i.e. recruitment by phone. We were able to recruit only $3.5 \%$ of the total eligible population. The non-response analysis showed some differences between the current study sample and the AMK population. A notable difference was the smaller proportion of emotionally abused children in the study sample. A possible explanation might be found in the definition of emotional abuse. Defining emotional abuse is complicated because of the thin line between emotional abuse and poor or dysfunctional parenting. This complicates problem recognition of emotional abuse within society, leading to denial of child maltreatment in cases of emotional abuse (Wolfe \& Mclsaac, 2011). Physical abuse and sexual abuse are more frequently recognized by society as types of child maltreatment. Those in the category of emotional abuse who were eligible to participate might not have identified themselves as eligible subjects for the study, and might have been more likely to refuse participation. In addition, cases in which emotional neglect was verified were more prevalent in the study sample than in the AMK population. We assume that this might also be caused by self-selection, Neglectful parents have problems of information processing regarding their children's emotions and behaviors, which may affect their childrearing behavior and maladaptive attributions (Hildyard \& Wolfe, 2007). They lack the ability to respond to the child's needs and might regard omission as less severe than abuse. Also, socioeconomic disadvantages and poverty are known to be risk factors for neglect (Nelson, Saunders \& Landsman, 1993; Schumacher, Smith Slep, \& Heyman, 2001). If parents are able to attribute the absence of appropriate actions to external factors, they may feel less responsible, take the maltreatment report less personally, and may therefore be more willing to participate in the study. In addition, emotional neglect is more prevalent among mentally handicapped parents (Nelson et al., 1993), which is hard to recognize for the research assistants. Mentally handicapped people are more easily convinced to participate in studies, as they have trouble anticipating the consequences and are sensitive to authority, possibly including the AMK employees who suggested they participate in our study.

Another finding of the non-response analysis was that the proportion of cases in which the family was reported by the AMK to child protection services was lower in the study sample than in the AMK population. This 
finding could also be explained by self-selection. In the Netherlands, families are reported to child protection services if they are unwilling to accept care. As participation in the study was voluntary, it could be expected that families who were open to AMK intervention would be more willing to participate than families who refused the help suggested by the AMK. Hence, it seems likely that maltreatment might be more severe or more chronic in cases in which voluntary care was rejected, and the quality of life scores of these maltreated children may be even lower. This would imply that the findings of our study are conservative, and that research into the quality of life outcomes of severe and chronic maltreatment is required.

Second, no representative recent Dutch norm population providing information on all the age groups was available. The only Dutch study providing norm data unfortunately did not include children in the 5-7 year age group. Hence, norm data from American samples (Varni et al., 2001; Varni et al., 2007) were used for additional analyses. However, it might be unjustified to assume that data obtained in American society are comparable to those for Dutch society. Also, the norm data from Varni and colleagues from 2001 might be somewhat outdated, and their comparison between maltreated and non-maltreated children from individual age groups (Varni et al., 2007) was performed on small samples ( $N$ between 11 and 26). Three comparisons with different norm populations were made to minimize the extent to which these flaws influenced the outcomes. Nevertheless, they should be taken into account when interpreting the results.

A third limitation is the cross-sectional design, which precludes conclusions about causality.

Fourth, internal consistency for some of the quality of life dimensions was unfortunately low. This may have been caused by the relatively small number of items per dimension (8 items for physical health, 5 items for social, emotional and school functioning), as sufficient internal consistency was found for the larger psychosocial health dimension (15 items) and for overall quality of life (23 items). Findings of other studies are in line with this suggestion (Engelen et al., 2009; Roizen, Rodriquez, Bauer, Medin, Bevilacqua, et al., 2008). In addition, lower internal consistency was found for the youngest age group (5-7 years), especially on the subdimensions. A substantial number of children in this study sample (28.9\%) were between 5 and 7 years old. The low Cronbach's alpha values for this age group may have contributed to the lower Cronbach's alpha in the study sample as a whole (Coghill, Danckaerts, Sanuga-Barke, \& Sergeant, 2009; Matza, Swensen, Flood, Secnik, \& Leidy, 2004). 
Notwithstanding these limitations, the results of this study suggest a negative association between child maltreatment and self-reported quality of life outcomes. Financial problems were found to be associated with lower quality of life in maltreated children. This study was the first to examine self-reported quality of life in a sample of maltreated children shortly after a report to an AMK. Future studies should examine how the quality of life of maltreated children develops over time. 


\section{References}

Afifi, T.O., Murray, W.E., Cox, B.J., de Graaf, R., ten Have, M., \& Sareen, J. (2007). Child abuse and health-related quality of life in adulthood. The Journal of Nervous and Mental Disease, 195(10), 797-804.

Al-Fayez, G.A., Oheari, J.U., \& Gado, O.M. (2012). Prevalence of physical, psychological, and sexual abuse among a nationwide sample of Arab high school students: Association with family characteristics, anxiety, depression, self-esteem, and quality of life. Social Psychiatry and Psychiatric Epidemiology, 47, 53-66.

Alink, L.R.A., van IJzendoorn, M.H., Bakermans-Kranenbrug, M.J., Pannebakker, F.D., Vogels, T., \& Euser, S. (2011). Kindermishandeling in Nederland anno 2010: De tweede Nationale Prevalentiestudie Mishandeling van Kinderen en Jeugdigen (NPM-2010) (Child maltreatment in the Netherlands in 2010: the second prevalence study of the maltreatment of children and adolescents in the Netherlands). Leiden: Casimir Publishers.

Baeten, P. (2009). Protocol van handelen bij vermoedens van kindermishandeling in relatie van afhankelijkheid en onvrijheid (Manual- How to act in case of suspected child maltreatment in relationships of dependence and restricted freedom). Utrecht: MO Groep.

Barnett, R.A., \& Hunter, M. (2012). Adjustment of siblings of children with mental health problems: Behaviour, self-concept, quality of life and family functioning. Journal of Child and Family Studies, 21, 262-272.

Bastiaansen, D., Koot, H.M., Bongers, I.L., Varni, J.W., \& Verhulst, F.C. (2005). Measuring quality of life in children referred for psychiatric problems: Psychometric properties of the PedsQL 4.0 generic core scales. Quality of Life Research, 13, 489-495.

Bell, A. (2007). Designing and testing questionnaires for children. Journal of Research in Nursing, 12, 461-471.

Chen, E., Matthews, K.A., \& Boyce, W.T. (2002). Socioeconomic differences in children's health: How and why do these relationships change with age? Psychological Bulletin, 128(2), 295-329.

Coghill, D., Danckaerts, M., Sanuga-Barke, E., \& Sergeant, J. (2009). Practitioner review: Quality of life in child mental health. Conceptual challenges and practical choices. Journal of Child Psychology and Psychiatry, 50(5), 544-561.

Cohen, J. (1988). Statistical Power Analysis for the Behavioral Sciences ( $2^{\text {nd }}$ ed.). New Jersey: Lawrence Erlbaum Associates.

Corso, P.S., Edwards, V.J., Fang, X., \& Mercy, J.A. (2008). Health-related quality of life among adults who experienced maltreatment during childhood. American Journal of Public Health, 98(6), 1094-1100.

Corso, P. S., \& Fertig, A. R. (2010). The economic impact of child maltreatment in the United States: Are estimates credible? Child Abuse \& Neglect, 34, 296-304.

Cremeens, J., Eiser, C., \& Blades, M. (2006). Characteristics of health-related self-report measures for children aged three to eight years: A review of the literature. Quality of Life Research, 15, 739-754.

Cronbach, L.J. (1951). Coefficient alpha and the internal structure of tests. Psychometrika, 16(3): 297-334.

Dubowitz, H., \& Bennett, S. (2007). Physical abuse and neglect of children. The Lancet, 369, 1891-1899.

Eiser, C., \& Morse, R. (2001). Can parents rate their child's health-related quality of life? Results of a systematic review. Quality of Life Research, 10, 347-357.

Engelen, V., Haentjens, M.M., Detmar, S.B., Koopman, H.M., \& Grootenhuis, A. (2009). Healthrelated quality of life of Dutch children: Psychometric properties of the PedsQL in the Netherlands. BMC Pediatrics, 9, 68-75.

Felder-Puig, R., Baumgartner, M., Topf, R., Gadner, H., \& Formann, A. K. (2008). Health-related quality of life in Austrian elementary school children. Medical Care, 46, 432-439. 
Felitti, V.J., Anda, R.F., Nordenberg, D., Williamson, D.F., Spitz, A.M., Edwards, V., ...Marks, J.S. (1998). Relationship of childhood abuse and household dysfunction to many of the leading causes of death in adults: The adverse childhood experiences (ACE) study. American Journal of Preventive Medicine, 14(4), 245-258.

Fuchs, M. (2005). Children and adolescents as respondents. Experiments on question order, response order, scale effects and the effect of numeric values associated with the response options. Journal of Official Statistics, 21(4), 701-725.

Gaspar, T., Ribeiro, J.P., Gaspar de Matos, M., Leal, I., \& Ferreira, A. (2012). Health-related quality of life in children and adolescents: Subjective well-being. The Spanish Journal of Psychology, 15(1), 177-186.

Gielen, A.C., McDonnell, K.A., Wu, A.W., O'Campo, P., \& Faden, R. (2001). Quality of life among women living with HIV: The importance of violence, social support, and self-care behaviors. Social Science and Medicine, 52(2), 315-322.

Gilbert, R., Widom, C.S., Browne, K., Fergusson, D., Webb, E., \& Janson, S. (2009). Burden of consequences of child maltreatment in high income countries. The Lancet, 373, 68-81.

Havasi, V. (2011). Financial situation and its consequences on the quality of life in the EU countries. Social Indicators Research. doi:10.1007/s11205-011-9901-y

Helsen, M., Vollebergh, W., \& Meeus, W. (2000). Social support from parents and friends and emotional problems in adolescence. Journal of Youth and Adolescence, 29(3), 319-335.

Hildyard, K., \& Wolfe, D. (2007). Cognitive processes associated with child neglect. Child Abuse \& Neglect, 31, 895-907.

Ingerski, L.M., Shaw, K., Gray, W.N., \& Janicke, D.M. (2010). A pilot study comparing traumatic stress symptoms by child and parent report across pediatric chronic illness groups. Journal of Developmental and Behavioral Pediatrics, 31(8), 1-7.

Jirojanakul, P., Skevington, S.M., \& Hudson, J. (2003). Predicting young children's quality of life. Social Science \& Medicine, 57, 1277-1288.

Jonzon, E., \& Lindblad, F. (2005). Adult female victims of child sexual abuse. Multi-type maltreatment and disclosure characteristics related to subjective health. Journal of Interpersonal Violence, 20, 651-668.

Kendall-Tacket, K.A., Meyer-Williams, L., \& Finkelhor, D. (1993). The impact of sexual abuse on children: A review and synthesis of recent empirical studies. Psychological Bulletin, 113, 164-180.

Klassen, A.F., Anthony, S.J., Khan, A., Sung, L., \& Klaassen, R. (2011). Identifying determinants of quality of life of children with cancer and childhood cancer survivors: A systematic review. Supportive Care in Cancer, 19(9), 1275-1287.

Lamers-Winkelman, F., Willemen, A.M., \& Visser, M.M. (2012). Adverse childhood experiences of referred children exposed to intimate partner violence: Consequences for their well-being. Child Abuse \& Neglect, 36(2), 166-179.

Margolin, G., \& Gordis, E. B. (2003). Co-occurence between marital aggression and parents' child abuse potential: The impact of cumulative stress. Violence and Victims, 18(3), 243-258.

Matza, L.S., Swensen, A.R., Flood, E.M., Secnik, K., \& Leidy, N.K. (2004). Assessment of healthrelated quality of life in children: A review of conceptual, methodological, and regulatory issues. Value in Health, 7(1), 79-92.

Michel, G., Bisegger, C., Fuhr, D.C., Abel, T., \& The KIDSCREEN group. (2009). Age and gender differences in health-related quality of life of children and adolescents in Europe: A multilevel analysis. Quality of Life Research Journal, 18, 1147-1157.

Nelson, E.C., Heath, A.C., Madden, P.A.F., Cooper, L., Dinwiddie, S.H., Bucholz, K.K., ...Martin, N.G. (2002). Association between self-reported childhood sexual abuse and adverse psychosocial outcomes: Results from a twin study. Archives of General Psychiatry, 59(2), 139-145.

Nelson, K.E., Saunders, E.J., \& Landsman, M.J. (1993). Chronic child neglect in perspective. Social Work, 38(6), 661-671.

Peeters, Y., \& Stiggelbout, A.M. (2010). Health state valuations of patients and the general public analytically compared: A meta-analytical comparison of patient and population health state utilities. Value in Health, 13(2), 306-309. 
Prosser, L.A., \& Corso, P.S. (2007). Measuring health-related quality of life for child maltreatment: A systematic literature review. Health and Quality of Life Outcomes, 5, 42-52.

Rajmil, L., Fernandez, E., Gispert, R., Rue, M., Glutting, J.P., Plasencia, A., Segura, A. (1999). Influence of proxy respondents in children's health interview surveys. Epidemiology Community Health, 53, 38-42.

Ravens-Sieberer, U., Erhart, M., Gosch, A., Wille, N., \& The European KIDSCREEN Group (2008). Mental health of children and adolescents in 12 European countries. Results from the European KIDSCREEN study. Clinical Psychology and Psychotherapy, 15, 154-163.

Roediger, H. L., Capaldi, E. D., Paris, S. G., Polivy, J., \& Herman, C. P. (2001). Psychologie. Een inleiding (Psychology. An introduction). Gent: Academia Press.

Roizen, M., Rodriquez, S., Bauer, G., Medin, G., Bevilacqua, S., Varni, J.W., \& Dussel, V. (2008). Initial validation of the Argentinean Spanish version of the PedsQI 4.0 Generic Core Scales in children and adolescents with chronic diseases: Acceptability and comprehensibility in low-income settings. Health and Quality of Life Outcomes, 6, 59-73.

Schumacher, J. A., Smith Slep A, M., \& Heyman, R. E. (2001). Risk factors for child neglect. Aggression \& Violent Behavior, 6, 231- 254.

Shen, C., \& Sambamoorthi, U. (2012). Health-related quality of life and financial barriers to care among women veterans. Women and Health, 52(1), 1-17.

Simon, N.M., Herlands, N.N., Marks, E.H., Mancini, C., Letamendi, A., Li, Z., ...Stein, M.B. (2009). Childhood maltreatment linked to greater symptom severity and poorer quality of life and function in social anxiety disorder. Depression and Anxiety, 26, 1027-1032.

Snoeren, F., Hoefnagels, C., Evers, S. M. A. A., \& Lamers-Winkelman, F. (2013). Design of a prospective study on mental health and quality of life of maltreated children (aged 5-16 years) after a report to an advice and reporting center in child abuse and neglect. BMC Public Health, 13, 942.

Springer, K.W., Sheridan, J., Kuo, D., \& Carnes, M. (2007). Long-term physical and mental health consequences of childhood physical abuse: Results from a large population-based sample of men and woman. Child Abuse \& Neglect, 31(5), 517-530.

Theunissen, N.C.M., Vogels, T.G.C., Koopman, H.M., Verrips, G.H.W., Zwinderman, K.A.H., Verloove-Vanhorick, S.P., \& Wit, J.M. (1998). The proxy problem: Child report versus parent report in health-related quality of life research. Quality of Life Research, 7, 387-397.

Trickett, P.K., Aber, J.L., Carlson, V., \& Cicchetti, D. (1991). Relationship of socio-economic status to the etiology and developmental sequelae of physical child abuse. Developmental Psychology, 27(1), 148-158.

Van Voorhis, C. R. W., \& Morgan, B. L. (2007). Understanding power and rules of the thumb for determining sample sizes. Tutorials in Quantitative Methods for Psychology, 3(2), 43-50.

Varni., J.W., Limbers, C., \& Burwinkle, T.M. (2007). Literature review: Health-related quality of life measurement in pediatric oncology: Hearing the voices of the children. Journal of Pediatric Psychology, 32(9), 1151-1163.

Varni, J.W., Seid, M., \& Kurtin, P. (2001). PedsQL 4.0: Reliability and validity of the Pediatric Quality of Life Inventory version 4.0 generic core scales in healthy and patient populations. Medical Care, 39, 800-812.

Varni, J.W., Seid, M., \& Rode, C.A. (1999). The PedsQL TM: Measurement Model for the Pediatric Quality of life Inventory. Medical Care, 37(2), 126-139.

Whiteman, D., \& Green, A. (1997). Wherein lies the truth? Assessment of agreement between parent proxy and child respondent. International Journal of Epidemiology, 26(3), 855-859.

World Health Organization Quality of Life Group (1995). The World Health Organization Quality of Life of Life Assessment (WHOQOL): Position paper from the World Health Organization. Social Science \& Medicine, 41(10), 1403-1409.

Wittenberg, E., Joshi, M., Thomas, K. A., \& McCloskey, L. (2007). Measuring the effect of intimate partner violence on health-related quality of life: A qualitative focus group study. Health and Quality of Life, 5, 67-73.

Wolfe, D.A., \& Mclsaac, C. (2011). Distinguishing between poor/dysfunctional parenting and child emotional maltreatment. Child Abuse \& Neglect, 35, 802-813. 


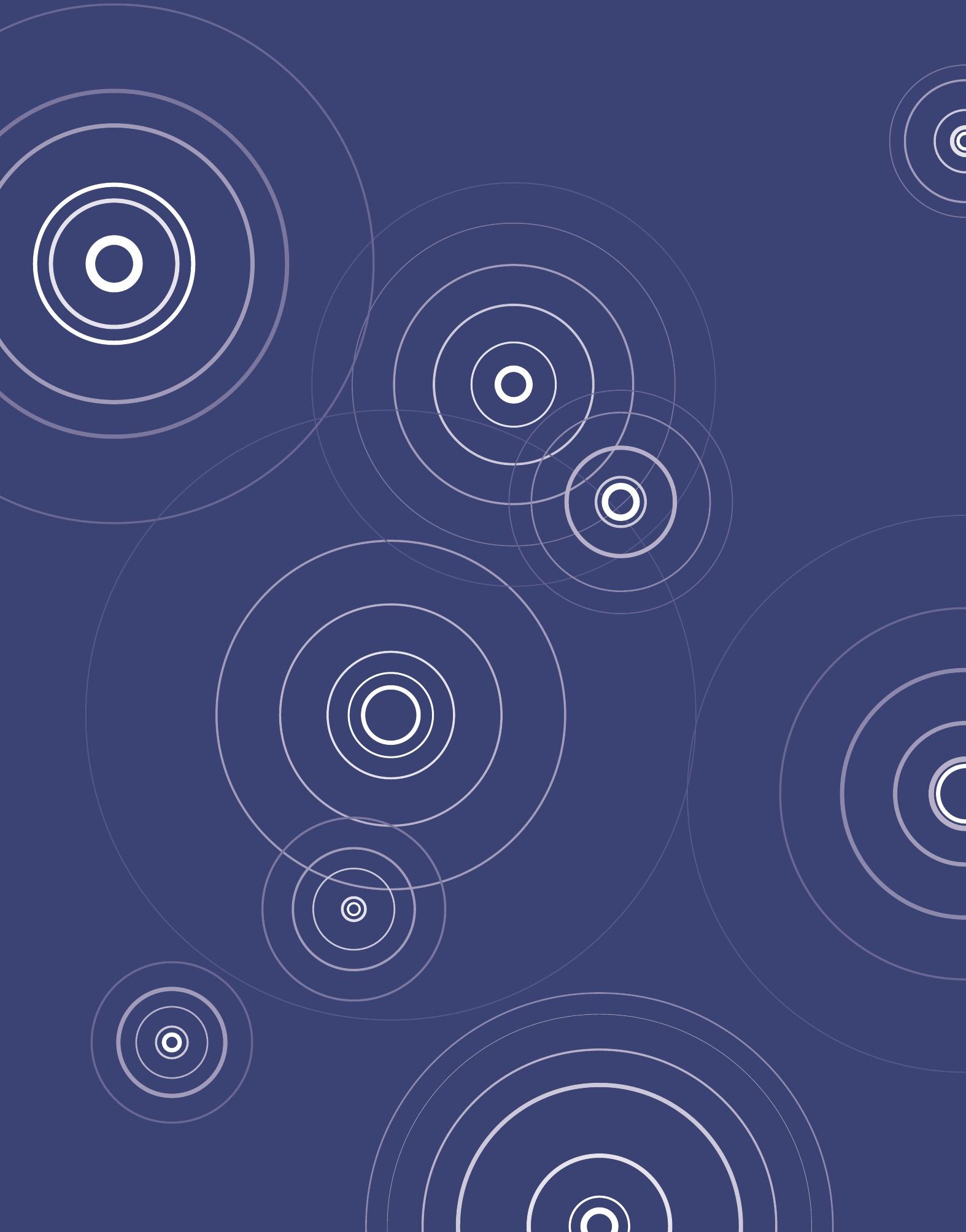




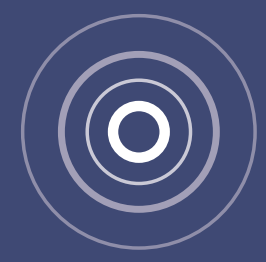

\section{CHAPTER 5}

Self-reported quality of life of maltreated children and factors associated:

A prospective study

F. Snoeren, C. Hoefnagels, S. M. A. A. Evers, T. Ambergen,

F. Lamers-Winkelman

Submitted at Child Development

O

(2)
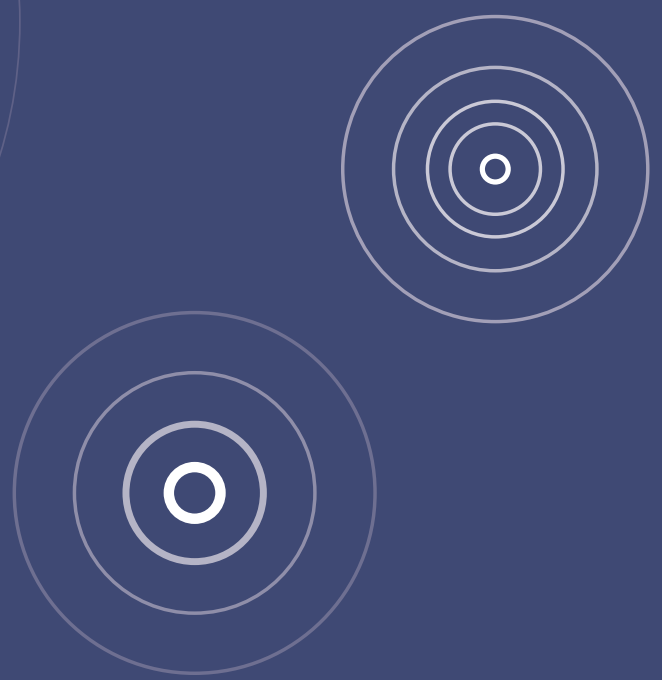


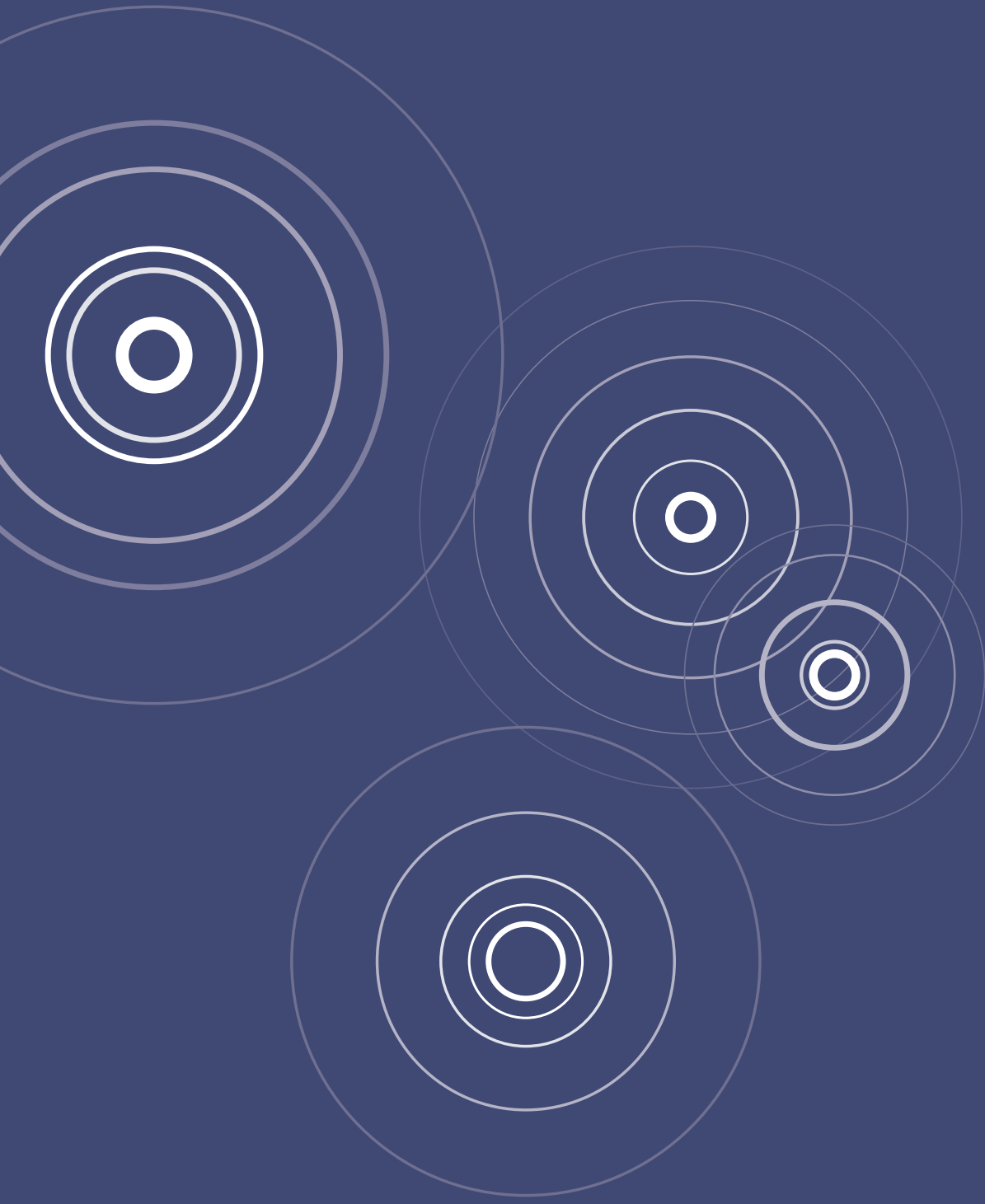

Abstract

Self-reported quality of life of maltreated children (5-16 years) $(N=209)$ was examined over 1.5 years after a reporting agency for child maltreatment became involved. There was an increase in the first 6 months, followed by a decrease at 1- and 1.5-year follow-up assessments. Three child factors, viz. older age, higher self-esteem and lower perceived stress, as well as one of the dimensions of parental quality of life, were associated with higher quality of life over time. To interpret the results, the care received by maltreated children should be recorded. Future research should focus on the interrelatedness of factors, including parental and family/environmental factors for which no association with children's quality of life was found. 


\section{Introduction}

Child maltreatment is a major problem all over the world, with substantial adverse outcomes both in childhood and in adulthood (Leeb, Lewis, \& Zolotor, 2011; Mills, Scott, Alati, O'Callaghan, Najman, \& Strathearn, 2013). In view of this great impact, most Western countries have agencies to which suspected cases of child maltreatment can be reported. These agencies investigate the report and if maltreatment is verified, they try to end the maltreatment and refer to appropriate care. The "Advies- en Meldpunten Kindermishandeling" (AMKs) are the Dutch reporting agencies. The estimated prevalence of maltreatment in the Netherlands in 2010 was 118,000 $(34 / 1,000)$ (Euser, Alink, Pannebaker, Vogels, Bakermans-Kranenburg, \& Van IJzendoorn, 2013), and the AMKs investigated over 19,000 child maltreatment reports in 2012 (Jeugdzorg Nederland, 2013). Ending the maltreatment and helping the children is very important, as longer duration of child maltreatment is associated with poorer outcomes (Gilbert, Widom, Browne, Fergusson, Webb, \& Janson, 2009; Jonson-Reid, Kohl, \& Drake, 2012; Jud, Landolt, Tatalias, Lach, \& Lips, 2013). The current study addresses two problems concerning maltreated children. First, in spite of the fact that the AMKs have been in existence for decades, it is unknown how the quality of life of maltreated children develops after an intervention by an AMK. Second, there is a need to identify factors associated with the quality of life outcomes of maltreated children, as this will help to identify characteristics of children who are at risk for poor quality of life, and thus need additional support.

There have been few studies on self-reported quality of life of children after maltreatment (Jud et al., 2013; Prosser \& Corso, 2007). Most studies that tried to examine the association between child maltreatment and quality of life used either proxies (for instance parents) to assess children's quality of life or they assessed the quality of life of adults who were maltreated during their childhood (Afifi, Murray, Cox, De Graaf, Ten Have, \& Sareen, 2007; Al-Fayez, Oheari, \& Gado, 2012; Corso, Edwards, Fang, \& Mercy, 2008). A disadvantage of the use of proxies is the discrepancies in answers between the children and proxies (Eiser \& Morse, 2001; Rajmil, Fernandez, Gispert, Rue, Glutting, Plasencia, \& Segura, 1999; Theunissen, Vogels, Koopman, Verrips, Zwinderman, Verloove-Vanhornick, \& Wit, 1998; Wallander, Schmitt, \& Koot, 2001). Discrepancies are mostly observed regarding emotional and social functioning, and less so regarding the physical, more observable domain (Eiser \& Morse, 2001; Ravens-Sieberer, Erhart, Wille, Wetzel, Nickel, \& Bullinger, 2006). In addition, in the case of child maltreatment, an abusive 
parent may not be the most reliable informant to report on the quality of life of the child (Corso \& Lutzker, 2006; Prosser \& Corso, 2006).

There are several reasons why quality of life research has so far mainly focused on adults. Children find it hard to clearly communicate their feelings and thoughts, and they may experience difficulties distinguishing between good and ill health and recognizing changes in health. This leads to complications when asking them to report on their quality of life (Mabugu, Revill, \& Van den Berg, 2013; Wallander et al., 2001). Nevertheless, it is important to study quality of life among children. First, childhood and adolescence are periods characterized by the development of cognitive skills and a changing dependency in relations, with increasing autonomy. These developmental differences between age groups should be addressed in quality of life research, as they may mean that children may have a different perception of quality of life than adults (Ravens-Sieberer et al., 2006; Wallander et al., 2001; Wille, Badia, Bonsel, Burstrom, Cavrini, Devlin, Egmar, et al., 2010). Child reports can be valid and reliable as long as children are approached with appropriate tools that help them understand the concept of quality of life (Bell, 2007; Eiser \& Morse, 2001; Fuchs, 2005; Mabugu et al., 2013), such as the use of pictures for small children, or different versions for different age groups, with age-specific terminology and age-specific answering options, for instance fewer answering categories for younger children (Mabugu et al., 2013; Ravens-Sieberer et al., 2006). Second, the impact of adverse life events, such as child maltreatment, may be different for children than for adults. Children have fewer opportunities to change the context in which they grow up. For example, they depend on their parents for financial resources and support (Coghill, Danckaerts, Sanuga-Barke, Sergeant, \& ADHD European Guidelines Group, 2009; Matza, Swensen, Flood, Secnik, \& Leidy, 2004).

There is also a need to identify factors that are associated with quality of life outcomes of maltreated children. Various factors relate to the quality of life of children, as it is after all a multi-dimensional concept, including physical, psychological, social, and environmental dimensions (school or neighborhood) (Ravens-Sieberer et al., 2006; Wallander et al., 2001; Wille et al., 2010). Relevant child factors associated with a higher quality of life of the child are higher self-esteem (Gaspar, Ribeiro, Gaspar de Matos, Leal, \& Ferreira, 2012; Marriage \& Cummins, 2004), greater social support (Gaspar et al., 2012; Herzer, Zeller, Rausch, \& Modi, 2011; Ingerski, Janicke, \& Silverstein, 2007), and less stress (Gospodarevskaya, 2013; Marriage \& Cummins, 2004; Villalonga-Olives, Rojas-Farreras, Vilagut, Palacio-Vieire, Valderas, Herdman, Ferrer, et al., 2010). In addition, socioeconomic disadvantages such as low 
family income, low parental education level and unemployment are family factors strongly related to poor quality of life in children (Drukker, Kaplan, Feron, \& Van Os, 2003; Jirojanukul, Skevington, \& Hudson, 2003). These studies also found environmental factors such as poor housing and neighborhood status, especially social isolation, to negatively affect quality of life in children (Drukker et al., 2003; Crowley \& Kazdia, 1998; Jirojanakul et al., 2003). It is unknown whether these factors are also associated with the quality of life outcomes of maltreated children.

The association between parental factors and children's quality of life outcomes has not widely been studied. Some studies have found child factors, such as the child's psychosocial functioning, to be associated with quality of life outcomes of parents (Crowley \& Kazdia, 1998; Litzelman, Catrine, Gangon, \& Witt, 2011). An association between parental functioning and children's quality of life outcomes can also be assumed. As far as we are aware, this study is the first to examine various parental factors, such as parent's quality of life, perceived social support and parenting stress in relation to the quality of life outcomes of maltreated children reported to an AMK.

This study focused on two gaps in the existing literature. First, it examined quality of life outcomes of maltreated children using child self-reports.

Second, it explored the association between various child, family/environmental and parental factors and the quality of life outcomes of these children. The primary aim of this study was to examine the course of the quality of life of maltreated children (aged 5-16 years) over a 1.5-year period after they were reported to an AMK. The second aim of this study was to examine various factors in relation to the self-reported quality of life of maltreated children. The child factors included perceived social support, perceived stress, and self-esteem. The family/environmental factors included neighborhood perception, ethnic background, family situation, and socioeconomic status and the parental factors were perceived social support, parental stress, and parental quality of life.

\section{Methods}

\section{Setting}

A total of 17 AMKs cover all regions in the Netherlands, which has a voluntary reporting system. These AMKs can be approached for professional advice or to file a report if child maltreatment is suspected, by both professionals and non-professionals, such as neighbors and family members. Such reports are 
then discussed in a multi-disciplinary meeting, in which a plan for the AMK investigation is drafted. These multi-disciplinary meetings usually involve at least one or two social workers, a doctor, a psychologist, and a team leader. An AMK investigation can take up to 13 weeks. During this time, the AMK investigates the child maltreatment report by talking to the parents and other people in the child's environment, such as the family doctor, teachers, social workers, and/or other family members. Children aged six years and older may also be interviewed for information. After this AMK investigation, all information is evaluated by the same multi-disciplinary team. They verify the maltreatment, assess whether the maltreatment has ended and refer the child and/or family to suitable voluntary care. If voluntary care is rejected, the AMK can report the family to child protection services, which can arrange more compulsory action (Baeten, 2009).

\section{Procedure}

A prospective study was performed in which parent-child dyads completed a questionnaire four times over a 1.5 year period (Snoeren, Hoefnagels, Evers, \& Lamers-Winkelman, 2013). Assessment 1 took place shortly after the child maltreatment report was filed with an AMK. Follow-up assessments were scheduled every six months (Figure 1).

For the purpose of this study, families meeting the inclusion criteria were approached by phone by an AMK social worker shortly after the parents were notified that a report of alleged child maltreatment had been filed. The first inclusion criterion was that one child, aged between 5 and 16 years, and one adult per family (the primary caretaker, usually one of the parents), had to be willing to participate. The reported child was usually invited, but if a report included more than one child, the oldest child was chosen. In some cases, the participating adult was the (suspected) abuser. Unfortunately, however, such abuse specifications were not accessible to the researchers. The second criterion was that the child maltreatment report had to concern physical abuse, emotional abuse, physical neglect, emotional neglect, and/or sexual abuse. Families who did not meet this criterion, such as those in reports of domestic violence, were not approached. Third, the verbal and cognitive skills of parents and child had to be sufficient to conduct an oral interview. An interpreter was available for Moroccan immigrant parents. After eligibility had been established and if both parent and child agreed to participate after receiving information by phone, the first assessment was scheduled. 


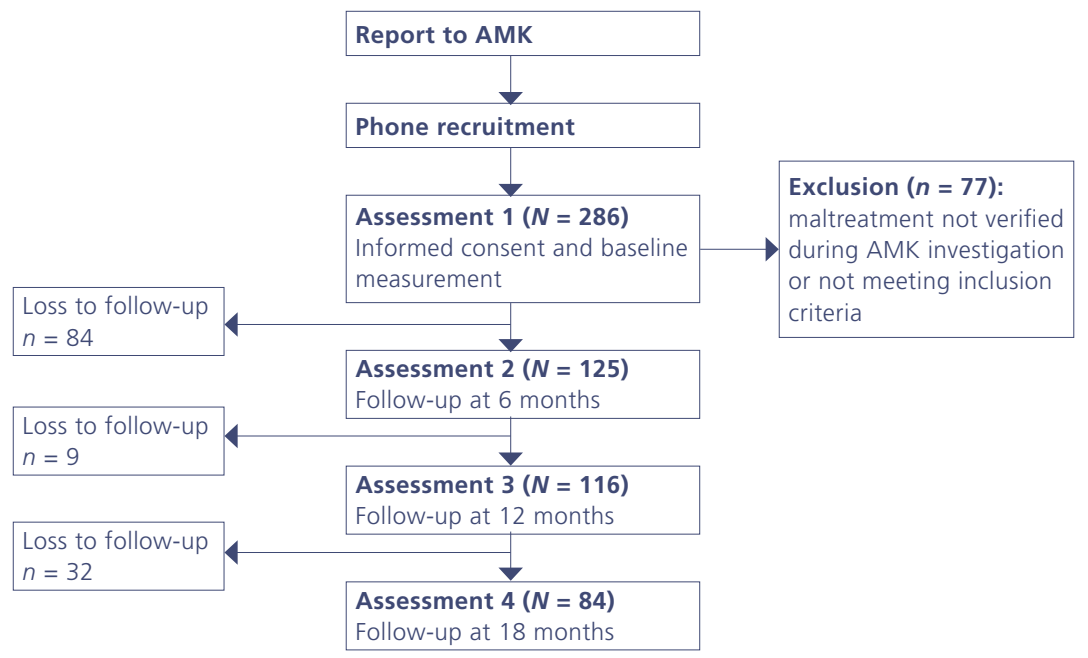

Figure 1. Flow chart of study design

The participation rate was 3.5\%; 286 parent-child dyads completed assessment 1. A low participation rate was expected because of the delicate subject of this study. We assume this percentage to be conservative due to some obstacles during the phone recruitment, such as missing phone numbers in AMK files, or families that could not be reached because phones were not answered or phone numbers had changed. As a result, not all eligible families could be invited for participation. Unfortunately, we did not keep records of the number of families that were not reached. Among the families that were reached, a substantial number were not willing to participate, the most commonly cited reasons being not wanting to discuss the AMK report or not wanting to burden the child during this stressful period (i.e. the AMK investigation). In addition, this study focused only on those families for whom the maltreatment was verified during the AMK investigation. Most AMK investigations were ongoing at the time when families were being recruited. Hence, 77 families were excluded later because the maltreatment status was confirmed as 'no maltreatment' or 'maltreatment not verified' after the AMK investigation. 
A member of the research team visited the family at a location of their choice, in most cases their own home. Both the parent and the child were asked to give written informed consent prior to completing the questionnaires. If reading and/or writing skills were poor, the research assistant helped by reading out the questions and writing down the answers. We asked whether parent and child could be interviewed in separate rooms, but the data for a subsample $(n=128)$ showed that in $51.6 \%$ of the cases, the parents or children did not agree with this arrangement. In these cases parents were allowed to be present, but not involved, when their children completed the questionnaire. After the questionnaires had been completed, the parents received a 10 euro gift voucher, while the children received a 5 euro gift voucher, and the younger children received an age-appropriate present. No referral procedures were needed because these are established within the AMKs. However, if research assistants were left with concerns about the child or the living situation, a GP connected to the study team could be contacted for consultation. The study was approved by the Dutch Medical Ethics Committee for Mental Health Care (METiGG) in September 2010.

\section{Outcome measures}

In addition to the dependent variable of quality of life, we studied child, family/environmental and parental factors, using age-appropriate self-report questionnaires for the child factors. Unfortunately, age-appropriate questionnaires were not available for all outcome measures for the youngest children.

Self-reported quality of life. Children's self-reported quality of life was the primary outcome measure of this study. It was assessed using one of the three age-appropriate versions (5-7, 8-11, 12-18 years) of the Dutch translation of the Pediatric Quality of Life Inventory (PedsQL; Engelen, Haentjens, Detmar, Koopman, \& Grootenhuis, 2009). Internal consistency of all versions was good ( $a=.82-.85$, Engelen et al., 2009; our sample $a=.73-.88$ ).

Children were asked to express their concerns on four dimensions: physical health (8 items), emotional functioning ( 5 items), social functioning (5 items), and school functioning (5 items) on a 5-point scale (3-point scale for the 5-7 years version). Missing values were dealt with at an individual level, in accordance with the instructions of the questionnaire manual. Scores were converted to a scale from 0 to 100 . A total score was obtained by adding up the scores on all dimensions (Varni, 2008). Wherever quality of life is mentioned in this paper, we refer to children's self-reported quality of life. 


\section{Child factors}

Perceived social support. Children's perceived social support was assessed using adapted versions of the Dutch Sociale Steun Lijst (SSL) for adults (Social Support Inventory; Van Sonderen, 1993). Children aged 12-16 years completed the SSL youngster version (Hoefnagels, Meesters, \& Simenon, 2007), while children aged 8-11 years completed the Perceived Social Support Questionnaire 8-11 (PSSQ8-11; Snoeren \& Hoefnagels, 2013). Children were asked to report their perceived social support on three subscales: daily emotional support (4 items), support in problem situations ( 8 items), and negative interactions ( 7 items), using a 4-point scale. Missing values were dealt with at an individual level in accordance with the instructions of the questionnaire manual. A total score for perceived social support was obtained by adding up the scores on the subscales for daily emotional support and support in problem situations. A total score for negative interactions was obtained separately (Van Sonderen, 1993). Internal consistency was sufficient for both versions ( $a=.78$, Hoefnagels et al., 2007; $a=.73$, Snoeren \& Hoefnagels, 2013; our sample $a=.67-.92$ ).

Children aged 5-7 years completed only the negative interactions subscale, using a 2-point scale (yes/no) ( $a=.57$; unpublished internal report by Snoeren \& Hoefnagels, 2011; our sample $a=.65$ ). Unfortunately, a prior study had shown that the internal consistency of the other subscales was inadequate for this age group (unpublished internal report by Snoeren \& Hoefnagels, 2011).

Perceived stress. Children's perceived stress was assessed using adapted versions of the Maastricht University Stress Instrument for Children (MUSIC; Kraag, Meesters, Van Bekkum, Fekkes, Kok, \& Huijer Abu-Saad, submitted). Children aged 12-16 years completed MUSIC, while children aged 8-11 years completed the Perceived Stress Questionnaire 8-11 (PSQ8-11; Snoeren \& Hoefnagels, 2013). Children were asked to report their perceived stress on two subscales: psychological stress (10 items) and physiological stress (10 items), on a 4-point scale. Individual missing values were imputed with the individual mean for the subscale, with a maximum of $20 \%$ missing. A total score was obtained by adding up the scores on both subscales. Internal consistency was sufficient for both versions ( $a=.85$, Hoefnagels et al., 2007; $a=.85$, Snoeren \& Hoefnagels, 2013; our sample $a=.85$ ).

Children aged 5-7 years completed an adapted version of the PSQ8-11, in which answering options were reduced to 'yes/no' instead of the 4-point scale ( $a=.60$; unpublished internal report by Snoeren \& Hoefnagels, 2011; our sample $a=.73$ ).

Self-esteem. Children's self-esteem was assessed using one subscale of the Self-Perception Profile for Adolescents (Harter, 2005). This questionnaire 
was translated into Dutch and adapted to an adolescent version, the Competentie Belevingsschaal voor Adolescenten (CBSA) for children aged 12-16 years, and a child version, the Competentie Belevingsschaal voor Kinderen (CBSK) for children aged 8-11 years (Treffers, Goedhardt, Veerman, Van den Berg, Ackeart, \& De Rycke, 2002; Veerman, Straathof, Trreffers, Van den Berg, \& Ten Brink, 2004). Children were asked to report their perceptions for six subscales, one of which was self-esteem (5 items for CBSA, 6 items for (BSK), using a 4-point scale. Some of the item scores were reversed so that a higher score corresponded with higher self-esteem. Individual missing values were imputed with the individual mean for the subscale, with a maximum of $20 \%$ missing. A total score was obtained by adding up the items of the self-esteem subscale. Internal consistency of the questionnaires was good ( $a=.66-.88$, Treffers et al., 2002; $a=.74$, Veerman et al., 2004; our sample $a=.87-.89$ ). No age-appropriate questionnaire with sufficient psychometric properties was available for the 5-7 years age group.

\section{Family/environmental factors}

Neighborhood perception. Neighborhood perception was assessed using the Dutch translation of the Neighborhood Characteristics Scale (Ross \& Mirowsky, 1999). Parents were asked to indicate their level of agreement with several statements regarding their neighborhood on two subscales: physical neighborhood disorder (13 items) and social neighborhood disorder (5 items), using a 5-point scale. Some of the item scores were reversed so that a higher score corresponded with higher neighborhood disorder for all items. Individual missing values were imputed with the individual mean on the subscale, with a maximum of $20 \%$ missing. A total score was obtained for each subscale by adding up the items scores. Although the original scale has good psychometric properties ( $a=.92$, Ross \& Mirowsky, 1999), no information is available on the psychometric properties of the Dutch translation. In our sample, the internal consistency was good $(a=.82-.88)$.

Family background information. Family background information regarding ethnicity, current family situation and socioeconomic disadvantages, including parental education level, employment status and presence of financial problems, was obtained from parents. 


\section{Parental factors}

Quality of life. Quality of life of the parents was assessed using the Dutch translation of the RAND 36-item Health Survey (RAND-36; Van der Zee \& Sanderman, 1993), a short version of the RAND Health Insurance Study Questionnaire (Brook, Ware, Davies-Avery, Stewart, Donald, Rogers, Williams, \& Johnston, 1979). Parents were asked to report their concerns regarding nine dimensions: physical functioning (10 items), social functioning (2 items), constraint due to physical problems (4 items), constraint due to emotional problems (3 items), mental health ( 5 items), energy ( 4 items), pain ( 2 items), perception of health (5 items), and change in health (1 item), using different multiple choice answering options for each item. Missing values were dealt with at an individual level and a total score was calculated for each dimension, in accordance with the instructions of the questionnaire manual. Some of the item scores were reversed so that a higher score corresponded with a better quality of life/health. Internal consistency of the dimensions was good ( $a=.71-.92$, Van der Zee \& Sanderman, 1993; our sample $a=.73-.94$ ).

Parenting stress. Parenting stress was assessed using an adapted version and translation of the Parenting Stress Index (Abadin, 1983) (Nijmeegse Ouderlijke Stress Index, short version (NOSI-K); De Brock, Verhulst, Gerris, Veerman, \& Abadin, 2006). Parents were asked to indicate their agreement with several statements concerning the upbringing of their child (25 items), using a 6-point scale. Missing values were dealt with at an individual level and a total score was calculated for each dimension, in accordance with the instructions of the questionnaire manual. A total score was obtained by adding up the scores on all items. Internal consistency was good ( $a=.97$, De Brock et al., 2006; our sample $a=.95$ ).

Perceived Social Support. Perceived social support was assessed using the Dutch Sociale Steun Lijst for adults (Social Support Inventory; Van Sonderen, 1993). Parents were asked to indicate their perceived social support regarding two dimensions: SSL-Interactions (SSL-I) (34 items) and SSL-Negative interactions (SSL-N) (7 items), using a 4-point scale. Missing values were dealt with at an individual level and a total score was calculated for each dimension, in accordance with the instructions of the questionnaire manual. A total score was obtained by adding up the item scores for each dimension. Internal consistency was good ( $a=.90-.93$ for SSL-I, $a=.69-.81$ for SSL-N, Van Sonderen, 1993; our sample $a=.95$ for SSL-I, $a=.88$ for SSL-N). 


\section{Analyses}

A non-response analysis was performed in which the study sample was compared with the AMK population regarding characteristics obtained from AMK records. The AMK population consisted of all children aged 5-16 years reported to the participating AMKs within the recruitment period. Differences in age of the children were examined using an independent samples t-test. Differences on the other characteristics were examined using Chi-square tests: these characteristics included the gender of the child, ethnicity (Dutch vs. non-Dutch), family situation (traditional family, single-parent family, shared parenthood, newly-formed family, other), outcome of the AMK procedure (no maltreatment, maltreatment not confirmed, maltreatment ended during AMK involvement, referral to voluntary care, report to child protection services, left with unknown destination, child died due to maltreatment), and type of maltreatment as verified by the AMK. Because many cases comprised more than one type of maltreatment, this characteristic was analyzed using dummy variables for physical maltreatment, emotional maltreatment, physical neglect, emotional neglect, and sexual abuse.

Next, a substantial number of participants were lost to follow-up. Differences between the sample of completers at assessment 4 and a sample of parent-child dyads who dropped out during the follow-up period were examined in a drop-out analysis using independent sample t-tests or Chi-square tests for the following characteristics: age of child and parent, gender of child and parent, parental education level, presence of financial problems, employment status, ethnicity, family situation, outcome of the AMK procedure, type of maltreatment, and the primary outcome measure of quality of life of the child. Missing data were imputed with regression imputation using Stata version 12, while taking into account possible predictors of missingness.

The research questions were examined by means of longitudinal multilevel analyses. Level 1 values were the repeated measures within parent-child dyads: time of assessment. Level 2 values marked parent-child dyads. First, research question 1 was addressed by examining changes in quality of life over time with a model in which quality of life was the dependent variable, only regressed by the time of assessment (consisting of assessments 1, 2, 3, and 4). Quality of life over time was examined for the full sample including all children aged between 5 and 16 years. In addition, age differences were taken into account by repeating the analyses for three age groups: 5-7 years, 8-11 years and 12-16 years. These age groups represent the Dutch introductory stage of primary school (4-7 years, though 4-year-old children were not 
included in this study), the advanced stage of primary school (8-11 years) and secondary school (12-16 years).

Second, factors associated with the children's quality of life over time (research question 2) were explored by running several models including various factors. Level 1 values were again the repeated measures within parent-child dyads: time of assessment. Level 2 values again marked parent-child dyads. Quality of life over time was again used as the dependent variable.

The child factors of perceived social support, perceived stress, and selfesteem, the environmental factor of neighborhood perception, and the parental factors of perceived social support, parenting stress, and quality of life were assessed at all four assessments. For these factors, their value over time was used in the analyses. For the factors of age and gender of child and parent and for all family factors, their value at assessment 1 was used in the analyses.

We started with an exploration phase in which factors were explored in three models: Model 1 explored all child factors: age, gender, perceived social support (consisting of: social support and negative interactions), perceived stress, and self-esteem. Since two age-appropriate questionnaires were used to measure self-esteem, the total scores were divided by the number of items of the subscales ( 5 for CBSA and 6 for CBSK), resulting in self-esteem values that could be compared. Model 2 explored all family/environmental factors: ethnicity, current family situation, parental education level, employment status, presence of financial problems, and neighborhood perception (consisting of: physical neighborhood perception and social neighborhood perception). Model 3 explored all parental factors: age, gender, perceived social support (consisting of: social support and negative interactions), parenting stress, and parental quality of life (consisting of nine factors corresponding with the nine dimensions). These factors were included in the models as fixed effects. 'Parent-child dyad' was included as a random effect. In models 1, 2 and 3, all factors with a $p$-value below 25 were selected as 'possibly' associated with quality of life. We chose a relatively large alpha criterion to ensure that factors were not erroneously deleted in this exploration phase, so all factors that could possibly be associated with quality of life would be included in the final model. The factors with a $p$-value below .25 were examined together in model 4. Possible age differences were adjusted for by also including interactions of selected variables with the factor of 'age of the child'. Factors that were not significant $(p>.05)$ were removed from the model. All factors with a $p$-value below .05 were assumed to be associated with children's self-reported quality of life over time.

Prior to the analyses, factors that were included in the models together 
were checked for collinearity by assessing a Variance Inflation Factor (VIF). If the VIF exceeds 10, collinearity needs to be considered (O'Brien, 2007). In addition, the influence of parent-child dyads being recruited by different AMKs and the influence of the presence of the parent while the child completed the questionnaire were examined, to be able to account for this in the analyses if necessary.

\section{Results}

\section{Sample characteristics}

Participants were 209 children and their parents. Children were between 5 and 16 years old $(M=10.13 ; S D=3.20), 108$ boys and 101 girls. Most families had a Dutch background (64.6\%) and $37.2 \%$ reported financial problems. Over half of the parents were unemployed (52.4\%) at the time of assessment 1 . All sample characteristics are listed in table 1.

\section{Non-response analyses}

The non-response analyses showed three significant differences between the study sample $(N=286)$ and the AMK population $(N=7932)$. First, the study sample included a lower percentage of non-Dutch families (38.1\%) than the AMK population (48.1\%) (Chi-square $(1)=10.85 ; p=0.001$ ). Second, there were differences in the types of maltreatment verified by the AMK: the study sample included a higher percentage of emotional neglect cases $(26.3 \% \mathrm{vs}$. $17.2 \%$; Chi-square $(1)=15.63 ; p=0.000)$ and a lower percentage of emotional abuse cases (48.0\% vs. $56.2 \%$; Chi-square $(1)=7.19 ; p=0.007$ ) compared to the AMK population. Third, the non-response analyses showed significant differences in terms of the outcome of the AMK procedure (Chi-square $(7)=26.7 ; p=0.000$ ). Post-hoc analyses on dummy variables showed that the study sample included a significantly lower percentage of cases that were reported to child protection services (8.2\% vs. $13.0 \%$; Chi-square $(1)=5.53 ; p=0.019)$. No significant differences were found between the study sample and the AMK population regarding the characteristics of age, gender, ethnicity, family situation, and the other types of maltreatment (physical abuse, physical neglect and sexual abuse; $p>.05$ ). 
Table 1.

Sample characteristics

\begin{tabular}{|c|c|c|c|c|}
\hline Variables & $n$ & $\%$ & $M$ & $S D$ \\
\hline Age of the child (years) & 209 & & 10.13 & 3.20 \\
\hline \multicolumn{5}{|l|}{ Gender of the child } \\
\hline Male & 108 & 51.9 & & \\
\hline Female & 101 & 48.1 & & \\
\hline Age of the parent (years) & 209 & & 38.58 & 8.67 \\
\hline \multicolumn{5}{|l|}{ Gender of the parent } \\
\hline Male & 38 & 17.8 & & \\
\hline Female & 171 & 82.2 & & \\
\hline \multicolumn{5}{|l|}{ Family situation } \\
\hline Traditional family & 81 & 38.8 & & \\
\hline Single parent family & 82 & 39.2 & & \\
\hline Shared parenthood & 9 & 4.3 & & \\
\hline Newly-formed family & 27 & 12.9 & & \\
\hline Other & 10 & 4.8 & & \\
\hline \multicolumn{5}{|l|}{ Education level of the parent } \\
\hline No education/primary school only & 24 & 11.7 & & \\
\hline Secondary school diploma & 55 & 26.7 & & \\
\hline Lower professional education & 38 & 18.4 & & \\
\hline Secondary professional education & 48 & 23.3 & & \\
\hline Tertiary education (bachelor/master) & 41 & 19.9 & & \\
\hline \multicolumn{5}{|l|}{ Employment status of parent } \\
\hline Employed & 99 & 47.6 & & \\
\hline Unemployed & 109 & 52.4 & & \\
\hline \multicolumn{5}{|l|}{ Financial problems } \\
\hline Yes & 77 & 37.2 & & \\
\hline No & 113 & 54.6 & & \\
\hline Refused to tell & 17 & 8.2 & & \\
\hline \multicolumn{5}{|l|}{ Type of maltreatment ${ }^{a}$} \\
\hline Physical abuse & 26 & 12.4 & & \\
\hline Physical neglect & 24 & 11.5 & & \\
\hline Emotional abuse & 122 & 58.4 & & \\
\hline Emotional neglect & 67 & 32.1 & & \\
\hline Sexual abuse & 40 & 19.1 & & \\
\hline
\end{tabular}

aMany cases comprised more than one type of maltreatment 


\section{Drop-out analyses}

The drop-out analyses showed one significant difference between the sample of completers at assessment $4(n=84)$ and the sample of parent-child dyads who had dropped out at one or more of the follow-up assessments $(n=125)$. The percentage of completers was higher for Dutch parent-child dyads $(46.5 \%)$ than for parent-child dyads of non-Dutch origin (29.5\%) (Chi-square $(1)=5.80 ; p=0.016)$. No significant differences were found between the groups regarding the characteristics of age, gender, family situation, outcome of the AMK procedure, or any of the types of maltreatment, nor regarding quality of life $(p>.05)$.

\section{Longitudinal multilevel analyses}

\section{(1) Quality of life outcomes over time}

Descriptives of self-reported quality of life at all assessments are presented in table 2. Results of the longitudinal multilevel analyses of the full sample of maltreated children and analyses of three age groups are presented in figure 2 and table 3.

Overall, the quality of life of maltreated children improved between assessments 1 and 2, i.e. over a period of 6 months after the AMK intervention. After assessment 2, the quality of life decreased significantly. The quality of life scores at assessment 4, 1.5 years after the AMK intervention, were lower than those measured at assessment 1.

\section{(2) Factors associated with quality of life outcomes over time}

There was no collinearity between the factors in the models, nor any association between the different AMKs and quality of life. Also the presence of a parent when the child completed the questionnaire was not related to the children's quality of life.

In the exploration phase, factors with a $p$-value below .25 were selected (factors with a $p$-value $<.05$ are marked). The selected child factors were: age of the child $(*)$, perceived stress $(*)$, and self-esteem $(*)$ (model 1 ). The only family/ environmental factor to be selected was the presence of financial problems $\left({ }^{*}\right)$ (model 2). Selected parental factors were age of the parent, perceived social support, perceived negative interactions, and three of the quality of life dimensions: constraint due to emotional problems, mental health, and pain (model 3). These factors were included in model 4, also in interaction with the age of the child, in order to examine possible age differences in outcomes. Model 4 showed four 
Table 2.

Mean and standard deviation of self-reported quality of life of the full sample and the individual age groups, at all assessments

\begin{tabular}{lllll}
\hline & $\begin{array}{l}\text { Full sample } \\
(n=209)\end{array}$ & $\begin{array}{l}5-7 \text { years } \\
(n=57)\end{array}$ & $\begin{array}{l}8-11 \text { years } \\
(n=78)\end{array}$ & $\begin{array}{l}12-16 \text { years } \\
(n=74)\end{array}$ \\
\hline Assessment 1 & $81.66(9.46)$ & $82.80(7.73)$ & $80.28(9.21)$ & $82.24(10.79)$ \\
\hline Assessment 2 & $84.77(9.72)$ & $84.39(8.37)$ & $83.89(11.23)$ & $85.99(8.95)$ \\
\hline Assessment 3 & $79.77(9.83)$ & $75.66(8.54)$ & $79.75(10.81)$ & $82.95(8.51)$ \\
\hline Assessment 4 & $79.04(9.52)$ & $76.81(9.93)$ & $79.03(9.46)$ & $80.76(9.02)$ \\
\hline
\end{tabular}

Table 3.

Estimates of fixed effects and standard errors of self-reported quality of life between the assessments (1-2; 2-3; 3-4) and over 1.5 years (assessment 1-4)

\begin{tabular}{lllll}
\hline & Assessment 1-2 & Assessment 2-3 & Assessment 3-4 & Assessment 1-4 \\
\hline Full sample & $3.11(0.69)^{* *}$ & $-5.00(0.63)^{* *}$ & $-0.73(.59)$ & $-2.62(0.62)^{* *}$ \\
\hline 5-7 years & $1.59(1.24)$ & $-8.73(1.20)^{* *}$ & $1.14(1.27)$ & $-5.99(1.31)^{* *}$ \\
\hline 8-11 years & $3.61(1.19)^{*}$ & $-4.14(1.13)^{* *}$ & $-0.72(0.82)$ & $-1.25(0.90)$ \\
\hline 12-16 years & $3.75(1.08)^{* *}$ & $-3.04(0.93)^{* *}$ & $-2.19(0.84)^{*}$ & $-1.48(1.01)$ \\
\hline
\end{tabular}

${ }^{*} p<.05,{ }^{* *} p<.001$

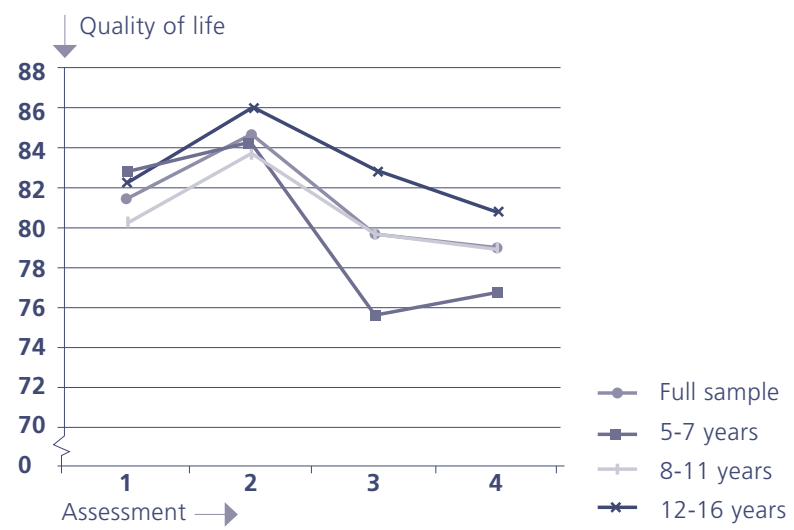

Figure 2. Quality of life of the full sample and the individual age groups at all assessments 
factors to be associated with children's self-reported quality of life over time: age of the child (Est. $0.82(0.20) ; p=.000)$, perceived stress (Est. $-0.71(0.05)$; $p=.000$ ), self-esteem (Est. $2.80(0.68) ; p=.000)$, and one of the dimensions of parental quality of life, viz. constraint due to emotional problems (Est. 0.02 $(0.01) ; p=.006)$. Results suggest that older age of the child, less stress perceived by the child, higher self-esteem perceived by the child, and less parental constraint due to emotional problems were associated with higher self-reported quality of life of the maltreated children. No interaction effects with the age of the child were found for any of the factors.

\section{Discussion}

\section{Quality of life outcomes over time}

The primary aim of this study was to examine the course of the self-reported quality of life of maltreated children over a 1.5-year period after they had been reported to an AMK. Results showed a significant increase in quality of life between the time the AMK became involved and the follow-up after 6 months, followed by a significant decrease between the 6-months and 1-year follow-up assessments. This decrease persisted, though not significantly, between the assessments at 1 and 1.5 years after the AMK became involved. Overall, results were the same for the three age groups (5-7, 8-11, 12-16 years). The oldest age group (12-16 years) had the highest quality of life over time, followed by the group aged 8-11 years, and the lowest quality of life outcomes were found for the youngest children (5-7 years). An explanation for the oldest age group showing the highest quality of life may be that as children grow older, they have more access to resources and social support outside the family, and they become less dependent on care from their parent(s), which may increase their well-being (Helsen, Vollebergh, \& Meeus, 2000; Ravens-Sieberer et al., 2006; Wallander et al., 2001).

There are several possible explanations for the temporary increase in quality of life at the 6-months follow-up assessment, and the decrease in quality of life after that. First, the increase during the first 6 months may be caused by children's feelings of hope that their situation will improve after the report to the AMK. The decrease in quality of life after 6 months might indicate that this hope gradually fades again. Second, since child maltreatment may be caused by poor parenting (Scannapieco \& Connell-Carrick, 2005), it is possible that the report to the AMK has alarmed the parents, resulting in better parenting and less maltreatment for a short while. If we assume this to be the case, the 
subsequent decrease in quality of life may indicate that parents are not able to retain their better parenting habits over an extended time period.

A third possible explanation is response shift. Response shift refers to a change in initial standards or values, and may occur when self-reports are used to collect data on quality of life. These changes are not caused by the intervention, in our case the AMK involvement, but by a change of reference framework. For example, the report to the AMK may have caused children to understand that their situation was abusive, and may have induced them to compare their situation with that of friends. As a result of this process of adopting new viewpoints, children's perception of their quality of life may have changed over time after the first assessment (Brossart, Clay, \& Willson, 2002; Schwartz, Feinberg, Julinskaia, \& Applegate, 1999).

For a better understanding of our quality of life findings over time and possible differences between subgroups, it is crucial to know if the maltreatment has ended permanently. The AMK does implement a follow-up assessment after three months, but the records of these assessments were not examined for the present study. Additional analysis of AMK records would enable us to answer questions such as whether there are differences in quality of life between children for whom maltreatment has ended and children for whom maltreatment continues, and whether the quality of life of maltreated children is associated with different types of child and family support provided. Possible explanations could also be derived from knowing what kind of interventions were recommended after the AMK became involved, and if the interventions were successful. This was, however, beyond the scope of this study.

\section{Factors associated with quality of life outcomes over time}

The secondary aim of this study was to explore various child factors, family/ environmental factors and parental factors in relation to the self-reported quality of life of maltreated children over time. Three child factors and one parental factor were associated with quality of life. First, our results showed that older age of the child was associated with higher quality of life over time. The findings regarding our primary research question (Figure 2) also confirmed this association. Yet, other studies found older age to be associated with lower quality of life (Michel, Bisegger, Fuhr, \& Abel, 2009; Ravens-Sieberer, Erhart, Gosch, Wille, \& European KIDSCREEN Group, 2008). Those studies were, however, performed among non-maltreated children. It is possible that where child maltreatment is involved, older children are not as adversely affected as younger children because, as explained above, they are less dependent on care from their parents and have more access to support 
outside their family (Helsen et al., 2000; Wallander et al., 2001).

Other child factors associated with a higher quality of life over time were lower perceived stress and higher self-esteem. These findings were expected, as the relations between stress and quality of life and between self-esteem and quality of life have also been found in several other studies (e.g. Gaspar et al., 2012; Marriage \& Cummins, 2004). The present study suggests that these findings can be generalized to maltreated children reported to an AMK. We did not find an association between children's perceived social support and quality of life, which is a relation that was found in prior studies with non-maltreated children (Gaspar et al., 2012). It is possible that perceived social support is not as relevant to the quality of life of maltreated children, or that it is not as relevant to changes in quality of life over time.

The only parental factor that was found to be associated with children's quality of life over time was one dimension of parental quality of life, viz. constraint due to emotional problems. Less parental constraint was associated with higher quality of life of maltreated children over time. There has been limited research into the association between parental distress and children's quality of life. Yoo and colleagues (2008) did, however, find parental distress to be associated with a risk of poor mental health in children, and they found a relation between parental distress and parent-child interaction. It is therefore likely that parental distress is also negatively associated with children's quality of life. Parental distress is a construct not identical to, but related to the construct of parental constraint that we studied.

An explanation for the absence of associations between the quality of life of maltreated children over time and other parental factors may be discrepancies in the way in which children and parents perceive their situations (Eiser \& Morse, 2001; Rajmil et al., 1999; Theunissen et al., 1998; Wallander et al., 2001). Some researchers even suggest that this discrepancy may be more prevalent in the case of maltreatment (Corso \& Lutzker, 2006; Prosser \& Corso, 2006). Parents and children in our study reported on the same family situation, but each from their own perspective. Another explanation may be that parents may be alarmed by the report to the AMK, and may therefore want to prove that they have their family situation under control. Hence, social desirability may have influenced the parents' answers to the questionnaire (see also Baeten, LamersWinkelman, \& Winder, 2007).

We also examined family/environmental factors. Contrary to our expectations, we did not find a significant association between these factors, especially socioeconomic disadvantage, and the quality of life of maltreated children over time, although such a relation was found in prior studies (Drukker 
et al., 2003; Jirojanakul et al., 2003). This discrepancy with other studies may have been caused by the different ways of operationalizing socioeconomic disadvantage between the studies. Moreover, the other studies were performed in other countries, with different socioeconomic conditions, which may have affected findings. The Netherlands has a relatively good social safety net, meaning that families can receive social security payments, as well as income supplements and/or food aid. As a result, socioeconomic disadvantages in the Netherlands may cause less severe hardship/burden than in other countries.

\section{Limitations}

There are some limitations to this study. First, caution should be exercised regarding the generalizability of the findings for two reasons. In the first place, participants of this study were all maltreated children reported to an AMK. These findings cannot be generalized to maltreated children who were not reported to an AMK, which is still the majority of maltreated children in the Netherlands. A second threat to the generalizability of the findings was possible selection bias. Our non-response analyses found differences between our study sample and the AMK population regarding ethnicity, in that our study sample consisted of significantly fewer people of non-Dutch origin than the overall AMK population. Hence, our findings may not apply to children of non-Dutch origin. In addition, there were significant differences regarding two types of maltreatment: our sample comprised more cases of emotional neglect, and fewer cases in which emotional abuse was verified by the AMK. This difference may be explained by self-selection, since participation in this study was voluntary. Emotional neglect is characterized by the absence of sufficient parenting (Hildyard \& Wolfe, 2007). Parents may attribute the absence of appropriate pedagogical actions to external factors, such as socioeconomic disadvantages and poverty (Nelson, Saunders, \& Landsman, 1993; Schumacher, Smith Slep, \& Heyman, 2001), and may therefore feel less responsible, take the maltreatment report less personally, and be more willing to participate in this study. The lower percentage of emotional abuse cases may be caused by parents not recognizing themselves as eligible subjects. There is a thin line between emotional abuse and poor parenting, which leads to parental denial of child maltreatment in cases of emotional abuse (Wolfe \& Mclsaac, 2011). Another finding of the non-response analyses was a difference in the percentage of cases that were reported to child protection services by the AMK. This may also be caused by self-selection. In the Netherlands, the main reason to report a family to child protection services is because voluntary care is rejected. Considering that participation in this study was voluntary, it is likely that 
families that are open to AMK interventions were also more willing to participate in this study than families that refused the help suggested by the AMK. The lower proportion of cases reported to child protection services may, however, imply that the study sample comprised more cases of less severe and/or less chronic maltreatment, which may have affected the study results.

Second, there was substantial loss to follow-up. This was mainly caused by participants who could not be reached, presumably because they had moved, and by participants who indicated they had no time to complete the questionnaire. A drop-out analysis to examine the extent to which drop-out was selective showed that being of non-Dutch origin was associated with higher loss to follow-up. Although the quality of life of drop-outs was similar to that of completers, results should be interpreted with caution concerning families of non-Dutch origin.

Third, studying the quality of life among children by self-report is a relatively new approach in this field of research. Instrument development has so far applied to children the dimensions that have proved of interest for adults, but there is little research regarding the quality of life dimensions that should be addressed when children are the study subjects (Ravens-Sieberer et al., 2006; Wallander et al., 2001). The instrument used in the present study addressed the usual dimensions and we do not know whether dimensions that were not examined, such as life perspective or autonomy, may matter and if so, to what extent in the case of maltreatment. In addition, it is unknown whether dimensions such as physical quality of life are perceived in the same way by maltreated children and by non-maltreated children. Future research should focus on examining which dimensions need to be addressed when assessing quality of life in a sample of maltreated children (Mabugu et al., 2013).

Fourth, the study design precludes conclusions about causality. Nevertheless, a major strength of this study was the prospective nature, in which self-reported quality of life was studied over time after child maltreatment and in relation to associated factors.

\section{Conclusion and implications}

This study on the self-reported quality of life of maltreated children over the 1.5-year period following a report to an AMK showed an increase in quality of life the first 6 months after AMK involvement, followed by a decrease over the next year. Our findings indicate that future research should examine what care is provided for and utilized by maltreated children and their families, to help us understand these results. Moreover, the way in which quality of life develops over longer periods of time would also be of interest to future research. 
This study adds new knowledge about factors associated with the self-reported quality of life of maltreated children over time. Four factors were found to be associated with higher quality of life of these children: older age, higher self-esteem, lower perceived stress of the child, and one of the parental quality of life dimensions, viz. less constraint due to emotional problems.

The results are of interest to the AMKs, but also to other professionals working with maltreated children and to policy makers. Our results suggest that in order to increase the quality of life of maltreated children, interventions may have to focus on enhancing feelings of self-esteem and on preventing perceived stress. However, it is possible that factors are interrelated, e.g. that child maltreatment causes higher perceived stress, lower self-esteem and lower quality of life. In that case an intervention aiming at one of these factors may influence the other factors as well. Future research should focus on the interrelatedness of factors, as this will yield information that may help improve interventions for maltreated children.

More research is also needed on the parental and family/environmental factors for which the present study did not find an association with the quality of life of maltreated children over time. Due to some of the limitations discussed above, it would be premature to rule out an association between these factors and the quality of life of maltreated children over time. Studying these factors in more detail may not only yield new and interesting insights into their association with the quality of life of children after maltreatment, it may also show possible interrelations between factors. These insights may contribute to referrals to optimal care for maltreated children. 


\section{References}

Abidin, R. R. (1983). Parenting Stress Index: Manual, Administration Booklet, and Research Update. Charlottesville, VA: Pediatric Psychology Press.

Afifi, T. O., Murray, W. E., Cox, B. J., de Graaf, R., ten Have, M., \& Sareen, J. (2007). Child abuse and health-related quality of life in adulthood. The Journal of Nervous and Mental Disease, 195(10), 797-804.

Al-Fayez, G. A., Oheari, J. U., \& Gado, O. M. (2012). Prevalence of physical, psychological, and sexual abuse among a nationwide sample of Arab high school students: Association with family characteristics, anxiety, depression, self-esteem, and quality of life. Social Psychiatry and Psychiatric Epidemiology, 47, 53-66.

Baeten, P. (2009). Protocol van handelen- Bij vermoedens van kindermishandeling in relatie van afhankelijkheid en onvrijheid (Manual- How to act in case of suspected child maltreatment relating to dependence and restriction of freedom). Utrecht: MO Groep.

Baeten, P., Lamers-Winkelman, F., \& Winder, L. (2007) Kindspoor, vroegtijdige signalering en aanpak van geweld in gezinnen ('Kindspoor', early monitoring and approach of violence within families). Den Haag: Stichting Bureaus Jeugdzorg Haaglanden/Zuid-Holland.

Bell, A. (2007). Designing and testing questionnaires for children. Journal of Research in Nursing, 12, 461-471.

Brook, R. J., Ware, J. E., Davies-Avery, A., Stewart, A. L., Donald, C. A., Rogers, W. H., Williams, K. N., \& Johnston, S. A. (1979). Overview of adult health status measures fielded in RAND's Health Insurance Study. Medical Care, 15, 724-735.

Brossart, D. F., Clay, D. L., \& Willson, V. L. (2002). Methodological and statistical considerations for threats to internal validity in pediatric outcome data: Response shift in self-report outcomes. Journal of Pediatric Psychology, 27(1), 97-107.

Coghill, D., Danckaerts, M., Sanuga-Barke, E., Sergeant, J., \& ADHD European Guidelines Group (2009). Practitioner Review: Quality of life in child mental health - conceptual challenges and practical choices. Journal of Child Psychology and Psychiatry, 50(5), 544-561.

Corso, P. S., Edwards, V. J., Fang, X., \& Mercy, J. A. (2008). Health-related quality of life among adults who experienced maltreatment during childhood. American Journal of Public Health, 98(6), 1094-1100.

Corso, P. S., \& Lutzker, J. R. (2006). The need for economic analysis in research on child maltreatment. Child Abuse \& Neglect, 30, 727-738.

Crowley, M. J., \& Kazdia, A. E. (1998). Child psychosocial functioning and parent quality of life among clinically referred children. Journal of Child and Family Studies, 7(2), 233-251.

De Brock, A. J. L. L., Verhulst, A. A., Gerris, J. R. M., Veerman, J. W., \& Abidin, R. R. (2006). NOSI-R. Nijmeegse Ouderlijke Stress Index. Handleiding (Dutch Parenting Stress Index. Manual). Lisse: Harcourt.

Drukker, M., Kaplan, L., Feron, F., \& Van Os, J. (2003). Children's health-related quality of life, neighborhood socio-economic deprivation and social capital. A contextual analysis. Social Science \& Medicine, 57, 825-841.

Eiser, C., \& Morse, R. (2001). Can parents rate their child's health-related quality of life? Results of a systematic review. Quality of Life Research, 10, 347-357.

Engelen, V., Haentjens, M. M., Detmar, S. B., Koopman, H. M., \& Grootenhuis, A. (2009). Health related quality of life of Dutch children: Psychometric properties of the PedsQL in the Netherlands. BMC Pediatrics, 9, 68-75.

Euser, S., Alink, L. R. A., Pannebakker, F., Vogels, T., Bakermans-Kranenburg, M. J., \& Van IJzendoorn, M. H. (2013). The prevalence of child maltreatment in the Netherlands across a 5-year period. Child Abuse \& Neglect, 37(10), 841-851.

Fuchs, M. (2005). Children and adolescents as respondents. Experiments on question order, response order, scale effects and the effect of numeric values associated with the response options. Journal of Official Statistics, 21(4), 701-725. 
Gaspar, T., Ribeiro, J. P., Gaspar de Matos, M., Leal, I., \& Ferreira, A. (2012). Health-related quality of life in children and adolescents: Subjective well-being. The Spanish Journal of Psychology, 15(1), 177-186.

Gilbert, R., Widom, C. S., Browne, K., Fergusson, D., Webb, E., \& Janson, S. (2009). Burden of consequences of child maltreatment in high income countries. The Lancet, 373(9657), 68-81.

Gospodarevskaya, E. (2013). Post-traumatic stress disorder and quality of life in sexually abused Australian children. Journal of Child Sexual Abuse, 22(3), 277-296.

Harter, S. (1985). The Self-Perception Profile for Children. Revision of the Perceived Competence Scale for Children. Denver, CO: University of Denver.

Helsen, M., Vollebergh, W., \& Meeus, W. (2000). Social support from parents and friends and emotional problems in adolescence. Journal of Youth and Adolescence, 29(3), 319-335.

Herzer, M., Zeller, M. H., Rausch, J. R., \& Modi, A. C. (2011). Perceived social support and its association with obesity specific health-related quality of life. Journal of Developmental \& Behavioral Pediatrics, 32, 188-195.

Hildyard, K., \& Wolfe, D. (2007). Cognitive processes associated with child neglect. Child Abuse \& Neglect, 31, 895-907.

Hoefnagels, C., Meesters, C., \& Simenon, J. (2007). Social support as predictor of psychopathology in the adolescent offspring of psychiatric patients. Journal of Child and Family Studies, 16, 91-101.

Ingerski, L. M., Janicke, D. M., \& Silverstein, J. H. (2007). Brief report: Quality of life in overweight youth - The role of multiple informants and perceived social support. Journal of Pediatric Psychology, 32(7), 869-874.

Jeugdzorg Nederland. (2013). AMK cijfers in 2012 (AMK annual report 2012). Zalsman: Zwolle.

Jirojanukul, P., Skevington, S. M., \& Hudson, J. (2003). Predicting young children's quality of life. Social Science \& Medicine, 57, 1277-1288.

Jonson-Reid, M., Kohl, P. L., \& Drake, B. (2012). Child and adult outcomes of chronic child maltreatment. Pediatrics, 129, 839-846.

Jud, A., Landolt, M. A., Tatalias, A., Lach, L. M., \& Lips, U. (2013). Health-related quality of life in the aftermath of child maltreatment: Follow-up study of a hospital sample. Quality of Life Research, 22(6), 1361-1370.

Kraag, G., Meesters, C., Van Bekkum, C., Fekkes, M., Kok, G., \& Huijer Abu-Saad, H. (submitted). The Development of the MUSIC, a short questionnaire for the assessment of stress symptoms in preadolescents.

Leeb, R. T., Lewis, T., \& Zolotor, A. J. (2011). A review of physical and mental health consequences of child abuse and neglect and implications for practice. American Journal of Lifestyle Medicine, 5(5), 454-468.

Litzelman, K., Catrine, K., Gangon, R., \& Witt, W. P. (2011). Quality of life among parents of children with cancer or brain tumors: The impact of child characteristics and parental psychosocial factors. Quality of Life Research, 20, 1261-1269.

Mabugu, T., Revill, P., \& Van den Berg, B. (2013). The methodological challenges for the estimation of quality of life in children for use in economic evaluation in low-income countries. Value in Health Regional Issues, 2, 231-239.

Marriage, K., \& Cummins, R. A. (2004). Subjective quality of life and self-esteem in children: The role of primary and secondary control in coping with every day stress. Social Indicators Research, 66, 107-122.

Matza, L. S., Swensen, A. R., Flood, E. M., Secnik, K., \& Leidy, N. K. (2004). Assessment of health-related quality of life in children: A review of conceptual, methodological, and regulatory Issues. Value in Health, 7(1), 79-92.

Michel, G., Bisegger, C., Fuhr, D. C., \& Abel, T. (2009). Age and gender differences in health-related quality of life of children and adolescents in Europe: A multilevel analysis. Quality of Life Research, 18(9), 1147-1157. 
Mills, R., Scott, J., Alati, R., O'Callaghan, M., Najman, J. M., \& Strathearn, L. (2013). Child maltreatment and adolescent mental health problems in a large birth cohort. Child Abuse \& Neglect, 37(5), 292-302.

Nelson, K.E., Saunders, E.J., \& Landsman, M.J. (1993). Chronic child neglect in perspective. Social Work, 38(6), 661-671.

O'Brien, R. M. (2007). A caution regarding rules of the thumb for Variance Inflation Factors. Quality \& Quantity, 41, 673-690.

Prosser, L. A., \& Corso, P. S. (2007). Measuring health-related quality of life for child maltreatment: A systematic literature review. Health and Quality of Life Outcomes, 5, 42-52.

Rajmil, L., Fernandez, E., Gispert, R., Rue, M., Glutting, J. P., Plasencia, A., \& Segura, A. (1999). Influence of proxy respondents in children's health interview surveys. Epidemiology Community Health, 53, 38-42.

Ravens-Sieberer, U., Erhart, M., Wille, N., Wetzel, R., Nickel, J., \& Bullinger, M. (2006). Generic healthrelated quality-of-life assessment in children and adolescents. Methodological considerations. Pharmacoeconomics, 24(12), 1199-1220.

Ravens-Sieberer, U., Erhart, M., Gosch, A., Wille, N., \& European KIDSCREEN Group. (2008). Mental health of children and adolescents in 12 European countries - Results from the European KIDSCREEN Study. Clinical Psychology and Psychotherapy, 15, 154-163.

Ross, C. E., \& Mirowsky, J. (1999). Disorder and decay: The concept of measurement of perceived neighborhood disorder. Urban Affairs Review, 3(34), 412-432.

Scannapieco, M., \& Connell-Carrick, K. (2005). Focus on the first years: Correlates of substantiation of child maltreatment for families with children 0 to 4. Children and Youth Services Review, 27(12), 1307-1323.

Schumacher, J. A., Smith Slep A. M., \& Heyman, R. E. (2001). Risk factors for child neglect. Aggression \& Violent Behavior, 6, 231-254.

Snoeren, F., \& Hoefnagels, C. (2014). Measuring perceived social support and perceived stress in primary school children in the Netherlands. Child Indicators Research, 7(3), 473-486.

Snoeren, F., Hoefnagels., C., Evers, S. M. A. A., \& Lamers-Winkelman, F. (2013). Design of a prospective study on mental health and quality of life of maltreated children (aged 5-16 years after a report to an advice and reporting center on child abuse and neglect. BMC Public Health, 13, 942-952.

Schwartz, C. E., Feinberg, R. G., Julinskaia, E., \& Applegate, J. C. (1999). An evaluation of a psychosocial intervention for survivors of childhood cancer: Paradoxical effects of response shift over time. Psycho-oncology, 8, 344-354.

Theunissen, N. C. M., Vogels, T. G. C., Koopman, H. M., Verrips, G. H. W., Zwinderman, K. A. H., Verloove-Vanhorick, S. P., \& Wit, J. M. (1998). The proxy problem: Child report versus parent report in health-related quality of life research. Quality of Life Research, 7, 387-397.

Treffers, Ph. D. A., Goedhardt, A. W., Veerman, J. W., Van den Bergh, B. R. H., Ackaert, L., \& De Rycke, L. (2002). Handleiding Competentie Belevingsschaal voor Adolescenten (Manual for the Perceived Competence Scale for Adolescents). Lisse: Swets Test Publishers.

Van der Zee, K. I., \& Sanderman, R. (1993). Het meten van de algemene gezondheidstoestand met de Rand-36: een handleiding (Measuring general health with the RAND-36: A manual). Groningen: Noordelijk Centrum voor Gezondheidsvraagstukken.

Van Sonderen, E. (1993). Het meten van de social steun met de Sociale Steun Lijst-Interacties en Sociale Steun Lijst-Discrepanties (Measuring social support with the Sociale Support Scale-Interactions and the Social Support Scale - Discrepancies). Groningen: Noordelijk Centrum voor Gezondheidsvraagstukken.

Varni, J. W. (2008). Scaling and scoring of the pediatric quality of life inventory PedsQL. Lyon: Mapi Research Trust.

Veerman, J. W., Straathof, M. A. E., Treffers, Ph. D. A., Van den Bergh, B. R. H., \& Ten Brink, L.T. (2004). Competentiebelevingsschaal voor kinderen (Perceived Competence Scale for Children). Amsterdam: Harcourt Test Publishers. 
Villalonga-Olives, E., Rojas-Farreras, S., Vilagut, G., Palacio-Vieire, J. A., Valderas, J. M., Herdman, M., Ferrer, M., et al. (2010). Impact of recent life events on the health-related quality of life of adolescents and youths: The role of gender and life events typologies in a follow-up study. Health and Quality of Life Outcomes, 8, 71-80.

Wallander, J. L., Schmitt, M., \& Koot, H. M. (2001). Quality of life in children and adolescents: Issues, instruments, and applications. Journal of Clinical Psychology, 57(4), 571-585.

Wille, N., Badia, X., Bonsel, G., Burstrom, K., Cavrini, G., Devlin, N., Egmar, A., et al. (2010). Development of the EQ-5D-Y: A child-friendly version of the EQ-5D. Quality of Life Research, 19(6), 875-886.

Wolfe, D. A., \& Mclsaac, C. (2011). Distinguishing between poor/dysfunctional parenting and child emotional maltreatment. Child Abuse \& Neglect, 35(10), 802-813.

Yoo, Y. S., Popp, J., \& Robinson, J. (2014). Maternal distress influences young children's family representations through maternal view of child behavior and parent-child interactions. Child Psychiatry \& Human Development, 45, 52-64. 


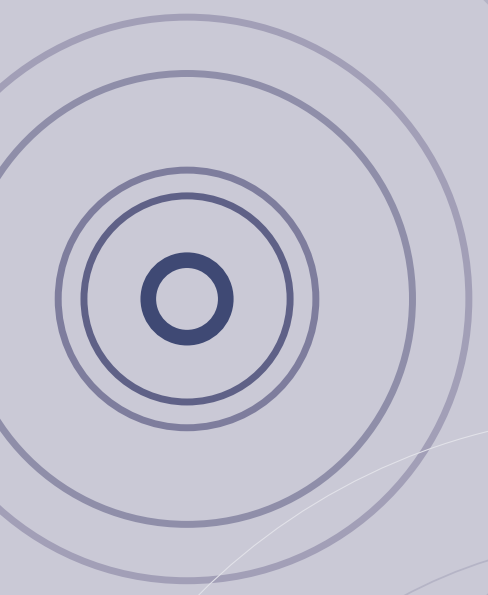




\section{Part III}

(a)

(a)

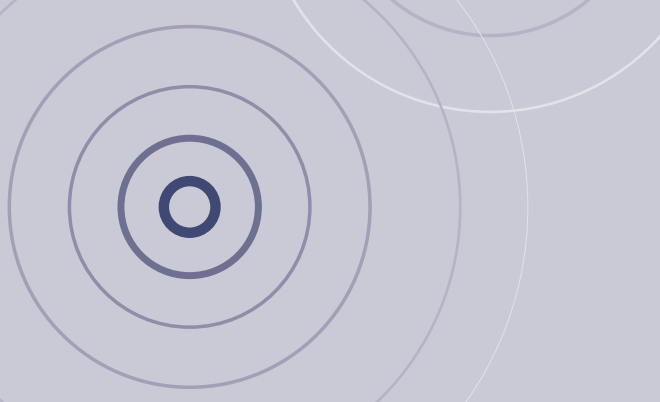




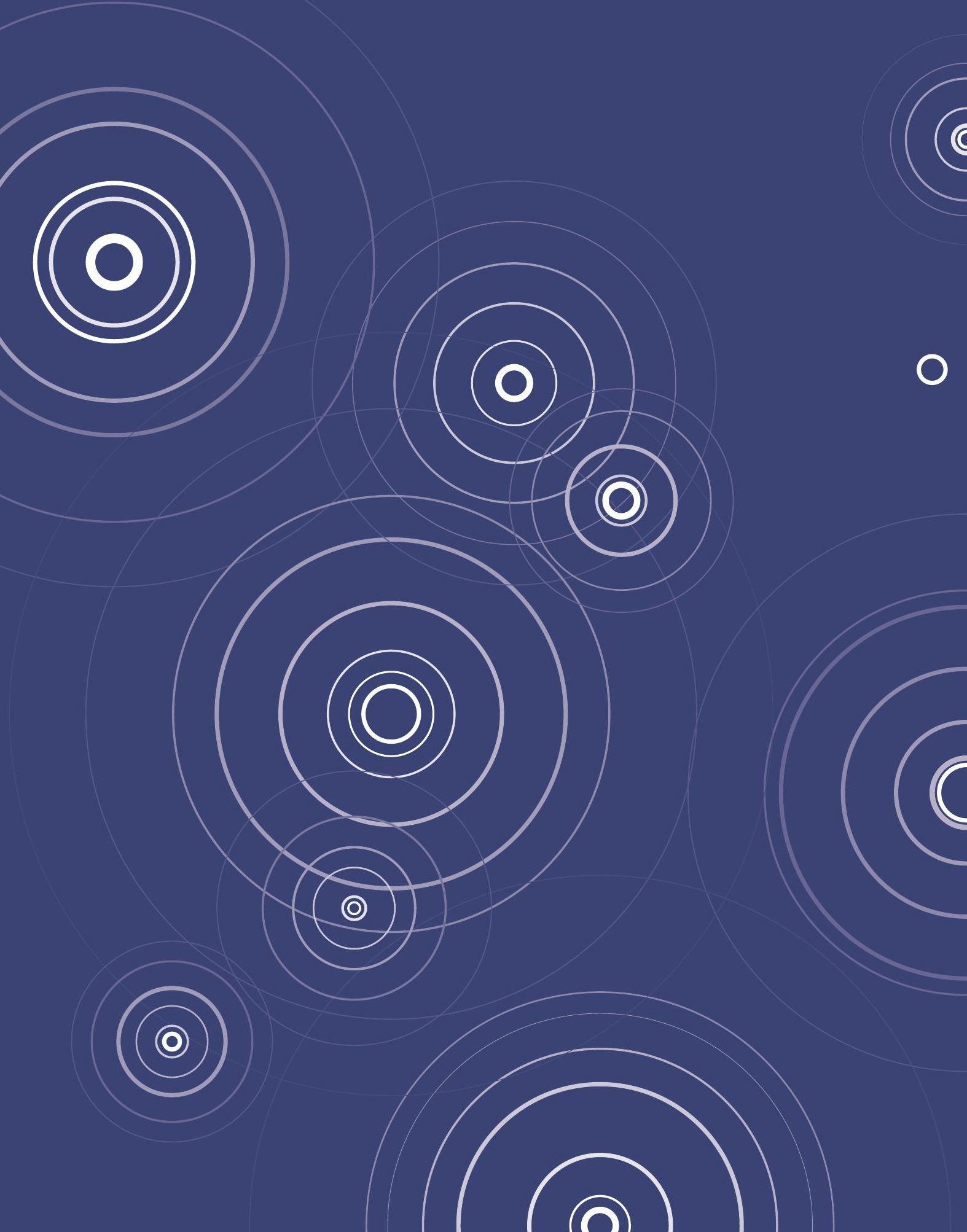




\section{O}

\section{CHAPTER 6}

Design of a quasi-experiment on the effectiveness and cost-effectiveness of using the child-interview intervention during the investigation following a report of child abuse and/or neglect

F. Snoeren, C. Hoefnagels, F. Lamers-Winkelman, P. Baeten \& S. M. A. A. Evers

Published in BMC Public Health (2013) 13, 1164-1171.

(2)

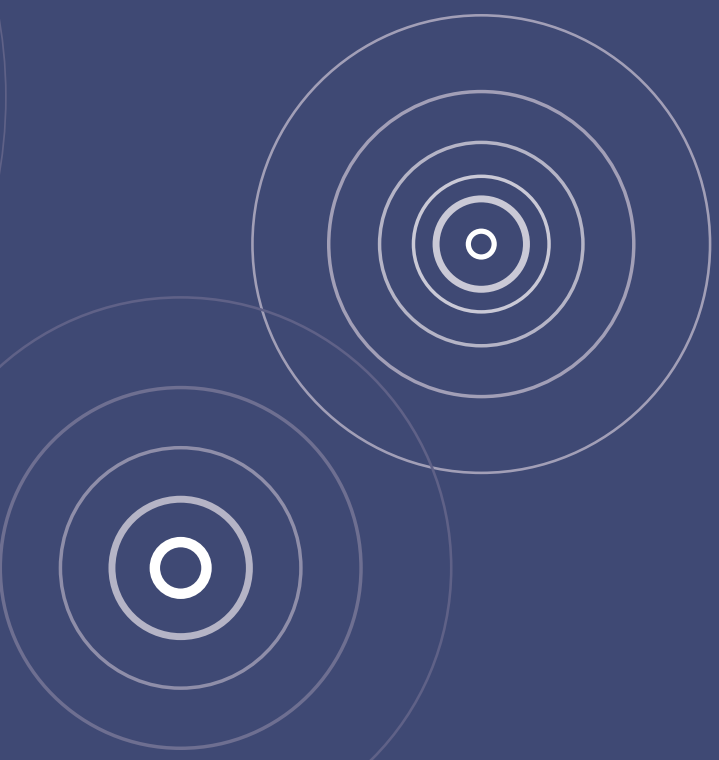




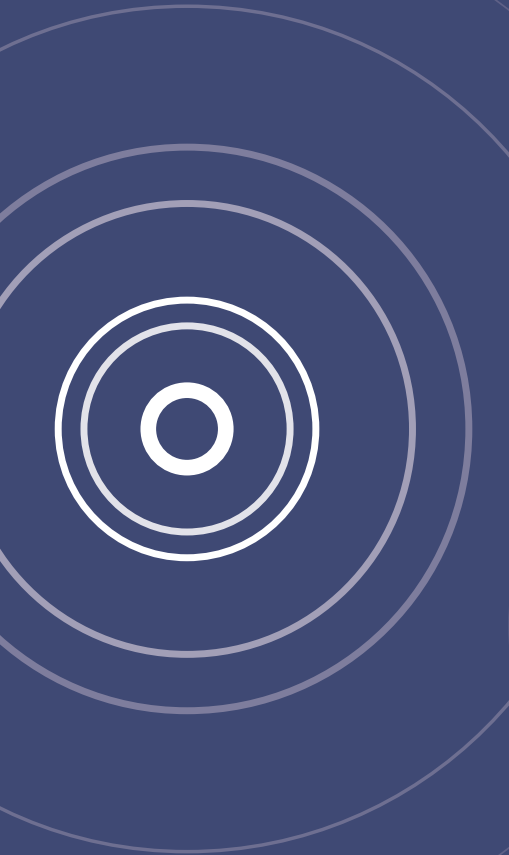

Abstract

Background: In the Netherlands, suspected cases of child maltreatment can be iepcrted to an advice and reporting center on child abuse and neglect (Advies- en Meldpunt Kindermishandeling or AMK). AMKs investigate these reports, screen for problems in the family and its surroundings and refer to child welfare. Over the last decades the focus of AMK investigations has changed from an adult-only approach to a more child-oriented approach using a child-interview intervention. The effects and cost-effectiveness of AMK involvement in the Netherlands have never been studied. The primary aim of this study is therefore to examine the effect of the participation of maltreated children (aged 6-18 years) in the child-interview intervention, on their mental health and quality of life. As a second aim, this study will examine the balance between additional costs and effects of the child-interview intervention in comparison with AMK investigation without the child-interview intervention (adult-only intervention).

Design/Methods: A quasi-experiment will be performed consisting of two post-intervention measurements of two nonequivalent groups: an intervention group, in which the child-interview intervention has been used during the AMK investigation, and a control group, in which the intervention has not been used (adult-only intervention). Participants from an ongoing prospective study on the mental health and quality of life of maltreated children after a report to an AMK, will be contacted to complete a questionnaire twice. Multivariate regression analyses will be used to determine effectiveness of the child-interview intervention. The economic evaluation will involve a cost-effectiveness analysis and a cost-utility analysis.

Results/Discussion: This will be the first study to examine the effect of AMK involvement in the Netherlands. Using the child-interview intervention during AMK investigation may prevent or reduce negative outcomes of child maltreatment, which may result in a lower consumption of healthcare and other services. In addition, the importance of economic evaluations is increasingly recognized, and economic evaluations about child maltreatment are scarce. Limitations include the risk of potential recall bias and selection bias.

Keywords: Child maltreatment, (Cost-)effectiveness, Economic evaluation, Quasi-experiment, Advice and reporting center on child abuse and neglect, Child-interview intervention 


\section{Background}

It is commonly known that child maltreatment has a huge impact on the lives of children and adults, as it is associated with both short- and long-term adverse life outcomes (Mills, Scott, Alati, O'Callaghan, Najman, et al., 2013; Leeb, Lewis, \& Zolotor, 2011). Studies have repeatedly shown the negative impact of child maltreatment on general and mental health (Dubowitz \& Bennett, 2007; Gilbert, Widom, Browne, Fergusson, Webb, et al., 2009; Nelson, Heath, Madden, Cooper, Dinwiddie, et al., 2002; Spriner, Sheridan, Kuo, \& Karnes, 2007) and quality of life (Afifi, Murray, Cox, De Graaf, Ten Have, et al., 2007; Al-Fayes, Oheari, \& Gado, 2012; Corso, Edwards, Fang, \& Mercy, 2008).

The prevalence of child maltreatment in the Netherlands in the 0-18 years age range has been estimated at 34 per 1,000 children in 2010 (Alink, Van IJzendoorn, Bakermans-Kranenburg, Pannebakker, Vogels, et al., 2011). In the Netherlands, suspected cases of child maltreatment can be reported to an advice and reporting center on child abuse and neglect (Advies- en Meldpunt Kindermishandeling or AMK), both by professionals and non-professionals, through a voluntary reporting system. The annual number of reports of suspected child maltreatment to these AMKs increased by $37.5 \%$ between 2006 and 2011 (Jeugdzorg Nederland, 2012; MOGroep Jeugdzorg, 2007). The AMKs investigate these reports and screen for problems in the family and its surroundings. If the report is substantiated, the AMK takes appropriate action, such as referring the child and family to child welfare and/or mental health organizations that can provide the necessary care. If voluntary care is rejected, the AMK can report the family to child protection services that can take court action or arrange the child to be placed in care outside the home. In case of substantiated violence, the AMK may file a report to the police (Baeten, 2009).

Over the last decades the focus of the AMK investigations has changed from an adult-only approach to a more child-oriented approach using a child-interview intervention. In the adult-only intervention, only adults, including parents, teachers and general practitioners, are asked to provide information to substantiate the alleged abuse. Children are not used as informants in this intervention, for two reasons: the belief that children could not provide reliable and accurate information and the belief that children should not be troubled with questions about maltreatment. Regarding the first reason, several studies have shown that children can be reliable informants (Everson \& Boat, 1989; Lamb, Orbach, Herschkowitz, Esplin, \& Horowitz, 2007; 
Patterson \& Pipe, 2009; Saywitz \& Camparo, 1998). The child-interview intervention includes children aged 6 years and over as informants in the AMK investigation, in addition to adult informants. The children are interviewed by an AMK employee. Just as in the adult-only intervention, the aim of this interview is to collect information on the alleged child maltreatment, the existence of any family problems, the child's needs for help and/or protection and the willingness to accept help and/or protection. An additional aim is to increase the child's sense of being in control. AMK workers have confirmed the value and relevance of this information provided by children. In their experience, the maltreated children can provide highly relevant information that is otherwise not retrieved and this child-interview intervention therefore results in potentially better tailored interventions.

Regarding the second reason, several studies have shown that talking about maltreatment experiences has positive effects on the children. These studies showed that talking about such experiences may be the start of the recovery process and may increase children's feelings of control and selfesteem (Black \& Ponirakis, 2000; Graham-Bermann, Kulkarni, \& Kanukollu, 2011; Palmer, Brown, Rae-Grant, \& Loughlin, 2000), whereas keeping maltreatment experiences a secret is associated with additional trauma (Hanson, Resnick, Kilpatrick, Saunders, Lipovsky, et al., 1992; Hebert, Tourigny, Cyr, McDuff, \& Joly, 2009). These findings suggest that the childinterview intervention is not only helpful for the referral to well-tailored care, but there are also benefits for the mental health and quality of life of these maltreated children. Nowadays all AMKs in the Netherlands have adopted the child-interview intervention and this is the preferred method according to the AMK manual (Baeten, 2009). Nevertheless, AMK records show that the adult-only intervention is still used in many AMK investigations. Little research has been done on the effects of specific AMK interventions (Solomon \& Asberg, 2013), and scientific evidence on the presumed superiority of this child-interview intervention in comparison to an adult-only intervention is lacking.

In addition, it is well documented that children who have been abused or neglected are more likely to experience adverse outcomes in a number of domains throughout their lives. This results in an increasing demand on multiple services, including healthcare, by both children and their families Solomon \& Asberg, 2013). Studies in the US have shown that substantial costs are associated with the impact of child maltreatment (Fang, Brown, Florence, \& Mercy, 2012; Fromm, 2001). In the Netherlands, Meerding (2005) estimated the economic burden of child maltreatment to be 965 million euros in 2003, 
which is about 138 euros per household annually. This was probably an underestimation, however, because the prevalence of child maltreatment in the Netherlands had not been studied yet and the estimates used were much lower than the recent prevalence rates reported by Alink and colleagues (2011).

Due to scarcity of resources, the importance of economic evaluation studies has been increasingly acknowledged over the last decade. These studies provide information on the impact of child maltreatment on society and the costs of its treatment, which will help identify cost-effective resources. This knowledge contributes to informed decisions on the funding of services and to policy improvements (Corso \& Fertig, 2010; Jones, Amaddeo, Barbui, \& Tansella, 2007). So far, however, economic evidence on child maltreatment is scarce (Corso \& Fertig, 2010; Corso \& Lutzker, 2006). Corso and colleagues performed two literature reviews (Corso \& Fertig, 2010; Corso \& Lutzker, 2006) and found that existing studies have focused mainly on cost of illness and do not include loss of quality of life. To our current knowledge, there have been five economic evaluations relating to child maltreatment, i.e. studies in which two or more interventions were analyzed in terms of the costs of effects. Three of these economic evaluations concerned prevention programs for parents (Barlow, Davis, McIntosh, Jarrett, Mockford, et al., 2007; Dalziel \& Segal, 2012; Maher, Corwin, Hodnett, \& Faulk, 2012). The other two studies focused on sexually abused children in secondary care (Gospodarevskaya \& Segal, 2012; McCrone, Weeramanthri, Knapp, Rushton, Trowell, et al., 2005). Economic evidence on the impact of child maltreatment and economic evaluations looking at interventions in this field have been scarce, especially in a Dutch context. The societal costs and effects of AMK involvement in the Netherlands have never been studied, even though AMKs have a pivotal function in stopping maltreatment, and thus in reducing its prevalence. Therefore, the primary aim of this study is to examine the effect of the participation of maltreated children aged 6-18 years in the AMK investigation (child-interview intervention) on their mental health and quality of life. As a second aim, this study will examine the balance between additional costs and effects of the child-interview intervention in comparison with AMK investigations without this intervention (adult-only intervention), from a societal perspective. 


\section{Design/methods}

\section{Study design}

To answer the research questions, a quasi-experiment will be performed in which respondents from an ongoing prospective study on the mental health and quality of life of maltreated children after a report to an AMK (Snoeren, Hoefnagels, Evers \& Lamers-Winkelman, 2013) will be asked to complete an additional questionnaire at follow-up assessments. The quasi-experiment will consist of two post-intervention assessments of two nonequivalent groups (intervention group and control group) (see Figure 1). The study sample of the prospective study consists of maltreated children and their primary caretaker. These parent-child dyads were recruited for participation in the prospective study during the AMK investigation following a report to an AMK. Based on information from AMK records, the study sample will be divided into two groups: an intervention group, in which the child-interview intervention was used during the AMK investigation, and a control group, in which the intervention was not used (adult-only intervention).

The gold standard for experimental and effectiveness and cost-effectiveness studies is a randomized controlled trial (RCT), in which participants are divided to two study groups based on random assignment. The Dutch Medical Ethics Committee for Mental Health Care (METiGG) did not approve of a RCT, because randomization might result in a parent-child dyad receiving a suboptimal approach (in this case the adult-only intervention), which the committee decided was not ethically acceptable in the case of vulnerable young children. Although evidence on the child-interview intervention is lacking, this is supported by Article 33 of the Declaration of Helsinki. This article states that it is not acceptable to withhold treatment/intervention when it is known that this treatment can be lifesaving or that abstinence might lead to irrecoverable damage to the subject (WMA, 2013).

While preparing for the study, however, we found from AMK records that although the child-interview intervention is the preferred method according to the AMK manual (Baeten, 2009), the child-interview intervention was not used during the investigation in a substantial number of AMK investigations. This enabled us to propose a quasi-experimental design in which an existing study sample (from the prospective study mentioned above) was divided into two groups based on the intervention they had received during the AMK investigation. Data collection for the quasi-experiment could be incorporated in this prospective study (Figure 1). This design would make it possible to answer the research questions without randomization, though a disadvantage 
of this design is the possibility of selection bias. The economic evaluation will involve a combination of a cost-effectiveness analysis (CEA) and a cost-utility analysis (CUA).

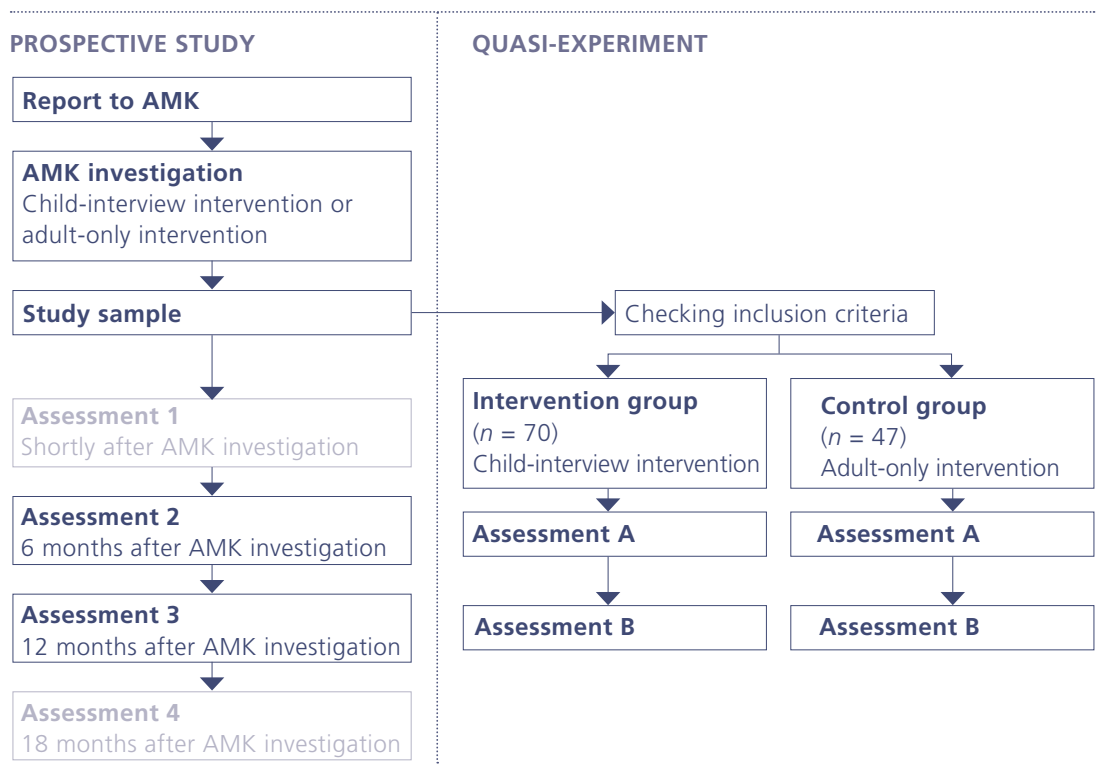

Note. Assessment 1 and 4 of the prospective study have no connection with the quasi-experiment

Figure 1. Flow chart of quasi-experimental study design

\section{Assessment}

This study will consist of two assessments: A and B (Figure 1). Assessment A will take place at the same time as assessment 2 of the prospective study (6 months after the AMK investigation). Assessment B will take place six months later, at the same time as assessment 3 of the prospective study (12 months after the AMK investigation).

At assessments $A$ and $B$, children and parents will be asked to complete a questionnaire. A member of the research team will meet the parent and child at a place of their choice (in most cases their own home) to assist them. The way in which the questionnaire is to be completed will be discussed with the parent and the child, and will depend on the participants' reading and writing skills. If reading and writing skills are poor, a research team member 
will read out the questions and write down the participant's answer on the questionnaire form. If reading and writing skills are sufficient, participants may choose to complete the questionnaire by themselves. To prevent the parents from influencing the children's answers, parents and children will be requested to complete their questionnaires in separate rooms. Respondents will be rewarded for their participation by a 10 euro gift voucher for the parents, the children will receive either a 5 euro gift voucher (children $>10)$ or an age-appropriate present (6-10 years).

\section{Target population}

The target population will consist of maltreated children aged between 6 and 18 years and their primary caretaker. Inclusion criteria are (1) a report to an AMK about physical and/or emotional abuse, physical and/or emotional neglect and/or sexual abuse, (2) one child per family. When a report relates to more than one child of the same family, the oldest child within the age range will be included, (3) sufficient verbal and cognitive capacities of both parent and child, as the study will use mainly self-report methods for data collection, and (4) no intention to leave the Netherlands within the next 6 months, in view of the follow-up period.

\section{Sample size and recruitment}

Participants from an ongoing prospective study on the mental health and quality of life of maltreated children after a report to an AMK (Snoeren et al., 2013) will be contacted to complete assessments A and B (see Figure 1). Parents and children will be asked to give written informed consent for their participation. Five dyads from the sample of this prospective study were excluded because they did not meet age criteria, while for 22 parent-child dyads maltreatment was not verified during the AMK investigation and for 17 dyads the type of maltreatment did not meet inclusion criteria of the quasiexperiment. Hence, the study sample for the present quasi-experiment will include 117 parent-child dyads. A sample size calculation confirmed that this is a sufficient number of participants. Based on the ability to detect a medium effect size or larger clinical effect (Cohen's $d>0.45$ ) (Lipsey \& Wilson, 1993) and tested at a conventional power of (1-beta) 0.80 and alpha of 0.05 (one-tailed testing), a total number of 110 parent-child dyads is required.

Supported by AMK records, this sample will be split up into two groups: an intervention group, in which the child-interview intervention was used during the AMK investigation, and a control group, in which the intervention was not used (adult-only intervention). 


\section{Child-interview intervention vs. adult-only intervention in AMK investigation}

All reports to an AMK are discussed in a multidisciplinary team meeting, which draws up a plan for the investigation. It is at this team meeting that the choice of AMK investigation with or without the child-interview intervention is made, based on information from the person who reported the alleged maltreatment.

AMK investigation without child-interview intervention. If the multidisciplinary team decides on AMK investigation without the intervention, only adults will be approached for information. The multidisciplinary team will decide which adults should be approached. Usually, the parents, teacher(s) and family doctor are part of this investigation, but other adults such as family members, social workers, therapists, or healthcare specialists can also be approached, depending on the social environment of the reported child/family. Information will be collected by phone, email or home visit.

AMK investigation including the child-interview intervention. In addition to information from adults (see above), the child and his/her siblings will be asked as informants. The child-interview intervention comprises the child being interviewed by an AMK employee. This interview takes place at the child's home or at school, in a separate room. The duration of the interview depends on the child's needs. The aim of the interview is for the AMK employee to discover if there are problems in the family or its surroundings, if the child needs care and what type of care would be suitable. An additional aim is to increase the child's sense of being in control.

The child-interview intervention used by the AMKs is part of the investigation to substantiate a report of suspected child maltreatment and to identify the needs for child and family care. It does not serve a forensic purpose.

\section{Outcome measures}

\section{(1) Effectiveness study}

Mental health. Children's mental health (in terms of internalizing and externalizing psychological problems) as observed by the parents, will be measured with the Dutch version of the Child Behavior Checklist (CBCL; Verhulst, Ende, \& Van der Koot, 1998). Parents will be asked to what extent they observe various behavioral and emotional problems in their child. The $\mathrm{CBCL}$ uses a 3-point scale and consists of 113 items. Internal consistency is good ( $a=.97$ ) (Verhulst et al., 1998).

Quality of life. Children's quality of life will be measured with one of three age-appropriate versions (5-7, 8-11, 12-18 years) of the Dutch translation of 
the Pediatric Quality of Life Inventory (PedsQL; Engelen, Haentjens, Detmar, Koopman, \& Grootenhuis, 2009). Children will be asked to express their concerns on the dimensions of physical health and psychosocial health, the latter consisting of the subdimensions of emotional functioning, social functioning and school functioning. The overall quality of life score will be obtained by adding up the scores on all dimensions. The PedsQL uses a 5-point scale (or a 3-point scale for the 5-7 version) and consists of 23 items. Internal consistency is good ( $a=.82-.85$ ) (Engelen et al., 2009).

\section{(2) Economic evaluation study}

Societal costs. Healthcare costs of the child and the family will be measured using an adapted version of the Trimbos Institute Medical Technology Assessment Cost Questionnaire for Psychiatry (TiC-P; Hakkaart-Van Roijen, Donker, \& Tiemens, 2002). This questionnaire will be completed by the parent. As the TiC-P is not completely suitable for this intervention, the TiC-P had to be adapted, using a bottom-up approach. In this procedure, AMK managers and AMK workers were asked to review the TiC-P for the purpose of studying a maltreated population and they were asked to add services that families that are reported to an AMK use regularly and that were missing from the TiC-P. This resulted in a suitable questionnaire to record societal costs of maltreated children and their families. The updated version of the TiC-P questionnaire included the following services: general practitioner, company doctor, first aid post at hospital, medical specialist at hospital, hospitalization (including general hospital, psychiatric hospital, rehabilitation center, university hospital), psychiatrist/psychologist/psychotherapist working at hospital, psychiatrist/psychologist/psychotherapist with private practice, physical therapist, alternative healer (e.g. homeopathy), self-help group therapy, child welfare service on outpatient basis, child welfare service as day care, child welfare service on inpatient basis, AMK, youth and family center, infant welfare center, regional public health service, home care, personal care budget (allocated by local government), social worker, school (including school doctor, compulsory education officer), police, probation service, addiction service, financial assistance, and lawyer/legal aid.

Costs will be valued on the basis of guideline prices derived from the updated Dutch manual for cost analysis in healthcare research (Hakkaart-Van Roijen, Tan, \& Bouwmans, 2010). As the guideline only includes healthcare costs, costs outside the healthcare sector will be valued separately.

Quality adjusted life years (QALYS). An increased quality of life is expressed as a utility value on a scale from 0 (death) to 1 (perfect quality of life). In health 
economics, utilities are combined with survival estimates and aggregated across individuals to generate quality adjusted life years (QALYS). A one-year increase in the duration of life (without change in quality of life), or an increase in quality of life from 0.5 to 0.7 utility units for five years, would both result in a gain of one QALY. Children's QALYs will be derived from a thermometer question. Children will be asked to answer the question: "On a scale from 1 to 10 , how healthy did you feel over the past 6 months?" The scores will be converted to utility scores by dividing by 10 , obtaining a score between 0.0 and 1.0 . The change in utility value between the two assessment points will be multiplied by the duration of the intervention effect to obtain the number of QALYs gained.

\section{Analyses}

Data will be analyzed according to the intention-to-treat principle. The similarity of baseline characteristics (socio-demographic characteristics, costs and outcomes) between the two AMK investigation interventions will be examined using univariate tests and Chi-square tests. Loss-to-follow up will be accounted for by imputing missing data using regression imputation.

\section{(1) Effectiveness study}

A multivariate regression analysis will be performed in which outcomes of mental health and quality of life will be compared between the child-interview intervention group and the control group (adult-only intervention). This will be done at follow-up (assessment B), 6 months after assessment A, which is a year after the intervention. Covariates will be taken into account.

\section{(2) Economic evaluation study}

In this study, additional costs and additional outcomes of the child-interview intervention will be compared with those of the adult-only intervention. The incremental cost-effectiveness ratio (ICER) will be expressed as the incremental costs per degree of improvement in mental health of the child-interview intervention group in comparison with the control group (adult-only intervention). The incremental cost-utility ratio (ICUR) will be expressed as the incremental costs per QALY of the child-interview intervention group in comparison with the control group (adult-only intervention).

The ICER (and ICUR) will be calculated using ICER $=(\mathrm{Ci}-\mathrm{CC}) /(\mathrm{Ei}-\mathrm{EC})$, where $\mathrm{Ci}$ is the annual total costs of the child-interview intervention, $\mathrm{Cc}$ the annual costs of the adults-only intervention, Ei the effect at 6-months follow-up for the child-interview intervention and Ec the effect at 6-months follow-up of the adult-only intervention. The robustness of the ICER will be checked by 
non-parametric bootstrapping (1000 times). The bootstrap replications will be used to calculate $95 \%$ confidence intervals around the costs. The bootstrapped ratios (ICER and ICUR) will be graphically presented in two ways: (1) plotted in a cost-effectiveness plane, in which the vertical line reflects the difference in costs and the horizontal line reflects the difference in effects, and (2) in a cost-effectiveness acceptability curve, showing the probability that the child-interview intervention is cost-effective based on a range of ceiling ratios (the maximum amount of money society is willing to pay to gain one extra unit of effect or a gain in QALY). Additionally, the robustness of the base-case findings will be assessed using a sensitivity analysis (Briggs, Wonderling, \& Mooney, 1997). This economic evaluation will be performed from a societal perspective. Bootstrapping will be carried out in Excel.

\section{Collaboration}

This study is a joint project of Trimbos-institute, the Netherlands Institute for Mental Health and Addiction (Utrecht), the CAPHRI School for Public Health and Primary Care, Maastricht University and VU University Amsterdam. The research is funded by the Netherlands Organisation for Health Research and Development (ZonMw) (project No. 15700.2012) and is registered in the Netherlands Trial Register, part of the Dutch Cochrane Centre (NTR3728). This study was approved by the Dutch Medical Ethics Committee for Mental Health Care (METiGG) in February 2012 (NL31267.097.10).

\section{Discussion}

The value of having children participate in the AMK investigations by using the child-interview intervention is increasingly being recognized. The intervention yields valuable information to substantiate the alleged maltreatment report, and the intervention is also expected to be beneficial for the mental health and quality of life of the maltreated children. However, this beneficial effect has not yet been studied. In addition, child maltreatment is associated with substantial societal costs because of the high demand for healthcare and other services by both the maltreated children and their families. Using the child-interview intervention may prevent or reduce negative outcomes of child maltreatment, which may result in a lower consumption of healthcare and other services.

Although the AMK manual suggests that using the child-interview intervention during AMK investigation is the preferred method, the AMKs in the Netherlands are still in a transition period as regards the nature of the 
investigation. From a small survey among AMKs we estimate that the adultonly intervention is still used in approximately $40 \%$ of all investigations by the AMKs. At this point in time, this enables us to answer the research questions by means of the proposed quasi-experimental design, before the child-interview intervention is fully adopted, as the percentage of cases in which the intervention is not used is still sufficient. We will be able to derive two study groups with acceptable sample sizes from an ongoing study examining the mental health and quality of life of children reported as being maltreated.

A strong point of the proposed study is the use of child self-reports to collect data on quality of life, one of the main outcome measures of the effectiveness study. Data on quality of life are often collected using proxies, but research findings show discrepancies between child and proxy reports (Eiser \& Morse, 2001). As a consequence, the value of obtaining children's self-reports is increasingly recognized and several studies have established the accuracy and reliability of child reports (Bell, 2007; Engelen et al., 2009; Eiser \& Morse, 2001; Fuchs, 2005).

Furthermore, not only will this be the first study to examine the effect of AMK involvement, it will also be the first economic evaluation performed in the Netherlands regarding an intervention for maltreated children. Since economic evaluations on child maltreatment have been scarce, it is expected that not all costs of healthcare and other services will be available yet. These costs will need to be valued for this study, so some of the costs will be based on estimates. Additionally, many aspects of utility measurement in children have not yet been fully developed. There is a lack of health state classification instruments that consider children's developmental stages, and there is a need to understand the role of proxies in assessing and valuing children's health (Griebsch, Coast, \& Brown, 2005). This is why we chose an alternative method: a visual analogue scale. The advantage of the thermometer method that will be used is that it is simple and therefore easily understood by children. However there are also disadvantages to this method, in that it generates values rather than utilities and does not involve an element of choice, nor decision-making under uncertainty, which may result in lower utility estimates.

A methodological concern for the quasi-experimental design of this study is the potential selection bias. All reports that are filed with the AMKs are discussed in a multidisciplinary team in which decisions about the best AMK investigation approach (child-interview intervention vs. adult-only intervention) are made. The choice of intervention is based on information collected from the reporter of the suspected child maltreatment. This reporter can be either a professional or non-professional (such as a neighbor), which may affect the 
quality and reliability of the information on which the multidisciplinary team must base their decision. In addition, AMK investigation using the child-interview intervention is the preferred method according to the manual for AMK investigations (Baeten, 2009). When the adult-only intervention is nevertheless chosen, there may be specific reasons for this, such as parents refusing their child's participation in the AMK investigation, the child having been seen by a therapist or social worker, in which case this professional is approached to prevent additional strain upon the child, and/or language barriers. As a result of these limitations, the two groups may not be comparable at baseline, causing a concern regarding internal validity.

Another limitation is the possible recall bias caused by the time that elapses between the assessment moments. A period of 3 months is generally used between assessments in economic evaluations. However, this study will use a period of 6 months because the assessment moments will be connected to those of the ongoing prospective study. Respondents may have difficulty remembering the exact number of times they used healthcare and other services, which may affect outcomes.

To conclude, within the constraints of ethical and legal standards, the quasi-experimental study design we chose is expected to provide information on the optimal approach for AMK investigation, in terms of effectiveness and cost-effectiveness. The aim of an AMK investigation is to refer the child and family to well-tailored care and to end substantiated maltreatment. The use of the child-interview intervention may contribute to the prevention of negative outcomes of child maltreatment, if using this intervention during the AMK investigation proves to result in better mental health and quality of life outcomes for maltreated children because well-tailored care can be provided on the basis of information that cannot be retrieved with the adult-only intervention. Policy makers are increasingly interested in the cost-effectiveness of methods being used, and cost-effectiveness studies are increasingly used in the development of new policies.

\section{Competing interests}

All authors declare that they have no competing interests.

\section{Authors' contributions}

All authors participated in describing the design of this study. FS drafted the manuscript. CH, FLW, PB and SMAAE contributed to the acquisition of funding for this study and participated in the writing of the manuscript by critically revising draft versions. All authors have read and approved the final manuscript. 


\section{References}

Afifi, T. O., Murray, W. E., Cox, B. J., de Graaf, R., ten Have, M., \& Sareen, J. (2007). Child abuse and health-related quality of life in adulthood. The Journal of Nervous and Mental Disease, 195(10), 797-804.

Al-Fayez, G. A., Oheari, J. U., \& Gado, O. M. (2012). Prevalence of physical, psychological, and sexual abuse among a nationwide sample of Arab high school students: Association with family characteristics, anxiety, depression, self-esteem, and quality of life. Social Psychiatry and Psychiatric Epidemiology, 47, 53-66.

Alink, L.R.A., van IJzendoorn, M.H., Bakermans-Kranenbrug, M.J., Pannebakker, F.D., Vogels, T., \& Euser, S. (2011). Kindermishandeling in Nederland anno 2010: De tweede Nationale Prevalentiestudie Mishandeling van Kinderen en Jeugdigen (NPM-2010) (Child maltreatment in the Netherlands in 2010: the second prevalence study of the maltreatment of children and adolescents in the Netherlands). Leiden: Casimir Publishers.

Baeten, P. (2009). Protocol van handelen- Bij vermoedens van kindermishandeling in relatie van afhankelijkheid en onvrijheid (Manual- How to act in case of suspected child maltreatment relating to dependence and restriction of freedom). Utrecht: MO Groep.

Barlow, J., Davis, H., Mclntosh, E., Jarrett, P., Mockford, C., \& Steward-Brown, S. (2007). Role of home visiting in improving parenting and health in families at risk of abuse and neglect: Results of a multicentre randomized controlled trial and economic evaluation. Archives of Disease in Childhood, 92(3), 229-233.

Bell, A. (2007). Designing and testing questionnaires for children. Journal of Research in Nursing, 12, 461-471.

Black, M. M., \& Ponirakis, R. (2000). Computer-administered interviews with children about maltreatment: Methodological, developmental, and ethical issues. Journal of Interpersonal Violence, 15(7), 682-695.

Briggs, A. H. , Wonderling, D. E., \& Mooney, C. Z. (1997). Pulling cost-effectiveness analysis by bootstrap: A non-parametric approach to confidence interval estimation. Health Economics, 6(4), 327-340.

Corso, P. S., Edwards, V.J., Fang, X., \& Mercy, J.A. (2008). Health-related quality of life among adults who experienced maltreatment during childhood. American Journal of Public Health, 98(6), 1094-1100.

Corso, P. S., \& Fertig, A. R. (2010). The economic impact of child maltreatment in the United States: Are estimates credible? Child Abuse \& Neglect, 34, 296-304.

Corso, P. S., \& Lutzker, J. R. (2006). The need for economic analysis in research on child maltreatment. Child Abuse \& Neglect, 30, 727-738.

Dalziel, K., \& Segal, L. (2012). Home visiting programmes for the prevention of child maltreatment: Cost-effectiveness of 33 programmes. Archives of Disease in Childhood, 97, 787-798.

Dubowitz, H., \& Bennett, S. (2007). Physical abuse and neglect of children. The Lancet, 369, 1891-1899.

Eiser, C., \& Morse, R. (2001). Can parents rate their child's health-related quality of life? Results of a systematic review. Quality of Life Research, 10, 347-357.

Engelen, V., Haentjens, M. M., Detmar, S. B., Koopman, H. M., \& Grootenhuis, A. (2009). Healthrelated quality of life of Dutch children: Psychometric properties of the PedsQL in the Netherlands. BMC Pediatrics, 9, 68-75.

Everson, M. D., \& Boat, B. W. (1989). False allegations of sexual abuse by children and adolescents. Journal of the American Academy of Child \& Adolescent Psychiatry, 28, 230-235.

Fang, X., Brown, D. S., Florence, C. S., \& Mercy, J. A. (2012). The economic burden of child maltreatment in the United States and implications for prevention. Child Abuse \& Neglect, 36, 156-165.

Fromm, S. (2001). Total estimated cost of child abuse and neglect in the United States: Statistical evidence. Chicago, IL: Prevent Child Abuse America. 
Fuchs, M. (2005). Children and adolescents as respondents. Experiments on question order, response order, scale effects and the effect of numeric values associated with the response options. Journal of Official Statistics, 21(4), 701-725.

Gilbert, R., Widom, C.S., Browne, K., Fergusson, D., Webb, E., \& Janson, S. (2009). Burden of consequences of child maltreatment in high income countries. The Lancet, 373, 68-81.

Gospodarevskaya, E., \& Segal, L. (2012). Cost-utility analysis of different treatments for posttraumatic stress disorder in sexually abused children. Child \& Adolescent Mental Health, 6, 15.

Graham-Bermann, S. A., Kulkarni, M. R., \& Kanukollu, S. (2011). Is disclosure therapeutic for children following exposure to traumatic violence? Journal of Interpersonal Violence, 26(5), 1056-1076.

Griebsch, I., Coast, J., \& Brown, J. (2005). Quality-adjusted-life-years lack quality in pediatric care: A critical review of published cost-utility studies in child health. Pediatrics, 115(5),e600-e608.

Hakkaart-van Roijen, L., Donker, M., \& Tiemens, B. (2002). Manual Trimbos/iMTA questionnaire for Costs associated with Psychiatric illness (TiC-P). Erasmus MC Rotterdam: Instituut voor Medische Technology Assessment.

Hakkaart-van Roijen, L., Tan, S. S., \& Bouwmans, C. A. M. (2010). Handleiding voor kostenonderzoek. Methoden en standaard kostprijzen voor economische evaluaties in de gezondheidszorg. Geactualiseerde versie 2010 (manual for costing in economic evaluation. Updated version 2010). Erasmus MC Rotterdam: Instituut voor Medische Technology Assessment.

Hanson, R. F., Resnick, H. S., Kilpatrick, D. G., Saunders, B. E., Lipovsky, J. A., \& Best, C. (1992). What factors are predictive of reporting of childhood sexual assault: are we just studying the tip of the iceberg? In Proceedings of the Ninth International Congress on Child Abuse and Neglect. Chicago, Illinois.

Hebert, M., Tourigny, M., Cyr, M., McDuff, P., \& Joly, J. (2009). Prevalence of childhood sexual abuse and timing of disclosure in a representative sample of adults from Quebec. Canadian Journal of Psychiatry, 54(9), 631-636.

Jeugdzorg Nederland. (2011). AMK cijfers in 2010 (AMK annual report 2010). Zalsman: Zwolle.

Jones, J., Amaddeo, F., Barbui, C., \& Tansella, M. (2007). Predicting costs of mental health care: A critical literature review. Psychological Medicine, 37(4), 467-477.

Lamb, M. E., Orbach, Y., Herschkowitz, I., Esplin, P. W., \& Horowitz, D. (2007). A structured forensic interview protocol improves the quality and informativeness of investigative interviews with children: A review of research using the NICHD investigative interview protocol. Child Abuse \& Neglect, 31, 1201-1231.

Leeb, R. T., Lewis, T., \& Zolotor, A. J. (2011). A review of physical and mental health consequences of child abuse and neglect and implications for practice. American Journal of Lifestyle Medicine, 5(5), 454-468.

Lipsey, M. W., \& Wilson, D. B. (1993). The efficacy of psychological, educational, and behavioral treatment. American Psychologist, 48, 1181-1209.

Maher, E. J., Corwin, T. W., Hodnett, R., \& Faulk, K. (2012). A cost-savings analysis of a statewide parenting education program in child welfare. Research on Social Work Practice, 22(6), 615-625.

McCrone, P., Weeramanthri, T., Knapp, M., Rushton, A., Trowell, J., Miles, G., \& Kolvin, I. (2005). Cost-effectiveness of individual versus group psychotherapy for sexually abused girls. Child \& Adolescent Mental Health, 10(1), 26-31.

132 childhood maltreatment). In Kindermishandeling: De politiek een zorg. Edited by Willems J, Baartman H, Bullens R. Amsterdam: SWP.

Mills, R., Scott, J., Alati, R., O'Callaghan, M., Najman, J. M., \& Strathearn, L. (2013). Child maltreatment and adolescent mental health problems in a large birth cohort. Child Abuse \& Neglect, 37(5), 292-302.

MOGroep Jeugdzorg (2007). Adviezen en meldingen over kindermishandeling in 2006 (AMK annual report 2006). Utrecht: Nederlands Jeugd instituut. 
Nelson, E.C., Heath, A.C., Madden, P.A.F., Cooper, L., Dinwiddie, S.H., Bucholz, K.K., ...Martin, N.G. (2002). Association between self-reported childhood sexual abuse and adverse psychosocial outcomes: Results from a twin study. Archives of General Psychiatry, 59(2), 139-145.

Palmer, S. E., Brown, R.A., Rae-Grant, N. I., \& Loughlin, M. J. (2000). Responding to children's disclosure of familial abuse: What survivors tell us. Child Welfare League of America, LXXVIII(2), 259-282.

Patterson, T., \& Pipe, M. (2009). Exploratory assessment of child abuse. Children's responses to interviewer's questions across multiple interview session. Child Abuse \& Neglect, 33, 490-504.

Saywitz, K., \& Camparo, L. (1998). Interviewing child witnesses: a developmental perspective. Child Abuse \& Neglect, 22(8), 825-843.

Snoeren, F., Hoefnagels, C., Evers, S. M. A. A., \& Lamers-Winkelman, F. (2013). Design of a prospective study on mental health and quality of life of maltreated children (aged 5-16 years) after a report to an advice and reporting center on child abuse and neglect. BMC Public Health, $13,942$.

Solomon, D., \& Asberg, K. (2012). Effectiveness of child protective services interventions as indicated by rates of recidivism. Child Youth Services Review, 34, 2311-2318.

Springer, K.W., Sheridan, J., Kuo, D., \& Carnes, M. (2007). Long-term physical and mental health consequences of childhood physical abuse: Results from a large population-based sample of men and woman. Child Abuse \& Neglect, 31(5), 517-530.

Verhulst, F.C., Ende, J. van der \& Koot, H.M. (1998). Handleiding voor de CBCL/4-18 18 (Manual Child Behavior Checklist/4-18). Rotterdam: Sophia Kinderziekenhuis, Erasmus MC.

World Medical Association (2013). Declaration of Helsinki. Ethical Principles for Medical Research Involving Human Subject. 64th WMA General Assembly in Fortaleza, Brazil: World Medical Association, Inc. 


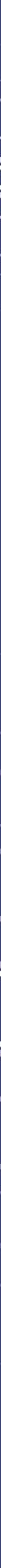




\section{O}

\section{CHAPTER 7}

Effect and economic evaluation of the child-interview intervention: The child as a participant in the investigation after a report of child maltreatment

F. Snoeren, C. Hoefnagels, F. Lamers-Winkelman, S.M.A.A. Evers

Submitted at BMC Public Health

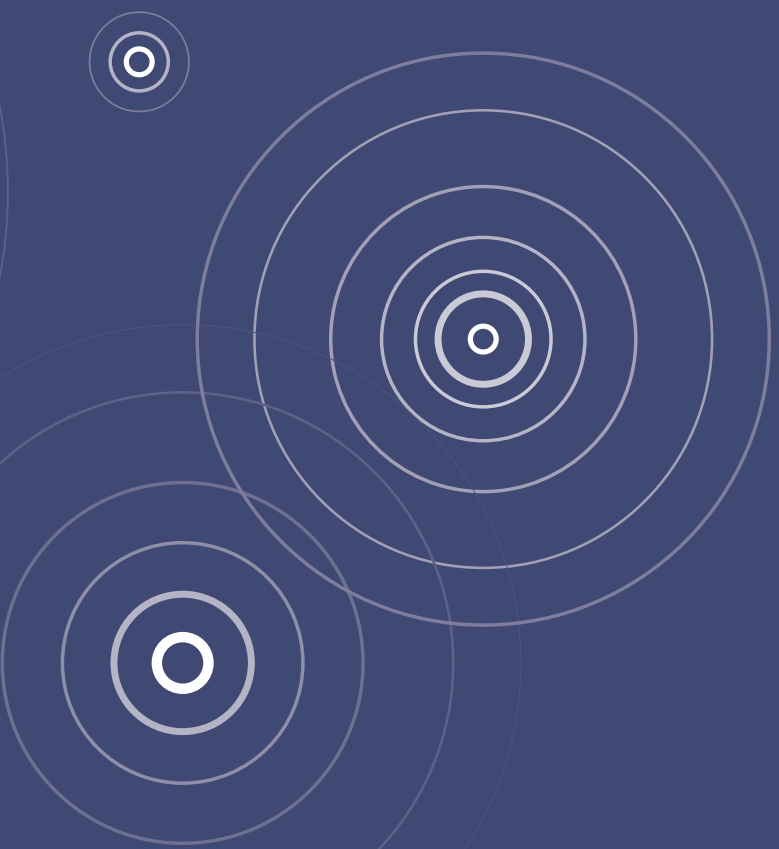




\section{Background}

It is well documented that children who have been abused or neglected are likely to experience adverse outcomes in a number of domains throughout their lives (Mills, Scott, Alati, O'Callaghan, Najman, et al., 2013; Leeb, Lewis, \& Zolotor, 2011). In the Netherlands, just as in other countries, suspicions of child maltreatment can be reported to an advice and reporting agency on child abuse and neglect: the Advies- en Meldpunt Kindermishandeling (AMK). After a child maltreatment report, the AMK collects information to either substantiate or disprove the report. This information is collected from the adults surrounding the child, including both of the parents, family member(s), and teacher(s), but the family doctor, social worker(s), therapist(s), or healthcare specialist(s) can also be approached. These days the child will also be asked for information. If the alleged maltreatment is verified, the AMK will take appropriate action, such as referral to family and child welfare and/or mental health organizations. If the family rejects voluntary care, the AMK can forward the report to child protection services for more compulsory action. Although the AMKs have been in place for decades, the effectiveness and cost-effectiveness of AMK interventions have not been studied yet.

Over the last decade, the focus of the AMK investigations has changed from and adult-only approach (Al intervention) to an approach that is more child-oriented ( $\mathrm{Cl}$ intervention). There are two main reasons for this shift from interviewing only adults to one in which the child also participates in the AMK investigation. First, studies have shown that children are able to provide reliable and accurate information (Lamb, Orbach, Herschkowitz, Esplin, \& Horowitz, 2007; Patterson \& Pipe, 2009). Second, it was formerly believed that children should not be troubled by asking them about the alleged maltreatment, since talking about previous experiences would mean additional trauma for the child. Several studies have shown the contrary: talking about maltreatment experiences may have a positive impact on children, because it may start the recovery process and may increase their self-esteem and feelings of being in control (Black \& Ponirakis, 2000; Graham-Bermann, Kulkarni, \& Kanukollu, 2011; Palmer, Brown, Rae-Grant, \& Loughlin, 2000). AMK workers have confirmed the value and relevance of the information provided by children. In their experience, the maltreated children can provide highly relevant information, which is otherwise not retrieved. Including this $\mathrm{Cl}$ intervention in the AMK investigation may therefore lead to better information to substantiate the report, which may result in better tailored child care.

Based on information about the suspected child maltreatment and 
circumstances of the child and family, the AMKs choose between two methods of investigation: the adult-interview intervention (Al intervention) or the child-interview intervention ( $\mathrm{Cl}$ intervention). The aims are the same for both interventions, i.e. the first aim of the interviews is to establish whether family members experience problems within or outside the family. Additionally, they explore the need for help and the willingness to accept help. In addition to these, the $\mathrm{Cl}$ intervention has a third aim: to give the child a sense of being in control and being understood (Baeten, 2009). The only difference is that in the $\mathrm{Al}$ intervention, only adults are interviewed to obtain information on the alleged maltreatment, while in the $\mathrm{Cl}$ intervention, both children (with a minimum age of six years) and adults are interviewed.

Nowadays the $\mathrm{Cl}$ intervention is the preferred approach for children aged six years and older according to the AMK manual (Baeten, 2009). However, AMK records show that the Al intervention is still used in about $40 \%$ of all child maltreatment investigations, and scientific evidence on the presumed superiority of this $\mathrm{Cl}$ intervention in comparison to $\mathrm{Al}$ intervention is lacking. Overall, there is a lack of studies on the effectiveness of interventions used in routine services of child protection, such as the Dutch AMKs (O'Brien, 2011; Tanaka, Jamieson, Wathen, \& MacMillan, 2010). The only existing studies (Trotter, 2008) have mainly limited themselves to analyzing registration data. They did not examine behavioral problems or quality of life as primary outcome measures of routine services interventions, although adverse effects of child maltreatment on behavioral problems and quality of life have been shown to be substantial (Afifi, Murray, Cox, De Graaf, Ten Have, et al., 2007; Corso, Edwards, Fang, \& Mercy, 2008; Dubowitz \& Bennett, 2007; Springer, Sheridan, Kuo, \& Carnes, 2007). This emphasizes the importance of comparing the effectiveness of the two above interventions. Therefore the first objective of this study was to examine the effectiveness of the $\mathrm{Cl}$ intervention in terms of the behavioral problems and quality of life of maltreated children (aged 6-18 years) in comparison with the Al intervention.

Additionally, the adverse outcomes of child maltreatment result in a high demand for multiple services, such as healthcare, social welfare, etc. by both children and their families (Solomon \& Asberg, 2012). Several studies in the United States have revealed the high costs associated with the consequences of child maltreatment (Fang, Brown, Florence, \& Mercy, 2012; Fromm, 2001). In the Netherlands, conservative estimates also indicate substantial costs caused by maltreatment. Meerding (2005) estimated the economic burden of child maltreatment to be 965 million euros in 2003, about 138 euros per household annually (Meerding, 2005). This estimate is assumed to be 
conservative, because the prevalence of child maltreatment in the Netherlands had not yet been studied when Meerding published his study, and the estimated prevalence rate he used $(50-80,000)$ was much lower than the prevalence rate of 118,000 (34 per 1,000) children found in a study from 2010 (Alink, Van IJzendoorn, Bakermans-Kranenburg, Pannebaker, Vogels, et al., 2011; Euser, Alink, Pannebaker, Vogels, Bakermans-Kranenburg, et al., 2013).

The current scarcity of financial resources and the high costs associated with the aftermath of child maltreatment emphasize the need for economic evaluations. Such evaluations can assist policy makers in their decision-making process, and cost-effective interventions reduce the economic burden to society. In 2006 and 2010, Corso and colleagues performed two literature reviews on economic analysis of child maltreatment (Corso \& Fertig, 2010; Corso \& Lutzker, 2006). These studies confirmed the scarcity of economic analysis regarding child maltreatment and emphasized the need for welldesigned economic evaluation studies and more focus on quality of life. To our knowledge, there have been five economic evaluations of child maltreatment interventions, i.e. studies in which two or more interventions were analyzed in terms of the costs of effects. Three of these economic evaluations concerned prevention programs for parents (Barlow, Davis, McIntosh, Jarrett, Mockford, et al., 2007; Dalziel \& Segal, 2012; Maher, Corwin, Hodnett, \& Faulk, 2012). The other two studies focused on sexually abused children in secondary care (Gospodarevskaya \& Segal, 2012; McCrone, Weeramanthri, Knapp, Rushton, Trowell, et al., 2005). We did not find any studies in which the costs and effects of the involvement of advice and reporting agencies for child maltreatment, such as the Dutch AMKs, were studied. In addition to the effectiveness study, the current study therefore included the first economic evaluation of the Dutch $\mathrm{Cl}$ intervention compared to the $\mathrm{Al}$ intervention. The second objective of this study was to examine the balance between additional costs and effects of the $\mathrm{Cl}$ intervention used as part of the AMK investigation, in comparison with the Al intervention. The economic evaluation was performed from a societal perspective and consisted of both a cost-utility analysis and a cost-effectiveness analysis.

\section{Methods}

\section{Study design}

A quasi-experimental design consisting of three post-intervention assessments of two nonequivalent groups was performed (Figure 1). Unfortunately, ethical 
considerations prevented us from examining the respondents prior to the intervention, as this intervention is part of the AMK investigation which starts immediately after a report has been filed to the AMK. Delaying the start of the AMK investigation could result in ongoing child maltreatment, which is not acceptable. The preferred design for effectiveness studies and economic evaluations is a randomized controlled trial (RCT), in which subjects are assigned to either the experimental or control group by randomization. If randomization does not take place, this may result in two nonequivalent groups. The Dutch Medical Ethics Committee for Mental Health Care (METiGG) did not approve of an RCT in this case because they found it unacceptable to withhold treatment/intervention when it is assumed that this intervention (in this case the $\mathrm{Cl}$ intervention) can be lifesaving, or that abstinence might lead to irrecoverable damage to the subject (Article 33, WMA, 2013). In the case of an RCT, some of the subjects could receive the less favorable intervention (in this case the Al intervention) after being reported to an AMK. The METiGG therefore decided that this would not be acceptable in a study in which maltreated children are the subjects, but regarded a quasi-experiment as acceptable.

To enable us to conduct an effectiveness and economic evaluation, this study used data from an - at that time - ongoing prospective study on the behavioral problems and quality of life of maltreated children after a report to an AMK (Snoeren, Hoefnagels, Evers, \& Lamers-Winkelman, 2013), using a quasi-experimental setup. The effectiveness part of this study (objective 1) required no additional data. For the economic evaluation (objective 2), additional data on resource use were collected. For this reason, parent-child dyads who were participating in the abovementioned prospective study and who met the inclusion criteria of the present study were asked to complete an additional resource use questionnaire at two of the follow-up assessments, viz. 6 months and 12 months after the AMK investigation. Based on information from the AMK records, the sample of eligible participants was divided into two groups: a group in which the $\mathrm{Cl}$ intervention was used during the AMK investigation, and a group in which the Al intervention was used. This quasi-experiment was approved by METiGG in February 2012

\section{Target population and sample size}

The study sample consisted of maltreated children aged between 6 and 18 years and their primary caretaker, which in most cases was one of the parents. In some cases, the participating parent was the abuser. Unfortunately, records of abuse specifications beyond the type of maltreatment were not accessible 
to the researchers. To be eligible for the quasi-experiment, the alleged maltreatment had to be verified during the AMK investigation and the type of maltreatment had to be verified as involving physical abuse, emotional abuse, physical neglect, emotional neglect and/or sexual abuse.

Based on these criteria 117 parent-child dyads were eligible for this study. A sample size calculation confirmed that this was sufficient to study effects on behavioral problems and quality of life. Based on the ability to detect a medium effect size or a larger clinical effect (Cohen's $d>0.45)$ (Lipsey \& Wilson, 1993) and tested at a conventional power of (1-beta) 0.80 and an alpha of 0.05 (one-tailed testing), a total number of 110 parent-child dyads was required.

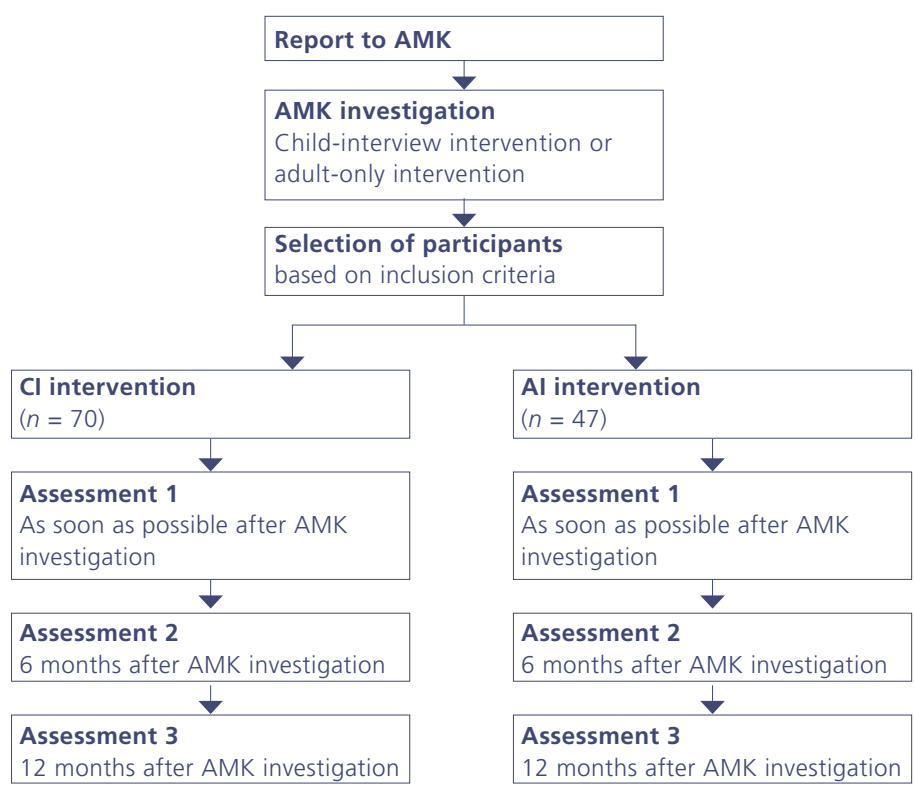

Figure 1. Flow chart of study design

\section{Assessment}

The study involved three assessments. Assessment 1 took place as soon as possible after the report to the AMK. Assessment 2 was done 6 months after the AMK investigation ( $\mathrm{Cl}$ intervention or $\mathrm{Al}$ intervention) and assessment 3 12 months after the AMK investigation (Figure 1). Data from all three 
assessments were used for the effectiveness study. The economic evaluation study used data from assessments 2 and 3, as these assessments retrospectively measured resource use over 6 months.

At all assessments, children and parents were asked to complete a questionnaire, each in a separate room to prevent them from influencing each other's answers. Prior to participation, parents and children were asked to give written informed consent. A research assistant was present to assist the participants, and he/she would meet the participants at a place of their choice, which in most cases was the home of the participants. For young children, or those whose reading and writing skills were poor, the member of the research team would read the questions out loud and write down the answers on the questionnaire form.

\section{Interventions}

This study compared two interventions: The adult-interview intervention (Al intervention) and the child-interview intervention ( $\mathrm{Cl}$ intervention). Both are used as part of the investigation following a child maltreatment report to an AMK. In the Al intervention, only adults are interviewed to substantiate the alleged child maltreatment. In an AMK investigation using the $\mathrm{Cl}$ intervention, both adults and children are interviewed to substantiate the alleged child maltreatment. Both interventions are initial interviews aiming to: (1) discover the existence of problems within and outside the family, (2) explore if the family needs help and is willing to accept help. The only difference between the interventions is that in the $\mathrm{Cl}$ intervention children also participate in the AMK investigation. The additional aim of the $\mathrm{Cl}$ intervention is to give the child a sense of being in control.

Al intervention. Information to substantiate the alleged child maltreatment is collected by interviewing adults only. When a report of suspected child maltreatment is filed with an AMK, it is discussed in a multidisciplinary team meeting, in which professionals discuss which adults to approach for information. Usually, both parents, the teacher(s) and the family doctor are included in this investigation, but other adults such as (adult) family members, social worker(s), therapist(s), or healthcare specialist(s) can also be approached, depending on the social environment of the reported child/family. Information is collected by the AMK employee by phone, email contact or in a home visit.

$\mathrm{Cl}$ intervention. Information to investigate the alleged child maltreatment is collected by interviewing both adults and children. As described above, a multidisciplinary team decides which adults to approach for information. In addition to these adult interviews, children aged six years and older are also 
interviewed by an AMK employee as part of the AMK investigation. The interview takes place at the child's home or at its school, in a separate room. The duration depends on the child's needs and varies from about twenty minutes to over an hour. Based on a small survey the estimated average time is 45 minutes. The $\mathrm{Cl}$ intervention as part of the AMK investigation does not serve a forensic or clinical purpose. By exploring the child's needs and by asking the child about its own experiences and wishes, the child interview contributes to referral to well-tailored care and it gives the child the feeling of being in control of its own situation.

\section{Outcome measures}

\section{(1) Effectiveness study:}

Behavioral problems. Children's behavioral problems were measured with the Dutch version of the Child Behavior Checklist (CBCL; Verhulst, Ende \& Van der Koot, 1998). Parents were asked to what extent, on a 3-point scale (0-1-2), they observed various problems in their child. The total score was obtained as the sum of the scores on all items. The CBCL consists of 113 items and has good internal validity $(a=.97)$ (Verhulst et al., 1998). Data on behavioral problems were collected at all assessments.

Quality of life. Children's quality of life was measured with the Dutch translation of the Pediatric Quality of Life Inventory (PedsQL; Engelen, Haentjens, Detmar, Koopman, \& Grootenhuis, 2009). Three age-appropriate versions (5-7, 8-11, 12-18 years) were used. The PedsQL consists of four subdimensions: physical functioning, emotional functioning, social functioning and school functioning. Children were asked to express their concerns on these dimensions on a 5-point scale (or a 3-point scale for the 5-7 version). Items were reverse-scored and linearly transformed to a $0-100$ scale $(0=100,1=$ $75,2=50,3=25,4=0$ ). The total quality of life score was obtained by adding up the scores on all dimensions. The PedsQL consists of 23 items and the questionnaire has good internal consistency ( $a=.82-.85)$ (Engelen et al., 2009). Quality of life data were collected at all assessments.

\section{(2) Economic evaluation study:}

Societal costs. This economic evaluation was performed from a societal perspective, assessing AMK intervention costs, health care costs, and social welfare costs, as well as costs of the use of other services.

AMK intervention costs: The resource use related to the AMK investigation, including time spent on interviews and to document their outcomes. The $\mathrm{CI}$ 
intervention involves an additional child interview, which takes an average of about 3 hours (interview and documentation). The average costs of the Al intervention are 2,047 euros, and an additional 199.29 euros was valued for the $\mathrm{Cl}$ intervention, using the cost price for social work (Table 1).

Costs of resource use: Thorn and colleagues (2013) recommend adjusting an existing questionnaire to identify main costs because this method is less costly than developing a new questionnaire, and contributes to consistency across studies (Thorn, Coast, Cohen, Hollingworth, Knapp, et al., 2013). Information on resource use was therefore gathered with an adjusted version of the Trimbos Institute Medical Technology Assessment Cost Questionnaire for Psychiatry (TiC-P; Hakkaart-Van Roijen, Donker, \& Tiemens, 2002). A bottom-up approach was used to adjust the TiC-P so as to make it suitable to record resource use by maltreated children and their families. Experts and AMK employees were asked to review the TiC-P and to add services that families who are reported to AMKs use regularly and that were missing from the existing questionnaire. The services included in the adjusted questionnaire are listed in table 1. Parents were asked to report retrospectively if and how often (number of contacts) the family (child and/or other family members) had used each of the services over the last 6 months. Data on resource use were collected at assessments 2 and 3.

Table 1 presents standard cost prices (or estimates) for all services. The societal costs were calculated by multiplying the number of contacts by their standard cost price. Dutch guidelines for cost analysis were used, so the cost prices of health care use were derived from the Dutch manual for cost analysis in health care (Hakkaart-Van Roijen, Tan, \& Bouwmans, 2010). Other cost prices were based on a new costing manual by Drost and colleagues (2014), obtained from professional associations or based on assumptions (Table 1). All costs were estimated for the reference year 2013. Prices were indexed using the price index figures from Statistics Netherlands and are presented in euros.

Quality Adjusted Life Years (QALYs). QALYs are calculated by multiplying survival by utilities. Utility values range from 0 (death) to 1 (perfect healthrelated quality of life). In this study, we used a rating scale. At assessments 2 and 3, children were asked: "On a scale from 1 to 10, how healthy did you feel over the past 6 months?" Utilities were calculated by dividing these rating scale scores by 10 . Usually, the change in utility value between two assessment points is multiplied by survival to obtain the number of QALYS gained. Unfortunately, there were a lot of missing values (64\%) at assessment 2 , while the percentage of missing values was substantially lower (27\%) at 
assessment 3 . Since the correlation between the rating scale values for assessments 2 and 3 was strong for the children who completed the rating scale at both assessments $(r=.852 ; p<.000)$, we decided to use imputation according to the last-observation-carried-forward principle, which resulted in 91 values for assessment 3 ( $22 \%$ missing). To be able to perform the costutility analysis, we used these single rating scale values from assessment 3 to obtain a QALY estimate.

\section{Analyses}

All analyses were conducted according to the intention-to-treat principle. Loss-to-follow up was accounted for by replacing all missing values using regression imputation, performed in Stata version 12. Possible bias caused by loss-to-follow up was examined with an analysis in which people who dropped out were compared with the sample of completers on the following socio-demographic characteristics: age and gender of child and parent, ethnic background (Dutch vs. non-Dutch), living situation (comprising traditional family, single-parent family, shared parenthood, newly-formed family, other), parental education level, work status (employed vs, unemployed) and presence of financial problems. In addition, type of maltreatment as verified by the AMK was examined. Since many cases comprised more than one type of maltreatment, this characteristic was analyzed using dummy variables: physical maltreatment, emotional maltreatment, physical neglect, emotional neglect, sexual abuse. Independent samples t-tests were used for all continuous variables and Chi-square tests for the categorical variables.

Similarity of baseline characteristics between the $\mathrm{Cl}$ intervention and $\mathrm{Al}$ intervention groups regarding the above-mentioned socio-demographic and maltreatment characteristics was also studied prior to the analysis. Variables showing differences at baseline were taken into account in the analyses.

\section{(1) Effectiveness study:}

Analysis of outcomes

Differences in outcomes between the $\mathrm{Cl}$ intervention group and the $\mathrm{Al}$ intervention group were examined at assessment 1 (shortly after the child maltreatment report), assessment 2 (6 months after AMK investigation) and assessment 3 (1 year after AMK investigation) using multivariate regression analysis. Imputed outcomes in terms of behavioral problems and quality of life were regressed on the intervention dummy while taking into account variables for which differences at baseline were found. 
Table 1.

Mean number of contacts with service providers 0-6 months and 6-12 months after AMK investigation, and cost price per contact (indexed for 2013)

\begin{tabular}{|c|c|c|}
\hline & \multicolumn{2}{|c|}{$\mathrm{Cl}$ intervention group } \\
\hline & $0-6$ months & $6-12$ months \\
\hline Service provider & $M(S D)$ & $M(S D)$ \\
\hline AMK follow-up & $0.43(1.10)$ & $0.20(0.58)$ \\
\hline General practitioner & $2.02(3.24)$ & $1.96(2.74)$ \\
\hline Company doctor & $0.16(0.65)$ & $0.17(0.61)$ \\
\hline First-aid post at hospital & $0.18(0.65)$ & $0.12(0.44)$ \\
\hline Medical specialist at hospital & $0.83(3.24)$ & $0.60(1.21)$ \\
\hline $\begin{array}{l}\text { Hospitalization } \\
\text { (including general hospital, psychiatric } \\
\text { hospital, rehabilitation center, university } \\
\text { hospital) }\end{array}$ & $0.10(0.42)$ & $2.49(17.96)$ \\
\hline $\begin{array}{l}\text { Psychiatrist/ psychologist/ psychotherapist } \\
\text { working at hospital }\end{array}$ & $0.84(3.35)$ & $1.47(4.96)$ \\
\hline $\begin{array}{l}\text { Psychiatrist/ psychologist/ psychotherapist } \\
\text { with private practice }\end{array}$ & $1.36(3.50)$ & $2.11(5.33)$ \\
\hline Physical therapist & $1.32(7.31)$ & $0.80(3.47)$ \\
\hline Alternative healer (e.g. homeopathy) & $0.11(0.65)$ & $0.22(1.33)$ \\
\hline Self-help group therapy & $0.15(0.80)$ & $0.04(0.56)$ \\
\hline Child welfare service on outpatient basis & $2.41(5.82)$ & $1.82(4.54)$ \\
\hline Child welfare service as day care & $0.22(1.19)$ & $0.11(0.84)$ \\
\hline Child welfare service on inpatient basis & $0.20(1.67)$ & $0(0)$ \\
\hline Youth and family center & $0.15(0.98)$ & $0.16(0.73)$ \\
\hline Infant welfare center & $0.07(0.29)$ & $0.09(0.33)$ \\
\hline Regional public health service & $0.08(0.31)$ & $0.14(0.67)$ \\
\hline Home care & $0.36(2.87)$ & $0.86(5.78)$ \\
\hline Personal care budget (euros) & $7.10(28.68)$ & $1.69(14.10)$ \\
\hline Social work & $1.42(6.01)$ & $2.04(7.02)$ \\
\hline $\begin{array}{l}\text { School (including school doctor, compulso- } \\
\text { ry education officer) }\end{array}$ & $1.88(3.58)$ & $1.25(1.71)$ \\
\hline Police & $0.07(0.39)$ & $0.11(0.58)$ \\
\hline Probation service & $0.19(1.55)$ & $0.01(0.12)$ \\
\hline Addiction service & $0.05(0.27)$ & $0(0)$ \\
\hline Financial assistance & $0.20(0.84)$ & $0.24(0.98)$ \\
\hline Lawyer/legal aid & $1.35(4.39)$ & $1.37(4.38)$ \\
\hline
\end{tabular}


Al intervention group

\begin{tabular}{cccl}
$0-6$ months & $6-12$ months & & \\
$\boldsymbol{M}(\boldsymbol{S D})$ & $\boldsymbol{M}(\boldsymbol{S D})$ & Cost price $€$ & Assumptions \\
\hline $0.27(1.03)$ & $0.14(0.61)$ & $66.43^{\mathrm{a}}$ & Valued as social worker \\
\hline $3.51(7.82)$ & $2.79(3.94)$ & $27.59^{\mathrm{a}}$ & \\
\hline $0.02(0.15)$ & $0.07(0.44)$ & $22.96^{\mathrm{b}}$ & \\
\hline $0.35(0.86)$ & $0.35(0.67)$ & $154.32^{\mathrm{a}}$ & \\
\hline $1.45(3.73)$ & $1.73(3.69)$ & $73.58^{\mathrm{a}}$ & \\
\hline $3.43(14.35)$ & $1.84(8.78)$ & $444.57^{\mathrm{a}}$ & Valued as general hospital
\end{tabular}

\begin{tabular}{|c|c|c|c|}
\hline $1.10(3.83)$ & $0.84(2.06)$ & $73.58^{a}$ & $\begin{array}{l}\text { Valued as medical } \\
\text { specialist in hospital }\end{array}$ \\
\hline $0.68(1.71)$ & $0.79(2.16)$ & $81.76^{a}$ & \\
\hline $1.83(5.32)$ & $1.41(4.37)$ & $36.79^{a}$ & \\
\hline $0.28(1.48)$ & $0(0)$ & $59.61^{b}$ & \\
\hline $0.13(0.65)$ & $0.06(0.44)$ & $12.78^{a}$ & Valued as informal care \\
\hline $1.57(4.39)$ & $2.05(7.06)$ & $174.76^{\mathrm{a}}$ & \\
\hline $0.18(1.17)$ & $0.63(3.05)$ & $157.39^{a}$ & \\
\hline $0.00(0.08)$ & $0.06(0.44)$ & $237.10^{\mathrm{a}}$ & \\
\hline $0.22(0.78)$ & $0.04(0.20)$ & $66.43^{a}$ & Valued as social worker \\
\hline $0.18(0.56)$ & $0.30(1.08)$ & $58.25^{\mathrm{a}}$ & Valued as nurse \\
\hline $0.15(0.51)$ & $0.11(0.43)$ & $58.25^{\mathrm{a}}$ & Valued as nurse \\
\hline $1.35(5.24)$ & $2.63(11.53)$ & $35.77^{a}$ & Rate per hour \\
\hline $87.58(583.17)$ & $1.81(11.66)$ & & $\begin{array}{l}\text { Tariff is allocated by local } \\
\text { government }\end{array}$ \\
\hline $1.94(5.94)$ & $3.25(7.51)$ & $66.43^{a}$ & \\
\hline $1.85(3.16)$ & $1.77(3.31)$ & $30,0^{c}$ & Valued as tutoring \\
\hline $0.09(0.35)$ & $0.04(0.20)$ & $32.16^{c}$ & \\
\hline $0.55(3.51)$ & $0(0)$ & $32.16^{c}$ & \\
\hline $0.51(3.50)$ & $0.04(0.29)$ & $164.76^{a}$ & $\begin{array}{l}\text { Valued as welfare service } \\
\text { on outpatient basis }\end{array}$ \\
\hline $0.32(1.25)$ & $0.34(1.08)$ & $66.43^{a}$ & Valued as social worker \\
\hline $0.66(1.37)$ & $0.26(0.56)$ & 572 & Fee for legal aid lawyer \\
\hline
\end{tabular}

c Drost, R. M. W. A., Paulus, A. T. G., Ruwaard, D., \& Evers, S. M. A. A. (2014). Handleiding intersectorale kosten en baten van (preventieve) interventies: Classificatie, Identificatie en Kostprijzen (Manual for costs and benefits of (preventive) interventions: Classification, Identification and Cost prices). Maastricht: Universiteit Maastricht/Health Services Research, CAPHRI. 


\section{(2) Economic evaluation study:}

\section{Analysis of societal costs}

The total societal costs of the $\mathrm{Cl}$ and $\mathrm{Al}$ intervention groups, 1 year after the AMK investigation, were calculated by adding up the costs at assessments 2 and 3. The relevance of differences in costs at assessment 2 (0-6 months), assessment 3 (6-12 months) and total societal costs was examined by means of non-parametric bootstrapping (1,000 times).

\section{Cost-utility analysis}

Differences in QALYs between the $\mathrm{Cl}$ and $\mathrm{Al}$ intervention groups were examined using an independent samples t-test. To examine the cost-utility of the $\mathrm{Cl}$ intervention, an Incremental Cost-Utility Ratio (ICUR) was calculated, in which the additional intervention costs were divided by the difference in QALYs between the two groups. The ICURs expressed the incremental costs (or savings) per QALY gained of the $\mathrm{Cl}$ intervention group relative to the $\mathrm{Al}$ intervention group. In order to assess sampling uncertainty, the robustness of the ICUR was checked using non-parametric bootstrapping (5,000 times).

The comparisons of the bootstrapped simulated ICURs are presented in a cost-utility plane, with differences in costs on the vertical axis and QALYs gained on the horizontal axis. If the majority of estimates appear in the north-west quadrant of the plane, this means that the $\mathrm{Cl}$ intervention results in a loss of QALYs against additional costs compared to the Al intervention. The $\mathrm{Cl}$ intervention would then be inferior from an economic perspective. If the majority of the estimates appear in the south-east quadrant, this means that the $\mathrm{Cl}$ intervention results in QALYs gained against less costs than the $\mathrm{Al}$ intervention, which indicates that the $\mathrm{Cl}$ intervention is dominant. If the majority of the estimates appear in one of the other quadrants, the additional costs or savings have to be weighed against QALYs lost or gained. Interpreting the ICURs in the north-east quadrant and the south-west quadrant requires willingness-to-pay (WTP) thresholds. If the ICUR is below the threshold, the intervention is acceptable from an economic point of view. The Dutch Council for Public Health and Health Care has shown that a range of thresholds of WTP between 12,000 and 80,000 euros (Council for Pulbic Health and Health Care, 2006) for a utility is acceptable, depending on the seriousness/significance of the health state/illness that the intervention targets. There is no literature on WTP for child maltreatment interventions. A threshold of 20,000 euros is commonly used if the exact threshold is not known. This threshold seems acceptable and may be somewhat low, considering the substantial adverse outcomes associated with child maltreatment and the relevance of this 
subject in Dutch politics/media. To show the likelihood that $\mathrm{Cl}$ intervention is cost-effective at different thresholds, we present a cost-effectiveness acceptability curve (CEAC) to show the probability that the $\mathrm{Cl}$ intervention is beneficial, given a varying threshold for the willingness to pay for each QALY gained. The CEACs are also based on bootstrapping.

\section{Cost-effectiveness analysis}

The cost-effectiveness analysis was performed following the same steps, except that improvement in behavioral problems/quality of life was used instead of QALYS, resulting in a cost-effectiveness ratio (ICER). In an economic evaluation, a high score reflects better functioning and a low score worse functioning. As a result, the $C B C L$ scores were reversed so that high scores corresponded with less behavioral problems. The ICERs expressed the incremental costs (or savings) per degree of improvement in behavioral problems/quality of life of the $\mathrm{Cl}$ intervention group relative to the $\mathrm{Al}$ intervention group. One degree of improvement corresponds with an increase of 1 point in behavioral problems/ quality of life outcome. Uncertainty was again assessed by non-parametric bootstrapping (5,000 times) and the simulated ICERs are presented in both a cost-effectiveness plane and an cost-effectiveness acceptability curve (CEAC).

\section{Sampling uncertainty and sensitivity analysis}

The robustness of the findings was examined by performing three sensitivity analyses. First, being of non-Dutch origin was a predictor of loss-to-follow up. As it is not known whether being of non-Dutch origin results in outcomes comparable to those of the Dutch sample, a subgroup analysis was performed in which separate ICERs were calculated for the Dutch subgroup and for the non-Dutch subgroup. The subgroup analysis related to behavioral problems and quality of life.

Second, the missing values on the rating scale for assessment 2 forced us to use an alternative method to obtain QALYs. As a result, the robustness of these QALYs was examined by calculating an additional ICUR for a subgroup with completers of the rating scale at assessment 3 only (before imputation). This ICUR was compared with the ICUR of the QALYs after imputation, which was used in the cost-utility study.

Third, although economic evaluations from a societal perspective are standard in the Netherlands, other countries use a health and social care perspective as a standard. We therefore performed a sensitivity analysis (on behavioral problems and quality of life) from a health and social care perspective. 
This analysis excluded resource use in other sectors than the health and social sector, in this case: school, police, probation service, financial assistance, and lawyer/legal aid.

\section{Results}

\section{Missing data}

At the third assessment, $17.1 \%$ of the data was missing. Missing data were mainly caused by participants who could not be reached, presumably because they had moved, and by participants who stated they had no time to complete the questionnaire. Analysis comparing participants who dropped out with completers showed that ethnicity was a predictor of loss-to-follow up (27.5\% loss-to-follow up in the non-Dutch origin group vs.10.8\% in the Dutch origin group). No other differences were found.

\section{Sample characteristics}

Table 2 presents the sample characteristics and similarity at assessment 1 of both the $\mathrm{Cl}$ intervention group and the $\mathrm{Al}$ intervention group. Significant differences between the groups were found for age of the child $(t=3.58$; $p=.001)$ and age of the parent $(t=2.82 ; p=.006)$. The ages of both child and parent were higher in the $\mathrm{Cl}$ intervention group. In addition, the employment rate was higher in the $\mathrm{Cl}$ intervention group (71.7\% vs. $50.0 \%)$ than in the $\mathrm{Al}$ intervention group. There were no significant differences at baseline between the groups on the other socio-demographic characteristics or the maltreatment characteristics.

\section{(1) Effectiveness study:}

Analysis of outcomes

Multivariate regression analyses were performed with behavioral problems and quality of life as dependent variables, regressed by the intervention dummy and including age of the child, age of the parent and work status of the parent as confounding variables. Results are presented in table 3. There were no significant differences between the $\mathrm{Cl}$ and $\mathrm{Al}$ intervention groups regarding behavioral problems or quality of life at any of the assessments. 
Table 2.

Sample characteristics and similarity at assessment 1 between the $\mathrm{Cl}$ intervention group and $\mathrm{Al}$ intervention group

\begin{tabular}{|c|c|c|c|c|}
\hline & $\begin{array}{l}\mathrm{Cl} \text { intervention } \\
\text { group }\end{array}$ & $\begin{array}{l}\text { Al intervention } \\
\text { group }\end{array}$ & & \\
\hline Continuous variables & $M(S D)$ & $M(S D)$ & $t$ & $p$ \\
\hline Age of child & $11.66(3.25)$ & $9.51(3.04)$ & 3.58 & $.001^{*}$ \\
\hline Age of parent & $40.97(6.86)$ & $37.26(7.11)$ & 2.82 & $.006^{*}$ \\
\hline Dichotomous variables & $\%$ & $\%$ & $\mathrm{Chi}^{2}$ & $p$ \\
\hline Gender of child - male & 51.4 & 53.2 & 0.04 & .852 \\
\hline Gender of parent - male & 50.0 & 47.8 & 0.05 & .820 \\
\hline Ethnicity - Dutch (vs. non-Dutch) & 66.2 & 65.2 & 0.01 & .916 \\
\hline Work status - Employed & 71.7 & 50.0 & 5.68 & $.014^{*}$ \\
\hline Financial problems: & & & 3.52 & .172 \\
\hline Yes & 62.3 & 46.8 & & \\
\hline No & 31.9 & 44.7 & & \\
\hline Education level: & & & 0.93 & .921 \\
\hline no education / primary school only & 12.9 & 12.8 & & \\
\hline high school & 18.6 & 25.5 & & \\
\hline lower professional education & 45.7 & 42.6 & & \\
\hline secondary professional education & 18.6 & 14.9 & & \\
\hline bachelor's/master's degree & 4.3 & 4.3 & & \\
\hline Living situation: & & & 4.07 & .397 \\
\hline Traditional family & 32.9 & 31.9 & & \\
\hline single-parent family & 38.6 & 44.7 & & \\
\hline shared parenthood & 7.1 & 0.0 & & \\
\hline newly formed family & 14.3 & 12.8 & & \\
\hline Other & 7.1 & 10.6 & & \\
\hline \multicolumn{5}{|l|}{ Type of maltreatment: } \\
\hline Emotional neglect & 29.4 & 28.3 & 0.02 & .894 \\
\hline Physical neglect & 10.4 & 15.9 & 0.72 & .397 \\
\hline Emotional abuse & 59.7 & 68.2 & 0.82 & .365 \\
\hline Physical abuse & 13.4 & 4.5 & 2.35 & .123 \\
\hline Sexual abuse & 28.4 & 20.5 & 0.88 & .348 \\
\hline
\end{tabular}

${ }^{*} p<.05$ 
Table 3.

Differences in behavioral problems and quality of life between the $\mathrm{Cl}$ intervention group and the Al intervention group at assessments 1, 2 and 3

\begin{tabular}{lllll}
\hline & $\mathrm{Cl}$ intervention group & Al intervention group & & \\
\hline Assessment 1 & $\boldsymbol{M}(\boldsymbol{S D})$ & $\boldsymbol{M}(\boldsymbol{S D})$ & $\boldsymbol{F}$ & $\boldsymbol{p}$ \\
Behavioral problems & $34.29(25.78)$ & $33.99(21.47)$ & 0.17 & .679 \\
Quality of life & $82.17(9.38)$ & $80.24(8.93)$ & 0.86 & .355 \\
& & & & \\
Assessment 2 & $\boldsymbol{M}(\boldsymbol{S D})$ & $\boldsymbol{M}(\boldsymbol{S D})$ & $\boldsymbol{F}$ & $\boldsymbol{p}$ \\
Behavioral problems & $30.70(22.16)$ & $32.34(20.22)$ & 0.01 & .916 \\
Quality of life & $85.61(9.30)$ & $84.03(13.95)$ & 0.08 & .779 \\
& & & & \\
Assessment 3 & $\boldsymbol{M}(\boldsymbol{S D})$ & $\boldsymbol{M}(\boldsymbol{S D})$ & $\boldsymbol{F}$ & $\boldsymbol{p}$ \\
Behavioral problems & $27.37(20.92)$ & $30.25(16.35)$ & 0.21 & .647 \\
Quality of life & $81.10(10.95)$ & $78.40(10.46)$ & 0.53 & .466 \\
\hline
\end{tabular}

\section{(2) Economic evaluation study:}

Analysis of societal costs

Table 4a presents the societal costs of the $\mathrm{Cl}$ and $\mathrm{Al}$ intervention groups at assessments 2 and 3, i.e. 0-6 months and 6-12 months after the AMK investigation, respectively. No significant differences regarding total costs were found between the groups at any of the assessments. At assessment 3, significant differences between the $\mathrm{Cl}$ and $\mathrm{Al}$ intervention groups were found regarding the use of first aid at hospital $(p=.048)$, with costs being higher for the Al intervention group.

The exploration of the total societal costs, adding up the costs at 0-6 months and 6-12 months, found significantly lower costs in the $\mathrm{Cl}$ intervention group regarding the use of first aid at hospital $(p=.049)$ but significantly higher costs in the $\mathrm{Cl}$ intervention group for the use of a lawyer/legal aid $(p=.045)$. There were no significant differences between the $\mathrm{Cl}$ and $\mathrm{Al}$ intervention groups regarding total societal costs one year after the AMK investigation (Table 4b). 


\section{Cost-utility analysis}

Prior to the cost-utility analysis, the difference in QALYs between the $\mathrm{CI}$ and $\mathrm{Al}$ intervention groups was examined. The mean value for the $\mathrm{Cl}$ intervention group was 0.79 (0.21) compared to a mean of 0.70 (0.33) for the Al intervention group, a non-significant difference. The ICUR calculated for the QALYs was dominant (i.e. ICUR $=-9,484.01$ euros, which means that for each QALY gained, 9,484.01 euros of societal costs are saved).

The ICUR is affected by a certain level of uncertainty, which is shown by the cost-utility plane (Figure $2 \mathrm{a}$ ). Each dot represents a bootstrap replication $(5,000$ times) of the ICUR. On the cost-utility plane, $65 \%$ of the dots are located in the dominant, south-east quadrant, indicating a probability of $65 \%$ that the $\mathrm{Cl}$ intervention results in more QALYs gained against lower costs. Only $2 \%$ of the dots are located in the inferior north-west quadrant. The acceptability curve (Figure 2 b) shows a probability of $71 \%$ that the $\mathrm{Cl}$ intervention is more acceptable than the Al intervention at a WTP of zero. When the WTP for one QALY gained was set at 20,000 euros, this probability of the $\mathrm{Cl}$ intervention resulting in more QALYs gained compared to the $\mathrm{Al}$ intervention increased to $93 \%$.

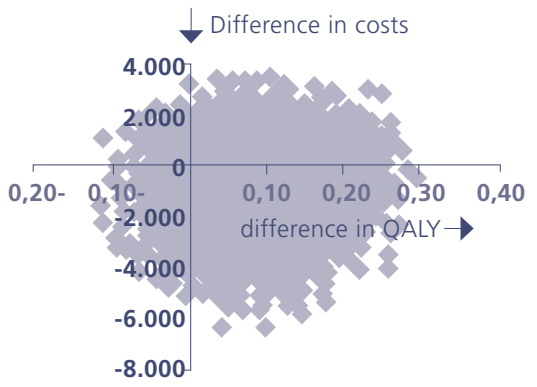

Figure 2a. Cost-utility plane

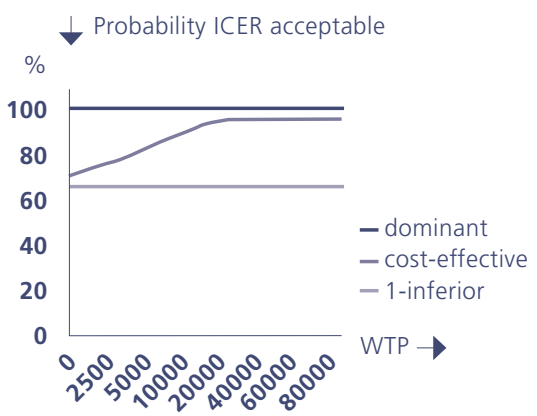

Figure 2b. CEAC of QALY 
Table 4a.

Differences in costs of resource use between the $\mathrm{Cl}$ and $\mathrm{Al}$ intervention groups 0-6 months and 6-12 months after AMK investigation.

\begin{tabular}{|c|c|c|}
\hline & \multicolumn{2}{|c|}{ 0-6 months } \\
\hline & $\mathrm{Cl}$ Intervention & Al Intervention \\
\hline & $M(S D)$ & $M(S D)$ \\
\hline AMK intervention & $2,047(0)$ & $2,047(0)$ \\
\hline $\mathrm{Cl}$ intervention & $199.29(0)$ & $0(0)$ \\
\hline \multicolumn{3}{|l|}{ Service provider } \\
\hline AMK follow-up & $28.47(72.92)$ & $17.51(68.48)$ \\
\hline General practitioner & $55.77(89.33)$ & $96.76(215.69)$ \\
\hline Company doctor & $3.61(14.95)$ & $0.49(3.35)$ \\
\hline First-aid post at hospital & $25.35(100.45)$ & $54.18(133.32)$ \\
\hline Medical specialist at hospital & $60.21(238.79)$ & $106.68(274.35)$ \\
\hline $\begin{array}{l}\text { Hospitalization } \\
\text { (including general hospital, psychiatric } \\
\text { hospital, rehabilitation center, university } \\
\text { hospital) }\end{array}$ & $31.76(174.60)$ & $1522.89(6417.54)$ \\
\hline $\begin{array}{l}\text { Psychiatrist/ psychologist/ psychotherapist } \\
\text { working at hospital }\end{array}$ & $59.62(246.52)$ & $79.73(282.00)$ \\
\hline $\begin{array}{l}\text { Psychiatrist/ psychologist/ psychotherapist } \\
\text { with private practice }\end{array}$ & $108.81(286.52)$ & $55.67(139.66)$ \\
\hline Physical therapist & $46.78(268.96)$ & $67.43(195.88)$ \\
\hline Alternative healer (e.g. homeopathy) & $6.81(38.70)$ & $16.49(88.51)$ \\
\hline Self-help group therapy & $1.86(10.27)$ & $1.63(8.26)$ \\
\hline Child welfare service on outpatient basis & $421.17(1,016.92)$ & $274.04(767.12)$ \\
\hline Child welfare service as day care & $34.18(187.32)$ & $27.46(183.62)$ \\
\hline Child welfare service on inpatient basis & $47.83(396.71)$ & $0(0)$ \\
\hline Youth and family center & $9.49(65.25)$ & $14.13(51.71)$ \\
\hline Infant welfare center & $3.62(16.92)$ & $10.10(32.98)$ \\
\hline
\end{tabular}




\section{6-12 months}

\begin{tabular}{|c|c|c|c|}
\hline Diff. Cl-AI & $\mathrm{Cl}$ Intervention & Al Intervention & Diff. Cl-Al \\
\hline$M(\mathrm{Cl} 95 \%)$ & $M(S D)$ & $M(S D)$ & $M(\mathrm{Cl} 95 \%)$ \\
\hline 0 & $0(0)$ & $0(0)$ & 0 \\
\hline 199.29 & $0(0)$ & $0(0)$ & 0 \\
\hline $\begin{array}{c}10.96 \\
(-18.68-36.15) \\
\end{array}$ & $13.45(38.49)$ & $9.20(40.60)$ & $\begin{array}{c}4.25 \\
(-11.52-18.34) \\
\end{array}$ \\
\hline $\begin{array}{c}-40.99 \\
(-111.61-11.46) \\
\end{array}$ & $54.12(75.47)$ & $77.10(108.69)$ & $\begin{array}{c}-22.98 \\
(-59.66-10.84) \\
\end{array}$ \\
\hline $\begin{array}{c}3.12 \\
(-0.18-7.08) \\
\end{array}$ & $3.94(14.08)$ & $1.53(10.05)$ & $\begin{array}{c}2.41 \\
(-2.05-6.69) \\
\end{array}$ \\
\hline $\begin{array}{c}-28.82 \\
(-74.62-15.71)\end{array}$ & $18.10(61.84)$ & $53.91(102.65)$ & $\begin{array}{c}-35.81 \\
(-69.09--3.84)^{*}\end{array}$ \\
\hline $\begin{array}{c}-46.47 \\
(-147.82-42.43) \\
\end{array}$ & $44.27(88.98)$ & $127.06(271.69)$ & $\begin{array}{c}41.03 \\
(-170.04-11.34) \\
\end{array}$ \\
\hline $\begin{array}{c}-1491.13 \\
(-3,521.03-103.70)\end{array}$ & $1106.28(7,985.66)$ & $818.86(3,902.70)$ & $\begin{array}{c}287.42 \\
(-1,662.60-2,696.38)\end{array}$ \\
\hline $\begin{array}{c}-20.11 \\
(-126.92-74.87)\end{array}$ & $108.02(365.31)$ & $61.65(151.43)$ & $\begin{array}{c}46.36 \\
(-41.42-153.50)\end{array}$ \\
\hline $\begin{array}{c}53.14 \\
(-18.73-136.29) \\
\end{array}$ & $172.46(435.84)$ & $64.36(176.29)$ & $\begin{array}{c}108.09 \\
(0.37-224.32) \\
\end{array}$ \\
\hline $\begin{array}{c}-20.65 \\
(-102.62-70.87) \\
\end{array}$ & $29.43(127.84)$ & $51.71(160.85)$ & $\begin{array}{c}-22.28 \\
(-78.31-28.88) \\
\end{array}$ \\
\hline $\begin{array}{c}-9.68 \\
(-41.68-11.59) \\
\end{array}$ & $12.88(79.18)$ & $0(0)$ & $\begin{array}{c}12.88 \\
(0.11-35.37) \\
\end{array}$ \\
\hline $\begin{array}{c}0.23 \\
(-3.00-3.66) \\
\end{array}$ & $0.56(4.58)$ & $0.83(5.59)$ & $\begin{array}{c}-0.27 \\
(-2.31-1.24) \\
\end{array}$ \\
\hline $\begin{array}{c}147.13 \\
(-196.49-465.91) \\
\end{array}$ & $317.46(793.84)$ & $357.55(1,233.86)$ & $\begin{array}{c}-40.09 \\
(-488.94-315.09) \\
\end{array}$ \\
\hline $\begin{array}{c}6.72 \\
(-62.39-73.16)\end{array}$ & $17.13(131.77)$ & $99.19(479.26)$ & $\begin{array}{c}-82.06 \\
(-226.15-23.44)\end{array}$ \\
\hline $\begin{array}{c}47.83 \\
(0.38-148.74) \\
\end{array}$ & $0(0)$ & $15.13(103.75)$ & $\begin{array}{c}-15.13 \\
(-53.39--12.93) \\
\end{array}$ \\
\hline $\begin{array}{c}-4.64 \\
(-25.01-15.84) \\
\end{array}$ & $10.54(48.81)$ & $2.98(13.56)$ & $\begin{array}{c}7.56 \\
(-2.75-20.12) \\
\end{array}$ \\
\hline $\begin{array}{c}-6.48 \\
(-18.00-2.87)\end{array}$ & $5.16(19.27)$ & $17.43(63.30)$ & $\begin{array}{c}-12.27 \\
(-34.69-2.61)\end{array}$ \\
\hline
\end{tabular}




\begin{tabular}{|c|c|c|}
\hline & \multicolumn{2}{|c|}{ 0-6 months } \\
\hline & $\mathrm{Cl}$ Intervention & Al Intervention \\
\hline & $M(S D)$ & $M(S D)$ \\
\hline Regional public health service & $4.46(18.14)$ & $8.85(29.81)$ \\
\hline Home care & $12.78(102.64)$ & $48.11(187.33)$ \\
\hline Personal care budget (euros) & $6.57(28.43)$ & $85.93(583.36)$ \\
\hline Social work & $92.09(399.22)$ & $126.75(395.16)$ \\
\hline $\begin{array}{l}\text { School (including school doctor, } \\
\text { compulsory education officer) }\end{array}$ & $55.18(107.82)$ & $55.37(94.65)$ \\
\hline Police & $2.30(12.63)$ & $2.79(11.27)$ \\
\hline Probation service & $5.97(49.97)$ & $17.79(112.77)$ \\
\hline Addiction service & $7.06(43.78)$ & $84.13(576.79)$ \\
\hline Financial assistance & $12.79(55.71)$ & $21.54(83.18)$ \\
\hline Lawyer/legal aid & $761.17(2,512.57)$ & $365.71(786.14)$ \\
\hline Total costs & $4,151.98(3,350.96)$ & $5,209.17(7,424.54)$ \\
\hline
\end{tabular}

*Significant difference in costs between the $\mathrm{Cl}$ and $\mathrm{Al}$ intervention groups $(p<.05)$ 


\section{6-12 months}

\begin{tabular}{|c|c|c|c|}
\hline Diff. Cl-AI & $\mathrm{Cl}$ Intervention & Al Intervention & Diff. CI-Al \\
\hline$M(\mathrm{Cl} 95 \%)$ & $M(S D)$ & $M(S D)$ & $M(\mathrm{Cl} 95 \%)$ \\
\hline $\begin{array}{c}-4.40 \\
(-15.73-4.58)\end{array}$ & $8.47(38.49)$ & $6.23(25.11)$ & $\begin{array}{c}2.24 \\
(-8.47-14.85)\end{array}$ \\
\hline $\begin{array}{c}-35.34 \\
(-99.14-18.00) \\
\end{array}$ & $30.66(206.90)$ & $94.02(412.37)$ & $\begin{array}{c}-63.36 \\
(-208.79-37.07) \\
\end{array}$ \\
\hline $\begin{array}{c}-79.36 \\
(-271.77-10.85)\end{array}$ & $1.69(14.10)$ & $1.81(11.66)$ & $\begin{array}{c}-0.13 \\
(-5.11-5.06)\end{array}$ \\
\hline $\begin{array}{c}-34.66 \\
(-186.49-110.46)\end{array}$ & $135.69(466.48)$ & $216.19(498.66)$ & $\begin{array}{c}-80.51 \\
(-252.89-100.27)\end{array}$ \\
\hline $\begin{array}{c}-0.19 \\
(-38.36-36.92)\end{array}$ & $37.61(51.36)$ & $53.03(99.37)$ & $\begin{array}{c}-15.42 \\
(-49.58-10.21)\end{array}$ \\
\hline $\begin{array}{c}-0.49 \\
(-4.50-3.87)\end{array}$ & $3.68(18.60)$ & $1.37(6.56)$ & $\begin{array}{c}2.31 \\
(-1.50-7.57)\end{array}$ \\
\hline $\begin{array}{c}-11.82 \\
(-50.83-14.16)\end{array}$ & $0.46(3.84)$ & $0(0)$ & $\begin{array}{c}0.46 \\
(-0.41-1.67)\end{array}$ \\
\hline $\begin{array}{c}-77.07 \\
(-269.57-15.38) \\
\end{array}$ & $0(0)$ & $7.01(48.07)$ & $\begin{array}{c}-7.01 \\
(-26.90-5.88) \\
\end{array}$ \\
\hline $\begin{array}{c}-8.75 \\
(-38.72-15.94)\end{array}$ & $15.98(65.06)$ & $22.78(71.83)$ & $\begin{array}{c}-6.80 \\
(-33.37-17.97)\end{array}$ \\
\hline $\begin{array}{c}395.45 \\
(-188.02-1,077.28) \\
\end{array}$ & $782.25(2,502.37)$ & $149.45(320.22)$ & $\begin{array}{c}632.80 \\
(109.09-1,284.66) \\
\end{array}$ \\
\hline $\begin{array}{c}-1,057.19 \\
(-3,614.89-1,060.46)\end{array}$ & $2,930.28(8,724.04)$ & $2,310.40(4,367.38)$ & $\begin{array}{c}619.88 \\
(-2,107.09-3,346.84)\end{array}$ \\
\hline
\end{tabular}


Table 4b.

Differences in costs of resource use between the $\mathrm{Cl}$ and $\mathrm{Al}$ intervention groups 1 year after AMK investigation.

\begin{tabular}{|c|c|c|c|}
\hline & CI Intervention & Al Intervention & Diff. Cl-AI \\
\hline & $M(S D)$ & $M(S D)$ & $M$ Diff. (Cl 95\%) \\
\hline AMK intervention & $2,047(0)$ & $2,047(0)$ & 0 \\
\hline $\mathrm{Cl}$ intervention & $199.29(0)$ & $0(0)$ & 199.29 \\
\hline \multicolumn{4}{|l|}{ Service provider } \\
\hline AMK follow-up & $41.92(83.94)$ & $26.71(77.52)$ & $\begin{array}{c}15.20 \\
(-17.07-44.69)\end{array}$ \\
\hline General practitioner & $109.88(136.10)$ & $173.86(295.39)$ & $\begin{array}{c}-63.98 \\
(165.51-13.05)\end{array}$ \\
\hline Company doctor & $7.54(23.69)$ & $2.02(10.52)$ & $\begin{array}{c}5.53 \\
(-0.69-12.00) \\
\end{array}$ \\
\hline First-aid post at hospital & $43.45(124.10)$ & $108.09(194.61)$ & $\begin{array}{c}-64.64 \\
(-130.66--3.74)^{a} \\
\end{array}$ \\
\hline $\begin{array}{l}\text { Medical specialist at } \\
\text { hospital }\end{array}$ & $104.48(275.52)$ & $233.73(401.64)$ & $\begin{array}{c}-129.25 \\
(-265.84--9.93)\end{array}$ \\
\hline $\begin{array}{l}\text { Hospitalization } \\
\text { (including general } \\
\text { hospital, psychiatric } \\
\text { hospital, rehabilitation } \\
\text { center, university } \\
\text { hospital) }\end{array}$ & $1,138.04(7,983.10)$ & $2,341.75(7,435.98)$ & $\begin{array}{c}-1,203.71 \\
(-4,208.97-1,750.96)\end{array}$ \\
\hline $\begin{array}{l}\text { Psychiatrist/ psychologist/ } \\
\text { psychotherapist working } \\
\text { at hospital }\end{array}$ & $167.64(492.79)$ & $141.38(309.65)$ & $\begin{array}{c}26.25 \\
(-121.97-163.03)\end{array}$ \\
\hline $\begin{array}{l}\text { Psychiatrist/ psychologist/ } \\
\text { psychotherapist with } \\
\text { private practice }\end{array}$ & $281.27(581.40)$ & $120.03(260.70)$ & $\begin{array}{c}161.24 \\
(5.55-327.21)\end{array}$ \\
\hline Physical therapist & $76.21(368.29)$ & $119.14(274.18)$ & $\begin{array}{c}-42.93 \\
(-148.74-87.57) \\
\end{array}$ \\
\hline $\begin{array}{l}\text { Alternative healer (e.g. } \\
\text { homeopathy) }\end{array}$ & $19.70(117.34)$ & $16.49(88.51)$ & $\begin{array}{c}3.21 \\
(-37.53-42.13)\end{array}$ \\
\hline Self-help group therapy & $2.42(11.15)$ & $2.46(9.84)$ & $\begin{array}{c}-0.05 \\
(3.43-3.66) \\
\end{array}$ \\
\hline $\begin{array}{l}\text { Child welfare service on } \\
\text { outpatient basis }\end{array}$ & $738.64(1506.71)$ & $631.59(1419.15)$ & $\begin{array}{c}107.05 \\
(-433.33-669.68) \\
\end{array}$ \\
\hline $\begin{array}{l}\text { Child welfare service as } \\
\text { day care }\end{array}$ & $51.31(229.35)$ & $126.65(507.84)$ & $\begin{array}{c}-75.34 \\
(-244.31-52.55) \\
\end{array}$ \\
\hline $\begin{array}{l}\text { Child welfare service on } \\
\text { inpatient basis }\end{array}$ & $47.83(396.71)$ & $15.13(103.75)$ & $\begin{array}{c}32.69 \\
(-40.16-145.76) \\
\end{array}$ \\
\hline Youth and family center & $20.03(80.23)$ & $17.12(55.02)$ & $\begin{array}{c}2.92 \\
(-21.60-19.04)\end{array}$ \\
\hline
\end{tabular}




\begin{tabular}{|c|c|c|c|}
\hline & $\mathrm{CI}$ Intervention & Al Intervention & Diff. Cl-AI \\
\hline & $M(S D)$ & $M(S D)$ & $M$ Diff. (Cl 95\%) \\
\hline Infant welfare center & $8.78(28.80)$ & $27.53(75.79)$ & $\begin{array}{c}-18.75 \\
(-45.09-1.46) \\
\end{array}$ \\
\hline $\begin{array}{l}\text { Regional public health } \\
\text { service }\end{array}$ & $12.92(44.48)$ & $15.08(39.44)$ & $\begin{array}{c}-2.15 \\
(17.00-14.11) \\
\end{array}$ \\
\hline Home care & $43.44(308.66)$ & $142.14(445.94)$ & $\begin{array}{c}-98.70 \\
(-248.75-12.26) \\
\end{array}$ \\
\hline $\begin{array}{l}\text { Personal care budget } \\
\text { (euros) }\end{array}$ & $8.26(31.38)$ & $87.74(583.46)$ & $\begin{array}{c}-79.49 \\
(-284.75-12.16) \\
\end{array}$ \\
\hline Social work & $227.78(813.32)$ & $342.95(735.66)$ & $\begin{array}{c}-115.17 \\
(-400.64-171.68)\end{array}$ \\
\hline $\begin{array}{l}\text { School (including school } \\
\text { doctor, compulsory } \\
\text { education officer) }\end{array}$ & 92.79 (135.98) & $108.40(129.18)$ & $\begin{array}{c}-15.61 \\
(-62.09-36.25)\end{array}$ \\
\hline Police & $5.97(22.10)$ & $4.16(12.74)$ & $\begin{array}{c}1.81 \\
(-3.92-, 8.86) \\
\end{array}$ \\
\hline Probation service & $6.43(50.06)$ & $17.79(112.77)$ & $\begin{array}{c}-11.36 \\
(-52.18-13.96) \\
\end{array}$ \\
\hline Addiction service & $7.06(43.78)$ & $91.14(624.85)$ & $\begin{array}{c}-84.08 \\
(-306.79-16.71) \\
\end{array}$ \\
\hline Financial assistance & $28.77(108.40)$ & $44.32(113.48)$ & $\begin{array}{c}-15.55 \\
(-56.27-27.15) \\
\end{array}$ \\
\hline Lawyer/legal aid & $1,543.42(3,859.19)$ & $515.17(884.11)$ & $\begin{array}{c}1,028.25 \\
(182.60-2,072.67)^{\mathrm{a}}\end{array}$ \\
\hline Total costs & $7,082.76(9,424.57)$ & $7,519.57(8,615.41)$ & $\begin{array}{c}-437.32 \\
(-3,692.49-2,986.22)\end{array}$ \\
\hline
\end{tabular}

a Significant difference in costs between the $\mathrm{Cl}$ and $\mathrm{Al}$ intervention groups $(p<.05)$

\section{Cost-effectiveness analysis}

An ICER was calculated for the outcome measures for behavioral problems and quality of life. The ICER for behavioral problems was dominant (i.e. ICER $=-188.15$ euros, meaning that for 1 point improvement in behavioral problems, savings of societal costs amount to 188.15 euros).

The cost-effectiveness plane shows $47 \%$ of the dots in the dominant quadrant, indicating a probability of $47 \%$ that the $\mathrm{Cl}$ intervention results in less behavioral problems against lower costs; there is an $11 \%$ probability that the $\mathrm{Cl}$ intervention is inferior (Figure 3a). The acceptability curve for the ICER is presented in figure $3 \mathrm{~b}$. The $\mathrm{Cl}$ intervention had a probability of $60 \%$ of resulting in less behavioral problems than the Al intervention at a WTP of zero. When the WTP for one point improvement was set at 10,000 euros, the probability of the $\mathrm{Cl}$ intervention being more acceptable increased to $76 \%$. At a threshold of 20,000 euros, this probability is still $76 \%$. 
The ICER for quality of life was also dominant (i.e. ICER $=-160.92$ euros, meaning that each point of increase in quality of life, saves 160.92 euros of societal costs). Figure $3 c$ presents the cost-effectiveness plane: $57 \%$ of the dots are located in the dominant quadrant, indicating a probability of $57 \%$ that the $\mathrm{Cl}$ intervention results in a better quality of life against lower costs, while there was a $4 \%$ probability that the $\mathrm{Cl}$ intervention results in a poorer quality of life against higher costs. The acceptability curve of the ICER shows a probability of $61 \%$ that the $\mathrm{Cl}$ intervention results in a better quality of life than the Al intervention at a WTP of zero. This percentage increased to a stable $91 \%$ at a WTP of 2,500 euros or over (Figure $3 d$ ).
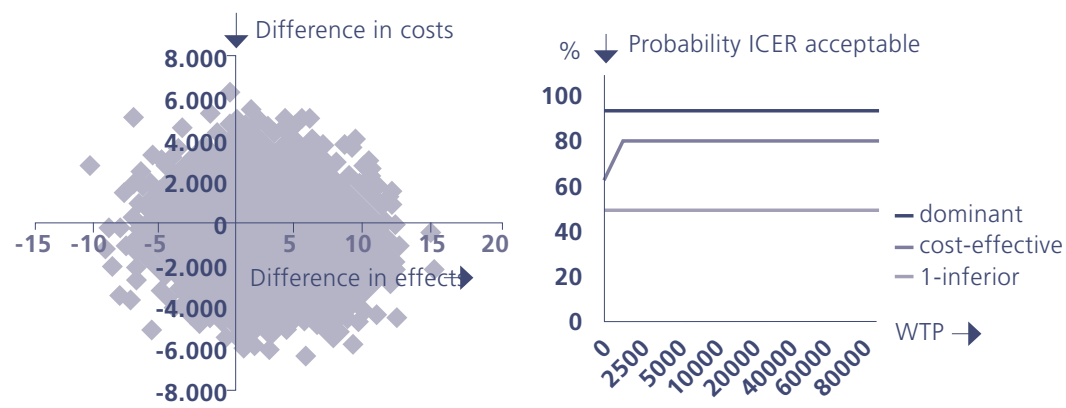

Figure 3a Effectiveness plane of behavioral problems

Figure 3b CEAC of behavioral problems
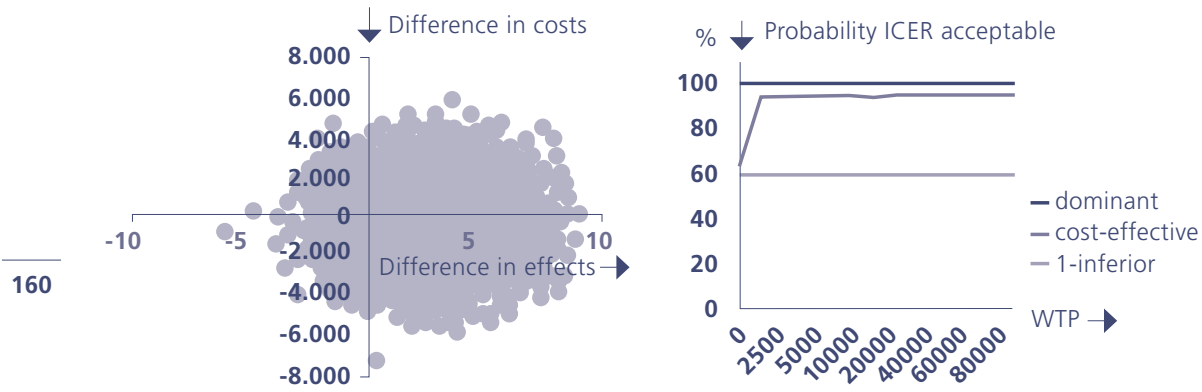

Figure 3c Effectiveness plane of quality of life

Figure $3 d$ CEAC of quality of life 


\section{Sensitivity analysis}

Acceptability curves of the sensitivity analyses are presented in figure $4 \mathrm{a}-4 \mathrm{~g}$.

First, since being of Dutch vs. non-Dutch origin was a predictor of loss-tofollow up, a subgroup analysis of participants of Dutch origin versus participants of non-Dutch origin was performed regarding behavioral problems and quality of life. For the Dutch subgroup, the behavioral problems ICER was dominant (i.e. ICER $=-293.59$ euros), with $70 \%$ and $3 \%$ of the dots located in the dominant and inferior quadrants, respectively. At a WTP of zero, the likelihood of the $\mathrm{Cl}$ intervention being more acceptable than the Al intervention was $77 \%$, while at a threshold of 20,000 euros, this probability was $90 \%$ (Figure $4 a$ ). For the non-Dutch subgroup, the behavioral problems ICER was also dominant (i.e. ICER $=-533.24$ euros). The distribution of the cost-effectiveness plane shows a percentage of only $14 \%$ of the dots in the dominant quadrant and $42 \%$ in the inferior quadrant. The acceptability curve shows a decrease from $38 \%$ likelihood that the $\mathrm{Cl}$ intervention is more acceptable than the $\mathrm{Al}$ intervention at a WTP equal to zero, compared to $34 \%$ at a threshold of 20,000 euros (Figure 4b).

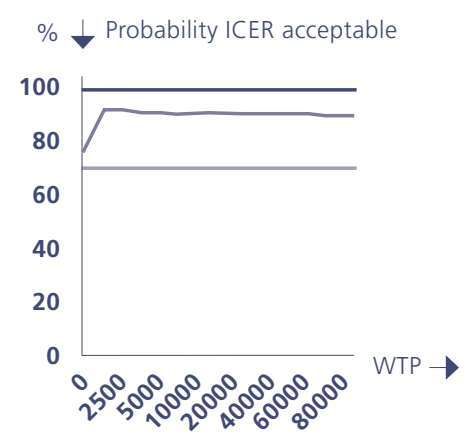

Figure 4a CEAC of behavioral problems of the Dutch sample

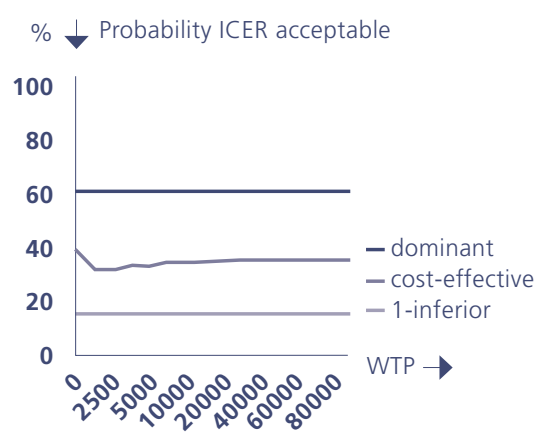

Figure $4 b$ CEAC of behavioral problems of the non-Dutch sample 
The ICER for quality of life of the Dutch subgroup was dominant (i.e. ICER = -438.74 euros). Most of the dots $(71 \%)$ are located in the dominant quadrant of the plane. At a WTP of zero, the probability of the $\mathrm{Cl}$ intervention resulting in a higher quality of life than the Al intervention was $76 \%$, increasing to a stable $94 \%$ at a WTP of 2,500 euros (Figure 4C). The ICER for the non-Dutch subgroup was inferior (i.e. ICER $=873.01$ euros). Most dots are located in the north-east quadrant of the cost-effectiveness plane, indicating a probability of $43 \%$ that the $\mathrm{Cl}$ intervention results in better quality of life against higher costs. At a WTP equal to zero, the likelihood of the $\mathrm{Cl}$ intervention being more acceptable than the $\mathrm{Al}$ intervention was $38 \%$. This percentage increased to $62 \%$ at a WTP of 2,500 euros and was also $62 \%$ at the threshold of 20,000 euros (Figure 4d). The results of these sensitivity analyses indicate that the $\mathrm{Cl}$ intervention has a higher likelihood of being more acceptable to people of Dutch origin.

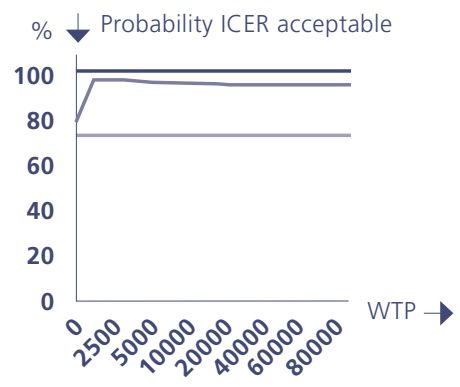

Figure 4C. CEAC of quality of life of the Dutch sample

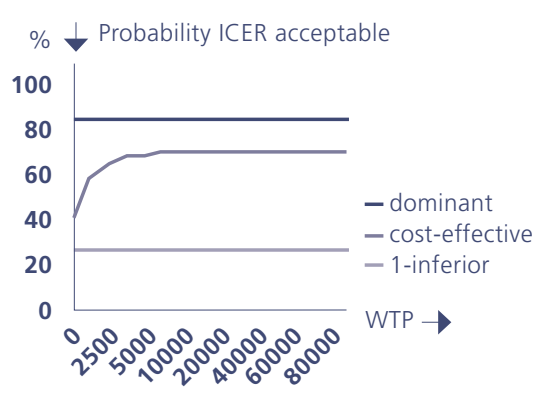

Figure $4 d$. CEAC of quality of life of the non-Dutch sample

The second sensitivity analysis explored the robustness of the QALYs. The ICUR calculated specifically for the subgroup of completers of assessment 3 was dominant (i.e. ICUR $=-5,216.53$ euros). Most of the dots ( $55 \%$ ) are located in the dominant quadrant of the plane. The probability of the $\mathrm{Cl}$ intervention resulting in more QALYs gained was $59 \%$ at a WTP of zero. At a WTP of 20,000 euros, this probability increased to $89 \%$ (Figure 4 e), which is comparable to the QALY outcomes of the sample $(n=91)$ used for the cost-utility analysis in this study. 


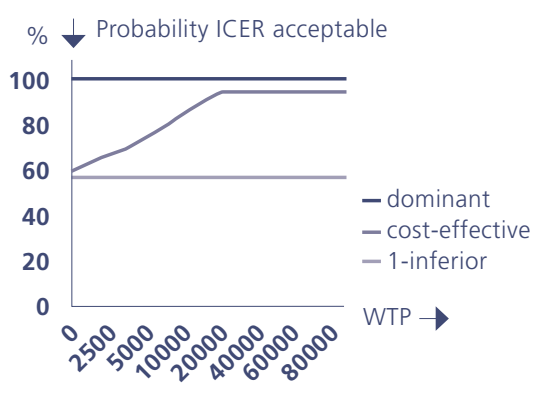

Figure 4e. CEAC of the QALY on a sample of completers only

A third cost-effectiveness analysis was performed from a health and social care perspective. The ICER for behavioral problems was dominant (i.e. ICER = -613.04 euros). Most of the dots (63\%) are located in the dominant quadrant of the cost-effectiveness plane. At a WTP of zero, the probability of the $\mathrm{Cl}$ intervention resulting in less behavioral problems compared to the $\mathrm{Al}$ intervention was $83 \%$. At the threshold of 20,000 euros, this probability was $76 \%$ (Figure $4 \mathrm{f}$ ). Results showed that the $\mathrm{Cl}$ intervention has a slightly higher probability of resulting in less behavioral problems than the Al intervention when only health and social care costs are considered, because at a WTP of zero, the likelihood of the $\mathrm{CI}$ intervention group resulting in less behavioral problems was $83 \%$, compared to $60 \%$ when the economic evaluation was performed from a societal perspective.

The ICER for quality of life was also dominant (i.e. ICER $=-524.31$ euros). Most of the dots $(76 \%)$ are located in the dominant quadrant of the plane. At a WTP of zero, the probability of the $\mathrm{Cl}$ intervention resulting in better quality of life outcomes was $83 \%$. At the threshold of 20,000 euros, this value was $92 \%$ (Figure $4 \mathrm{~g}$ ). For quality of life, the probability that the $\mathrm{Cl}$ intervention is more acceptable than the Al intervention is $61 \%$ from a societal perspective and $83 \%$ from a health and social care perspective at a WTP of zero. This probability increased to over $90 \%$ for both perspectives at a WTP of 2,500 euros. 


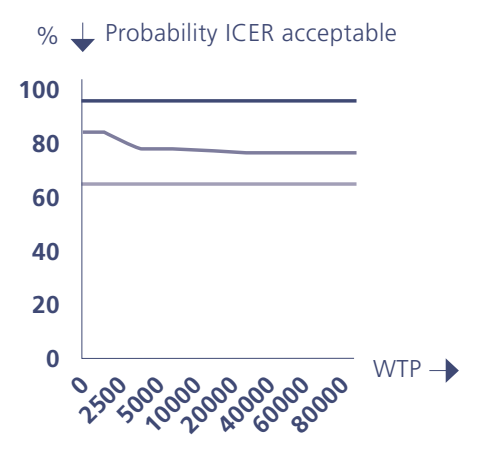

Figure $4 f$. CEAC of behavioral problems from a health and social care perspective

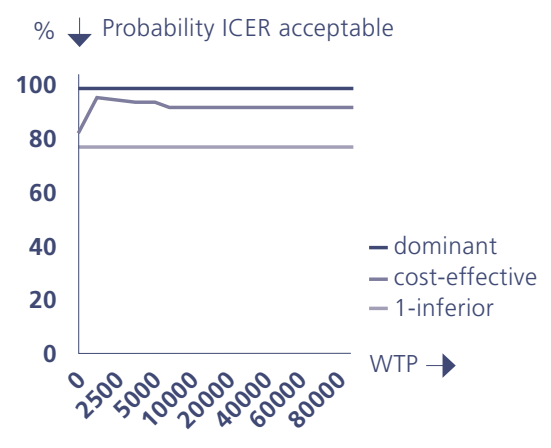

Figure $4 g$. CEAC of quality of life from a health and social care perspective

\section{Discussion}

\section{Effectiveness study}

The first objective of this study was to examine the effectiveness of AMK investigations using the $\mathrm{Cl}$ intervention in comparison with the $\mathrm{Al}$ intervention. No significant differences in behavioral problems or quality of life were found, which indicates that using the $\mathrm{Cl}$ intervention is not more effective than using the Al intervention.

\section{Economic evaluation study}

The second objective of the study was to perform an economic evaluation examining the balance between additional costs and effects of AMK investigations using the $\mathrm{Cl}$ intervention in comparison with those using the Al intervention. All ICERs were dominant. At a WTP of 20,000 euros, the likelihood that the $\mathrm{Cl}$ intervention is cost-effective was found to be $93 \%$ for QALYs, 76\% for behavioral problems and $91 \%$ for quality of life. The results of the cost-effectiveness and cost-utility analyses are thus in favor of the $\mathrm{Cl}$ intervention. 


\section{Sensitivity analyses}

All sensitivity analyses confirmed the robustness of the findings of this study. First, a subgroup analysis based on origin (Dutch vs. non-Dutch) showed that the likelihood of the $\mathrm{Cl}$ intervention resulting in less behavioral problems and a better quality of life was higher for people of Dutch origin. In the Dutch subgroup, at a willingness to pay threshold of 20,000 euros, the $\mathrm{Cl}$ intervention had a likelihood of being more acceptable than the $\mathrm{Al}$ intervention of $90 \%$ for behavioral problems and $94 \%$ for quality of life. These likelihoods were substantially lower for the non-Dutch subgroup (34\% and $62 \%$, respectively). A possible explanation may be found in differences between cultures. For example, a large part of the non-Dutch subgroup had a Moroccan background. In Morocco, issues such as family problems are dealt with within the family; it is not an issue that is discussed outside the house. Also, values differ between cultures. What is considered child maltreatment in the Netherlands may not be recognized as such in other cultures. Children of non-Dutch origin may be less used to talking about the issues raised in the child interview or they may not recognize the issues.

The second sensitivity analysis examined the strength of the QALYs with an analysis including only completers of the rating scale at assessment 3 . The results ( $89 \%$ probability that the $\mathrm{Cl}$ intervention is more acceptable at the WTP threshold of 20,000 euros) are comparable with the cost-utility analysis on the sample used after last-observation-carried-forward imputation, where rating scale values on assessment 2 were imputed on assessment 3 (probability $93 \%$ ). The results imply that the method used in this study to estimate utilities was suitable. However, the QALYs in this study did not result from a change in quality of life over time, which remains a limitation of this study.

The third sensitivity analysis involved a cost-effectiveness analysis from a health and social care perspective. At a WTP of zero, the probability of the CI intervention resulting in less behavioral problems and better quality of life was higher from a health and social care perspective: $83 \%$ for both outcome measures, in comparison with $60 \%$ from a societal perspective. At the WTP threshold of 20,000 euros, the likelihood of the $\mathrm{Cl}$ intervention being more acceptable than the Al intervention was the same from both perspectives (76\% for behavioral problems and $91 \%$ for quality of life). These results indicate that the $\mathrm{Cl}$ intervention also has the highest probability of being cost-effective in countries where a health and social care perspective is regarded as the standard, regardless of the WTP threshold. 


\section{Limitations}

One limitation of this study is the quasi-experimental study design. The gold standard for effectiveness studies and economic evaluations is a randomized controlled trial. Unfortunately, the Dutch Medical Ethics Committee for Mental Health Care (METiGG) did not approve of such a study because this would mean that one of the intervention groups, while also consisting of vulnerable young children, would not receive optimal care (WMA, 2013). As a result, participants of an ongoing prospective study (Snoeren et al., 2013) were asked to complete an additional questionnaire at follow-up assessments. The study sample was split up into two groups based on AMK records. Motives known to us for chosing the $\mathrm{Al}$ intervention over the $\mathrm{Cl}$ intervention are: age of the child (minimum age is six years) or the child has already been interviewed by another professional. Nevertheless, we were not able to get clear insight in the reasoning behind the decision for the $\mathrm{Cl}$ or $\mathrm{Al}$ intervention for the participants of this study. Therefore selection bias is a possibility. Selection bias may represent a concern regarding internal validity. To minimize the consequences of this limitation, the similarity of the study groups was assessed at baseline, and significant differences were taken into account in the analysis.

The second limitation is that of possible recall bias. A recall period of two to three months is generally used in economic evaluation studies to measure resource use (Severens, Mulder, Laheij, \& Verbeek, 2000). However, this study used participants from another study, for whom the follow-up assessments had already scheduled at every 6 months (Snoeren et al., 2013). Recall bias may affect the data on resource use, because participants may have difficulty retrospectively remembering the exact number of times they used various services over a period of 6 months. However, we do not assume that recall bias influenced the findings of this study. Since recall bias does not depend on the $\mathrm{Cl}$ intervention or $\mathrm{Al}$ intervention, the potential for recall bias is expected to be equal in both groups.

Third, the QALYs in this study were derived from a rating scale, which, however was not completed by all children, resulting in too little data to calculate QALYs the usual way. QALYs are a measure of change in quality of life over time, usually calculated as the change in value between two assessments multiplied by the duration of the intervention effect. Unfortunately, missing data at assessment 2 mean that the QALYs in this study were mainly based on a single assessment (assessment 3). There is a need for an additional cost-utility study to examine whether the present findings can be replicated.

The use of the rating scale is not the preferred method in economic 
evaluations, because although it is simple and therefore easily understood by children, it generates values rather than utilities, and does not involve an element of choice, nor decision-making under uncertainty, which may result in lower utility estimates. More suitable methods include time trade-off and standard gamble (Dolan \& Sutton, 1997; Morimoto \& Fukui, 2002).

Fourth, since it can be assumed that the QALY scores and costs at baseline are predictors of follow-up outcomes, an adjustment of baseline differences has been recommended for QALYs by Manca and colleagues (2005) and for costs by Van Asselt and colleagues (2009). The recommended method is to conduct the analyses on data before baseline adjustment and to perform a sensitivity analysis including baseline adjustment. However, our present study involved no baseline assessment, so no additional sensitivity analyses after baseline adjustment were needed.

\section{Future implications}

As regards the $\mathrm{Cl}$ intervention that is the subject of this study, future research should include in-depth analysis to identify characteristics of children who benefit most from the $\mathrm{Cl}$ intervention. This information may help professionals in their decision regarding the preferred method for AMK investigation after child maltreatment reports. In addition, since the $\mathrm{Cl}$ intervention has a low likelihood of being more acceptable than the Al intervention for children of non-Dutch origin, future research should focus on interventions that reduce the behavioral problems and improve the quality of life of maltreated children of non-Dutch origin.

Economic evaluations regarding child maltreatment interventions are scarce for several reasons. First, due to developmental limitations there are few validated tools to measure changes in utilities for children. Usually, parents are used as proxies, but in the case of child maltreatment, parents may not serve as reliable proxies, because they may be the abusers (Corso \& Lutzker, 2006). The EuroQol Group, developer of the EQ-5D questionnaire which is regularly used for adults (The EuroQol Group, 1990), has recently developed a child-friendly version for children (8-11 years) and adolescents (12-18 years). The psychometric properties of the EQ-5D-Y have been reported (Wille, Badia, Bonsel, Burstrom, Cavrini, et al., 2010). A Dutch version is now also available, but its psychometric properties are yet to be examined.

In this study we tried to measure changes in quality of life using a rating scale, at two assessment moments. We were not able to collect sufficient data at all assessments, which underlines the difficulty of measuring changes in quality of life in children. Fortunately, we were able to perform a cost-utility 
analysis based on QALY estimates and generate preliminary data on the effects of an intervention used by Dutch AMKs. Nevertheless, future research should include the development and validation of suitable instruments to measure changes of quality of life in children.

Economic evaluations in child maltreatment are not easy to perform. Resource use measurement instruments and guidelines for costing generally only focus on health care services, whereas valid instruments for measuring and valuing resource use beyond the health care sector are not yet available. In this study we therefore used estimates to calculate costs to society. Future research should focus on developing instruments for child and youth services within and outside the healthcare sector.

\section{Conclusion}

This is the first study to examine the effect of the involvement of a reporting agency for child abuse and neglect, and also the first economic evaluation performed in the Netherlands regarding an intervention for maltreated children. Although the results show that both investigation methods used by the AMKs are comparable in costs and outcomes, and this study does not yield conclusive proof of the superiority of the $\mathrm{Cl}$ intervention for maltreated children, AMK employees report that using the $\mathrm{Cl}$ intervention as part of the AMK investigation helps them provide care that is tailored to the child's needs. They believe that interviewing the children gives these children a sense of being in control of their own situation, which will likely benefit them in the future. If AMK employees feel more competent and they succeed in providing tailored care as a results of the information provided by the children during the child-interview, beneficial effects of the $\mathrm{Cl}$ intervention on behavioral problems and quality of life may be found on the long term. Moreover, the comparison of additional costs and effects in the cost-effectiveness analysis showed that the $\mathrm{Cl}$ intervention is likely to result in savings to society.

\section{Collaboration}

This study is a joint project of the Trimbos institute (Netherlands Institute for Mental Health and Addiction, Utrecht), the CAPHRI School for Public Health and Primary Care of Maastricht University, and VU University Amsterdam. The research is funded by the Netherlands Organization for Health Research and Development (ZonMw) (project No. 15700.2012) and is registered in the Netherlands Trial Register, part of the Dutch Cochrane Centre (NTR3728). This study was approved by the Dutch Medical Ethics Committee for Mental Health Care (METiGG) in February 2012 (NL31267.097.10). 


\section{Competing interests}

All authors declare that they have no competing interests.

\section{Authors' contributions}

FS drafted the manuscript. SMAAE made substantial contributions to the analysis and interpretation of data. $\mathrm{CH}$ and SMAAE contributed to the acquisition of funding for this study and $\mathrm{CH}, \mathrm{FLW}$ and SMAAE participated in the writing of the manuscript by critically revising draft versions. All authors have read and approved the final manuscript. 


\section{References}

Afifi, T. O., Murray, W. E., Cox, B. J., de Graaf, R., ten Have, M., \& Sareen, J. (2007). Child abuse and health-related quality of life in adulthood. The Journal of Nervous and Mental Disease, 195(10), 797-804.

Alink, L.R.A., van IJzendoorn, M.H., Bakermans-Kranenbrug, M.J., Pannebakker, F.D., Vogels, T., \& Euser, S. (2011). Kindermishandeling in Nederland anno 2010: De tweede Nationale Prevalentiestudie Mishandeling van Kinderen en Jeugdigen (NPM-2010) (Child maltreatment in the Netherlands in 2010: The second prevalence study of the maltreatment of children and adolescents in the Netherlands). Leiden: Casimir Publishers.

Baeten, P. (2009). Protocol van handelen- Bij vermoedens van kindermishandeling in relatie van afhankelijkheid en onvrijheid (Manual- How to act in case of suspected child maltreatment relating to dependence and restriction of freedom). Utrecht: MO Groep.

Barlow, J., Davis, H., Mclntosh, E., Jarrett, P., Mockford, C., \& Steward-Brown, S. (2007). Role of home visiting in improving parenting and health in families at risk of abuse and neglect: Results of a multicentre randomized controlled trial and economic evaluation. Archives of Disease in Childhood, 92(3), 229-233.

Bell, A. (2007). Designing and testing questionnaires for children. Journal of Research in Nursing, 12, 461-471.

Black, M. M., \& Ponirakis, R. (2000). Computer-administered interviews with children about maltreatment: Methodological, developmental, and ethical issues. Journal of Interpersonal Violence, 15(7), 682-695.

Corso, P. S., Edwards, V.J., Fang, X., \& Mercy, J.A. (2008). Health-related quality of life among adults who experienced maltreatment during childhood. American Journal of Public Health, 98(6), 1094-1100.

Corso, P. S., \& Fertig, A. R. (2010). The economic impact of child maltreatment in the United States: Are estimates credible? Child Abuse \& Neglect, 34, 296-304.

Corso, P. S., \& Lutzker, J. R. (2006). The need for economic analysis in research on child maltreatment. Child Abuse \& Neglect, 30, 727-738.

Council for Public Health and Health Care(2006). Zinnige en duurzame zorg (Sensible and Sustainable Care). Council for Public Health and Health Care.

Dalziel, K., \& Segal, L. (2012). Home visiting programmes for the prevention of child maltreatment: cost-effectiveness of 33 programmes. Archives of Disease in Childhood, 97, 787-798.

Dolan, P., \& Sutton, M. (1997). Mapping visual analogue scale health state valuations onto standard gamble and time trade-off values. Social Science \& Medicine, 44(10), 1519-1530.

Drost, R. M. W. A., Paulus, A. T. G., Ruwaard, D., \& Evers, S. M. A. A. (2014). Handleiding intersectorale kosten en baten van (preventieve) interventies: Classificatie, Identificatie en Kostprijzen (Manual for costs and benefits of (preventive) interventions: Classification, Identification and Cost prices). Maastricht: Universiteit Maastricht/Health Services Research, CAPHRI.

Dubowitz, H., \& Bennett, S. (2007). Physical abuse and neglect of children. The Lancet, 369, 1891-1899.

Engelen, V., Haentjens, M. M., Detmar, S. B., Koopman, H. M., \& Grootenhuis, A. (2009). Health related quality of life of Dutch children: Psychometric properties of the PedsQL in the Netherlands. BMC Pediatrics, 9, 68-75.

Euser, S., Alink, L. R. A., Pannebakker, F., Vogels, T., Bakermans-Kranenburg, M. J., \& Van IJzendoorn, M. H. (2013). The prevalence of child maltreatment in the Netherlands across a 5-year period. Child Abuse \& Neglect, 37(10), 841-851.

Fang, X., Brown, D. S., Florence, C. S., \& Mercy, J. A. (2012). The economic burden of child maltreatment in the United States and implications for prevention. Child Abuse \& Neglect, 36, 156-165. 
Fromm, S. (2001). Total estimated cost of child abuse and neglect in the United States: Statistical evidence. Chicago, IL: Prevent Child Abuse America.

Gospodarevskaya, E., \& Segal, L. (2012). Cost-utility analysis of different treatments for post-traumatic stress disorder in sexually abused children. Child \& Adolescent Mental Health, 6, 15.

Graham-Bermann, S. A., Kulkarni, M. R., \& Kanukollu, S. (2011). Is disclosure therapeutic for children following exposure to traumatic violence? Journal of Interpersonal Violence, 26(5), 1056-1076.

Hakkaart-van Roijen, L., Donker, M., \& Tiemens, B. (2002). Manual Trimbos/iMTA questionnaire for Costs associated with Psychiatric illness (TiC-P). Erasmus MC Rotterdam: Instituut voor Medische Technology Assessment.

Hakkaart-van Roijen, L., Tan, S. S., \& Bouwmans, C. A. M. (2010). Handleiding voor kostenonderzoek. Methoden en standaard kostprijzen voor economische evaluaties in de gezondheidszorg. Geactualiseerde versie 2010 (Manual for costing in economic evaluation. Updated version 2010). Erasmus MC Rotterdam: Instituut voor Medische Technology Assessment.

Lamb, M. E., Orbach, Y., Herschkowitz, I., Esplin, P. W., \& Horowitz, D. (2007). A structured forensic interview protocol improves the quality and informativeness of investigative interviews with children: A review of research using the NICHD investigative interview protocol. Child Abuse \& Neglect, 31, 1201-1231.

Leeb, R. T., Lewis, T., \& Zolotor, A. J. (2011). A review of physical and mental health consequences of child abuse and neglect and implications for practice. American Journal of Lifestyle Medicine, 5(5), 454-468.

Lipsey, M. W., \& Wilson, D. B. (1993). The efficacy of psychological, educational, and behavioral treatment. American Psychologist, 48, 1181-1209.

Maher, E. J., Corwin, T. W., Hodnett, R., \& Faulk, K. (2012). A cost-savings analysis of a statewide parenting education program in child welfare. Research on Social Work Practice, 22(6), 615-625.

Manca, A., Hawkins, N., \& Sculpher, M. J. (2005). Estimating mean QALYs in trial-based cost-effectiveness analysis: The importance of controlling for baseline utility. Health Economics, 14(5), 487-496.

McCrone, P., Weeramanthri, T., Knapp, M., Rushton, A., Trowell, J., Miles, G., \& Kolvin, I. (2005). Cost-effectiveness of individual versus group psychotherapy for sexually abused girls. Child \& Adolescent Mental Health, 10(1), 26-31.

Meerding, W. (2005). Maatschappelijke kosten van kindermishandeling (Costs to society of childhood maltreatment). In Kindermishandeling: De politiek een zorg. Edited by Willems J, Baartman H, Bullens R. Amsterdam: SWP.

Mills, R., Scott, J., Alati, R., O'Callaghan, M., Najman, J. M., \& Strathearn, L. (2013). Child maltreatment and adolescent mental health problems in a large birth cohort. Child Abuse \& Neglect, 37(5), 292-302.

Morimoto, T., \& Fukui, T. (2002). Utilities measured by rating scale, time trade-off, and standard gamble: Review and reference for health care professionals. Journal of Epidemiology, 12(2), 160-178.

O'Brien, M. (2011). Measuring the effectiveness of routine child protection services: The results from an evidence based strategy. Child \& Youth Services, 42(4), 303-316.

Palmer, S. E., Brown, R.A., Rae-Grant, N. I., \& Loughlin, M. J. (2000). Responding to children's disclosure of familial abuse: What survivors tell us. Child Welfare League of America, LXXVIII(2), 259-282.

Patterson, T., \& Pipe, M. (2009). Exploratory assessment of child abuse. Children's responses to interviewer's questions across multiple interview session. Child Abuse \& Neglect, 33, 490-504.

Severens, J. L., Mulder, J., Laheij, R. J. F., \& Verbeek, A. L. M. (2000). Precision and accuracy in measuring absence from work as a basis for calculating productivity costs in the Netherlands. Social Science \& Medicine, 51, 243-249.

Snoeren, F., Hoefnagels, C., Evers, S. M. A. A., \& Lamers-Winkelman, F. (2013). Design of a prospective study on mental health and quality of life of maltreated children (aged 5-16 years) after a report to an advice and reporting center on child abuse and neglect. BMC Public Health, $13,942$. 
Solomon, D., \& Asberg, K. (2012). Effectiveness of child protective services interventions as indicated by rates of recidivism. Child Youth Services Review, 34, 2311-2318.

Springer, K.W., Sheridan, J., Kuo, D., \& Carnes, M. (2007). Long-term physical and mental health consequences of childhood physical abuse: Results from a large population-based sample of men and woman. Child Abuse \& Neglect, 31(5), 517-530.

Tanaka, M., Jamieson, E., Wathen, N., \& MacMillan, H. L. (2010). Methodological standards for randomized controlled trials of intervention for preventing recurrence of child physical abuse and neglect. Child Abuse Review, 19, 21-38.

The EuroQol Group (1990). EuroQol- A new facility for the measurement of health-related quality of life. Health Policy, 16(3), 199-208.

Thorn, J. C., Coast, J., Cohen, D., Hollingworth, W., Knapp, M., Noble, S. M., Ridyard, C., Wordsworth, S., \& Hughes, D. (2013). Resource-use measurement based on patient recall: Issues and challenges for economic evaluation. Applied Health Economics and Health Policy, 11, 155-161.

Trotter, C. (2008). What does client satisfaction tell us about effectiveness? Child Abuse Review, $17,262-274$.

Van Asselt, A. D. I., Van Mastrigt, A. P. G., Dirksen, C. D., Arntz, A., Severens, J. L., \& Kessels, G. H. (2009). How to deal with cost differences at baseline. Pharmacoeconomics, 27(6), 519-528.

Verhulst, F.C., Ende, J. van der \& Koot, H.M. (1998). Handleiding voor de CBCL/4-18 18 (Manual Child Behavior Checklist/4-18). Rotterdam: Sophia Kinderziekenhuis, Erasmus MC.

Wille, N., Badia, X., Bonsel, G., Burstrom, K., Cavrini, G., Devlin, N., Egmar, A., et al. (2010). Development of the EQ-5D-Y: a child-friendly version of the EQ-5D. Quality of life research, 19(6), 875-886.

World Medical Association (2013). Declaration of Helsinki. Ethical Principles for Medical Research Involving Human Subject. 64th WMA General Assembly in Fortaleza, Brazil: World Medical Association, Inc. 


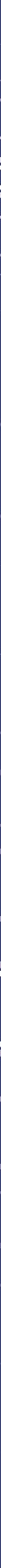




\section{(2)}

\section{CHAPTER 8}

General Discussion

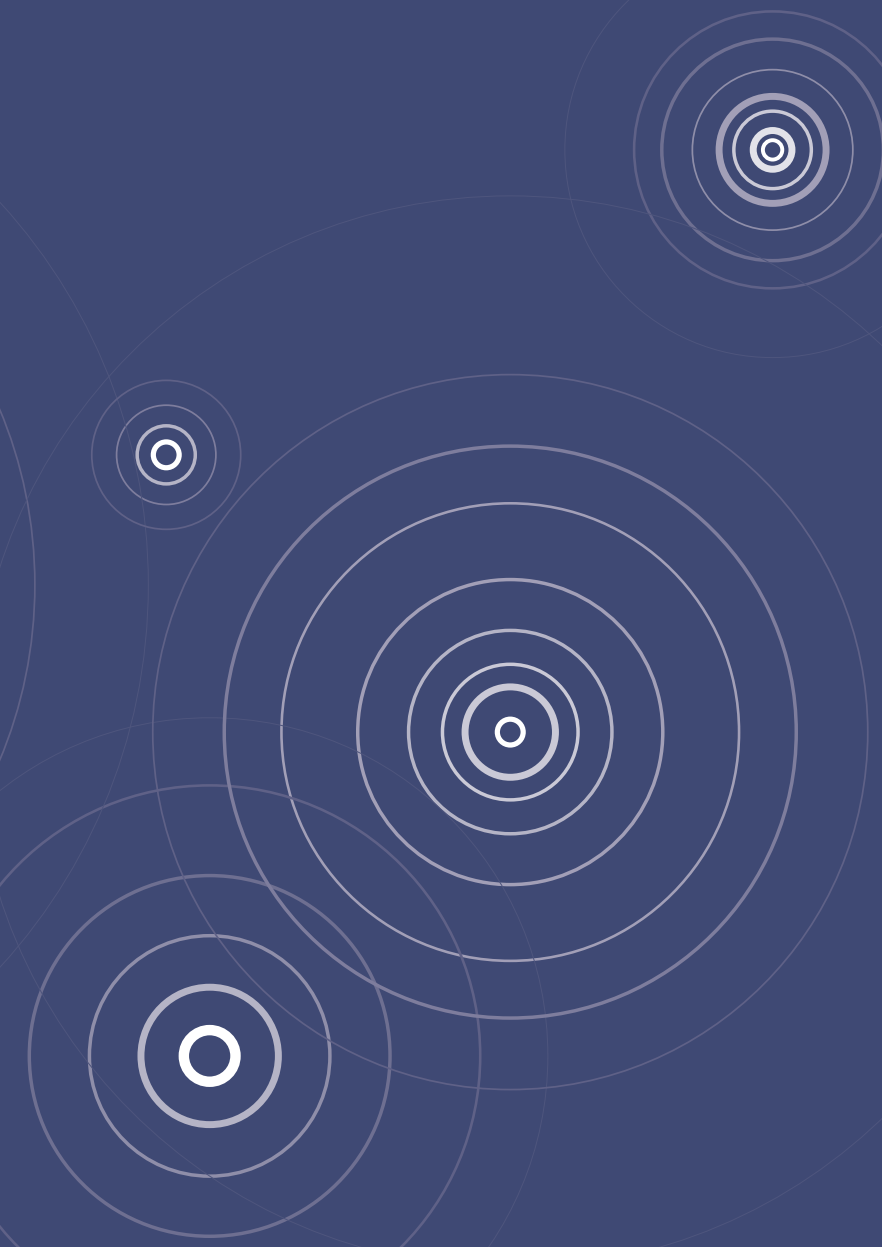




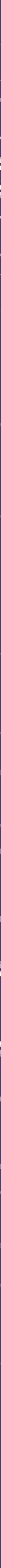


The research reported on in this thesis addressed the central topic of 'giving children a voice' in three ways. The first step was the development of questionnaires by which children can self-report on issues regarding their well-being, in this case perceived social support and perceived stress (Part I). Enabling children to self-report requires reliable self-report questionnaires, but reliable questionnaires for young children with regard to constructs related to well-being are scarce (Lippman, Moore, \& Mclntosh, 2011). Nevertheless, asking children to self-report is the first step towards obtaining information about children's own views of their life. This information can be used for both practice and research. The other studies reported on in this thesis (Parts II and III) all focused on child maltreatment and the way in which maltreated children can be given a voice.

The second step in addressing the central topic of 'giving children a voice' involved asking maltreated children to self-report for the purpose of data collection for scientific research. Maltreated children were asked to self-report on their quality of life shortly after the maltreatment experiences. They were followed for 1.5 years, during which they completed a questionnaire four times. The maltreated children were also asked to self-report on other issues that may have been associated with their quality of life outcomes, such as perceived social support and perceived stress, using the self-report questionnaires specifically developed for use in this study.

Thirdly, children should also be given a voice in routine practice. To this end, we examined the effectiveness of the 'child-interview' intervention ( $\mathrm{Cl}$ intervention), an intervention in which maltreated children are interviewed following a maltreatment report to an advice and reporting agency on child abuse and neglect (AMK). The $\mathrm{Cl}$ intervention was compared with the adultonly intervention (AI intervention), in which maltreated children are not interviewed following such a maltreatment report.

This general discussion chapter first summarizes the main findings reported in the thesis, after which the main limitations and strengths of the research are discussed, followed by implications for future research and for practice.

\section{Main findings}

\section{Part I}

Two self-report questionnaires were developed to measure perceived social support and perceived stress among children aged between 8 and 11 years. The aim was to examine the internal consistency, test-retest reliability, and 
dimensionality of these questionnaires. Overall, moderate to good internal consistency and test-retest reliability were found for both questionnaires. Since the child questionnaires were developed by adjusting adolescent questionnaires, we also tested their dimensionality to examine whether the underlying dimensions of the adolescent questionnaires were also found in the present child sample. An exploratory factor analysis (PAF) with a factor limit based on the number of subscales/dimensions of the adolescent questionnaires, found almost identical fits between the dimensions in the child questionnaires and those of the adolescent questionnaires. The findings suggest that both self-report measures seem feasible and psychometrically satisfactory for use among children aged 8-11 years (Chapter 2).

\section{Part II}

In part II, the self-reported quality of life of maltreated children was addressed, using a prospective design in which data were collected at four assessments, with 6 -month intervals. The first aim was to compare the self-reported quality of life of maltreated children at assessment 1 with three different norm populations from the general population. Factors associated with the quality of life of maltreated children at assessment 1 were explored as well. The second aim was to examine self-reported quality of life of maltreated children over time (assessments 1-4) and the potential association with child, family/ environmental, and parental factors.

At assessment 1, which took place shortly after the report to the AMK, quality of life outcomes of maltreated children were compared with quality of life outcomes of the general population. Three comparisons were made: (1) with an American norm population consisting of children aged 5-16 years, (2) with Dutch norm scores for subgroups 8-11 and 12-16 years, (3) with American norm scores of individual one-year age groups (5-16 years), comparing children of the same age group. Significantly lower quality of life outcomes were found for the sample of maltreated children aged 5-16 years. The subgroup comparison showed a lower quality of life for children aged 8-11 years, while the comparison for the individual one-year age groups showed the quality of life of children aged 8 and 9 to be significantly lower than that of their non-maltreated peers. No significant differences were found for the other one-year age groups (Chapter 4).

The relation between demographic, socio-economic and maltreatment characteristics and the quality of life of maltreated children at assessment 1 was also explored. The presence of financial problems in the family was the only characteristic associated with the quality of life of maltreated children, 
resulting in lower quality of life. No other characteristics were found to be associated with self-reported quality of life outcomes at assessment 1 (Chapter 4).

Longitudinal analysis of self-reported quality of life over time, at assessments 1-4, showed a significant increase in quality of life between the moment the AMK became involved and the follow-up assessment after 6 months, followed by a significant decrease between the 6-month follow-up and the 1-year follow-up. This decrease persisted, though it was no longer significant, between the assessments at 1 and 1.5 years after AMK involvement. The child factors older age, lower perceived stress and higher self-esteem were associated with higher self-reported quality of life over time. One of the dimensions of parental quality of life, viz. constraint due to emotional problems, was also found to be negatively associated with the quality of life of the maltreated children over time. No association was found between any of the other child, family/environmental and parental factors we studied and the self-reported quality of life of the maltreated children over time (Chapter 5).

The chapters 4 and 5 are based on the same sample. Nevertheless, different sample sizes are reported in the chapters, because we used two different sources to obtain the maltreatment verification status of the AMK investigation (inclusion criterion). For the study reported in chapter 4, these data were obtained from AMK employees, who searched the AMK registration records. For the study reported in chapter 5 , these data were obtained from the AMK registration system directly. By then, at the end of the 1.5 year data collection, all case files were closed and fully updated in the AMK registration system. Based on these updated data, an additional 19 parent-child dyads were excluded.

\section{Part III}

Part III of this thesis focused on the $\mathrm{Cl}$ intervention in comparison with the Al intervention. Both interventions can be used in the AMK investigation following a report of suspected child maltreatment. The first aim of our study was to examine the effect of the $\mathrm{Cl}$ intervention on the behavioral problems and self-reported quality of life of maltreated children. The second aim was to examine the balance between additional costs and effects of the $\mathrm{Cl}$ intervention in comparison with the Al intervention.

Multivariate regression analyses showed no significant differences between the two interventions in terms of effects on behavioral problems and self-reported quality of life. The results of the economic evaluation favored the $\mathrm{Cl}$ intervention. All ICERs were dominant, and at a willingness-to-pay of 
20,000 euros, the probability of the $\mathrm{Cl}$ intervention being more acceptable than the Al intervention was $93 \%$ if the QALY measure was used as an outcome, vs. $76 \%$ when looking at behavioral problems and $91 \%$ for quality of life (Chapter 7). Although quality of life is usually part of the QALY measure, the QALY in this study was based on a rating scale. Quality of life was one of the primary outcome measures assessed with the Dutch translation of the Pediatric Quality of Life Inventory (PedsQL; Engelen, Haentjens, Detmar, Koopman, \& Grootenhuis, 2009)

\section{Main limitations}

The studies in this thesis were subject to some limitations. The main limitations with regard to recruitment and drop-out, the instruments, the design, and the generalizability of the studies are addressed below.

\section{Recruitment and drop-out}

The recruitment for Parts II and III of the study resulted in a low estimated participation rate of $3.5 \%$. Some obstacles were encountered during the recruitment, such as missing phone numbers in AMK records, or families that were not reached during the time slots that were available to call eligible participants. Sometimes a language barrier complicated the recruitment phone calls. We did not keep records of the number of possible participants that were not reached or the number of missing phone numbers, so it is not possible to calculate a participation rate based only on the participants that we were able to reach who were eligible, but refused participation. As a result, the participation rate of $3.5 \%$ documented in this thesis is a conservative estimate.

There was also a substantial (60\%) loss during follow-up, mainly caused by families that had moved and did not leave a new address and participants who said they had no time for follow-up assessments. Loss to follow-up was expected because families of maltreated children tend to move frequently (Eckenrode, Rowe, \& Laird, 1995). Also, families reported to AMKs are often 'multi-problem' families, so new or ongoing problems are likely to occur during the follow-up period, which may cause them to drop out (Jaffee, Caspi, Moffitt, Polo-Tomas, \& Taylor, 2007). This is why we invested much time and effort in recruiting a study sample large enough to anticipate and compensate for this expected loss during follow-up. 


\section{Issues regarding the instruments}

There were some concerns regarding the use or development of the instruments for the studies in this thesis. In Part I, questionnaires for adolescents were used to develop questionnaires for children. However, in view of the developmental differences between children and adolescents, it may be premature to assume that perceived social support and perceived stress have the same underlying dimensions for children as for adolescents. Studying the construct validity should be considered to rule out the possibility that dimensions that are important to children were overlooked because they were not part of the adolescent questionnaire. Nevertheless, our preliminary test of dimensionality did support the assumption that the underlying dimensions were comparable for children and adolescents.

Part II used the PedsQL to measure the self-reported quality of life of maltreated children. Although the PedsQL has proved to be a reliable instrument to measure self-reported quality of life in children in the general population (Engelen et al., 2009; Varni, Seid, \& Kurtin, 2001), it is unknown whether additional dimensions, such as life perspective or autonomy, may matter in case of child maltreatment. The PedsQL addresses only the usual dimensions of quality of life (physical functioning, emotional functioning, social functioning, and school functioning). Whether additional dimensions should be part of the questionnaire for use with maltreated children remains to be examined. It is also unknown whether maltreated children perceive dimensions, such as physical quality of life, in the same way as non-maltreated children (Mabugu, Revill, \& Van den Berg, 2013).

In Part III, QALYs were derived from a rating scale. This is not the preferred method to measure changes in quality of life in an adult population, but the questions asked in other more suitable methods are too complicated for children to answer. Moreover, the rating scale was not completed by all children at both assessments, resulting in a QALY estimate based on a single assessment, whereas QALYs are usually a measure of change in quality of life over time. As a result, our findings in QALY terms should be interpreted with caution. A sensitivity analysis did suggest, however, that the method used in this study to estimate the QALY was satisfactory.

\section{Issues regarding the design}

The study designs used in Parts II and III were subject to some limitations. Although both studies in Part II provided unique information about the self-reported quality of life of maltreated children and the associated factors, the designs preclude statements of causality. Part III was subject to limitations 
caused by its quasi-experimental design, which was chosen because the Dutch Medical Ethics Committee for Mental Health Care did not approve the use of an RCT. Therefore, the participants were divided into the study groups (Al or $\mathrm{Cl}$ intervention group) based on the intervention that had taken place during the AMK investigation. This AMK investigation was completed prior to the recruitment for the study, so random assignment was not possible, as the intervention to be used in a particular case was decided during the multidisciplinary AMK meeting. Despite the fact that we compared the $\mathrm{Al}$ and $\mathrm{Cl}$ intervention groups at assessment 1 and adjusted for differences (in age and employment rate) in the analyses, our results could have been affected by differences between groups that could not be accounted for because they were unknown.

For the economic evaluation in Part III, participants of the prospective study of Part II were asked to complete an additional questionnaire at two of the follow-up assessments to collect data on resource use. Economic evaluations to measure resource use generally use a recall period of three months. However, the prospective study was an ongoing study, and follow-up assessments were scheduled every 6 months. We decided not to alter this schedule, so recall bias is a possibility.

Another limitation was that maltreated children and their parents were asked to participate in these studies shortly after a report of suspected child maltreatment had been filed to an AMK. It would be interesting to have information on the self-reported quality of life and other factors we studied prior to the report to an AMK. Obviously it is not possible to ask participants to complete a questionnaire prior to them being reported to an AMK.

\section{Generalizability}

Three comments could be made regarding the generalizability of the findings. In the first place, these studies were performed among maltreated children who were reported to an AMK. It is unknown whether the findings also apply to maltreated children who were not reported to an AMK. The group of non-reported maltreated children is much larger than the reported group, in view of the fact that the AMKs receive about 19,000 reports each year, while the prevalence of child maltreatment in the Netherlands was estimated at 118,000 in 2010 (Alink, Van IJzendoorn, Bakermans-Kranenburg, Pannebakker, Vogels, et al., 2011; Euser, Alink, Pannebakker, Vogels, Bakermans-Kranenburg, et al., 2013). The number of 19,000 AMK reports is debatable, considering that $11.7 \%$ of the reports in 2012 could not be verified and $7.5 \%$ were falsified (Jeugdzorg Nederland 2013). On the other hand, many reports 
included more than one child per family. In any case, it is clear that the majority of maltreated children in the Netherlands still do not come to the attention of the AMKs.

Secondly, selection bias cannot be ruled out, which would be a threat to generalizability. Selection bias may have been caused by the recruitment by phone, because not all eligible participants were reached. It may also have been caused by self-selection, because participation in the study was voluntary. The non-response analysis suggested that the study sample may have consisted of less severe or less chronic cases of child maltreatment, because the percentage of families that were reported to child protection services by the AMK was lower in the study sample than in the general AMK population. AMKs only report to child protection services if voluntary care is rejected. Differences in the types of maltreatment that were verified were also found between the study sample and the AMK population, in that the study sample comprised more cases of emotional neglect and fewer cases of emotional abuse.

Thirdly, caution should be exercised regarding families of non-Dutch origin. Families of non-Dutch origin were hard to reach due to language barriers, and a drop-out analysis confirmed selective loss: more non-Dutch families than families of Dutch origin were lost to follow-up. In addition, a sensitivity analysis as part of the economic evaluation in Part III showed that the likelihood of the $\mathrm{Cl}$ intervention being more favorable than the $\mathrm{Al}$ intervention was substantially lower for participants of non-Dutch origin than for Dutch participants. Notwithstanding these concerns, we did not find an association between ethnicity and quality of life outcomes in the research discussed in Part II of the thesis, which would suggest that quality of life outcomes are not related to ethnic origin.

\section{Strengths}

Besides the above limitations, the studies in this thesis also had several strengths. Part I describes the development of two self-report questionnaires for children. No questionnaires were available at the start of this research project to measure perceived social support and perceived stress among children between 8 and 11 years. Using self-report questionnaires is important, because of the discrepancies found between child and proxy reports, especially when assessing subjective constructs concerning children's well-being (Rajmil, Fernandez, Gispert, Rue, Glutting, et al., 1999; Theunissen, Vogels, Koopman, Verrips, Zwinderman, et al., 1998). Our study tested the reliability and 
dimensionality of the questionnaires we developed for this age group, which were based on available adolescent questionnaires. The results showed that both questionnaires can be used to measure perceived social support and perceived stress among children in this age group. They could therefore be used to collect data on perceived social support and stress, for use in the studies discussed in Part II of this thesis.

The studies reported on in Part II of the thesis, were the first to examine the quality of life of maltreated children by self-report shortly after a report to a reporting agency on child abuse and neglect, such as the Dutch AMKs. Another strength was the 1.5 year follow-up period, which enabled us to study changes in self-reported quality of life of maltreated children over time. In addition to the quality of life outcomes, we explored whether several child, family/environmental, and parental factors were associated with quality of life outcomes of maltreated children. The association between parental factors and self-reported quality of life outcomes of maltreated children over time had not been studied before, as far as we are aware.

The studies in Part III were the first to examine the effect of interventions used by the AMKs. Moreover, this part of the thesis discussed the first economic evaluation regarding an intervention for maltreated children in the Netherlands. Internationally, economic evaluations regarding child maltreatment interventions have also been scarce (Corso \& Lutker, 2006; Corso \& Fertig, 2010).

\section{Implications for future research}

To begin with, more studies are needed to collect data that would enable comparison of the results with other samples of maltreated children. Such studies should also focus on developmental differences, as results presented in this thesis suggest small but noticeable differences between age groups.

Second, future research should focus on the development of validated self-report instruments to optimize measurement of quality of life, as well as changes in children's quality of life. Research into quality of life instruments for children could also examine which dimensions should possibly be added to optimize the measurement of the quality of life of maltreated children. It also remains to be studied whether maltreated children perceive quality of life dimensions, such as physical quality of life, in the same way as non-maltreated children (Mabugu, et al, 2013).

Instruments to measure changes in quality of life (utilities) are important for economic evaluations. Recently, a youth version of the EQ-5D, one of the 
best-known instruments to measure changes in the quality of life of adults, was developed (Wille, Badia, Bonsel, Burstrom, Cavrini, et al., 2010) and translated into Dutch. Its psychometric properties will hopefully be examined in the near future. Additionally, future research should focus on the development of instruments to collect data on the use of child and youth services within and outside the healthcare sector, to improve the interpretations of the findings. These services need to be valued for use in economic evaluations.

Third, our findings should be confirmed by means of additional studies on the factors associated with the quality of life outcomes of maltreated children over time, such as perceived stress and self-esteem. These studies could focus on the possible interrelatedness of these factors and quality of life in relation to child maltreatment. The studies reported on in this thesis used an exploratory approach to examine which factors were associated with the quality of life of maltreated children over time. Research addressing the interrelatedness of the factors using methods like structural equation modeling may provide additional information. Furthermore, the association between maltreatment characteristics and quality of life outcomes over time could be explored.

Fourth, studies using different designs, preferably long-term studies with a design that permits statements of causality, are suggested to better understand the relation between child maltreatment and its adverse effect on quality of life over time. It would be interesting to discover why the self-reported quality of life of the maltreated children of all age groups in our study first increased, then decreased over time after the AMK became involved.

Fifth, to better understand the findings of our studies, more detailed information is required regarding the child and family welfare interventions that were recommended by the AMKs, and whether families complied with these interventions. Research could also examine what forms of child and family welfare interventions are most successful and for whom.

Sixth, economic evaluations are needed regarding child maltreatment interventions.

\section{Conclusion and implications for practice}

The results presented in Part I imply that perceived social support and perceived stress can reliably be measured among children aged 8-11 years. Giving these children a voice by asking them to self-report, would reduce incorrect interpretations regarding children's perceived social support and stress. Using child reports in addition to proxy reports is advisable considering 
the discrepancies that are regularly found between child and proxy reports when examining subjective constructs (Eiser \& Morse, 2001; Prosser \& Corso, 2007; Rajmil et al., 1999; Theunissen et al., 1998; Wallander, Schmitt, Burstrom, Cavrini, Devlin, et al., 2001).

This study obtained data on self-reported quality of life over time and associated factors (Part II). These results are of interest to the AMKs and other professionals working with maltreated children in that they provide information on factors that may make maltreated children more vulnerable to adverse quality of life outcomes. This information may help professionals to provide suitable care.

The results showed that it is possible to perform a study, based on self-report questionnaires, in which maltreated children are the participants. Furthermore, the findings may make professionals and policy makers aware of the serious adverse consequences of child maltreatment on quality of life. This hopefully emphasizes the importance of prevention of maltreatment and the importance to optimize suitable treatment for maltreated children. Part III addressed two AMK interventions, one in which adults are the only participants in the AMK investigation and one in which children are given a voice during the investigation. Although the superiority of the $\mathrm{Cl}$ intervention was not proven by this study, AMK social workers have expressed that the interviews with these children help them improve the referral process to tailored care. They believe that the child interviews strengthen children's feelings of being in control of their own situation, which will likely benefit them in the future. Besides providing useful information for the AMKs, our results are also relevant to policy makers. The outcomes can help them decide on adjustments in policy regarding child maltreatment. These days, financial resources are limited, and there are rapid changes in the child and family care sector in the Netherlands, which emphasizes the need for such information.

The main recommendation is to give maltreated children a voice by asking them to self-report on issues that concern them. Allowing children to express their thoughts, feelings, and concerns results in a great deal of valuable and relevant information which cannot be obtained from other sources. This information care be used to provide tailored care. 


\section{References}

Alink, L. R. A., Van IJzendoorn, M. H., Bakermans-Kranenburg, M. J., Pannebakker, F. D., Vogels, T., \& Euser, S. (2011). Kindermishandeling in Nederland anno 2010: De Tweede Nationale Prevalentiestudie Mishandeling van Kinderen en Jeugdigen (NPM-2010) (Child maltreatment in the Netherlands in the year 2010: the second prevalence study of the maltreatment of children and youth in the Netherlands). Leiden: Casimir Publishers.

Corso, P. S., \& Lutzker, J. R. (2006). The need for economic analysis in research on child maltreatment. Child Abuse \& Neglect, 30, 727-738.

Corso, P. S., \& Fertig, A. R. (2010). The economic impact of child maltreatment in the United States: Are estimates credible? Child Abuse \& Neglect, 34, 296-304.

Eckenrode, J., Rowe, E., \& Laird, M. (1995). Mobility as a mediator of the effects of child maltreatment on academic performance. Child Development, 66(4), 1130-1142.

Engelen, V., Haentjens, M. M., Detmar, S. B., Koopman, H. M., \& Grootenhuis, A. (2009).

Health related quality of life of Dutch children: Psychometric properties of the PedsQL in the Netherlands. BMC Pediatrics, 9, 68-75.

Eiser, C., \& Morse, R. (2001). Can parents rate their child's health-related quality of life? Results of a systematic review. Quality of Life Research, 10, 347-357.

Euser, S., Alink, L. R. A., Pannebakker, F., Vogels, T., Bakermans-Kranenburg, M. J., \& Van IJzendoorn, M. H. (2013). The prevalence of child maltreatment in the Netherlands across a 5-year period. Child Abuse \& Neglect, 37(10), 841-851.

Jaffee, S. R., Caspi, A., Moffitt, T. E., Polo-Tomas, M., \& Taylor, A. (2007). Individual, family, and neighborhood factors distinguish resilient from non-resilient maltreated children: A cumulative stressors model. Child Abuse \& Neglect, 31, 231-253.

Jeugdzorg Nederland. (2013). AMK cijfers in 2012 (AMK annual report 2012). Zalsman: Zwolle.

Lippman, L. H., Moore, K. A., \& McIntosh, H. (2011). Positive indicators of child well-being. Aconceptual framework, measures, and methodological issues. Applied Research Quality of Life, 6, 425-449.

Mabugu, T., Revill, P., \& Van den Berg, B. (2013). The methodological challenges for the estimation of quality of life in children for use in economic evaluation in low-income countries. Value in Health Regional Issues, 2, 231-239.

Prosser, L. A., \& Corso, P. S. (2007). Measuring health-related quality of life for child maltreatment: A systematic literature review. Health and Quality of Life Outcomes, 5, 42-52.

Rajmil, L., Fernandez, E., Gispert, R., Rue, M., Glutting, J. P., Plasencia, A., \& Segura, A. (1999). Influence of proxy respondents in children's health interview surveys. Epidemiology Community Health, 53, 38-42.

Theunissen, N. C. M., Vogels, T. G. C., Koopman, H. M., Verrips, G. H. W., Zwinderman, K. A. H., Verloove-Vanhorick, S. P., \& Wit, J. M. (1998). The proxy problem: Child report versus parent report in health-related quality of life research. Quality of Life Research, 7, 387-397.

Varni, J.W., Seid, M., \& Kurtin, P. (2001). PedsQL 4.0: Reliability and validity of the Pediatric Quality of Life Inventory version 4.0 generic core scales in healthy and patient populations. Medical Care, 39, 800-812.

Wallander, J. L., Schmitt, M., \& Koot, H. M. (2001). Quality of life in children and adolescents: Issues, instruments, and applications. Journal of Clinical Psychology, 57(4), 571-585.

Wille, N., Badia, X., Bonsel, G., Burstrom, K., Cavrini, G., Devlin, N., Egmar, A., et al. (2010). Development of the EQ-5D-Y: a child-friendly version of the EQ-5D. Quality of life research, 19(6), 875-886. 



\section{CHAPTER 9}

Summary 



\section{Part I}

There is growing interest in understanding and optimizing child development by giving children a voice. Asking children to self-report on topics regarding their well-being has increasingly been recognized as a valid approach, especially considering the discrepancies that are regularly found between child and proxy reports with regard to subjective topics. In the Netherlands, no self-report questionnaires were available to measure perceived social support and perceived stress among children aged between 8 and 11 years. We therefore developed these questionnaires by adjusting adolescent questionnaires for use among this younger age group. The aim of the study was to examine the internal consistency, the test-retest reliability and the dimensionality of the self-report questionnaires to measure perceived social support and perceived stress among children aged between 8 and 11 years. Overall, moderate to good internal consistency and test-retest reliability were found for both questionnaires. An exploratory factor analysis (principle axis factoring) suggested that the dimensions of the adolescent questionnaires were also found for the child questionnaires. The results indicate that both self-report questionnaires seem feasible and psychometrically suitable for use among children aged 8-11 years (Chapter 2).

\section{Part II}

Child maltreatment has considerable adverse consequences for physical and mental health. These days interest in quality of life is increasing, as this construct gives a more detailed view on an individual's overall functioning and perception of life. However, there have been few studies on perceived quality of life of child maltreatment victims. Part II of this thesis addresses the central topic of giving children a voice by describing a prospective study in which maltreated children (aged 5-16) were asked to complete a self-report questionnaire four times over a period of 1.5 years after being reported to a Dutch advice and reporting agency on child abuse and neglect (Advies- en Meldpunt Kindermishandeling; AMK). The design of this study is documented in Chapter 3. The first aim was to compare the self-reported quality of life of the maltreated children shortly after the report to the AMK (assessment 1) with that of norm populations from the general population (Chapter 4). The second aim was to examine the self-reported quality of life of the maltreated children over time (assessment 1-4). We also examined child, family/ 
environmental, and parental factors that could be associated with quality of life outcomes of maltreated children (Chapter 5).

In Chapter 4, the quality of life outcomes of the maltreated children at the first assessment, i.e. shortly after the report to the AMK, are compared with quality of life scores of norm populations from the general population. The results show slightly but significantly lower quality of life outcomes for maltreated children than for non-maltreated children. In addition, we explored the association between demographic, socio-economic, and maltreatment characteristics and quality of life outcomes shortly after the AMK report. The presence of financial problems in the family was associated with lower self-reported quality of life of the maltreated children. No other characteristics were found to be associated with the self-reported quality of life outcomes shortly after the report to the AMK.

Chapter 5 reports on a longitudinal analysis of self-reported quality of life over time, i.e. at assessments 1-4, which showed a significant increase in quality of life between the assessment shortly after the report to the AMK and the follow-up 6 months later. This increase was followed by a significant decrease between the 6-month follow-up and the 1-year follow-up. The decrease persisted, though not significantly, between the 1 and 1.5 year follow-up assessments. Child factors that were associated with higher self-reported quality of life of maltreated children over time were older age, lower perceived stress and higher self-esteem. One of the dimensions of parental quality of life, viz. constraint due to emotional problems, was found to be negatively associated with the quality of life of maltreated children over time. No association was found between self-reported quality of life and the other child (perceived social support), parental (parenting stress, perceived social support, quality of life) or family/environmental (neighborhood perception, ethnic background, family situation, and socioeconomic status) factors we studied.

\section{Part III}

A report of suspected child maltreatment to an AMK is followed by an investigation by the AMK to collect information in order to verify or falsify the alleged maltreatment. The AMKs can choose between two intervention methods for investigation: the adult-only intervention (Al intervention) in which only adults are interviewed, and the child-interview intervention (Cl intervention) in which not only the adults are interviewed but also the 
children. The $\mathrm{Cl}$ intervention is the preferred method according to the AMK manual, and is in line with the shift toward a more child-oriented approach.

In addition to an adverse impact of child maltreatment on the physical and mental health of children and their quality of life, there is also an impact on society. Maltreatment may cause children to develop physical or mental health problems. Maltreated children and their families are therefore likely to use multiple services, such as healthcare and social services, which may result in substantial societal costs. This financial burden to society emphasizes the need for economic evaluation studies, which enable policy makers to make decisions regarding the most cost-effective methods for use in practice. Part III of this thesis addresses the central topic of giving children a voice by reporting on the effectiveness and cost-effectiveness of the $\mathrm{Cl}$ intervention in comparison with the Al intervention. The design of this study is documented in Chapter 6 . The first aim was to examine the effect of the $\mathrm{Cl}$ intervention on the behavioral problems and self-reported quality of life of maltreated children. The second aim was to examine the balance between additional costs and effects of the $\mathrm{Cl}$ intervention in comparison with the $\mathrm{Al}$ intervention.

The analyses reported on in Chapter 7 showed no significant differences between the $\mathrm{Al}$ and $\mathrm{Cl}$ interventions regarding the effect on the behavioral problems and self-reported quality of life of maltreated children. The results of the economic evaluation were in favor of the $\mathrm{CI}$ intervention. All ICERs were dominant, and at a willingness-to-pay of 20,000 euros, the probability of the $\mathrm{Cl}$ intervention being more acceptable than the $\mathrm{Al}$ intervention was 93\% for the QALY measure, 76\% for behavioral problems, and $91 \%$ for quality of life.

\section{Conclusion and implications for research and practice}

To the best of our knowledge, this was the first time that the self-reported quality of life of maltreated children who were reported to an AMK was studied. Additional research is needed to enable comparison of these results with quality of life outcomes of other maltreated children, such as those not reported to AMKs. Future research should also focus on optimizing the assessment of quality of life in children, including maltreated children. There is a need to examine which quality of life dimensions apply to maltreated children and whether maltreated children perceive quality of life dimensions 
in the same way as non-maltreated children. Moreover, instruments to measure changes in quality of life (utilities) of children are necessary to enable economic evaluations.

Child maltreatment is likely result in substantial societal costs. Economic evaluations enable policy makers to make decisions regarding the most cost-effective methods for use in practice. Unfortunately, economic evaluations regarding interventions for maltreated children are still scarce and therefore recommended for the future. The research reported in this thesis was the first economic evaluation of an intervention used by an advice and reporting agency on child abuse and neglect, such as the Dutch AMKs.

This thesis provides information on the outcomes of maltreated children after they were reported to an AMK. Moreover, it reports factors that may make these children more vulnerable to adverse quality of life outcomes. Our results also showed that asking maltreated children to report on their situation results in valuable information, which may help AMK social workers and other professionals working with maltreated children to clarify the problem, which may contribute to better referral to tailored care. The results, in particular those of the economic evaluation of the $\mathrm{Cl}$ intervention, are also relevant to policy makers in that they assist them in the decision-making process regarding the prevention and treatment of child maltreatment.

To conclude, the results reported in this thesis have shown the importance of giving maltreated children a voice, as they can provide valuable and relevant information if they are asked to report on their thoughts, feelings, and concerns. This information care be used to provide tailored care. 



\section{Valorization}



The valorization table shows the relevance of the thesis to society specified by target group. The relevant messages from the thesis are reported as well as suggestions how to apply these messages in practice, the ways of dissemination of the messages by us and implications for future research and practice.

\section{Table summary}

The main messages from this thesis are:

- Self-reports can be used to obtain information on children's perceived personal situation (e.g. quality of life, perceived stress, perceived social support)

- Self-report instruments can generate a lot of relevant and valuable information on children's perceived personal situation (e.g. quality of life, perceived stress, perceived social support)

- Child maltreatment is associated with adverse quality of life outcomes for children

- Talking with maltreated children results in relevant and valuable information, which can help professionals in providing tailored care if children report on their needs

- $\mathrm{Cl}$ intervention may be cost-effective

What can target groups do to implement main messages:

- Professionals working with maltreated children should interview reported children at least once to clarify needs

- Professionals working with maltreated children could consider using self-report instruments to obtain information about the child's needs, which can be used as input for tailored care

- AMKs could play a role in after-care instead of 'only' referral to follow-up care

- Teachers, parents and professionals working with children, should report suspicions of child maltreatment to the AMK's

- Teachers, parents and children should be open to talk to children/peers about maltreatment experiences

- Policy makers and health care providers should focus on prevention of maltreatment and on implementation of cost-effective interventions when child maltreatment has been substantiated

- Scientists should consider to use self-report instruments when studying children's perceived personal situation 
Dissemination by us:

- Organize symposium for AMKs and health care professionals

- Report study results in journals relevant to target group

- Press release (around time of defense PhD thesis)

- Present at national and international conferences

- Initiate dialogue with policy makers about implementation of the results in daily practice

Implications for professionals working with maltreated children:

- Make child maltreatment part of education for professionals working with maltreated children

- More training on how to talk to maltreated children

- Encourage children to talk about their personal situation, also if child maltreatment is the subject

- Implement the child-interview in all AMK investigations (for children $>6$ years)

- Provide specialized care for maltreated children (e.g. psycho education or trauma therapy)

- An improved self-report instrument (e.g. quality of life instruments) could be implemented in follow-up treatment

Summary of implications for research

- Perform additional studies on quality of life outcomes, also among maltreated children to enable comparison of the findings

- Improve (or develop) a quality of life instrument for use among maltreated children

- Continue studying (interrelatedness of) factors associated with quality of life of maltreated children to understand predisposing factors

- Collect data on the child and family welfare interventions that were recommended by the AMKs and whether families complied to these interventions to better understand the findings in these studies.

- Study if there is an association between the end or recurrence of maltreatment and quality of life outcomes.

- Perform economic evaluations on interventions regarding child maltreatment 


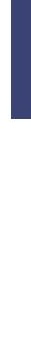




\begin{tabular}{|c|c|c|}
\hline Target Group & Message from this thesis & What can be done? \\
\hline AMK social workers & $\begin{array}{l}\text { - Self-reports can be used to } \\
\text { obtain information on children's } \\
\text { personal situation (e.g. quality } \\
\text { of life, perceived stress, } \\
\text { perceived social support) } \\
\text { - Self-report instruments } \\
\text { generate a lot of relevant and } \\
\text { valuable information on } \\
\text { children's personal situation } \\
\text { - Maltreated children can provide } \\
\text { relevant and valuable } \\
\text { information }\end{array}$ & $\begin{array}{l}\text { - Interview reported children at } \\
\text { least once to clarify needs } \\
\text { - Play a role in after-care instead of } \\
\text { 'only' referral to follow-up care: } \\
\text { e.g. by extending to several } \\
\text { follow-up evaluation moments } \\
\text { instead of one (after } 3 \text { months) } \\
\text { - As a supplement to the current } \\
\text { procedure, consider using } \\
\text { self-report instruments as input } \\
\text { for the procedure }\end{array}$ \\
\hline $\begin{array}{l}\text { Health care } \\
\text { professionals } \\
\text { (GP, social workers, } \\
\text { regional public } \\
\text { health service) }\end{array}$ & & $\begin{array}{l}\text { - Interview reported children at } \\
\text { least once to clarify needs } \\
\text { - Monitoring (in case of worry, } \\
\text { invite back for consult) } \\
\text { - Focus more on social-emotional } \\
\text { development instead of main } \\
\text { focus on physical development } \\
\text { - As a supplement to the current } \\
\text { procedure, consider using } \\
\text { self-report instruments as input } \\
\text { for the procedure }\end{array}$ \\
\hline Teachers & $\begin{array}{l}\text { - Child maltreatment is associated } \\
\text { with adverse quality of life } \\
\text { outcomes for children } \\
\text { - Talking with children results } \\
\text { in relevant and valuable } \\
\text { information }\end{array}$ & $\begin{array}{l}\text { - Be aware of negative outcomes of } \\
\text { child maltreatment } \\
\text { - Be aware of signals of child } \\
\text { maltreatment } \\
\text { - } \text { Report suspicions of child } \\
\text { maltreatment } \\
\text { - Work together with health care } \\
\text { professionals to provide tailored } \\
\text { care for maltreated children } \\
\text { - Talk to children about maltreat- } \\
\text { ment experiences }\end{array}$ \\
\hline
\end{tabular}

Policy makers $\quad$ - Cl intervention may be $\quad$ Focus on prevention and implemen-

- AMK cost-effective

management

- Government (national \& local)

$$
\text { cost-effective }
$$

- Talking with children results in relevant and valuable information tation of cost-effective interventions when child maltreatment has been substantiated.

\begin{tabular}{lll}
\hline $\begin{array}{l}\text { Health care } \\
\text { providers }\end{array}$ & $\begin{array}{l}\text { Child maltreatment is associated } \\
\text { with adverse quality of life }\end{array}$ & $\begin{array}{l}\text { Focus on prevention and implemen- } \\
\text { tation of cost-effective interventions }\end{array}$ \\
& outcomes for children & when child maltreatment has been \\
& substantiated.
\end{tabular}


Dissemination by us:

- Organize symposium for AMKs and health care professionals

- Report study results in journals relevant to target group

- Press release (around time of defense PhD thesis)

- Presentations at international conferences
Implications for practice and research:

- More training on talking with maltreated children: for all AMK workers, and after the merging of SHG and AMK also those of the (old) SHG.

- Consider certification of training to interview maltreated children
- Organize symposium for AMKs and health care professionals

- Report study results in journals relevant to target group

- Press release (around time of defense PhD thesis)

- Present at international conferences
- Make child maltreatment part of education

- More training on talking with maltreated children
- Report study results in journals relevant to target group

- Press release (around time of defense PhD thesis)

- Present at international conferences
- Make child maltreatment part of education

- More training on talking with maltreated children

- Use social media and national TV to draw attention to child maltreatment: e.g. Klokhuis child maltreatment special

- Be open and aware of child maltreatment in the own environment

- Encourage children to talk about their personal situation, also if child maltreatment is the subject

- Initiate dialogue with policy makers about implementation of the results in daily practice: e.g. by extending to several follow-up evaluation moments instead of one (after 3 months)

- Report study results in scientific journals

- Press release (around time of defense PhD thesis)

- Presentations at international conferences

- Report study results in scientific journals

- Press release (around time of defense PhD thesis)
- Implement a child-interview in all AMK investigations (for children $>6$ years)

- Provide specialized care for maltreated children (e.g. psycho education)

- Organize and/or intensify care for high risk populations

- Self-report instruments (e.g. quality of life instruments) could be implemented in follow-up treatment

- Consider AMK as central gate keeper?

- Provide specialized care for maltreated children in basic health care package (e.g. psycho education) 


\begin{tabular}{|c|c|c|}
\hline Target Group & Message from this thesis & What can be done? \\
\hline Scientists & $\begin{array}{l}\text { - Child maltreatment is } \\
\text { associated with adverse quality } \\
\text { of life outcomes for children } \\
\text { - Talking with children results in } \\
\text { relevant and valuable } \\
\text { information } \\
\text { - Self-report instruments } \\
\text { generate a lot of relevant and } \\
\text { valuable information on } \\
\text { children's personal situation } \\
\text { - Cl intervention may be } \\
\text { cost-effective }\end{array}$ & $\begin{array}{l}\text { - Consider use of self-report } \\
\text { instruments when studying } \\
\text { children's personal situation }\end{array}$ \\
\hline
\end{tabular}

\begin{tabular}{|c|c|c|}
\hline Media & $\begin{array}{l}\text { - Child maltreatment is } \\
\text { associated with adverse quality } \\
\text { of life outcomes for children } \\
\text { - Talking with children results in } \\
\text { relevant and valuable } \\
\text { information }\end{array}$ & $\begin{array}{l}\text { - Increase awareness of negative } \\
\text { outcomes of child maltreatment } \\
\text { - Increase recognition of child } \\
\text { maltreatment }\end{array}$ \\
\hline
\end{tabular}

Parents/family - Child maltreatment is associated with adverse quality

- Work together with health care of life outcomes for children professionals to provide tailored - Talking with children results in care for maltreated children relevant and valuable information

(maltreated)
Children

Children
- Children have the right to talk about their maltreatment experiences. When children talk, they can help professionals to provide the best tailored care for them and for their family

- It helps professionals in proving tailored care if children report on their needs
- Talk about maltreatment experiences 
Dissemination by us:

- Presentations at national and international conferences

- Report study results in national and international journals

- Press release (around time of defense PhD thesis)
Implications for practice and research:

- Can the age limit to interview reported children be scaled down?

- Perform additional studies on quality of life outcomes, also among maltreated children to enable comparison of the findings

- Study which quality of life dimensions are important for maltreated children to improve quality of life measurement among maltreated children

- Continue studying (interrelatedness of) factors associated with quality of life of maltreated children.

- Collect details on the child and family welfare interventions that were recommended by the AMKs and whether families complied to these interventions to better understand the findings in these studies.

- Study if there is an association between the end or reoccurrence of maltreatment and quality of life outcomes.

- perform economic evaluations on interventions regarding child maltreatment

- Press release (around time of defense PhD

- Contribute to shift towards more child oriented practice: giving children a voice thesis)

- Presentations at national and international conferences

- Use social media and national tv to draw attention to child maltreatment: e.g. Klokhuis child maltreatment special

- Report study results in national and international journals

- Press release (around time of defense PhD thesis)

- Initiate dialogue with policy makers about implementation of the results in daily practice

- Report study results in journals relevant to target group

- Check possibilities for parenting training if in need

- Be open and aware of child maltreatment in the own environment

- Encourage children to talk about their personal situation, also if child maltreatment is the subject

- Initiate dialogue with policy makers about implementation of the results in daily practice

- Report study results in journal relevant to children: e.g. Kidsweek
- Be open and aware of child maltreatment in the own environment

- Invite each other to talk about one's personal situation, also if child maltreatment is the subject 





\section{Deel I}

Het wordt steeds belangrijker gevonden om kinderen een stem te geven. Hierdoor kunnen kinderen beter begrepen worden en kan hun ontwikkeling worden geoptimaliseerd. Er worden aanzienlijke verschillen gevonden tussen de antwoorden die kinderen op vragenlijsten geven over subjectieve onderwerpen (zoals kwaliteit van leven) en de antwoorden van proxies over hetzelfde onderwerp. Daarom wordt er steeds vaker de voorkeur aan gegeven om kinderen zelf de vragenlijsten in te laten vullen als het gaat om onderwerpen die betrekking hebben op het welbevinden van het kind zelf. Wij hebben vragenlijsten ontwikkeld om sociale steun en ervaren stress te meten bij kinderen tussen de 8 en 11 jaar, omdat deze tot op heden in Nederland niet beschikbaar waren. Hiervoor hebben we twee bestaande vragenlijsten voor jongeren aangepast voor gebruik bij een jongere doelgroep. Het doel van het onderzoek dat wordt besproken in deel 1 van dit proefschrift, was om de interne betrouwbaarheid, de test-hertest betrouwbaarheid en de dimensionaliteit te onderzoeken van deze nieuw ontwikkelde zelfrapportage vragenlijsten. De interne betrouwbaarheid en test-hertest betrouwbaarheid van beide vragenlijsten bleek over het algemeen voldoende tot goed. Een verklarende factor analyse (principle axis factoring) geeft de indruk dat aan de vragenlijsten voor de kinderen dezelfde dimensies ten grondslag liggen als aan de vragenlijsten voor jongeren. De resultaten tonen aan dat beide zelfrapportage vragenlijsten over voldoende psychometrische kwaliteiten beschikken en geschikt zijn voor gebruik in de doelgroep van kinderen tussen 8 en 11 jaar (hoofdstuk 2).

\section{Deel II}

Kindermishandeling heeft aanzienlijke nadelige gevolgen voor de fysieke en mentale gezondheid. Kwaliteit van leven is steeds vaker onderwerp van onderzoek, aangezien dit construct een gedetaileerd beeld geeft van het algehele functioneren van het individu en diens perceptie op het leven. Desalniettemin hebben maar weinig studies de ervaren kwaliteit van leven van slachtoffers van kindermishandeling onderzocht. Deel II van dit proefschrift gaat in op het centrale thema geef kinderen een stem, door een prospectieve studie te bespreken waarin de kwaliteit van leven van mishandelde kinderen (5 tot 16 jaar) centraal staat. Deze kinderen hebben vier keer zelfrapportage vragenlijsten ingevuld over een periode van 1,5 jaar nadat een vermoeden van kindermishandeling was gemeld bij het Advies- en Meldpunt Kinder- 
mishandeling (AMK). Het design van dit onderzoek is beschreven in hoofdstuk 3. De eerste doelstelling was het vergelijken van de door hen zelf gerapporteerde kwaliteit van leven kort na melding bij het AMK (meetmoment 1) met de kwaliteit van leven van norm populaties afkomstig uit de algehele bevolking (hoofdstuk 4). De tweede doelstelling was het onderzoeken van het beloop van de zelf gerapporteerde kwaliteit van leven van deze mishandelde kinderen over 1,5 jaar na de AMK melding (meetmoment 1 tot en met 4). Daarnaast werd onderzocht in hoeverre het beloop van de kwaliteit van leven van mishandelde kinderen samenhangt met verscheidende kind-, familie/ omgevings- en ouderkenmerken (hoofdstuk 5).

In hoofdstuk 4 wordt de door hen zelf gerapporteerde kwaliteit van leven van mishandelde kinderen op het eerste meetmoment, zo snel mogelijk na de melding bij het AMK, vergeleken met de kwaliteit van leven van norm populaties afkomstig uit de algehele bevolking. Mishandelde kinderen blijken een significant lagere kwaliteit van leven te rapporteren dan niet-mishandelde kinderen. We hebben ook onderzocht of er samenhang bestaat tussen demografische, socio-economische en mishandelingskenmerken en de kwaliteit van leven zoals gerapporteerd kort na de melding bij het AMK. De aanwezigheid van financiele problemen in het gezin bleek samen te hangen met een lagere kwaliteit van leven. Er werd geen samenhang gevonden tussen kwaliteit van leven kort na de AMK melding en de andere kenmerken die werden onderzocht.

In hoofdstuk 5 worden de resultaten van de longitudinale analyse van het beloop van kwaliteit van leven over 1,5 jaar na de AMK melding, meetmoment 1 tot en met 4, beschreven. In de 6 maanden na de AMK melding is er sprake van een significante toename in kwaliteit van leven, gevolgd door een significante afname in de periode tussen de vervolgmetingen na 6 en 12 maanden. Tussen de vervolgmetingen na 12 en 18 maanden blijft de kwaliteit van leven dalen, deze afname is echter niet significant. Kindfactoren die bleken samen te hangen met een hogere kwaliteit van leven van mishandelde kinderen in de 1,5 jaar na AMK melding waren: een hogere leeftijd, minder ervaren stress en een sterker gevoel van eigenwaarde. Onder de ouderfactoren werd een negatieve samenhang gevonden met één van de dimensies van kwaliteit van leven van de ouder, namelijk beperkt worden door emotionele problemen. Er werd geen samenhang gevonden tussen de kwaliteit van leven van de mishandelde kinderen zoals gerapporteerd over 1,5 jaar na AMK melding en de andere onderzochte kindfactoren (ervaren sociale steun), ouderfactoren (opvoedstress, ervaren sociale steun en kwaliteit van leven) of familie-/omgevingsfactoren (buurtperceptie, afkomst, gezinssitiuatie en socio-economische status). 


\section{Deel III}

Nadat een vermoeden van kindermishandeling gemeld wordt bij het AMK, wordt door middel van een AMK onderzoek vastgesteld of dit vermoeden terecht/onterecht is. Het AMK kan kiezen voor twee verschillende methoden om informatie te verzamelen: een procedure waarbij informatie wordt verzameld door alleen met volwassenen te praten (adult-only (Al) intervention), en een procedure waarbij naast gesprekken met volwassen ook een kindinterview plaats vindt (child-interview (CI) intervention). De voorkeur gaat tegenwoordig uit naar de procedure met het kind-interview ( $\mathrm{Cl}$ intervention). Deze procedure is ook opgenomen in de AMK handleiding die ten grondslag ligt aan het AMK onderzoek. Daarnaast sluit de procedure met het kindinterview aan bij de verschuiving die plaatsvindt naar een meer kind-gerichte benadering.

Naast de negatieve gevolgen van kindermishandeling voor de fysieke en mentale gezondheid en kwaliteit van leven van kinderen, zijn er ook negatieve gevolgen voor de maatschappij. Doordat kinderen mogelijk fysieke en/of mentale gezondheidsproblemen ontwikkelen als gevolg van kindermishandeling, bestaat grote kans dat deze kinderen en hun families een beroep zullen doen op verschillende typen zorg, denk aan gezondheidszorg en maatschappelijke hulpverlening. De kosten daarvan voor de maatschappij zijn aanzienlijk. Het is van belang om economische evaluaties uit te voeren, omdat de resultaten van dergelijke studies beleidsmakers ondersteunen bij het nemen van beslissingen met betrekking tot de aanbeveling en implementatie van kosten-effectieve interventies voor de praktijk. Deel III van dit proefschrift gaat in op het central thema geef kinderen een stem door verslag te doen van de effectiviteit en kosten-effectiviteit van de AMK procedure met kind-interview in vergelijking met de AMK procedure zonder het kindinterview. Het design van dat onderzoek wordt beschreven in hoofdstuk 6 . De eerste doelstelling was om te onderzoeken wat het effect van de AMK procedure met kind-interview was op de gedragsproblemen en de kwaliteit van leven van mishandelde kinderen. De tweede doelstelling was het opmaken van de balanstussen extra kosten en effecten van de AMK procedure met kind-interview ten opzichte van AMK procedure zonder kind-interview.

De analyses gerapporteerd in hoofdstuk 7 laten zien dat er geen significante verschillen zijn tussen de AMK procedure met het kind-interview en de AMK procedure zonder het kind-interview wat betreft de gedragsproblemen en de kwaliteit van leven van mishandelde kinderen. De resultaten van de economische evaluatie zijn ten gunste van de AMK procedure met het kind-interview. Alle 
ICERs waren dominant. Uitgaande van de QALY als uitkomstmaat, was er 93\% kans dat de AMK procedure met kind-interview tot betere resultaten zou leiden van de AMK procedure zonder het kind-interview bij een willingnessto-pay van 20.000 euro. Voor de uitkomstmaat gedragsproblemen was dit percentage $76 \%$ en voor de uitkomstmaat kwaliteit van leven, was de kans $91 \%$ dat de AMK procedure met het kind-interview tot betere resultaten zou leiden dan de AMK procedure zonder het kind-interview.

\section{Conclusies en aanbevelingen voor onderzoek en praktijk}

Voor zover bij ons bekend was dit de eerste keer dat de kwaliteit van leven van mishandelde kinderen na melding bij een AMK is onderzocht met zelfrapportage vragenlijsten. Aanvullend onderzoek is nodig om een vergelijking mogelijk te maken tussen de kwaliteit van leven van deze mishandelde kinderen met andere mishandelde kinderen, onder andere mishandelde kinderen die niet zijn gemeld bij een AMK. Daarnaast zou in de toekomst onderzocht kunnen worden hoe instrumenten die de kwaliteit van leven van kinderen, waaronder mishandelde kinderen, meten, verbeterd kunnen worden. Dergelijk onderzoek zou zich moeten richten op de vraag welke dimensies van kwaliteit van leven van toepassing zijn op mishandelde kinderen. Het is namelijk de vraag of mishandelde kinderen de verschillende dimensies waaruit kwaliteit van leven bestaat op dezelfde wijze ervaren als nietmishandelde kinderen. Bovendien is er behoefte aan instrumenten die de verandering in kwaliteit van leven (utiliteiten) meten, omdat dergelijke instrumenten nodig zijn voor economische evaluaties.

Kindermishandeling leidt tot aanzienlijke maatschappelijke kosten en beleidsmakers laten zich bij besluitvorming veelal leiden door de resultaten van economische evaluaties. Economische evaluaties naar interventies op het gebied van kindermishandeling zijn helaas nog schaars. Dergelijke onderzoeken zijn daarom van belang voor de toekomst. De economische evaluatie die onderdeel uitmaakt van dit proefschrift was de eerste in zijn soort die inging op een procedure die wordt gebruikt door AMK's en soortgelijke instanties internationaal. 
Dit proefschrift geeft informatie over hoe het met mishandelde kinderen gaat nadat zij zijn gemeld bij het AMK. Ook worden factoren gerapporteerd die kinderen mogelijk kwetsbaar maken voor een lagere kwaliteit van leven. De resultaten laten zien dat door kinderen te vragen zelf vragenlijsten in te vullen, waardevolle informatie wordt verkregen die AMK medewerkers en andere hulpverleners die werken met mishandelde kinderen kan helpen in de probleem verheldering. Dit draagt op positieve wijze bij in het verwijsproces naar passende hulp. De resultaten, en dan met name die van de economische evaluatie van de AMK procedure met kind-interview, zijn ook relevant voor beleidsmakers omdat deze hen ondersteunen in het nemen van beslissingen met betrekking tot preventie en behandeling van kindermishandeling.

Tot slot, de resultaten van de studies beschreven in dit proefschrift benadrukken hoe belangrijk het is om mishandelde kinderen een stem te geven. Aan mishandelde kinderen vragen om hun gedachten, gevoelens en zorgen te verwoorden levert waardevolle en relevante informatie op. Deze informatie kan worden gebruikt om tijdig de juiste hulp in te zetten. 

Dankwoord 

En dan, na vijf jaar hard werken, de nodige dosis tegenslag, maar ook vele leuke en bijzondere momenten en af en toe een vleugje stress, is het proefschrift af! Maar dat zou niet gelukt zijn zonder de steun van anderen. Enkelen daarvan benoem ik hieronder.

Cees: Samen hebben we dit project tot een goed einde gebracht. Het zat wel eens tegen, bijvoorbeeld in de eerste fase toen we alsmaar geen toestemming kregen van de METC, maar we hebben ook van blijdschap door de kamer gedanst, bijvoorbeeld als ZonMw ons uitstel gaf om dit mooie onderzoek af te kunnen ronden. Jij ging met een kritische blik door al mijn concept manuscripten, en daagde me daarmee uit goed na te denken over de betekenis van resultaten voor wetenschap en praktijk.

Francien: Van jouw kreeg ik altijd meteen antwoord op vragen en feedback op stukken tekst. Jij lijkt dag en nacht aan het werk te zijn. Jouw hart voor je vak en bevlogenheid zijn een inspiratie voor me. Ik vond het dan ook leuk dat we elkaar wat beter hebben leren kennen in Portsmouth afgelopen zomer. Silvia: Jouw vertrouwen in mij was vaak een oppepper. Op momenten dat ik twijfelde of het allemaal nog wel zou gaan lukken, kreeg ik van jou altijd de bemoedigende blik die mij ook weer vertrouwen gaf. Ondanks de grote afstand was je voor mij altijd goed bereikbaar. Je reisde vele malen van Maastricht naar Utrecht voor overleg, en als dat echt niet lukte dan konden we altijd bellen of Skypen.

Paul, Irene en Gert: Ik kon jullie bellen voor een brainstorm, maar ook voor pilot projecten stond bij AMK Haaglanden en AMK Gelderland de deur altijd open. Jullie hebben een zeer waardevolle bijdrage geleverd aan het onderzoek.

Maar ook:

Alle AMK's die deelnamen aan de werving van het onderzoek: AMK Amsterdam, AMK Midden-Brabant, AMK West-Brabant, AMK Gelderland, AMK Haaglanden, AMK Rotterdam, AMK Utrecht en AMK Zuid-Holland. Alle interviewers: Annelies, Audrey, Devi, Ebru, Else, Hilde, Jacintha, Lieke, Liesbeth, Lucy, Nell, Marleen, Roxanne, Simone, Tamar.

Nelke, mijn superstagiaire, die ik het laatste half jaar dataverzameling kon toevertrouwen zodat ik aan dit proefschrift kon schrijven. Zonder jullie, geen onderzoek. Dank voor de inzet!

En niet te vergeten, een speciaal bedankje voor alle ouders en kinderen die hebben deelgenomen aan de dataverzameling van het onderzoek. 
Natuurlijk geen proefschrift zonder trouwe meelezers: Eric, Marlous, Anouk, Lieke, bedankt!

Peggy, niemand heeft zoveel tekst doorgeworsteld als jij. Jouw kritische vragen en opmerkingen (zonder boterham) hielpen me de tekst aan te scherpen. Daarnaast was je altijd beschikbaar om te sparren tijdens een borrel. Hopelijk nu snel een keer sparren in de boksring.

Eline: Jij verzorgde de kers op mijn taart. Je wist mijn vage, onhandige uitleg te vertalen tot dit prachtige boekje.

Ghislaine: Wat er ook gebeurt, jij steunt me altijd door dik en dun. Zelfs vanuit het buitenland kon ik je bellen voor advies. Of het om een snel kopje koffie gaat, een lunch met broodje geitenkaas of een etentje bij kaarslicht, ik voel me daarna altijd opgepept en vol nieuwe energie.

Simone: Onze collegiale band groeide onder het genot van de nodige kopjes ochtendkoffie al snel uit tot een hechte vriendschap. Door jouw probleemoplossend vermogen verdwenen mijn onderzoeksproblemen altijd als sneeuw voor de zon. Fijn dat je al jouw onderzoekservaring en -inzicht met mij wilde delen onder het genot van lunch of borrel of tijdens onze maandelijkse ontspanningsdag in de sauna.

Esther: Samen lachen en samen huilen. Need I say more?

Martijn: Bij jou vond ik de rust die ik zo hard nodig had. Mijn huis werd mijn werkplek en jouw huis werd mijn thuis. Het was heerlijk werken met onze zondag samen in het vooruitzicht. Ondanks dat het proefschrift af is, laat ik me die zondagen samen natuurlijk niet meer afpakken! Je weet.

Gineke: We zijn allebei altijd druk druk druk. Toch geniet ik erg van onze sporadische bijklets-avonden. Ik heb veel bewondering voor jouw netwerkvaardigheden, daar kan ik veel van leren.

Eelke: Mijn gepromoveerde zusje en daarmee mijn grote voorbeeld. Menig keer heb ik de 'Skype hulplijn' ingezet en dan bleek het drama altijd wel mee te vallen. Wat zul je soms om me gelachen hebben. Hopelijk kunnen we in de toekomst ook blijven Skype-Iunchen.

Jasper: Je incasseerde (of negeerde?) mijn uitbarstingen als ik stress had, je voorzag me van de nodige kopjes thee, maar je kwam ook naar Trimbos om data in te voeren. Op basis van mijn knullige knip en plak voorbeeld maakte je een prachtige poster voor mijn posterpresentatie in San Diego. Op jou kon ik altijd rekenen! 
Mama: Fijn dat je me zo hebt gesteund de afgelopen tijd en dat je zo trots op me bent. Ik maak het je niet altijd makkelijk. Hopelijk is er meer tijd voor leuke moeder-dochter dingen nu het proefschrift af is. 

Curriculum Vitae 

Froukje Snoeren was born on May 281982 in Oirschot, the Netherlands. She grows up in Bergen op Zoom and graduates from scholengemeenschap 't Rijks in 2000. She moves to Tilburg and starts a study HBO Pedagogics at Fontys Hogeschool Tilburg in 2001. In 2004, she spends six months in Stellenbosch (South Africa) for an internship. Here she works on several projects for children in a deprived urban area. In the final year of her study, she works with children with emotional and behavioral problems at PI School Hondsberg, Oisterwijk. Here she also performs a study on the ways in which teachers can contribute to the mourning process of intellectually disabled children. After graduating in 2005, she proceeds with a Master Education and Behavioral Development at Utrecht University in Utrecht. In 2007 she spends six months in Gainesville (USA) to perform a meta-analysis on the relationship between self-determination, learning strategies and learning outcomes at the University of Florida. With the study 'ARC Self-Determination Scale: Validation of the Dutch translation', she obtains a Masters degree in June 2008. Froukje decides to travel for almost a year and in July 2009 she starts her PhD project at Trimbos-institute (Utrecht) in collaboration with CAHPRI, School for Public Health and Primary Care Maastricht University. Results of this PhD project are described in this thesis. 



\section{Publications}



Snoeren, F., \& Hoefnagels, C. (2014). Measuring perceived social support and perceived stress in primary school children in the Netherlands. Child Indicators Research, 7(3), 473-486.

Snoeren, F., Hoefnagels., C., Evers, S. M. A. A., \& Lamers-Winkelman, F. (2013). Design of a prospective study on mental health and quality of life of maltreated children (aged 5-16 years) after a report to an advice and reporting center on child abuse and neglect. BMC Public Health, 13, 942-952.

Snoeren, F., Hoefnagels., C., Lamers-Winkelman, F., P. Baeten, \& Evers, S. M. A. A. (2013). Design of a quasi-experiment on the effectiveness and cost-effectiveness of using the child-interview intervention during the investigation following a report of child abuse and/or neglect. BMC Public Health, 13, 1164.

Unger-Snoeren, F., Baeten, P., \& Hoefnagels, C. (2010). Praten met Kinderen. Tijdschrift Kindermishandeling, 3(2), 28-30.

\section{Co-authored}

Cuijpers, P., Smit, F., Unger-Snoeren, F., Stikkelbroek, Y., ten Have, M., \& de Graaf, R. (2011). Disease burden of childhood adversities in adults: A population-based study. Child Abuse \& Neglect, 35(11), 937-945.

Polak, G., Romijn, G., Snoeren, F., Speetjens, P., \& Hoefnagels, C. (2013). Onderzoek naar voorspellers van herhaalde meldingen van huiselijk geweld. Utrecht: Trimbos-instituut.

\section{Submitted manuscripts}

F. Snoeren, C. Hoefnagels, S. M. A. A. Evers, F. Lamers-Winkelman (submitted at Journal of Interpersonal Violence). The quality of life of maltreated children who have been reported to advice and reporting centers on child abuse and neglect.

F. Snoeren, C. Hoefnagels, S. M. A. A. Evers, T. Ambergen, F. Lamers-Winkelman (submitted at Child Development). Self-reported quality of life of maltreated children and factors associated: A prospective study.

F. Snoeren, C. Hoefnagels, F. Lamers-Winkelman, S.M.A.A. Evers (submitted at BMC Public Health). Effect and economic evaluation of the childinterview intervention: The child as a participant in the investigation after a report of child maltreatment. 
๑ 2014 Froukje Snoeren, Utrecht

Graphic design Eline Pellis

elinepellis.com | info@elinepellis.com 